Children's experiences and conceptualisations of child-adult relations within, and beyond, their families.

Susan Milne

PhD

The University of Edinburgh 2009 





\section{DECLARATION}

I declare that this thesis is of my own composition, based on my own work, with acknowledgement of other sources, and has not been submitted for any other degree or professional qualification.

A version of Chapter 6 has been published in the journal 'Mobilities', March 2009, 4 (1) 103-118 (http://dx.doi.org/10.1080/17450100802657988).

Susan Milne 


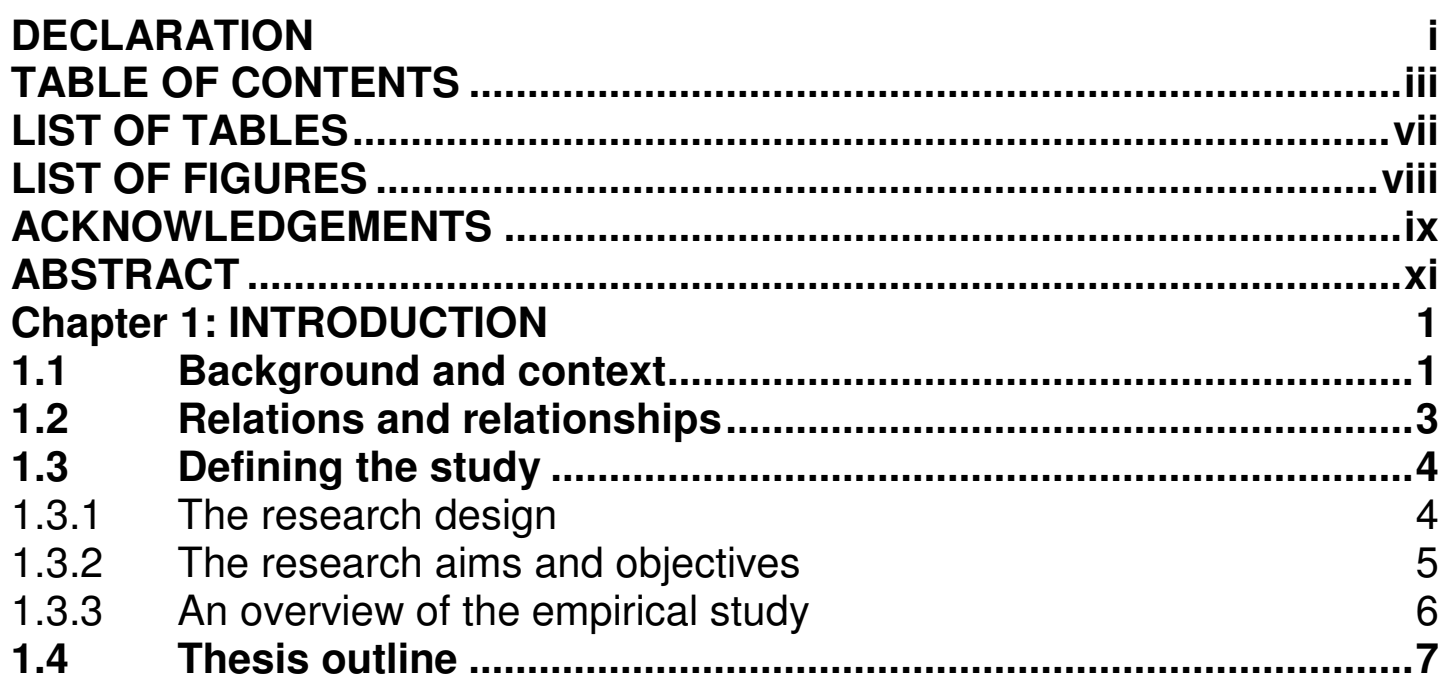

Chapter 2: CHILDREN AND CHILDHOOD: THEORETICAL AND EMPIRICAL CONTEXTS

2.1 The theorising of child and childhood........................................14

2.1.1 Conflicting constructions of child and childhood 15

$\begin{array}{ll}2.1 .2 & \text { Childhood as a generational concept } \\ & 17\end{array}$

$\begin{array}{lll}2.1 .3 & \text { Theorising age } & 20\end{array}$

2.2 The places and spaces of childhood ........................................22

2.2.1 Home, school and 'club': The 'right' places for children? 23

$\begin{array}{ll}\text { 2.2.2 Children in public spaces and places } & 25\end{array}$

2.2.3 Children and risk in public 28

$\begin{array}{lll}2.2 .4 & \text { Children's mobility } & 31\end{array}$

2.3 Child-adult contacts and relationships.....................................34

2.3.1 Familial child-adult contacts and relationships 35

2.3.2 Child-adult contacts and relationships in institutional settings 38

2.3.3 Children's contacts and relationships with other adults 40

2.4 Conclusion ............................................................................43

Chapter 3: METHODOLOGY 45

3.1 Overview....................................................................................45

3.1.1 Methods: The rationale and operation 45

Familiarisation through participant observation ....................................45

Task centred methods: Drawings and Family Trees ...............................47

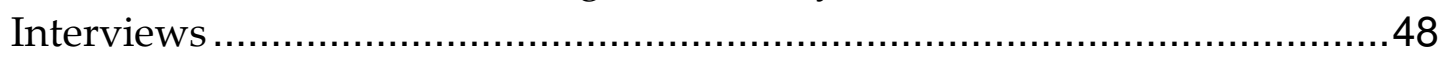

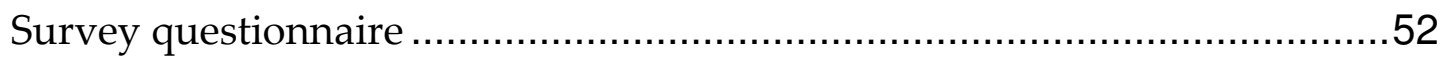

Analysing the survey data ........................................................ 54

3.1.2 Data collection time-frames 55

3.1.3 The research participants 58

The children in Swinburn Primary School ..............................................59

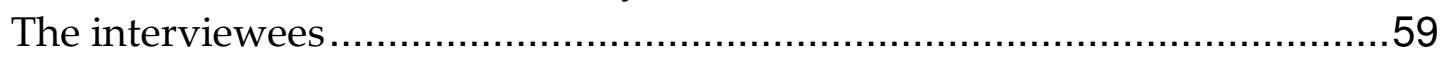




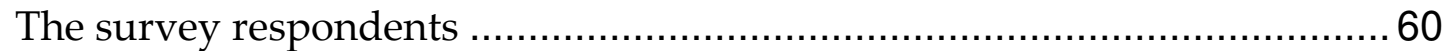

3.2 Accessing and representing children's knowledge ....................61

3.2.1 A child standpoint methodology 62

3.2.2 Participant observation 64

$\begin{array}{lll}3.2 .3 & \text { Interviews } & 66\end{array}$

$\begin{array}{lll}3.2 .4 & \text { Task centred methods } & 67\end{array}$

3.2.5 A self-completion questionnaire 68

3.3 Linking methods and methodologies.........................................71

3.3.1 Reviewing the rationale for linking methods 71

3.3.2 The practice and problems of linking methods: Data collection 73

3.3.3 The practice and problems of linking data: Data analysis 73

$\begin{array}{lll}\text { 3.3.4 Representing children's knowledge } & 74\end{array}$

3.4 Ethical practice and reflexivity................................................. 75

$\begin{array}{lll}3.4 .1 & \text { Consent } & 76\end{array}$

3.4.2 Confidentiality, privacy and anonymity 81

3.4.3 Researcher roles and responsibility 83

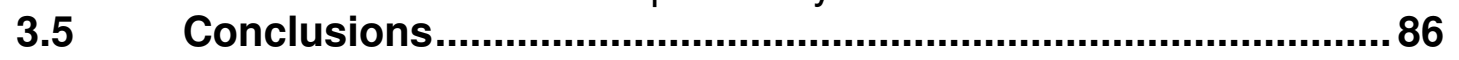

Chapter 4: CHILDREN, THEIR FAMILIES AND THEIR RELATIONSHIPS WITH RELATIVES $\quad 87$

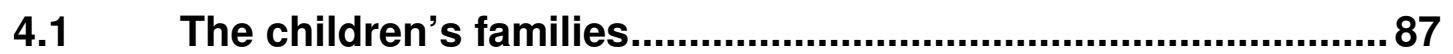

4.1.1 Parenting structures $\quad 88$

4.1.2 Family trees 91

4.1.3 Real, step and assigned relatives 97

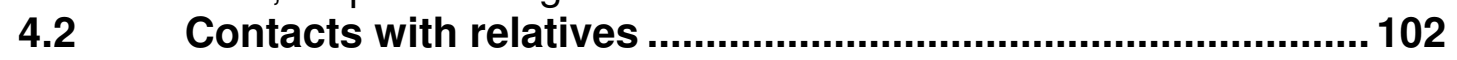

4.2.1 Spatial, geographical and temporal proximity 103

4.2.2 Family contacts 104

4.2.3 Support to and from relatives 107

4.3 Children's individual relationships with relatives ................... 110

4.3.1 Independent and autonomous contacts 111

4.3.2 Individual relationships 113

4.3.3 The importance of older sisters 115

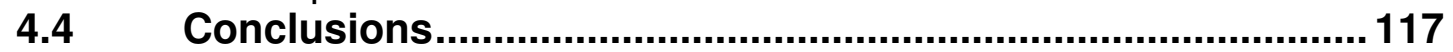

Chapter 5: CHILDREN'S CONTACTS WITH FAMILIAR ADULTS IN THEIR

NEIGHBOURHOODS $\quad 119$

5.1 The Children's neighbourhoods ............................................120

$\begin{array}{ll}5.1 .1 & \text { The physical environment } \\ 5.120\end{array}$

$\begin{array}{lll}\text { 5.1.2 Children's use of their neighbourhoods } & 127\end{array}$

5.1.3 Children's views about living on a 'scheme' 130

5.2 Contacts with adults in the neighbourhood ............................136

$\begin{array}{ll}\text { 5.2.1 Neighbours } & 137\end{array}$

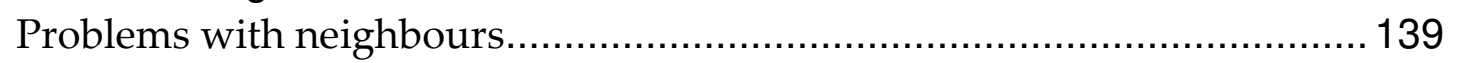

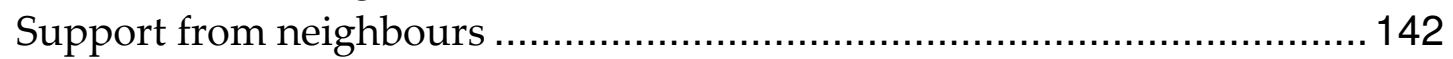

5.2.2 Parental and family friends 143

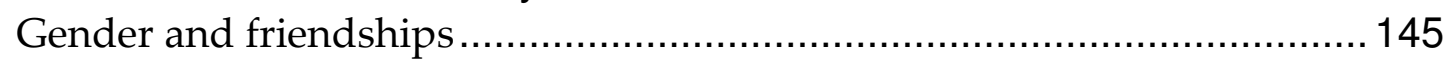

$\begin{array}{lll}\text { 5.2.3 Friends' parents and families } & 148\end{array}$ 
5.2.4 Workers in children's clubs 150

5.2.5 Other adults in the neighbourhood 153

5.3 Individual relationships with familiar adults ..........................156

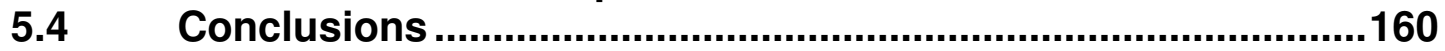

Chapter 6: CHILDREN BEYOND THEIR NEIGHBOURHOODS:

ENCOUNTERS WITH ADULTS IN THE PUBLIC WORLD 165

6.1 Moving into the public world ................................................167

6.1.1 The public world 168

6.1.2 Leisure opportunities beyond the neighbourhood 168

6.1.3 Being independently mobile 173

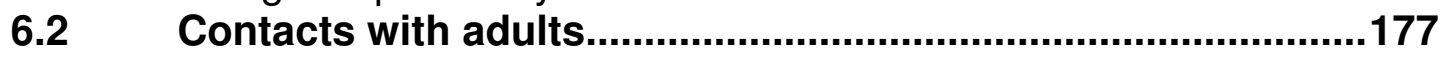

6.2.1 Encounters with adults in public 177

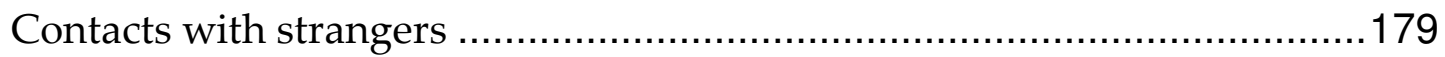

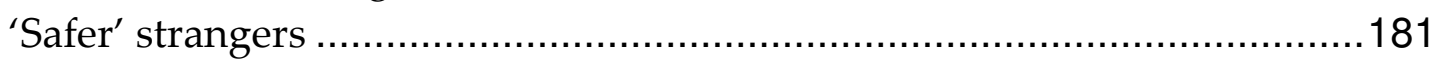

6.2.2 Encounters with public workers 182

6.3 Experiencing the public world as children .............................186

6.3.1 Having a non-adult status 187

Limited funds ................................................................................... 189

6.3.2 Experiencing autonomy in the public world 190

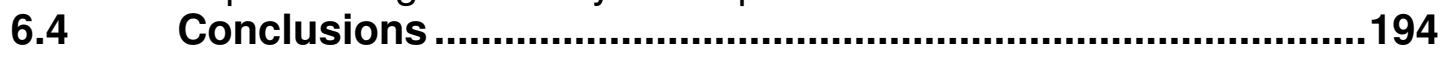

Chapter 7: DEVELOPING A RELATIONSHIP WITH AN ADULT 199

7.1 Child-adult contacts in context ............................................200

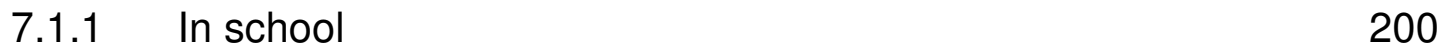

7.1.2 Outside the school 203

$\begin{array}{lll}7.1 .3 & \text { The Children's Project } & 204\end{array}$

7.1.4 Within the research engagement 207

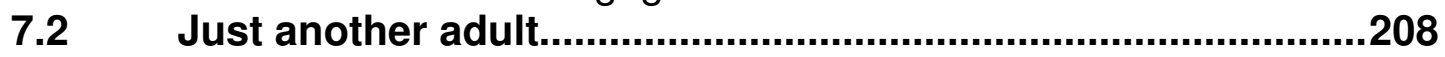

$\begin{array}{ll}7.2 .1 & \text { Distancing } \\ 7.2 .209\end{array}$

7.2.2 A familiar adult role 211

7.2.3 Change in adult behaviour, change in child responses 213

7.3 A different type of adult? .........................................................214

$\begin{array}{lll}\text { 7.3.1 A non-conformist } & 215\end{array}$

$\begin{array}{lll}\text { 7.3.2 } & \text { Trustworthy } 218\end{array}$

7.4 Blurring child-adult boundaries ............................................222

7.4.1 Inclusion in children's worlds? 222

$\begin{array}{lll}7.4 .2 & \text { Physicality } & 224\end{array}$

7.4.3 A bridge to the adult world? 228

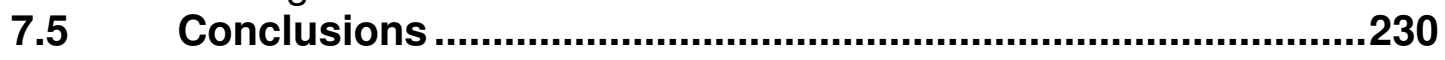

Chapter 8: CHILDREN'S CONSTRUCTIONS OF ADULT AND

ADULTHOOD 235

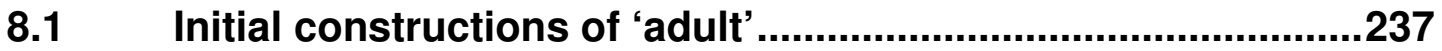

8.1.1 Age, size and growth 237

8.1.2 Age defined activities 239

8.1.3 Teenage 241

8.2 Children's further constructions of 'adult' ..............................242 
8.2.1 Adult behaviours 243

8.2.2 Adult behaviour towards children 245

8.2.3 Adult responsibilities towards children 251

8.3 Adults as a different generation or social group......................257

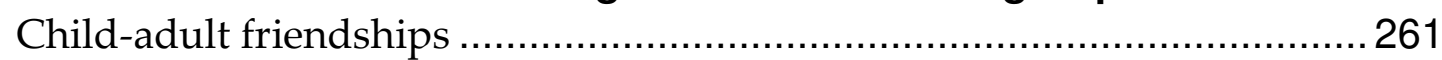

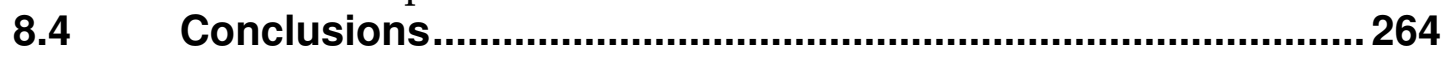

Chapter 9: CONCLUSIONS AND CONTRIBUTIONS 269

9.1 Exploring child-adult relations and relationships: Drawing

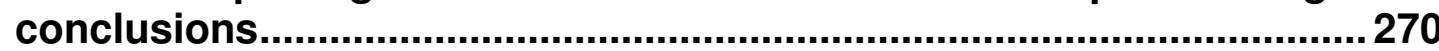

9.1.1 Child-adult contacts and interactions 271

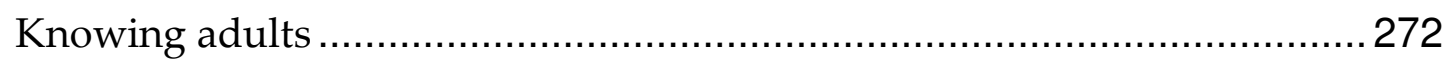

9.1.2 Children's individual relationships with adults 274

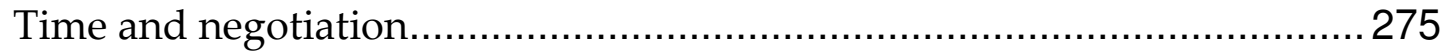

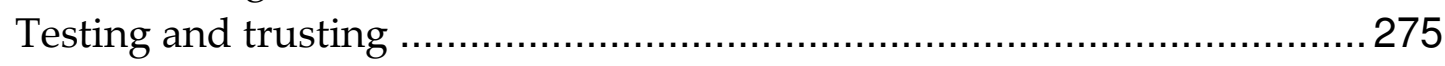

9.1.3 Children's constructions of 'child' and 'adult' 276

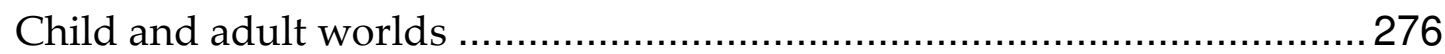

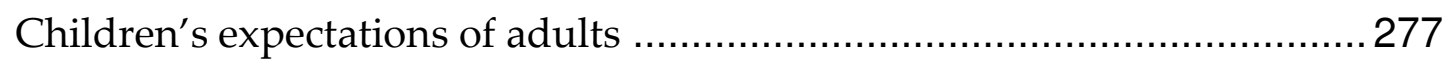

9.1.4 Familial and familiar connections in urban areas of deprivation 278

9.1.5 Children's mobilities in the public world 279

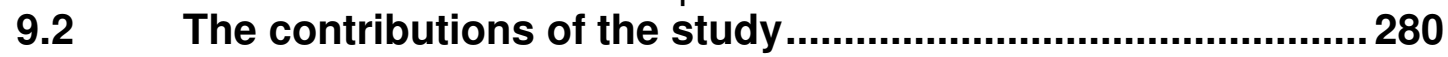

9.2.1 Contributing to academic knowledge and debate 281

9.2.2 Contributing to public policy 284

9.3 Methodological findings and conclusions.............................285

9.3.1 Contributing to research debate and practice 286

9.3.2 Contributing to 'professional' practice 287

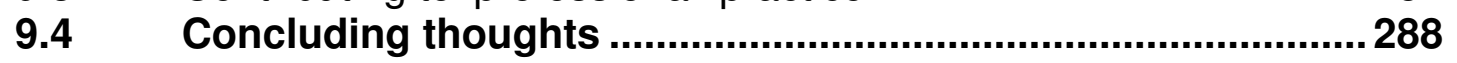

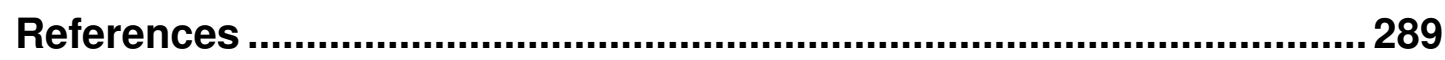

Appendix 1: Letter to the Director of Education 317

Appendix 2: The Children in Swinburn Primary School 319

Appendix 3: List of Transcribed Interviews 321

Appendix 4: Individual Interview Topic Guide 323

Appendix 5: A Survey of the Lives of Children and their Relationships with Adults $\quad 325$

Appendix 6: Meeting with Research Advisors 337

Appendix 7: Piloting the Questionnaire 339

Appendix 8: Letter to Head Teachers 343

Appendix 9: Research with P6 children in Swinburn 345

Appendix 10: A Survey of the Lives of Children and their Relationships with

Adults

Appendix 11: A Survey of the Lives of Children and their Relationships with

Adults 349

Appendix 12: Feedback to the children in Swinburn 351 


\section{LIST OF TABLES}

Table $3 a \quad$ Timetable of the Research Process

Table $3 b \quad$ Details of the Interviews

Table $3 c \quad$ Details of the Survey Population

Table 4a Interviewees' family connections

Table $4 b \quad$ Survey children's reports of their parenting structures

Table 5a Survey children's reports of where they played and the

Table 5b Interview children: Range of regular activities

Table 5c Survey children's reports of the number of houses they had lived in.

Table $5 d \quad$ The reasons why survey children liked the area where they

Table $5 e \quad$ The reasons why survey children did not like the area where they lived

Table $5 f \quad$ Survey children's reports of how they 'got on with' particular groups of adults

Table $5 g \quad$ Survey children's reports of 'spending time' with different groups of adults

Table $5 h \quad$ The proportions of girls and boys, in the survey, reporting which adults they felt that they could ask help from if their parents were not at home

Table $5 i \quad$ The proportions of girls and boys, in the survey, reporting that they 'got on very well with' particular groups of adults

Table 6a Survey children's reports of visiting cinemas, swimming pools and the city centre without adult accompaniment

Table $6 b \quad$ The places that interviewees spoke of visiting without accompaniment from an adult or older child

Table 6c Survey children's reports of the means of travel to: a cinema, a swimming pool and the city centre

Table $6 d \quad$ Survey children's reports of having problems 'people working in shops'

Table 6e Survey children's reports of the frequency of their visits to: a cinema, a swimming pool and the city centre 


\section{LIST OF FIGURES}

Fig. 4.1 John A's family: A 'vertical family structure' 93

Fig. 4.2 Lynney's family: An 'extended family network' 95

Fig. 4.3 John Bs family: A 'horizontal family structure' 96

Fig. 5.1 Detail of naming places and of fence details 122

Fig. 5.2 Details of flats with external balcony walkways 123

$\begin{array}{lll}\text { Fig. } 5.3 \quad \text { Details of the neighbourhood } & 124\end{array}$

$\begin{array}{lll}\text { Fig. } 5.4 \quad \text { Details of rubbish in the neighbourhood } & 125\end{array}$

Fig. 5.5 'Anonymous' people watching the football game 125

$\begin{array}{lll}\text { Fig. 5.6 The group drawing by the 'football' boys } & 126\end{array}$

Fig.6.1 A diagrammatic map of the children's journeys from their $\quad \mathbf{1 7 0}$ neighbourhoods to swimming pools, cinemas and shopping facilities 


\section{ACKNOWLEDGEMENTS}

I would like to express my gratitude to all those who have supported me in undertaking this study.

Firstly, to the children who participated in the research, and to their teachers. Especially to Angel, Breanna, Courtney, Crombie, Gums, Hayley, James, John A, John B, Lily, Lynney, Nicolle, Peter, Sarah, Stacey, Star, Stitch, the P6 and $\mathrm{P7}$ teachers and the Head Teacher who all allowed me so much freedom in Swinburn Primary School.

Secondly, to my supervisors Lynn and Kathryn, without whom I would not have persevered and finally reached completion, many thanks for sticking with me and helping me to find ways through my writing blocks.

Lastly, many thanks to past and present colleagues from $10 \mathrm{~B} / \mathrm{P}, \mathrm{CMB}$ and CRFR and to friends and family, for all your encouragement and assistance. Particularly to Alix, Barbara, Chris, Helen, Jackie, Julie, Lisa, Louise, Martin, Sue, Tina, Vicky and Bill, my dad, for reading through my various drafts and for keeping me going. 


\section{ABSTRACT}

This study explored children's experiences and perceptions of adults and childadult relations and relationships. Child-adult relations involve the conceptualisation of adults and children as distinct social groups and child-adult relationships are inter-personal relationships between individuals that cross the boundary between these groups. The focus of this study was children's contacts and relationships with adults and how these relationships informed children's constructions of child-adult relations.

The study took place in the context of concern about distance between child and adult worlds generating negative stereotypes and distrust between the two social groups and an interest in children's perspectives. A multi-stage, multi-method study was undertaken with children aged 10/11 years living in the relatively deprived, 'Social Inclusion Partnership' (SIP), areas of a Scottish city. A period of familiarisation, through participant observation, was undertaken with Year 6 children in one school, followed by paired and individual interviews with 17 children. A survey was then conducted with 375 children in primary schools across the SIP areas.

In general it seemed that 'relationships' with individual adults, other than with parents, were not particularly important to the children, who, with a few exceptions, did not seek out such adults and generally indicated a preference for spending time with other children. However, knowing and being able to identify adults within and beyond their families was very important to children's sense of self and to their feelings of belonging to a family and within a neighbourhood.

The children did experience their worlds and those of adults as separate. Mobility beyond their neighbourhood without adult accompaniment, to visit swimming pools, cinemas, and retail facilities, provided children with opportunities to observe and experience a range of 'unknown' adults, and particularly 'public workers'. This experientially confirmed their conceptualisations of adults as a separate social group occupying a higher status than children.

The research process in itself indicated that in some circumstances children did have an interest in interacting with adults, and that time, negotiation, testing and trusting were part of the relationship forming process. The child-adult relationships formed in this study through engagement in 'joint enterprises', of play and research project, provide evidence for the possibilities of positive 'generational proximity' between children and adults. 


\section{Chapter 1 INTRODUCTION}

The boundaries between childhood and adulthood are drawn ever more distinctly as children's lives are separated from those of adults.

(Mayall 2002: 3)

This thesis presents the background, methodology, findings and conclusions to my study of children's perspectives of their relations with adults. I analyse how children aged 10/11 years, living in deprived areas of a Scottish city, described their contacts, interactions and relationships with adults within their families, local neighbourhoods and beyond these in the 'public world'. I also analyse how the children conceptualised adult, adulthood and childadult relations.

In this introductory chapter, I provide a background and context to the study before defining the terms relations and relationships. I then present details of the study in terms of the research aims and objectives, and provide an overview of the empirical investigation. Finally, I summarise each thesis chapter.

\subsection{Background and context}

The study of children and their childhoods has developed, since the mid 1990's, across a range of disciplines. Within this broad field there has been a growing interest in the nature of generational and intergenerational relations between those defined as children and those defined as adults. Whilst, within the UK, there has been a move towards greater consultation with 
children, there is a normative view that children are different from adults and are at odds with the adult world. Adults as individuals and as a society find difficulties in balancing the conceptions of children as vulnerable and dependent with those of their evident capabilities.

The background to this research is my personal concern about the ways in which adults in the UK view children as needing different or alternative facilities. I believe that this viewpoint not only leads to the separation of children from adult society, but that such separation creates distrust and different treatment between the social groups. Leach proposes that if it is assumed that children do not 'have the same senses and sensibilities' as adults, it is not 'axiomatic' that they will be treated fairly (1994: 204). This issue has recently been acknowledged by the Scottish Government in their campaign 'See the person, not the age', (Scottish Government 2008), which is discussed in more detail in Chapter 2.

Coming to doctoral research after twenty-five years of working with children, young people and their families in education, health and social work settings I began to reflect upon how my interest in child-adult relations had developed. I sense that much of it is grounded in my own childhood experiences and my desire, as an adult, to treat children with more respect and autonomy than I had been allowed. Thus my personal and professional interest in children's 'rights' led not only to the research topic, but to hear children's perspectives on their situations. What do children think about adults? Which adults do they know? With which adults do they spend time? Throughout the study I am as interested in the process of the child participant-adult research relationship, as in the conceptual elements of child-adult relations. 
The knowledge gained from the answers to these questions is valuable in contributing to debates about the social construction of childhood and how particular social policies impact on children's lives.

\section{$1.2 \quad$ Relations and relationships}

The two interconnecting concepts of relations and relationships form the framework for the study. I am primarily concerned with child-adult relations, and how children and adults, as defined social groups, relate to and make connections with each other. The study of child-adult relations may be compared to that of male-female relations, or of the relations between the peoples of two neighbouring countries. Using the term 'relations' enables focus on how a group of children might interact with a group of adults, or vice versa, and also on the ways they think and speak about each other as separate, but linked, social categories, as in 'children these days are...' or 'adults are always...'. In this thesis, the term 'relationship' is used in the sense of a more inter-personal, individual connection with another person. If one speaks of having a relationship with another person, or even with a group of people, some form of direct knowledge of the other is implied, or that there is some form of link. This can be based on kinship, as in the use of 'my relations', but may also be developed through direct close interactions.

I start from a concern about relations between children and adults in the public world, those called 'social relations'. However, my premise is that a person's actual contacts, and more importantly their personal relationships with individual members of a different social group, influence their views of members of that group. I am therefore interested in investigating both childadult relations and relationships. This includes brief contacts or interactions 
between children and adults as well as ongoing relationships, and also how children think and speak about adults.

\subsection{Defining the study}

This section defines my particular focus, in terms of the child-adult relations and relationships I will concentrate on. The research aims and objectives are laid out, together with an overview of the empirical research.

\subsubsection{The research design}

My main area of interest is child-adult relations within a neighbourhood context, particularly in terms of the contacts and connections children had with adults beyond their homes and schools, and especially in public spaces and places. However, as the study unfolded, knowledge of the children's relationships with their parents was necessarily gathered as part of understanding their relationships with adults beyond the home.

From the outset, I decided that areas with a high child population within a city $^{1}$ would provide an appropriate research setting. My examination of the 2001 Census data (Scottish Census Records) revealed that such areas tended to be those which contain fairly large public housing schemes. I made a further supposition that children living in these schemes would be more likely to be observable in public spaces outside their homes because of the smaller size of houses and gardens compared to homes in more affluent areas. Children in such areas are also likely to be more visible, in transit on the streets, because of lower rates of car ownership (White et al 2000). In

\footnotetext{
${ }^{1}$ Prout (2003) refers to a UN estimation that by $202560 \%$ of the world's children will live in cities.
} 
Scotland, at the time that the research commenced, these public housing schemes tended to be situated in Social Inclusion Partnership (SIP) ${ }^{2}$ areas.

I am interested in the contacts and relationships children choose to have with adults and in the public contacts between children and adults which arise through the course of everyday social life. A further interest is the individual relationships children had with different adults in addition to those which were ascribed, or with their school teachers.

\section{3 .2}

\section{The research aims and objectives}

The overall aim of the research is to explore child-adult relations from the perspectives of children. The specific objectives are defined as follows:

To investigate the contacts and interactions that children, living in urban Social Inclusion Partnership (SIP) areas, have with adults, particularly those other than their parents or schoolteachers, as individuals and groups in different public and private settings within their residential neighbourhoods.

- To investigate the nature of these children's individual relationships with adults within and beyond their families: aunts and uncles; parents'

\footnotetext{
${ }^{2}$ Exclusion, disadvantage and poverty in childhood 'are central concerns of the New Labour Government since coming to office in 1997' (Cockburn 2002: 3). In Scotland many of the initiatives created were located in, and funded through, the Social Inclusion Partnerships (SIPs). These were established by the Scottish Executive in 1999 although approximately half of the SIPs were previously Priority Partnership and Regeneration Programmes Areas. (Scottish Government 1999). SIPs were multi-agency partnership bodies (Kemp et al 2002). In 2004/2005 the SIPs were integrated with Community Planning Partnerships and from April 2005, the Community Regeneration Fund replaced SIP funding (Communities Scotland). There are key differences between children living in SIP areas, and those living in other parts of Scotland. In 1999/2000 the differences were: a greater number of female headed households; a greater variation in family structures; lower educational qualifications for head of household; a lower proportion of people working within the household; and a lower proportion of car ownership (Kemp et al 2002).
} 
friends; friends' parents; family friends; neighbours and other 'familiar' adults.

* To consider how children's contacts, interactions and relationships with these different adults influence their constructions of child, adult, childhood and adulthood, and their feelings about their status as children, in settings beyond the home and the school.

- To contribute to debate and practice regarding research with children through the provision of detailed descriptions and reflexive analysis of the processes and methods used.

\subsubsection{An overview of the empirical study}

The empirical research was undertaken with children aged 10/11 years living in SIP areas within a Scottish city. An iterative methodology of participant observation, interviews and a questionnaire survey was used to enable the research to develop from the children's foci of interest. The sampling frame was Primary Schools situated within SIP neighbourhoods. The participant observation and interviews took place between April 2004 and February 2005 with children in their $6^{\text {th }}(\mathrm{P} 6)$ and then $7^{\text {th }}(\mathrm{P} 7)$ years of Swinburn (a fictitious name) Primary School. Research relationships were established through participant observation undertaken during twice-weekly visits to the school, primarily at break and lunch times. A series of paired and individual interviews was then undertaken with the 17 children who were able to gain parental permission for involvement in the research. From paired interviews, in which the children were asked to talk about 'the adults they knew', a semistructured format was developed for the individual interviews. The initial findings from this qualitative phase were used to develop a questionnaire that was subsequently administered by the researcher to P6 children in schools across all the SIP areas. The data collected are: 41 days of field notes 
from the visits to Swinburn school, together with 17 family trees produced by the children who participated in interviews; transcripts of 41 group, paired and individual discussions and interviews; and survey questionnaires from a further 375 children.

\section{$1.4 \quad$ Thesis outline}

Chapters 2 and 3 provide overviews and discussion of the theoretical and methodological contexts of the study. The substantive findings are then presented in the following 5 chapters. Each of these draws on different combinations of data produced during the research process. The first three of the substantive chapters, Chapters 4-6, focus on different spatial contexts of children's lives: the home, the neighbourhood and the broader public world of the city. Their sequence is designed to mirror the developing range and breadth of children's lives and contacts with others. Chapter 7 focuses on a specific type of child-adult relationship, that between the child participants and myself as adult researcher. The final substantive chapter, Chapter 8 , moves from the detail of child-adult contacts to an analysis of how the children appeared to understand adult and adulthood, and to make sense of their relations with adults.

\section{Chapter 2: Children and childhood: theoretical and empirical contexts,} outlines contemporary theorising within the interdisciplinary field of childhood studies. It draws attention to contradictory views of the nature of children and childhood, and the resulting difficulties of making sense of the position of children in the social world. The concepts of generation and age are examined as means of understanding the ways in which childhood and adulthood, and children and adults are separated. Theoretical and empirical 
literature, point not only to children being distanced from adults in social space, but also in the expectation that there are certain places that are 'for' children and others where they do not belong. The impact of these views on children's social mobilities is also considered. Existing studies and reports relating to children's contacts and interactions with familial, institutional and 'other' adults are reviewed, as are academic and lay discussions relating to children and risk, in the public world. Finally, the chapter highlights a tendency for previous studies of child-adult relationships to focus on formal ones between children and parents or pupils and teachers, rather than more informal contacts and relations between children and other adults.

Chapter 3: Methodology, Inspired by Morrow and Richards (1996) and Barker and Weller (2003), this chapter presents the research process as a negotiated process between the child-participants and the adult researcher. Through a consideration of the use of participant observation, interviews and a self-completion questionnaire survey the idea of a child-standpoint methodology is discussed. There is exploration of the rationale for, practice and problems of using an iterative, multi-staged approach as a means of exploring emergent themes, and of enabling children to express their views and contribute their knowledge. Particular attention is paid to the following ethical issues: consent; confidentiality, privacy and anonymity; and researcher roles and responsibility.

\section{Chapter 4: Children, their families and their relationships with relatives,} sets data from the 17 interviewees and their diagrammatic family trees alongside the findings from the broader survey. This provides a descriptive overview of the range of children's perceptions of 'family'. Drawing on the interview and survey data, there is discussion of the relevancy of the spatial 
and temporal proximity of grandparents, aunts and uncles, and older siblings for children's contacts and relationships with these relatives. A distinction is made between family contacts; defined as those made by children together with their parents, and contacts that children had that were without their parents or that were undertaken autonomously. Children's individual relationships with their relatives are examined, in particular those with older sisters.

\section{Chapter 5: Children's contacts with familiar adults in their} neighbourhoods, begins with a description of Swinburn, before outlining children's use, and viewpoints, of their neighbourhoods. Descriptions of their knowledge of and contacts with their parents' friends, friends' parents, geographical neighbours, workers in children's clubs, and other local adults are examined and compared using interview and survey data. The children's reports of independent engagements with familiar adults are considered in relation to the formation of individual relationships.

\section{Chapter 6: Children beyond their neighbourhoods: Encounters with adults} in the public world, uses interview data and written answers to survey questions, set within broader statistical data, to provide accounts of children's mobility into and through the world beyond their neighbourhoods, and of their encounters with adults in this process. The children commented on the contacts and interactions they had with adults as they ventured from their local areas to the wider public world of the city, without adult accompaniment. They spoke of specific encounters with adults in public and with those who worked in public transport, retail and leisure facilities such as buses, swimming pools and cinemas. These encounters are analysed in terms of the children's experiences of restriction and autonomy. 
The children's perceptions of, and strategies for, dealing with strangers are also explored.

Chapter 7: Developing a Relationship with an Individual Adult draws on interview data and field notes to investigate the relationships that individual children in Swinburn Primary school developed with me over the course of the year. The specific socio-spatial contexts of our contacts are explored, as are the different ways in which the children defined the terms of their engagement with me. These included viewing me as just another adult, or as a different type of adult, and their consideration of my inclusion in their worlds or their engagement with me on a more individual and 'adult' basis. In the conclusion, links are made with the methodological process.

In the final substantive chapter, Chapter 8: Children's constructions of adult and adulthood, interview accounts together with written responses to questions in the survey, provide details of their thoughts about differences between adults and children. Their distinctions range from those of age and size, towards more complex ideas about adult behaviour and responsibilities, both in general, and those specifically directed towards children. The processes the children used in expressing and developing their knowledge of the nature of adults and adulthood are examined, as are their considerations of the possibility for friendships between children and adults.

Chapter 9: Conclusions and contributions, draws together the findings, presented within individual chapters, in relation to the initial aims and objectives of the study and revisits the theoretical and methodological debates presented in Chapters 2 and 3. The contributions of the study to theoretical debate and research practice are highlighted, along with those relating to policy and to the practice of professionals working with children, 
and in communities. In the last section, I reflect back over the study and its strengths and weaknesses, and conclude with my thoughts on the future of child-adult relations.

Although media reference to 'paedophobia' (Guardian 2006), as an adult fear of children, has not diminished my initial concerns about the separation of child and adult lives, and strained relations between children and adults, the study has demonstrated that children perceive positive child-adult relations to be possible. 


\section{Chapter 2}

\section{CHILDREN AND CHILDHOOD: THEORETICAL AND EMPIRICAL CONTEXTS}

This chapter examines theoretical understandings and previous empirical investigations in relation to the three thematic areas of the study of children and their childhoods that emerged during the study. These are: theorising child and childhood; the places and spaces of childhood; and child-adult contacts and relationships. Starting with an outline of contemporary theorising within the interdisciplinary field of childhood studies, attention is drawn to contradictory views of the nature of children and childhood and the resulting difficulties of making sense of children's position in the social world. The theoretical approach of viewing childhood as a relational category and the use of the concept of 'generation', rather than of 'child', are examined as ways of developing understanding of relations between children and adults as separate social groups. As stated in Chapter $1^{3}$, the overall focus of this study is on children's perspectives of their social relations with adults.

In viewing children as a separate social group, adults have provided specific places for children and seen their social status as different, within and beyond these 'child' contexts, the consequences of which influence children's opportunities for and experiences of spatial mobility. Drawing on the work of children's geographers, distinction is made between children's presence in 'appropriate', generally institutional, settings, and in public places and spaces. Particular note is made of academic and lay discussions relating to children and risk in the public world. Attention then focuses on academic knowledge of children's contacts with adults within these contexts. Existing

\footnotetext{
${ }^{3}$ Section 1.2
} 
studies and reports are reviewed in relation to children's interactions and relationships with familial, institutional and 'other' adults. The conclusion highlights existing theoretical and empirical understandings of child-adult relations and relationships and points to gaps in academic knowledge.

\section{$2.1 \quad$ The theorising of child and childhood}

The study of children and childhood was dominated by psychological theory until the early 1990s, with a focus on the development and socialisation of children as they moved from dependency, through ages and stages, towards adulthood (Kelle 2001; Mayall 1994a). Social studies of childhood, developed over the past two decades, draw upon a range of disciplines and offer a much broader methodology for the study of children's lives. Within this theoretical approach, childhood is seen as a socially constructed phenomenon, a social category which, though its manifestation varies at different times and in different cultures, is an integrated and permanent structural feature of society (Mayall 1994a; 2002; Brannen et al 2000; Qvortrup 1994). Children are viewed not only as social actors but also as agents operating with knowledge and self-reflexivity in their current daily lives, rather than in a future orientation as in the process of becoming adults (Alanen 2000). Their competency rather than dependency is acknowledged as is their capacity for moral interpretation (Wyness 2000; Mayall 1994b).

Whilst this interdisciplinary approach aids theoretical and practical understandings of children's lives, there is criticism that developmental aspects of childhood, such as children's own understandings of their evolving identities, have not been sufficiently considered (Haavind 2005). Additionally, Prout, in suggesting a need to move beyond the dualisms of 
individual and society, being and becoming, and structure and agency towards 'an included middle' (2005: 67), acknowledges the value of discussion around the concept of generational relations. Yet, whilst these developments are taking place, it is useful to examine the nature of conflicting constructions, of child and childhood, before considering empirical studies.

\subsubsection{Conflicting constructions of child and childhood}

Mayall (2002) outlines various ways in which the term child is used, from a term denoting kinship, as in parent and child, to legal definitions and understandings in relation to ages. Child is often referred to as a social stage along with those of baby and teenager, and used to define the social status of children at primary, as opposed to students at secondary, school. 'Child' is also used as a relational term and in contradistinction to adult (Mayall 2002: 191). Children are viewed as different from adults, as separate, as other and thus physically marginalised (Leach 1994; Scott et al 1998; Williamson and Butler 1995; Jones 2001; James 1993; Qvortrup 1994; Gillis 2003). They are also 'subjugated to adult definitions of child and childhood' (Qvortrup 1994: 4). When children 'do not conform to adult idealizations, they are perceived as fallen angels, or worse as little monsters' (Gillis 2003: 161).

As a social status, socially constructed in time and place, the nature of childhood is influenced by changing viewpoints and policies (James et al 1998). Thus, it may be better to speak of childhoods and to understand the particular social, political and cultural context of those childhoods being referred to at any given time (Mayall 1994a; Lee 1999; Wyness 2000). For example, Mayall (2002) outlines a range of differences in the daily lives of children in the UK and those in Finland in terms of family versus state 
responsibility for children; class and income differentials; whether children are seen as vulnerable or independent; and the prioritisation of child protection or of children's participation. One reason for such difference may be that the concept of Children's Rights is more established in Scandinavian countries (Brannen 1999).

Within the UK the Children's Rights discourse and the resulting policy shift appear to have enabled a cultural change from seeing children's views as unimportant, towards greater consultation with them and an increase in their participation (Williamson and Butler 1995; Prout 2000; Such and Walker 2004; Hill 2006a). Yet, developmental theories still underlie our educational system and influence the everyday thoughts of adults and of children themselves (Hill and Tisdall 1997; James et al 1998; Scott et al 1998; Mayall 2002).

Contemporary sociological thinking is viewed as being at odds with everyday and institutional conceptions of childhood and there are difficulties in balancing the conceptions of vulnerability and dependence with those of independence. Making sense of children's position within modern society where the boundaries between adult and child are more contested exposes the ambiguity of childhood and a need to cope with the competing discourses of protection and participation (Wyness 2000; Wyness et al 2004). Mayall (1994a) notes the lack of fit between the obligation for adults, as individuals and the state, to provide for and protect children and the recognition of children's competencies and rights. In expressing concern that the ambiguity between being capable of independent actions yet being assigned a dependent status may be lost, Lee (2001) asserts that agency should not be confused with independence. Whilst the conceptualisation of children as 'beings', has helped to focus attention on their experiences and 
actions in the present they are also developing and can be viewed as incomplete, as can adults, and therefore must be seen as 'becomings' as well as 'beings' (Prout 2002)

\subsubsection{Childhood as a generational concept}

The concept of generation is often used as a means of identifying ways in which people are able, or not able, to relate to each on the basis of age. By identifying others, or ourselves, as members of a particular age-cohort, or generation, who experienced similar social factors, we also provide a location in historical time (Arber 2003). In kinship terms generation implies genealogies and succession along family lines, although it is also used to indicate 'social' descent, as in 'second generation sociologists' (Alanen 2001a:14 referring to Corsten 1999). Mannheim's work is relevant here. He was interested in whether, through the passage of time and the sharing of similar experiences, a generation became constructed, in terms of sharing a collective identity that influences their behaviour and makes it different from other generations. For Mannheim, 'whether or not a generation exists is an empirical and contingent question' (Prout 2005: 77). In contrast, for Alanen (2001a), generation is a structure which separates children from adults as a social group and it becomes necessary to use the term as a concept once child-adult differences are established. The concept is therefore applicable to all children at all times (Christensen and Prout 2003). Alanen (2001a; 2004) examines the ways in which the term is used in childhood sociology, differentiating between the sociologies of children, deconstructive sociology and the structural sociology of childhood. In the former two, she views the use of generation primarily as a descriptive notion, including children's 'experiences or views of other generational groupings' (Alanen 2001a: 12). However, when the phenomenon of childhood is seen in a structural context, 
“generation' becomes an analytical issue and a problem to work on' (Alanen 2001a: 13). Alanen's approach differs from Qvortrop's (1994) interest in the concept of generation primarily in terms of a macro-analytical approach, for although she views the idea of 'generationing' as being linked to structural elements, she considers that focus on relational practices enables generation to be used within the micro-study of children's everyday lives (Alanen 2001a). Use of the term 'relational thinking', enables examination of the possibilities and limitations 'determined by the specific structures (regimes, orders) within which persons are positioned as children' together with greater consideration of children as agents not just actors (Alanen 2001a: 21).

Mayall (2001) argues that a generational perspective is useful for examining child-adult relations on three levels: interactions between individual children and adults; interactions between groups of children and groups of adults; and the separation of children from other social groups as generations or cohorts. The following three examples are of studies that specifically take a generational approach. The first examined individual child-adult relations. Alanen's (2001b) concern with problematising the generational structuring of children and parents and the generational structures involved in producing specific generational practices led her to examine the origins of these processes and whether their source was from within the family or wider networks. In the next two studies, whilst interactions between individual children and adults are considered, the primary focus is on relations between the two groups. Thomson et al seek to understand how social and intergenerational changes affect sources of moral authority. In reflecting upon their methods, they found that the conversations between young people and adults enabled 'a negotiation of meanings and relationships between the generations' (2003: 77). In their study of young people's 
participation in an arts organisation, Mannion and l'Anson found that the approach of involving young people in the research process enabled reflection upon the relational process. Their analysis of the practices within the organisation revealed the overlapping child and adult identities and both children and adults as 'partial 'becomings" (2004: 316). The results of both these studies indicate that the adults involved reassessed their generational position in relation to that of children.

The use of a relational approach enables generation, rather than children, to become the focus of concern, in a process similar to the way in which concern for women and their lives has shifted to the study of gender (Prout 2005). In viewing childhood as a permanent element of the social life, generation is conceptualised as a structure, similar to those of class, gender or race (Alanen 2001a; 2003; 2004). Arguments over ontological differences and natural rights, together with concerns about the power of one social group to manipulate, coerce or treat another group differently, previously present in relation to concepts of class, gender and race, have also arisen in relation to generation (Qvortrop 1994). Adults can be seen to use their power and position to define what it means to be adult and have othered children in a similar way to the dominant group's use of othering through sexism and racism. In viewing a link with feminist sociology, Mayall (2002) sees the study of generationing processes as essentially a political move to raise the social status of children.

In practical terms, one way in which these processes can be observed, in interactions between individual children and adults and those between the two social groups, is through the use of Mayall's notion of generational proximity as: 
'a continuum ranging from conflict to harmony in child-adult relations, where at one end the generations may be experienced as separate and in opposition to each other and at the other children and adults may be engaged in a joint enterprise, in harmony with similar goals, and with a mutual reinforcement of their satisfaction with the enterprise and the social relationships embedded in it and strengthened through it'.

Mayall (1998: 138)

Whilst viewing a generational approach as a useful means of considering, in principle, the constructions of both childhood and adulthood, Prout considers that this approach, along with focus on the lifecourse, needs to problematise the taken-for granted dualism of childhood and adulthood and 'trace the heterogeneous networks within which they are constructed' (2005: 144).

\subsection{3}

Theorising age

Alanen (2001b) considers that relational conceptualisation can be viewed as separate to and unconnected with age, and Mayall states that children can be viewed as a 'minority' where the commonalities of being a child 'override details of gender, ethnicity and age' (2002: 137). Yet there is concern that 'children' are presented as a homogenous group without differentiation in terms of the complex and contradictory phenomena of gender and ethnicity (Morrow and Connolly 2006). Thorne (2004a) suggests that age differentials within childhood should be brought more into focus when considering the relevance of the intersection of other lines of difference and inequality.

Whilst there is general acceptance of Ritala-Koskinen's (1994) suggestion, that there is no one childhood that is the same for all children, there is also recognition that children face a commonality of generationally based exclusion and encountered experiences resulting from their assignment to 
the structural category of child (Matthews 2003; Qvortrop 1994). Age can be viewed as an essential characteristic of childhood, not only in terms of providing the key division between childhood and adulthood, but between children. In societies where it is used as the indicator for status 'it can be viewed as a 'social' rather than 'natural' variable among children' (James et al 1998: 175).

In everyday life in the UK, childhood is separated from adulthood on the basis of age and within childhood there are various markers, delineated by age, which chart a child's progress towards adulthood. When the study of childhood was concerned with explanations of children's development and socialisation in the norms of society, the focus was on infancy and adolescence (James et al 1998). Teenagers as a social category are viewed as troublesome and experience anxiety in relation to their social status (Cahill 1990; Holloway and Valentine 2000; Gordon et al 2005). In contrast, children in the middle years, defined as between the ages of 8 and 12 years (or sometimes between those of 4 and 10 years) are seen as unproblematic (Borland et al 1998; James et al 1998; Jones and Cunningham 1999).

Yet, within childhood studies there is a now a growing number of articles relating to research undertaken with children in their middle years, for example, those in the ESRC Childhood 5-16 Programme. The reason for the apparently growing interest in the middle years of childhood is unclear because, as James et al (1998) state, researchers do not always specify why they selected this particular age group for study. However, it appears that one reason may be the range of changes faced by this age group. It is suggested that around the ages of 10-12 children's experiences of the public world increase significantly (Hart 1979; Jones and Cunningham 1999; 
Valentine 2004). They are given greater 'parental licence' (Hillman et al 1990; O'Brien et al 2000) to venture to more places. Researchers in the UK have also focused on the particular changes faced by this age group. For example, the transition from Primary and Secondary school (see Lucey and Reay 2000; Graham and Hill 2003) Caulfield et al 2005; Weller 2007) where the move from being the oldest in the primary school to being the youngest at secondary is seen as 'a rite of passage' (Pratt and George 2005: 16). In addition, this transition is associated with travelling further to school and with growing autonomy and greater choices in independent movement (Brannen et al 2000; Jones and Cunningham 1999). The individualisation process is also likely to be more intense in the approach to early adolescence (Brannen et al 2000: 6)

Whilst studies may focus on a particular age of children because of the nature of research questions, or because age provides a convenient tool for selecting a population to study (Qvortrup 1994), James et al (1998) suggest that there should be a questioning of taken-for-granted differences. This could include how age categories, meanings and relations are constructed through everyday interactions, and not only institutionally, as in Solberg's (1990) work on how the content of Norwegian childhoods was shaped through parent-child negotiation.

\subsection{The places and spaces of childhood}

In addition to the positioning of children in social space, they are also located physically in particular places. Physical space is considered as 'a distance stretching out in all directions'; whereas place is 'a more delimited setting...a space with special meanings and attributes' (Rasmussen 2004: 165, drawing 
on Relph 1976). The idea of place, as a space designated by those who experience it and attribute meanings to it, enables links to be made between views of children's 'place' in society and "proper' places for children' (Connolly and Ennew 1996: 131). Children are noticeable in relation to their setting, whether they are seen to be in places designated as appropriate for them, or viewed as out of place, because they are in adult territory (James et al 1998).

This section considers the ways in which places and spaces of the everyday worlds of children, in middle childhood have been researched and theorised, making a distinction between the location of children in appropriate settings, the home, school and other institutions, and children in places and spaces beyond these, in settings that are generally termed public. When considering how children manage spaces, in terms of the ambiguities between the regulation of their lives by adults and the greater acceptance of their agency, the notion of boundary is useful (Hill 2005b). The term, used by parents to establish limits to their children's movements and relationships, is also relevant when considering how children themselves negotiate social space, and risk. The examination of children and risk is a key concern in academic and lay discussions on children in the public world. In addition, a related area of study, which is gaining more academic interest, is that of the children's mobilities.

\subsection{1}

\section{Home, school and 'club': The 'right' places for children?}

Social attitude studies in the UK tend to find that the home, and with mother, are seen as the most appropriate place for young children to spend their time before they are old enough to enter the institutionalised setting of the school (Himmelweit and Sigala 2004). It is therefore unsurprising that there is an 
everyday assumption that these are the 'right' places for children to be. In viewing children as members and the responsibility of their families, and particularly their parents, their lives have been familialised and 'the home' is seen to create a sense belonging in the togetherness of the family, which is separate from the rest of the world (Brannen and O'Brien 1996). When studies have focussed on children within the family and in domestic space the term 'home' is used not only to refer to the physical space of the house, but also to the nature of family life (McKie and Lombard 2005). Qvortrop (1994) asks if the notion of childhood is viewed as belonging to the family or as being more institutionalised outside the family. However, Oldman (1994) sees the two notions as complementary rather than as contradictory. Not only are there a range out of school care clubs, to support working parents, but parents can benefit from children's placement in institutions, because of the employment opportunities such settings offer in 'childwork' (Oldman 1994: 45).

The application of a stage of schooling to define an age group of children, as in primary-aged children, also appears to reflect a normative usage in defining children by school attendance. Schools and children's clubs separate children into protected settings 'environments which have been created by adults and designated [as such] by them' (Rasmussen 2004: 155). Smith and Barker (2000), in outlining recent UK policy to expand the amount of out of school provision express academic concerns about the institutionalisation of children's activities. No longer is children's childhood activity of play unprogrammed or controlled by those engaged it, but instead it is organised by adults (Jones and Cunningham 1999; Chawla and Malone 2003; Mayall 1998). Not only is play structured by adults in out of school clubs but also in 
commercial playgrounds (Alder and Alder 1994; Smith and Barker 2000; McKendrick et al 2000).

Rasamussen and Smidt define the home, school and organised leisure activities for children as the 'institutionalised triangle' (2003: 97). Although this is possibly more of a feature for Danish (Rasamussen and Smidt 2003), Finnish (Alanen 2001b) and German (Zeiher 2003) children in their middle years, there are similar echoes in Britain. Alanen (2001b) identifies four principle domains in which children spend time: friendship, family, school and special interest. Zeiher (2001b) concludes that one impact of the institutionalisation, or insularisation of children's lives, is that they were only visible as they move between 'islands' of activity. The process of ferrying children between such places is also seen further to limit their social presence (Bucher 1990).

However, the home and school should not be viewed as bounded spaces, but as porous and interconnected with other aspects of the lives of children and their families (Holloway and Valentine 2000). Similarly, Hill considers that the boundaries between the private home and the public world are increasingly artificial with electronic media 'bringing the world at large into the home' (2005b: 80).

\subsubsection{Children in public spaces and places}

Despite the apparent tendency towards the conceptualisation of childhood in terms of familialisation, institutionalisation or insularisation, there has been interest in children's lives in the public realm and studies of their use of local environments dating back to the mid 1950s (O'Brien et al 2000). In laying out an agenda for the geography of children, particularly in relation to contemporary western (urban) societies, Matthews and Limb (1999) suggest 
that researchers should examine how children experience and see the world beyond the home, school and playground. In focusing on these areas, that they term the 'fourth environment', they are concerned with 'a geography of the outdoors' (Matthews and Limb 1999: 65). Matthews suggests how 'the street', as a metaphor for 'outdoor spaces in the public domain, acts as a liminal setting or a site of passage' (2003: 101).

Various studies examine children's use of, and relationship to, the physical and built environments of the external world (Valentine et al 1998; Matthews et al 2000; O'Brien et al 2000; Ross 2002; Chawla and Malone 2003; Rasamussen and Smidt 2003; Elsley 2004; Thomas 2005; Woolley 2006). This includes how they construct meanings and respond to the world around them. In these studies interest primarily focuses on what Rasmussen refers to 'children's places' (2004:165) in terms of the places that children connect with and create, rather than 'places for children' (2004:165) which are those that have been defined for them by adults. A further field of study considers children in the public space, as opposed to that which is private or institutionalised. Here the focus is mainly on children in their neighbourhoods and opportunities for their participation and involvement in community activities such as renewal projects (Mathews et al undated; O'Brien 2003). There is often overlap between the two areas of interest especially in relation to children's feelings about their neighbourhood and notions of social capital. Furthermore, Horton and Kraftl (2006) suggest that children's geographies should focus on children's everyday practices and performances of geographies, with specific consideration of the ways in which meanings and knowledge are perceived and represented through the body and emotions. 
Public space includes areas and locales in towns and cities, outside the private space of the home and workplace, 'where people can congregate, socialise and organise in relatively unregulated ways'. Private life occurs within the domestic realm, with public life taking place in all other areas outside it. Public open spaces include areas in local neighbourhoods such as local parks and playgrounds recognised as children's play areas. Although shopping malls may be seen as public spaces or places, Valentine views them as "surrogate "private spaces" (2004: 84). An additional distinction is given to notions of public spaces by Harden (2000) who distinguishes between different spheres of public space, with children tending to regard those nearest to their houses as local and those further away as public. Whilst the notions of public and private domains are popularly used, Sheller and Urry suggest that they should be dispensed with as increasingly mobility in various forms enables people to be 'public in private' and 'private in public' (Sheller and Urry 2003; Sheller 2004: 108).

Within public space, there is an expectation for children to be invisible (Mathews 2003). Unaccompanied children are viewed as not belonging, and older children are expected to defer to adult expectations. The control of spatiality, and what constitutes acceptable behaviour, is part of the process of defining the social category of youth and child as non-adult and adult hostility used as an expression of adult power (Massey 1998; Valentine 2004). Whilst concern may be expressed for young children, there is an 'institutionalised mistrust of marginalised youth' (Stephen and Squires 2004) resulting in desires for their exclusion. Valentine (2004) asks whether public areas can really be called such, if young people are marginalised or excluded. 
Examination of children's relationships with spaces and places in their local neighbourhoods has included the links between children's views of their neighbourhood and social cohesion and social capital (Chawla and Malone 2003; Morrow 1999b, 2003; Sampson et al 1999). Public space can be viewed as both a backdrop for social relations and a product of them (Valentine 2004). In their physical move away from the constraints of childhood the street offers children a site for developing an understanding of social relations in the transition to adulthood (Matthews 2003). In starting from the view that 'the liveability of public spaces is a key policy concern' Dines et al $(2006 ; 1)$ examine the role of open public spaces (for adults) in providing places for social encounters where people can experience diversity (they were primarily concerned with ethnic diversity) on an everyday basis. They found that places which offered possibilities for casual social encounters helped build tolerant attitudes and were seen as key elements in people's commitment to their area. The building of tolerance between social groups is also reflected in Mitchell et al's argument for a greater presence of children in public environments as a means of enhancing communities. However, they do recognise the barriers of the social construction of children as vulnerable in discouraging them 'not only from talking to strangers but also from acknowledging 'unknown adults' in the public domain' (2007: 616)

\subsubsection{Children and risk in public}

When considering why children are often viewed as 'out of place' beyond home, school and club, and in public, the concept of risk arises. Whether this is because of their age and the assumption that they are at risk, 'in danger' if not accompanied by an adult, or that as teenagers they are seen as troublesome and 'a danger' (Cahill 1990: 395). 
Concern with the risks to children, or indeed from them, is reflective of the general risk anxiety that pervades late modernity. Whether risks are greater or lesser than in previous times their character is different and their impact greater, particularly because of a 'heightened degree of risk reflexivity'. Such reflexivity may, in Gidden's view, result in lay people having a reliance on expert knowledge or produce, in Beck's terms, a 'critique of expertise' (Lupton 1999: 181). Both of these views result in a tendency to believe that children's participation in the public world needs overseeing by adults (Harden 2000). Furthermore, a tendency for parents and children to externalise risk and public concerns about the risks to children in the world beyond the home and the school, have resulted in a proliferation of media interest in, and child safety campaigns focusing on, the concept of stranger danger.

Parental and child perceptions of physical and social risks in the world outside the home are the concern of various studies (Valentine 1997b; 1997c; 1997d; Kelley et al 1998; Scott et al 1998; Harden 2000; Backett-Milburn and Harden 2004). This includes children's safety strategies and help-seeking behaviours (Pain et al 2005; Turner et al 2006; Spilsbury 2002). Harden (2000) found that in theorising about risk, children differentiated between risks in the local sphere and those in public life, the distinction being familiarity or unfamiliarity with places and the people in them. She reports that, whilst acknowledging the message of stranger danger, the children in her study found contradictions in it and did not always accept it. They recognised the importance of broadening their range of experiences in order to develop their own knowledge of places and people. However, such opportunities were limited by adult structures and this factor, together with parental and public 
risk anxiety, resulted in children's lack of trust in other people and a view of public places as risky (Harden 2000).

Scott et al (1998) suggest that this risk anxiety needs to be set in the context of children's daily lives; how they move around and the nature and location of leisure spaces and places. Whilst children may welcome the preventative aspects of adult control Kelley et al (1997) report that they also experience these as restricting. Christensen and Mikkelsen (2008) argue that children occupy complex landscapes of risk in their everyday activities and that risk engagement is an important resource through which they learn from their own mistakes.

Traditionally, girls have been perceived as at greater risk in public space than have boys. However, Valentine's research suggests:

\begin{abstract}
'that parents held a more complex and contradictory view of gender, viewing girls as more capable of negotiating public space safely than boys because they are thought to have greater self-awareness, sexual maturity and sense of responsibility'
\end{abstract}

(Valentine 1997a: 57)

Furthermore, although concern about children in public space may be well meaning, it appears to result in an increasing control of children's everyday lives, limiting their freedom and subsequently making the world a more dangerous place for them (Mcneis and Gill 2006). Additionally, polices and services developed for children are increasingly separated from those relating to adults (Mcneish and Gill 2006). As a result of studying how children from disadvantaged areas deal with risks within their own communities, Turner et al (2006) found that the children's main approach was the avoidance of difficult situations and learning from each other. 
Turner et al suggest that 'adult interventions value and integrate with the measures used by young people themselves to keep safe' (2006: 463).

\subsubsection{Children's mobility}

Interest in the ways in which children, in their middle years explore the world beyond the family, in terms of the spaces and places beyond their houses has involved examination of their independent mobilities (Hillman et al 1990; O'Brien et al 2000). Children's mobility in the city and opportunities for interaction is viewed as an essential part of city life (O'Brien et al 2000, referring to Webber). Yet $\mathrm{O}^{\prime}$ Brien et al (2000) report academic and media concern that children are becoming too controlled and are loosing the freedom to range. Whilst these studies examine children's movements independently of adults, Meire suggests that they are not necessarily autonomous:

'Independent mobility' is defined as the freedom given to children (by their parents) to travel around on their own - without adult supervision or more specifically without being accompanied by an adult...but [they can] nevertheless be monitored in an indirect way...'autonomous mobility' implies freedom of movement and of choice.'

Meire (2004:103)

The extent of children's experiences of the public world is seen to increase around the ages of 10-12, as they are given greater parental licence (Hillman et al 1990; O'Brien et al 2000). This includes permission to venture to more places, including city centres (Woolley et al 1999). Whilst there has been an indication of a slight decline in independent mobility only a minority of children were found to lead very spatially restricted lives (Hillman et al 1990; O'Brien et al 2000; O'Brien 2003). O'Brien's (2003) finding that this included slightly more girls and children from minority ethnic families supports those 
of Hart (1979) and Moore (1986) although Valentine (1997a) and Matthews et al (2000a) consider that the gender gap is narrowing.

As non-car users, children may rely on parental lifts to access places due to parental restrictions or through their own heightened sense of danger (Barker 2006). Such reliance could limit children's autonomous movements, thereby decreasing their independence. Furthermore, children, along with poor people, can be seen as 'automobility's immobilized others' (Thomsen 2004). For not only are some places only accessible by car, and greater car use increases accident rates for pedestrians, but also independent mobility is decreased because of concerns about personal risk:

'Whereas the car driver minimizes personal risks by increasing the safety of the car, the risks that non-drivers face from automobility are to a great extent beyond personal choice and may thus be understood in terms of danger.'

Thomsen (2004: 516 referring to Luhmann 1991)

When considering the necessity of travel for social life, Urry (2003) suggests that people need to travel to fulfil a range of obligations. His paper focuses on adults, but the two obligations that appear most relevant to children are those of social obligation, and an obligation to place. In relation to social obligation he speaks of particular obligations to familial celebrations and occasions, in the sense that people may feel that they have to attend such events as birthdays and family meals. Whilst children may be involved in such events, their attendance may be more a matter of compulsion rather than an obligated choice. Where choice, and, therefore, a sense of individual obligation, might be more apparent is in a child's autonomous decision to visit a friend or family member. Children, like adults, may choose to make physical visits, because, despite the increasing range of ways of maintaining 
contacts, there are strong normative expectations of face-to-face meetings. 'As Goffman argued: 'Co-presence renders persons uniquely accessible, available, and subject to one another" (Urry 2003: 163).

Urry's concept of obligation to place also involves the notion of embodiment. He argues that people need to visit places such as the seaside and historic houses not just to see them, as they could in a book or on film, but to 'experience 'for oneself', directly through a 'face-to-place' co-presence with the body immersed in that 'other' place' (Urry 2003: 163).

A developing area of study, relevant to children's mobilities in the public world and their embodied experiences, is that of children's consumer culture: what they buy, take in, desire and the identities that are constructed for and by them (Khan, 2006). For Khan this consumption was principally concerned with goods, although he does mention movies and theme parks. Cook's (2003) interest in children's consumer biographies includes the emplacement of meanings. That is the meanings, producers and children as consumers, applied to specific spaces and places. He concluded that commercial selling spaces directed at children both affirmed children as legitimate social actors and reinforced distinctions between child and adult. Although interest in this field is predominantly in the USA (also see Linn 2004; Martens et al 2004), Russell and Tyler (2005) examine the place of gendered consumer culture in girls' transition from childhood to teenage status.

Some attention has also been paid to children as consumers of transport, fulfilling social obligations and connecting with their social networks and also enjoying the process of travel as a social experience (Urry 2003; 
Axhausen 2002). Miere (2003) refers to children's group movements as semi rather than fully autonomous mobility.

Information and communication networks may appear to decrease the necessity of travel, as people are able to remain in the privatized spaces of the home and car and still be in touch with wider social networks. Nevertheless:

'The enacting of new practices of mobility and communication enwraps those who are excluded as much as those who are included insofar as infrastructural and cultural changes have far reaching effects on the entire realm of political and social action.'

(Sheller 2004:46)

This statement highlights the possible impact of new practices of mobility on children's presence in the public world. If less affluent adults and children are restricted in their access to new forms of information and communication they could become socially isolated and politically disenfranchised. Thus, children's invisibility, or their visibility, in spaces and places beyond the school and organised facilities could become more problematic and risky. Furthermore, if there is a reconceptualisation of the purpose and design of such public provision for children, particularly in relation to a discourse that views some children as vulnerable and others as threatening, there is the possibility for the reconfiguration of not only child-adult relationships, but also of those between adults (Moss and Petrie 2002).

\subsection{Child-adult contacts and relationships}

Social relations between adults and children have been considered in studies of children's geographies. Local neighbourhoods are viewed as providing 
spaces and places of interaction (More 1986). Contacts between people are considered to be important for creating a sense of belonging within these localities (Morrow 2003). Yet, there has been relatively little specific research on child-adult face-to-face interactions in local or public arenas, or of broader social relations between the categories of children and adults. Additionally, whilst there is recognition of the impacts of friendships, neighbourhood and wider political, economic and social contexts on children's lives, studies of their personal relationships and the interconnecting networks, have centred primarily on kin, peers, and formal others (Brannen et al 2000).

Given the amount of information on couple and parent-child relationships, and the fact that other adult personal relationships are relatively underresearched this lack of information on children's relationships is unsurprising (Jamieson et al 2006). Interest in the role of personal relationships in relation to social connectedness, and in the changing nature of practices of intimacy has not extended to children.

\subsubsection{Familial child-adult contacts and relationships}

When considering familial child-adult relations there appears to be an assumption that children belong with, and are the responsibility of, their families. Despite the increase in divorce and co-habitation rates, most children in the UK live in families. However, the term family is not a neutral one: it is socially constructed and applied to a variety of configurations of people and relationships who may, or may not, be included in family activities (Sirota 2001). Smart et al (2001) suggest that families are whatever family members say they are. The idea of family involves the interconnectedness of individuals, where social ties are seen as more important than family form (Brannen et al 2000). Therefore, it may be more appropriate 
to speak of 'doing family', rather than of 'being family' (Morgan 1996; Silva and Smart 1999). Finch (2007) extends this theorising further by suggesting the importance of 'display' in contemporary family relationships. Brannen et al's (2000) argument is that the doing needs to be displayed and understood by others in order to be effective. When there are changes in family relationships across space and time and personal identities there may be a need for the idea of 'family' to be established, or re-established. As an example, Finch (2007, referring to Gillies et al 2003), points to the need for a renegotiated parent-teenager relationship to be displayed, in recognition of the child becoming an adult. Tools used in the process of display include physical objects, gift giving and family narratives.

Research interest in the impact of these changing family forms on children's everyday lives and their experiences of childhood has been concerned with transformations at a macro-level and negotiations at a micro-level (Jensen and McKie 2003). For example, Ribbens McCarthy et al (2000) examine how divorce, separation and re-partnering influenced adult views of children as dependent and constructions of child, adult and of family responsibilities. Although the focus of studies has been on the children, this appears to be on the basis of adult accounts. Smart (2006) suggests that there is little knowledge of children's views, possibly because children are not encouraged to speak about their family relationships in public because the family is still a private matter.

If children belong in and with their families, the most central relationship they have with an adult is that with a parent or parental substitutes. The 'family' is seen to shape the content of childhood primarily through parentchild interaction, specifically negotiation (Solberg 1990). Notions of family 
relations and the child-parent relationships are not always clear and appear to be intertwined. For example, the value which children attach to receiving care and respect from their families, together with the ability to be themselves could be viewed as being given primarily by a parent, or parental substitutes. Likewise, recognition of their agency, rather than their dependency particularly in terms of care and well-being is likely to come from parents. However, interdependency and reciprocity are also features of adults' familial and family-like relationships (Crow and Allan 1994; Pahl and Spencer 2004).

Although many studies have not sought to distinguish between children's relationships with their mothers and those with their fathers, Mayall (2002) notes the particular importance of mothers in children's accounts, and Hallden (1994) found different patterns of interaction between mothers and daughters and mothers and sons. Studies have focussed on parent-child interactions in terms of the child's socialisation (Hill and Tisdall 1997). However, within the increasing recognition of children's agency and role in their own development, interest has developed in the role that negotiation plays in parent-child communications and interactions (Solberg 1990; Borland et al 1998). Whilst children recognise and accept parental authority in terms of provision and protection, they also wish their competencies to be recognised (Brannen et al 2000; Mayall 2002).

There has been reference to the place of extended kin in the lives of children including grandparents, and especially grandmothers (Morrow 1998; Brannen et al 2000; Smart et al 2001; Hill and Tisdall 1997; Ross et al 2005) Mayall 2002). However, in general, there has been little detail, and the voices of children in their middle years have been missing or overshadowed by 
those of adults. Additionally, although there have been studies of children's perceptions of their sibling relationships ( see McNamee, 1997; Morrow 1998; Brannen et al 2000; Mauthner 2002; 2005; Edwards et al 2005a; 2005b; Gillies and Lucey 2006; Punch 2007), there has been little reference to relationships between children and their adult siblings, i.e. those over 18 .

\subsubsection{Child-adult contacts and relationships in institutional settings}

As a primary site of childhood in the middle years, the school is a very different social environment from the home especially in relation to the interpretation of children's agency (Hill and Tisdall 1997; Mayall 1994b). In school, teacher authority and the purposes and functions of education result in child-adult relations being characterised by power and control. Children's status is subordinate as they are treated as a group and as objects, or projects, of socialisation. Further more individual relationships between teachers and pupils are viewed as inappropriate (Devine 2002; Mayall 1994b; 1998). Children strive for identity and desire connections with other children, producing what Devine calls child culture in 'the backstage regions of school life' (2002: 315). In this context children are seen to make secondary adjustments to the rules by appearing to follow instructions, whilst actually disregarding them (Corsaro 1997; Thorne 2004b). In order to gain their cooperation in the learning process teachers need to negotiate or bargain with children, as a group, and child culture becomes 'front stage' (Devine 2002: 316)

In addition to considering teachers to be formal others in children's lives Brannen et al (2000) found that children also referred to their relationships with doctors and social workers. There is recognition of children's contacts with a range of professional workers and others who organise activities for 
children in, and out, of school (Rasamussen and Smidt 2003; Oldman 1994). This has promoted discussion of child-adult interactions as an aspect of the institutionalisation of play and the formalisation of children's contacts with adults (McKendrick and Bradford 2001; Smith and Barker 2000; Alanen 2001b; Zeither 2003a; Oldman 1994). James et al (1998: 189) view these as 'mediated relationships' centred on adult organised activities. Whilst a child may identify with a worker through their gender or ethnicity, children tend to see themselves treated as group members rather than individuals, in a process similar to pupil-teacher interactions (Barker and Smith 2001; Milne 2003).

Williamson and Butler (1995) mention 'helping' adults and provide details of the nature of child-adult relationships in terms of the reasons children talked, or did not talk, to adults. The views children expressed in that study, such as the importance of adults listening to them, are reflected in the Children's Charter (Scottish Executive 2004). In addition, when speaking to young people in residential care, Hallett et al (2003) found a perception that talking to an adult could result in problems being made worse.

Although studies have examined informal supports in later adolescence (see Blyth et al 1982; Beam et al 2002), there appears to be little research on childadult relationships within the growing range of 'professional' supports available to primary aged children through various programmes ${ }^{4}$ Additionally, despite the developing range of children's participation projects and initiatives, investigation of the nature of child-adult relations and relationship generally appears limited (although see Kirby and Gibbs 2006; Blanchet-Cohen and Rainbow 2006). However, Mannion and l'Anson

\footnotetext{
${ }^{4}$ For example 'Big Brother, Big Sister'; 'Pyramid Trust for Children'; 'The Place 2 Be'.
} 
(2004) provide a useful, if adult focussed, discussion of the benefits to adultchild relations from children's participation in an arts organisation. In addition to children's participation in various adult structures, there is interest in the development of intergenerational programmes as a means of addressing issues of social deprivation and social exclusion within communities. In the assessment of a secondary school's intergenerational mentoring project, its value was viewed as follows:

'It has helped to create, in part at least, a more inclusive local society in which active citizenship through the mentor volunteers has helped young people develop positive intergenerational relationships and a more productive outlook for their collective futures.'

Ellis (2003: 40)

This is obviously an adult viewpoint and the report lacks any mention of the views that the young people may have had. What benefits did they think that the adult mentor volunteers might have gained in relation to developing positive intergenerational relationships?

\subsubsection{Children's contacts and relationships with other adults}

In addition to the study of children's participation in institutional settings, there has been interest in their involvement in community activities ${ }^{5}$. Such interest appears to stem partly from the participation side of the Children's Rights agenda and also from interest in children's wellbeing and the impact their neighbourhoods have on various realms of children's lives (for example, see Morrow 2000; Backett-Milburn et al 2003). Social relations within the neighbourhood are viewed as important for individual social identity and life chances and are also mentioned by children as indicators of social cohesion (Forrest and Kearns 2001; Chawla and Malone 2003). Forrest

${ }^{5}$ See 2.2 .2 
and Kearns point to the role that 'low levels of interaction, acquaintance, courtesy and everyday kindness' (2001: 2132) play in positive neighbourhood relations, suggesting that these aspects of interpersonal contact might be particularly important for children, because of their limited resources.

Previous studies mention children's relationships with neighbours and parental friends (Morrow 2000; 2004). Some also use Brofenbrenner's concept of micro-, meso- and exosystems to examine different levels of children's social networks (Nestmann and Hurrelmann 1994; McKendrick et al 1998). Whilst relatively few data are available from these studies the importance of particular adults to adolescents, as examined by Blyth et al (1982) and Beam et al (2002), points to the importance of characteristics such as being fun to be with (Beam et al 2002). In addition, Turner et al (2006) outline the spectrum of children's views about adults in their communities from those who were friendly and helpful, to problems with neighbours and strange adults. Concerns with children's safety, in relation to their contact with adults beyond the family and institutional settings, might appear to be a plausible reason for the lack of data, yet it is only fairly recently that studies have explored adult relationships beyond the family. For example, Allan (1996) examines adult social networks and the interconnections between an individual person's different sets of relationships. Others studies focus on neighbour relations and relationships (Crow et al 2002; Boyce 2006; Stokoe 2006). Within the study of intimate relationships there is a developing interest in the personal relationships of adults beyond those of co-resident couple-hood (Jamieson et al 2006). There is a conclusion that 'personal relationships have become more contingent, negotiated and self-directed' (Gillies 2003: 2). Yet, if social ties are narrower and relationships more private, particularly within the home as suggested by Morgan (1996), 
Jamieson (2003) asks what opportunities there are for children to engage in 'practices of intimacy' beyond the family.

In addition to contacts with familiar adults, children's mobilities in the world beyond their neighbourhoods bring them into contact with 'unknowns' (Wells 2005). Cahill (1990) provides details about child-adult relations in public spaces. He explored the collective conceptions of children and childhood in America through observations and reports of children's participation, behaviour and treatment in public life (streets, shops, parks, restaurants). One issue he identifies is that of moral responsibility, the notion that somebody must hold responsibility for a child's behaviour. If a child cannot take responsibility for itself, someone who will take responsibility for them must accompany them. He states that older children are continually monitored by adults because 'unlike adults they are seldom given the benefit of doubt and unlike younger children, they are not relieved of moral responsibility for their acts' (Cahill 1990: 398). The result is an asymmetrical, and often strained, relationship between children and adults in public places, and a desire for segregation in time and place (Cahill 1990). Hillman calls for:

'Environments which are 'accessible to children outside the home ... free of overt adult supervision and rich in opportunities for stimulating their interaction both with friends and strangers so that they can best develop socially and emotionally as well as physically.'

Hillman (2006: 67)

There are a number of reports reflecting social and political concern about negative public attitudes towards children and young people (see Anderson et al 2005; Margo et al 2006; SCCYP 2007; Furedi 2008; Barnardo's 2008) and 'paedophobia' (Guardian 2006). The Scottish Government's recent television campaign, 'See the person, not the age', seeks not only to 'highlight the 
positive and valuable contributions that older people make to life in Scotland today... [But] it also looks at the similar negative perceptions faced by younger people' (Scottish Government 2008).

\section{$2.4 \quad$ Conclusion}

The examination of studies of children's lives presented in this chapter reveals limited information, other than with parents and school teachers, on the nature, construction and impact of children's contacts and relationships with adults. There is also a growing interest in children's internal knowledge and how they construct meanings and respond to the world around them. However, most studies of children and their neighbourhoods have concentrated on the physical aspects and given little detail of social interactions. In particular, there appears to have been no specific study of the social relations and relationships between children and adults within local neighbourhoods.

Adult conceptualisations of the nature of children and childhood appear to have resulted in informal contacts between children and adults, especially unknown adults, being seen as representing 'a risk', not only to children from adults, but also to adults from children. The increasing institutionalisation of children and the view that children's relationships with adults are centred on kin suggests that the separation of children and adults is probably most marked where informal relationships, with neighbours, family friends and other adults, are concerned. Comparison with the study of adult relationships, where interest in neighbour relations and intimate relationships other than couple relationships is only relatively recent, suggests that there may be a general form of sociological privileging 
of formal over informal relationships. Focus on parent-child and teacherpupil relationships may reinforce social policies that exacerbate the tendency to privatisation, family orientedness and institutionalisation of childhood. Consequently, there appears to be a need for empirical work that focuses on the nature of informal child-adult contacts, inter-actions and relationships. 


\section{Chapter 3}

\section{METHODOLOGY}

Within this study I have prioritised children's voices and sought to engage with them as active participants, through an iterative, multi-stage methodological approach. Data were collected through participant observation, interviews and a self-completion questionnaire survey. Family trees were also produced by the interviewees.

The chapter begins with an overview of the methods used and details of the child participants. Subsequent sections contain further reflection on my methodology, choice of data collection techniques and ethical issues.

\subsection{Overview}

This section presents details of the rationale for the choice of particular methods, their purpose and the ways in which they were operationalised. A chart of the timings of each data collection and analysis stage is provided, together with details of the research participants.

\subsubsection{Methods: The rationale and operation}

Each phase of data collection was informed by the previous ones to enable the children to express their views and contribute their knowledge.

\section{Familiarisation through participant observation}

Although I agree with the point made by Leyshon 2002, in his study of young people in rural areas, that schools are settings in which contacts between children and adult researchers are legitimised I also recognised that 
conducting interviews in the context of this institutionalised setting could produce barriers for children. I therefore decided to begin with a 3 month period of familiarisation.

Through the method of participant observation I sought to get to know the children, sensitise myself to their language and perspectives and access their 'cultures of communication' (Christensen and James 2000: 7). This process provided opportunities for the children to get to know me, the purpose of my research and laid the foundation for the development of research relationships within the subsequent interviews.

The familiarisation process was undertaken through twice weekly visits to Swinburn Primary School during the summer term of 2004. These visits were timed to include morning break and lunch periods as times when the children had most autonomy in their choice of actions and activity. I participated in playground activities, ate lunch with them and sat in class joining in lessons, or helping with their work. Although I spoke with the teachers, I positioned myself in a 'least adult' role with the children and rarely ventured into the staffroom (Mandell 1991).

Towards the end of the familiarisation phase most ${ }^{6}$ of the P6 children participated in group discussions, where they each selected a pseudonym. I had organised these as a forum for the children to talk about the research and to consider if they wanted to take part in the next phase when I would be 'interviewing them', asking questions about their lives and their families.

\footnotetext{
${ }^{6}$ All of the children, except one, who were present, participated. The one child said that her mother said she was not to take part in the research.
} 
In order to maintain contact, during the school summer holidays, with the 17 children $^{7}$ who had agreed, and been given parental permission, to participate in interviews stage, I made arrangements meet them at a local Children's Project. Over the six week holiday, 6 of these children arrived for sessions at the Project where we created their family trees, talked, but mainly spent time playing.

At the end of each day of participant observation, whether in school or the Children's Project, I made chronological accounts of my observations and encounters together with my thoughts and feelings. In addition to providing data which informed my knowledge of individual children and their daily lives, my field notes helped me to chart the development of the researcher relationship and also the children's interpretations of myself as an adult ${ }^{8}$.

\section{Task centred methods: Drawings and Family Trees}

Within the process of developing an exploratory study I had thought that task-based or project methods might be part of the participant observation or interview stages. Possibly as a structured activity as suggested by Morrow (1999a) which would provide actual data or as in Morgan's (1997) idea of a stimulus material, similar to a vignette, to promote the children's thinking (Finch 1987).

In fact, I only attempted two such activities. Firstly, I asked the children in the two P6 classes, to draw pictures of where they played when they were not in school. I suggested that they work together with those children with whom they played. I had hoped to use these drawing as stimulus materials in group or paired discussion. However, few children wanted to undertake

\footnotetext{
${ }^{7}$ List of the Children in Swinburn Primary School, see Appendix 2.

${ }^{8}$ See Chapter 7.
} 
the activity, preferring to spend their free lesson period playing. It seemed that drawing may have been too much like a school lesson. Drawings from five children are used as data in Chapter 5.

The production of family trees was a more successful activity which provided 'complementary insights' into children's accounts of their familial relationships (MacDougall et al 2005: 417). All 17 interviewees produced trees by writing the names of their relatives on different shaped pieces of paper, circles for females and triangles for males. These were then pasted onto a page in a format representing different connections between individuals, including lines for birth linkages. The information contained in these trees are used as data in Chapter 4, where 3 examples are also provided.

\section{Interviews}

When initially designing the research I had hoped to find a site in which to conduct an ethnography of child-adult relations. I had thought that conducting participant observation in a setting, beyond home and school, where children had regular and/or intense non-hierarchical ${ }^{9}$ interactions with adults, would provide a range of directly observable contacts from which to examine children experiences.

However, when this was not possible I decided to interview children to collect their accounts of their experiences of contacts, interactions and relationships with adults and their reflections about adults, adulthood and child-adult relationships. In contrast to interviews within an ethnographic

\footnotetext{
${ }^{9}$ By non-hierarchical I mean that child and adult participants are of equal status, within the setting. Whilst there may be an adult leader, there are child AND adult participants. For example in a community meeting or drama group.
} 
engagement, I was aware that the children would be removed from such relations in practice, other than those with myself and that this distance could, as Blaikie (2000) suggests, require them undertake more work in terms of recall.

I conducted initial interviews with children in pairs before individual ones. When viewing the research interview as a relational process within a particular social context as Alldred and Burman (2005) suggest, the power imbalances within a school setting can result in a child-adult interview being seen as a negative experience (Edwards and Alldred 1999). My choice to conduct the initial interviews with the children in pairs was based on a wish to follow Mayall's idea of undertaking 'research conversations with children' (2000: 122). I asked each of the children to select a friend with whom to be interviewed, with the condition that the friend had to be one of those for whom parental permission had been obtained, although one child ${ }^{10}$ insisted that I allow a different friend to join her.

During the familiarisation phase I had a range of conversations with the children and informally gained information about their lives. For the paired interviews I used an unstructured format to explore three broad topic areas:

- The adults they knew

- How they spent their time when they were not in school

- Their views of the local area.

It was my intention to develop a more semi-structured topic guide for the individual interviews from the responses to the paired ones. By not having a detailed topic guide I was able to encourage the children to lead the

10 One girl wanted her friend to join her as it was her last day at the school as she was moving away. In order to obtain this final interview I relented. 
conversations within the 3 areas of focus. Within each interview, before switching on the tape recorder I gave an explanation of the interview, asked for permission to record and reminded the children about confidentiality and anonymity. During these paired interviews joint narratives were developed between friends. However, where the children did not relate well, the process became more like a parallel interview causing difficulties for me, as the interviewer, in balancing each child's participation.

Through the process of transcribing the paired interview data I was able to identify key areas which featured across them and develop these into a more semi-structured topic guide for the individual interviews ${ }^{11}$. The main areas included: how they spend their time when not in school; places they go in and beyond the neighbourhood area; who they spend time with; their experiences and views of adults, and their reflections on their participation with an adult researcher in research on their relationships with adults.

A Friday morning was suggested by the head teacher as the least disruptive time for me to withdraw children from lessons, to conduct the paired and then the individual interviews, although the actual timing of the interviews were negotiated with each child individually. Interviews generally took place in the school library, without the presence of other adults, or children and lasted the 40 minute lesson period.

\section{Interview analysis}

The topic guide for the individual interviews served as an initial framework for interrogating and indexing all the interview data. I took an iterative and interactive process of seeking meaning within and between the paired and

\footnotetext{
${ }^{11}$ Individual Interview Topic Guide, see Appendix 4.
} 
individual accounts (see Rogers et al 2005). The familiarity I had gained of the children's lives, through participating and observing, provided me a context in which to interpret their words. All of the interviews were transcribed and initial descriptive thematic categories coded in NVivo. These codes were developed from the research objectives and the interview questions and added to as other themes arose in the process of immersion. The NVivo software was used primarily as a data management system which provided 'a way into the data' rather than representing 'analytical endproducts' Mason (1994: 94-5). The ongoing process of transforming the children's voices into theory (see Mauthner and Doucet 1998: 141 on moving from talk, to text, to theory) was undertaken by refining descriptive analysis into more abstract concepts through immersion in reading and re-reading the transcripts.

Initially I began using the 'framework' method of establishing descriptive and then analytical categories within NVivo (see Ritchie et al 2003, Chapter 9). However, whilst at times I returned to the computer package I found that immersing myself in the data through re-reading the hard copies and relistening to the children's voices, enabled me to develop the details and structures of the themes and to 'keep their voices alive' (Mauthner and Doucet 1998: 139). In addition, the process of writing, beginning with descriptive points, enabled me to develop my analytical interpretations.

This was an iterative process of going back and forward between the data, theory and elements of logic and common sense, including following the flow of individual children's accounts. An example of such a process can be seen in my analytical developments relating to children's mobilities. During the paired interviews, it became apparent that children in Swinburn were 
travelling to leisure facilities beyond the neighbourhood. More specific questions were then developed for the individual interviews ${ }^{12}$. Although full data, in the sense of complete coverage of all arising mobility issues, were not collected for all of the 17 children a chart ${ }^{13}$, which acknowledges omissions, nevertheless, provides a picture of the range of their mobilities. The children's individual accounts were analysed for explicit and implicit explanations for their autonomous or restricted movements, and perceptions of their encounters with adults. The conceptual and theoretical points developed from this analysis include: ability; co-presence; talking to strangers; adults in public and public workers ${ }^{14}$. Data from the survey were then used to provide a wider context.

\section{Survey questionnaire}

A survey of children attending other schools in the city's SIP areas was undertaken through the administration of a 12 page, 79 question, selfcompletion questionnaire ${ }^{15}$ to P6 children in their classrooms in 13 schools.

Although self-completion questionnaire surveys are commonly used with children, there are a range of criticisms. They are seen to reflect adult interests, position children as objects of research and possibly constrain them to participate (Morrow and Richards 1996; Denscombe and Aubrook 1992; Brannen et al 2000). There are concerns regarding: children's motivation to complete a structured questionnaire; their ability to understand written questions; the truthfulness of their responses and their views on answering questions in relation to parental occupation and income (Vaillancourt 1973;

\footnotetext{
${ }^{12}$ Questions 3-5c on the Individual Interview Topic Guide, see Appendix 4.

${ }^{13}$ See Fig 6.2

${ }^{14}$ See the conclusion to Chapter 6.

${ }^{15}$ The Questionnaire, see Appendix 5.
} 
Denscombe and Aubrook 1992; Brannen et al 2000). Whilst I appreciated these issues, I considered that using the questionnaire after the qualitative stage would address my concern about it being too adult-centric.

Whilst questionnaires may be popular in teen magazines as Lewis and Lindsay (2000) suggest, in research terms completing questionnaires in school with the class teacher present represents a different context and questionnaire completion can be seen as 'just another piece of schoolwork' (Denscombe and Aubrook 1992: 113). However, this is research method popular with children in school, perhaps because of its anonymity (Stafford et al 2003).

The questions were developed, with an Advisory Group of 6 children from Swinburn Primary School ${ }^{16}$, on the basis of initial findings from the interviews, and a feedback session ${ }^{17}$. The focus of the questions was derived from the research objectives and the key themes emerging from the qualitative work. The demographic variables selected were gender, ethnicity, family structure and family affluence. The questions on family structure were adapted from WHO (1998) and Highet (2005). When considering what indicators I could use for defining social class I took account of West et al's (2001) suggestion that children may not be able to give reliable reports of their parents' economic activity and occupation. In addition, the finding, by a number of authors (see Denscombe and Aubrook 1992; Brannen et al 2000) that some children do not want to be asked questions about their parents' jobs, resulted in the selection of an alternative structure, that of the 'Family Affluence Scale' (Currie 2001: 364). Factors on the scale which appeared relevant to this study were the possible influence of family car ownership,

\footnotetext{
${ }^{16}$ Notes from the Meeting with the Research Advisors, see Appendix 6.

17 See Appendix 12
} 
and whether a child spent time out of the house and in their immediate neighbourhood. Questions on independent mobility were developed from those used by O'Brien et al (2000). Questions relating to the children's views of their area and their community identity were based on scales used by Chawla and Malone (2003).

The questionnaire was piloted with 11 children from the classes I had been working with in Swinburn Primary School, these included children who had not wanted to participate in the interviews. Issues highlighted during this process $^{18}$ resulted in changes to the questions and format.

I administered the final questionnaire personally as Stafford et al (2003) suggest that this is generally preferred by children. I also knew from previous experience that the children were likely to have questions. Having sent parental permission forms ${ }^{19}$ and an information leaflet ${ }^{20}$ to the schools I arrived on the date agreed with the head teacher. In the room where those children with permission were assembled I briefly outlined the purpose of my research and of the survey questionnaire and answered initial questions. In most, although not all, cases the class teacher remained in the room. My presence enabled me to check the completion of the questionnaires. A total of 375 questionnaires were returned.

\section{Analysing the survey data}

The data from the questionnaires were coded and entered into SPSS. This process is part of the analysis and involves making a number of choices. In this study the answer options for each question had not been pre-coded.

\footnotetext{
18 Piloting the Questionnaire, see Appendix 7.

19 See Appendix 10

${ }^{20}$ See Appendix 11
} 
Whilst much coding was fairly obvious there were some instances, particularly in relation to section $\mathrm{E}^{21}$, where the data could be interpreted in different ways. For example, as answers to the questions ${ }^{22}$, asking for the ages of those who accompanied them to various activities, the children listed a number of ages. This listing suggested that they had been giving the age of each person. Three coding categories were set up for the answers to the questions. These were: the number of companions; the oldest age of companion and the youngest age.

Descriptive statistics, in terms of frequencies and cross-tabulations, were produced in relation to the themes developed from the interviews. In particular this included: parenting structures and contacts with familial adults (Chapter 4); views of the neighbourhood, contacts and interactions with familiar and other adults (Chapter 5); use of leisure and entertainment facilities; views on talking to strangers (Chapter 6). Data collected through the written answers were used as additional qualitative data along with that from the interviews.

\subsubsection{Data collection time-frames}

The study was designed as an iterative, multi-stage methodological approach where information collected in one stage would inform the next, in terms of substantive data and also collection processes. Due to the structure of the school year and particularly the division into terms and holiday periods the actual timing of the stages of data collection were fairly fixed (Table $3 a$ ).

Within the time-frame the knowledge gained from one stage informed the next. This was undertaken through immersion in the data, reading and re-

\footnotetext{
${ }^{21}$ See the questionnaire. Appendix 5

${ }^{22}$ Questions 43, 49 and 56 . See appendix 5
} 
reading field notes, transcribing interviews, re-reading and re-listening to the interviews, reflection and note taking. Reflection on my contacts with children in the familiarisation phase and interrogation of my field notes enabled identification of key themes related to my research objects. The discussion groups gave the children the opportunity to clarify their understanding of the study and to decide if they wished to participate in the interviews. Only 3 groups were transcribed, due to the poor quality of the recordings with too many children speaking at the same time. Transcription, immersion in and notes of the paired interview data informed the development of the topic guide for the individual interviews. Similarly, this transcription and immersion process used with data from the individual interviews informed the selection of questions for the survey, together with ideas from the Advisory Group ${ }^{23}$.

The coding and structured analysis of all the data was undertaken in a separate period after collection.

\footnotetext{
${ }^{23}$ See Appendix 6.
} 
Table 3a Timetable of the Research Process

\begin{tabular}{|c|c|c|c|c|}
\hline $\begin{array}{l}\text { Time } \\
\text { period } \\
\text { (school } \\
\text { term) } \\
\end{array}$ & Method & Population & Data Collected & $\begin{array}{l}\text { Data Management } \\
\text { and Analysis }\end{array}$ \\
\hline $\begin{array}{l}\text { April - } \\
\text { June } 04 \\
\text { (summer } \\
\text { term) }\end{array}$ & $\begin{array}{l}\text { Familiarisation } \\
\text { through } \\
\text { Participant } \\
\text { Observation } \\
\text { Children's } \\
\text { drawings of } \\
\text { where they } \\
\text { played } \\
\text { Group } \\
\text { Discussions }\end{array}$ & $\begin{array}{l}37 \text { children in } 2 \\
\text { P6 classes } \\
\text { 'Children in } \\
\text { Swinburn } \\
\text { Primary School' }\end{array}$ & $\begin{array}{l}21 \text { days of field } \\
\text { notes } \\
5 \text { drawings of } \\
\text { 'group play' } \\
6 \text { group } \\
\text { discussions }\end{array}$ & $\begin{array}{l}3 \text { discussions } \\
\text { (transcription, } \\
\text { immersion, notes) }\end{array}$ \\
\hline $\begin{array}{l}\text { July - } \\
\text { August } 04 \\
\text { (summer } \\
\text { holidays) }\end{array}$ & $\begin{array}{l}\text { Summer } \\
\text { Contact } \\
\text { Participant } \\
\text { Observation }\end{array}$ & $\begin{array}{l}6 \text { of the } 17 \\
\text { 'Interviewees' }\end{array}$ & $\begin{array}{l}8 \text { days of field } \\
\text { notes } \\
3 \text { paired/group } \\
\text { interviews } \\
2 \text { individual } \\
\text { interviews }\end{array}$ & $\begin{array}{l}\text { Field notes } \\
\text { interrogated } \\
\text { (transcription, } \\
\text { immersion, notes) } \\
\text { (transcription, } \\
\text { immersion, notes) }\end{array}$ \\
\hline $\begin{array}{l}\text { August - } \\
\text { October 04 } \\
\text { (new school } \\
\text { year) }\end{array}$ & $\begin{array}{l}\text { Participant } \\
\text { Observation } \\
\text { Paired/Group } \\
\text { Interviews }\end{array}$ & $\begin{array}{l}\text { 'Children in } \\
\text { Swinburn } \\
\text { Primary School' } \\
\text { (now in P7 } \\
\text { classes) } \\
17 \text { 'Interviewees' } \\
\text { (now in P7 } \\
\text { classes) }\end{array}$ & $\begin{array}{l}11 \text { days of field } \\
\text { notes } \\
13 \text { interviews }\end{array}$ & $\begin{array}{l}\text { Field notes } \\
\text { interrogated } \\
\text { Transcription and } \\
\text { re-reading all } \\
\text { interview transcripts. } \\
\text { Notes made, } \\
\text { themes and gaps in } \\
\text { info identified }\end{array}$ \\
\hline $\begin{array}{l}\text { November } \\
04- \\
\text { January } 05 \\
\text { (autumn - } \\
\text { spring } \\
\text { terms) }\end{array}$ & $\begin{array}{l}\text { Individual } \\
\text { Interviews }\end{array}$ & 17 'Interviewees' & $\begin{array}{l}20 \text { interviews } \\
17 \text { trees }\end{array}$ & $\begin{array}{l}\text { (transcription, } \\
\text { immersion, notes) } \\
\text { Coding of interview } \\
\text { data in NVivo }\end{array}$ \\
\hline $\begin{array}{l}\text { February - } \\
\text { April 05 } \\
\text { (spring } \\
\text { term) }\end{array}$ & $\begin{array}{l}\text { Design of } \\
\text { Survey } \\
\text { Questionnaire }\end{array}$ & $\begin{array}{l}\text { Research } \\
\text { Advisory Group } \\
6 \text { P7 children } \\
11 \text { P7 children in } \\
\text { Swinburn }\end{array}$ & $\begin{array}{l}\text { Draft questions } \\
\text { Questionnaire } \\
\text { Piloted }\end{array}$ & $\begin{array}{l}\text { Coding of interview } \\
\text { data in NVivo }\end{array}$ \\
\hline $\begin{array}{l}\text { May 05 } \\
\text { (summer } \\
\text { term) }\end{array}$ & $\begin{array}{l}\text { Survey } \\
\text { Questionnaire }\end{array}$ & $\begin{array}{l}\text { 'Survey } \\
\text { respondents' in } \\
13 \text { schools }\end{array}$ & $\begin{array}{l}375 \\
\text { questionnaires }\end{array}$ & \\
\hline $\begin{array}{l}\text { June - } \\
\text { August } 05\end{array}$ & $\begin{array}{l}\text { Survey } \\
\text { Questionnaire }\end{array}$ & & & SPSS Data entry \\
\hline $\begin{array}{l}\text { September } \\
05 \\
\text { Onwards }\end{array}$ & ALL & & & $\begin{array}{l}\text { 'Framework' and } \\
\text { immersion } \\
\text { analysis } \\
\text { SPSS analysis }\end{array}$ \\
\hline
\end{tabular}




\subsubsection{The research participants}

In order to prioritise the voices of children over those of adults, I sought to collect data only from them. Although I recognised that there was an argument for hearing the voices of all parties regarding relationship issues, I felt that to have included the viewpoints of adults could have led to falling into the trap identified by Leyshon of viewing children as a homogenous group in 'binary opposition' to adults (2002: 181).

The selection of the 10/11 year old age group was based on the literature and pragmatic reasons relating to undertaking research in schools. The literature (see Hart 1979; Jones and Cunningham 1999; Valentine 2004) suggests that at around the ages of 10-12 years children's experiences of the world increases and that they are given greater 'parental licence' (Hillman et al 1990; O'Brien et al 2000) to venture to more places. These children are on the edge of transition from childhood into adolescence, where the move from primary to secondary school is likely to increase opportunities for social contacts beyond the home. The choice of Primary Year 6 (P6) classes was based on the need to fit the different phases of my data collection round the demands of the school year.

It is argued that schools should not be used as research sites because they can limit children's choice about participation (Graue and Walsh 1998). However, as a universal provision they offered a more easily accessible means of reaching most of the children in a given geographical area (Borland et al 1998). Although children can be accessed through out of school provision, they can perceive this as an imposition on their free time activities (Milne 2003; Hill 2006). Whilst not all the children living in a particular area will 
attend the schools situated within it, most will. Permission to conduct the research was requested ${ }^{24}$ and received from the Local Authority Education Department. The engagement of individual children in the different stages of the research was on the basis of self-selection, the process of which is discussed later in this chapter ${ }^{25}$.

\section{The children in Swinburn Primary School}

This primary school was selected as the site for recruiting the interview participants on the basis of previous contact with the head teacher, which allowed for ease of access.

In Swinburn Primary School initial contacts were made with all of the thirtyseven children (20 girls and 17 boys), aged 10-11 years old, in the two P6 classes. Familiarisation, through participant observation was undertaken with them during the summer term, and recorded in field notes. In the thesis these children are referred to as 'children in Swinburn Primary School' and at times individuals may be referred to be name. ${ }^{26}$

\section{The interviewees}

Seventeen of the P6 children in Swinburn Primary School chose, and were able to obtain parental permission, to participate in the interview phase. The paired and individual interviews took place in the new school year when they were then in P7 classes. In the thesis these children are referred to as 'the interviewees' or 'the children who were interviewed'.

The 10 girls and 7 boys appeared to be fairly representative of their classmates. All were white, as were the remainder of the class. There was a

${ }^{24}$ Letter to the Local Authority, see Appendix 1.

25 See section 3.4.1

${ }^{26}$ See Appendix 2. 
mixture of abilities, including children seen by teachers and their peers as very bright, through to one with recorded learning disabilities. There were children who were viewed by teachers as troublesome, including one with ADHD and others who were very quiet. There was a similar mixture of children who were popular with others, and those who were not.

As the children made their own choice of partner for the paired interviews, some were selected more than once. This situation, together with contacts with 6 children during the summer holidays, resulted in individuals participating in between 2 and 6 recorded interviews (Table 3b).

\section{Table 3b Details of the Interviews}

\begin{tabular}{|l|l|l|l|l|l|}
\hline & $\begin{array}{l}\text { Total No. } \\
\text { of } \\
\text { Interviews }\end{array}$ & $\begin{array}{l}\text { Group } \\
\text { Discussions }\end{array}$ & $\begin{array}{l}\text { Paired } \\
\text { Interviews }\end{array}$ & $\begin{array}{l}\text { Individual } \\
\text { Interviews }\end{array}$ & $\begin{array}{l}\text { Children's } \\
\text { Project } \\
\text { Contact }\end{array}$ \\
\hline Angel & 2 & & 1 & 1 & \\
\hline Breanna & 3 & & 2 & 1 & \\
\hline Courtney & 3 & & 2 & 1 & $*$ \\
\hline Crombie & 4 & 1 & 2 & 1 & \\
\hline Gums & 4 & 1 & 2 & 1 & \\
\hline Hayley & 3 & & 2 & 1 & \\
\hline James & 5 & 1 & 2 & 2 & \\
\hline John A & 5 & 1 & 3 & 1 & $*$ \\
\hline John B & 6 & 1 & 3 & 2 & \\
\hline Lily & 3 & & 2 & 1 & \\
\hline Lynney & 3 & & 2 & 1 & \\
\hline Nicolle & 3 & & 2 & 1 & \\
\hline Peter & 5 & 1 & 2 & 1 & \\
\hline Sarah & 3 & & 0 & 3 & \\
\hline Star & 3 & & 2 & 1 & \\
\hline Stacey & 3 & & 1 & 2 & \\
\hline Stitch & 6 & 1 & 4 & 1 & \\
\hline
\end{tabular}

\section{The survey respondents}

In order to undertake the survey questionnaire contact was made with all of the primary schools within the city's S.I.P. areas. It was anticipated that not all schools would grant permission for the questionnaires to be used with 
their P6 children, but that a positive response from half would provide approximately 400 responses. Over half $(13)^{27}$ of the schools did give permission and out of a possible 425 children, 375 completed questionnaires. There were more boys than girls and more 10 than 11 year olds (Table 3c). Within the 13 schools $4.9 \%$ (18) children classified themselves as Asian, Black or Chinese. In the thesis these children are referred to as 'the survey respondents' or as 'children who undertook the survey'.

Table 3c Details of the Survey Population

\begin{tabular}{|l|l|l|l|l|}
\hline & $\begin{array}{l}\text { Number of } \\
\text { P6 children }\end{array}$ & $\begin{array}{l}\text { Number of } \\
\text { completed } \\
\text { questionnaires }\end{array}$ & $\begin{array}{l}\text { Girl:Boy } \\
\text { Ratio }\end{array}$ & $\begin{array}{l}\text { Age 10:11 } \\
\text { Ratio }\end{array}$ \\
\hline School 1 & 26 & 25 & $15: 10$ & $16: 9$ \\
\hline School 2 & 29 & 28 & $14: 14$ & $10: 14$ \\
\hline School 3 & 18 & 17 & $9: 8$ & $14: 2$ \\
\hline School 4 & 30 & 31 & $12: 19$ & $22: 10$ \\
\hline School 5 & 42 & 43 & $20: 23$ & $32: 10$ \\
\hline School 6 & 48 & 43 & $22: 21$ & $27: 11$ \\
\hline School 7 & 51 & 42 & $17: 25$ & $28: 13$ \\
\hline School 8 & 29 & 20 & $5: 15$ & $15: 5$ \\
\hline School 9 & 60 & 48 & $30: 18$ & $31: 13$ \\
\hline School 10 & 21 & 16 & $11: 5$ & $16: 3$ \\
\hline School 11 & 20 & 19 & $9: 9^{*}$ & $16: 3$ \\
\hline School 12 & 15 & 13 & $8: 5$ & $10: 13$ \\
\hline School 13 & 36 & 30 & $10: 20$ & $14: 11$ \\
\hline TOTAL & 425 & 375 & $182: 192^{*}$ & $248: 107+$ \\
\hline
\end{tabular}

* one child did not specify their gender

+20 children did not state their age

An understanding of children's perspectives and knowledge based on an analysis of their accounts is central to developing academic and public knowledge about the nature of contemporary childhoods. Researchers need not only to collect this knowledge, but also to present it for academic scrutiny and increasingly for professional and public information.

27 The number of schools approached is not stated, so as to preserve the anonymity of the city, the areas and especially the children. 
The idea of a child-standpoint methodology is outlined and then each of the four methods of data-collection is reflected upon in terms of its usefulness for accessing children's knowledge. The choices made in relation to the ways in which the knowledge of the study participants is represented in this thesis are also discussed.

\subsubsection{A child standpoint methodology}

Understanding children's perspectives does not involve just considering their viewpoints, but accepting their perspectives, conceptual constructions and reconstructions based on their daily interactions, as validated 'knowledge' (Mayall 2000: 120). This includes knowledge of their lives, and those of others, including evaluations of direct and indirect experiences and their constructions of meanings, for example of their developing identities (Kelle 2001). Yet this knowledge is often questioned because taking children seriously involves adults identifying and challenging their own beliefs about the nature of children and childhood (Waksler 1991). Whilst, as we have seen $^{28}$ this may not be something that is readily apparent in contemporary British society, in academic terms there is an increasing move towards not only viewing children as social actors, but also as competent interpretive social actors when participating in research (Christensen and James 2000 ).

When accessing children's knowledge, researchers have considered whether the task is similar to, or different from, undertaking research with adults. Greig and Taylor (1999) suggest that children are 'special', and therefore argue that research involving them is different from research with adults. However, viewing children in this way can confine them to the category of 'other', rendering them 'objects' of research rather than 'subjects' or

\footnotetext{
${ }^{28}$ See Chapter 2
} 
'participants'. Given the marginal position of children in society it is necessary to consider the power conferred on adults and the implications of this power within the research process (Morrow and Richards 1996). Suggestions for minimising the unequal power relationships between adult researchers and child participants appears to centre round an open, flexible and reflexive research methodology, the participation of children and taking account the influence of context on data (Davis 1998; Cockburn 2002; Green and Hart 1999).

Christensen and James (2000) suggest that instead of focusing on techniques researchers should develop an approach or methodology from their own standpoint. This meant taking account, as Lee (2001) suggests, of how my previous personal and professional experiences affect my priorities and assumptions. Having spent thirty years working in a professional capacity with children and young people, developing what I viewed to be a participatory approach, I was drawn to the idea of developing a child standpoint methodology. Similar to a feminist standpoint, the approach involves, 'giving due attention to people's experiences as a basis for analysing their social condition' and the daily relations between individuals and social groups (Mayall 2002: 122). In relation to children this means recognising their lower social status, compared to that of adults (Mayall 2002). A child standpoint methodology is concerned both with the means of accessing children's knowledge and with representing it 'in intersection with adult knowledge' Mayall (2002: 139). In outlining Smith's view, Lee states that the standpoint of the powerful yields a mistaken picture of society, while the standpoint of the weak yields a more accurate picture of society' (2001: 52). Whilst this appears to be a somewhat exaggerated claim I think that it is essential to access children's knowledge because, by providing a 
coherent account of how they experience and understand their social positioning, greater knowledge can be gained of how the social order works and, in turn, this can provide a basis for changing adult's views of adultchild relations. Although I am attracted to the notion of a child standpoint methodology I am aware of the criticism that, in viewing children as a 'minority' in a moral rather than demographic sense, the differences between children can be overlooked (James et al 1998). However, in specifically focusing on the views of children from relatively deprived backgrounds, I have sought to ensure that not only are the voices of these particular children heard, but also that their knowledge is recognised.

\subsubsection{Participant observation}

One of the key benefits of participant observation for a child standpoint methodology is the degree of closeness between the social phenomena under study reducing the amount of processing required by the participants (Blaikie 2000). Naturally occurring data are produced through the researcher's engagement with the participants, who, whilst active in this process, are generally not involved in recording or analysing the data, as these activities are undertaken by the researcher (Mayall 2002)

Participation in the playground, as childhood's domain (Moore 1986), was a successful means of developing contacts with the children, on their own terms, where they were able to choose whether or not to engage with me. In the dinner hall I requested, or was invited, to sit with children and eat lunch, I was the only adult to do so. I also queued with the children declining the instruction, from the dinner ladies, that adults could go to the front.

In order to maintain contact with the children during lessons I joined them in their classrooms. However, a teacher controlled setting and I was confused 
as to what role to play. At the suggestion of the teachers, or requests from children, I took on a role of helper in some lessons, but in music and art I participated along with the children, generally raising my hand to ask a question such as whether I could speak to the children as they worked. Although I helped the children with their work I was clearly not viewed as having any authority as children misbehaved in front of me, and encouraged me to unwittingly break 'rules' such as not whistling in the corridor. Whilst teacher control had some impact on their freedoms, their subversive activities and my collusion enabled the research engagement to develop.

On the 3 occasions I walked with children to their houses in order to gain parental permission for their participation in the project ${ }^{29}$, I found that I was in children's territory even more so than in the school playground. Whilst they were aware of the presence of adults around them there was a sense of freedom as they took me on their routes.

At the Children's Project, during the summer holidays, an implicit conflict arose as to who was ultimately controlling the activity agenda. For example, when two of the boys wanted to go to a play-park, I suggested taking the tape-recorder with us and for them to describe the area as in a 'neighbourhood walk' (Morrow 2001: 258). However, they developed an interest in playing with the tape recorder rather than in guiding me. The children's interest in playing during our sessions resulted from the choice to use the Children's Project, a venue full of toys together with my own reluctance to impose a too structured regime during their holiday period. Three boys were adept at using me as a 'responsible adult'30 to oversee their

\footnotetext{
${ }^{29}$ The irony of being in a position of needing to have unauthorised contact with a child in order to gain authorised contact is discussed further in section 3.4.1.

${ }^{30}$ See section 3.4 .3
} 
trips to a play-park that they were not allowed to visit without adult accompaniment. On these occasions I played with them on the playground equipment. My willingness to engage in physical play, even in the school playground seemed to be an important part of the participation process.

Through the method of participant observation the adult researcher is able to have closer contact with children's social worlds on an ongoing basis (James et al 1998; Davis et al 2000). However, participants are still subject to the generational order which positions adults as more powerful than children (Mayall 2000). Whatever role a researcher takes s/he is open to scrutiny by other adults and children themselves (Emond 2005).

Although this was the first time I had undertaken participant observation with children, the time I was available to the children and my willingness engage in their play on their own terms appeared to be central to the development of positive research relationships with individual children, and for their subsequent willingness to take part in the interview stage. I believe this to be especially true for the boys.

\subsection{3}

Interviews

It seemed that the loosely structured nature of the paired interviews enabled the children to have more control in their flow and direction. However, I found difficulties in the individual ones in balancing the achievement of conversational depth, covering the topics and letting the children define the direction. The nature of the interview conversations differed and the data obtained varied in quantity and substance across the interviews. This was partially because some children participated in more interviews than others, but more so as a result of the impact of varying contexts (see Green and Hart 1999). I use the concept of context not only to mean the physical settings, but 
also the nature of the relationship between a child and myself, or in as the paired interviews, between the two children. Individuals or pairs spoke about topics spontaneously, and in response to my questions because they were interested in the topic and/or in conversing with me and felt confident to do so.

Within the interviews, I came to view the children's accounts as stories. To use this term is not to devalue what the children spoke about as untruthful accounts or fictitious ideas, but as a way of accessing how they understood 'themselves-in-the-world' and made sense of their lives through the construction, representation and sharing of experiences (Engel 2005: 200). In this sense 'the story' is not only the content; the ideas, facts, thoughts and feelings, but the way it was put together. Through working with the children in pairs, they appeared to develop their knowledge of the topic of child-adult relationships by sharing ideas with others and jointly producing narratives.

In the analysis, I examined the possible purposes of the stories and the information they contained in terms of the anticipated effect on the recipients and the child to child, and child to adult interplay. Within the paired interviews joint narratives were developed between friends, but in other cases where the children did not relate well, the process became parallel individual interviews causing difficulties in balancing participation.

\subsubsection{Task centred methods}

Although the children enjoyed the task of constructing their family trees, with some asking me to make photocopies for them and others displaying interest in following lines of connections, in general they seemed to prefer to spend their time with me talking, viewing their contacts with me, in school time and especially during the holidays, as a break from school work. 
Careful planning is therefore needed to ensure that a particular task-centred method fits with a child standpoint methodology.

\subsubsection{A self-completion questionnaire}

My presence during the administering of questionnaires and encouragement to the children to ask questions fits with the idea of a child-standpoint methodology. However, there were other aspects of the use of a selfcompletion with children that caused me to question the fit.

Firstly there is the closed nature of many self-completion survey questions. For, whilst I provided opportunities for the children to make more qualified responses to some questions, more thorough planning and piloting would have enabled fuller development of questions that are open enough to be considered part of a child-standpoint methodology, yet still statistically rigorous.

There were particular issues relating to the survey concerning the way in which some questions were answered. Despite alterations being made to some, after the piloting, there was an ongoing issue of children's apparent wish to disregard the instruction to 'only tick one box'. I initially considered this to be a failure to understand instructions. Children were not reading the word 'mainly' and therefore answered all the things they did, or they may have been reading 'mainly', but not the instruction to 'only tick one box'. However, the problem remained even when the instruction to 'only tick one box' was removed from certain questions. Children appeared to want to give account of all the reasons that were relevant to them. This desire for correctness was also revealed by the frequency in which things were rubbed out, a possible school influence to get things 'right'? Children may not want to apply 'mainly' if they view different points as alternatives rather than 
graded priorities. For example, during the interviews, two boys said that they had a number of friends rather than a best friend, indicating friends were different and that one could not be prioritised over another.

For other questions, particularly those with a grid answer format, boxes were left blank and it appeared that children may have chosen not to answer questions they considered irrelevant. For the question 'Where do you play?' 31 there were missing values for the answer option, 'on your balcony'. Presumably boxes were left blank by children who did not have a balcony, and the option of 'never' (play there) did not fit their logic. Although this question could have had an option of 'does not apply' or 'not relevant', examination of the answers to questions where these options were available revealed that children still left sections blank.

There appeared to be a contradiction between a desire to give full and honest answers and the fact that, on occasion, children left questions unanswered. However, when I spoke to them as the questionnaires were handed in, the children's given reasons appeared to be essentially pragmatic. Particular questions may not have been worth answering if the child did not have strong views on that subject. Another possible explanation could be that they did not like the question as, during the piloting, two boys scored through questions 59 and 60. These questions asked about talking to adults: 'I feel able to talk to adults that I know very well (not my parents or school teachers), and 'I feel able to talk to adults that I do not know very well'. The reason the boys gave for not wanting to answer these questions, was that they were 'private' questions. Another boy, during the actual survey, also made the same comment. A possible reason for such a response could relate

\footnotetext{
31 The instruction was kept for some questions, e.g. Q34.
} 
to the messages children receive about talking to strangers, and/or to a desire to keep their relationships with particular adults private.

The questions that the children appeared to view as important or interesting are revealed by the effort they made to respond to the request for written answers, something significantly more girls did than boys ${ }^{32}$. However, the children's apparent desire for correctness also caused a problem. On checking the questionnaires, as they were handed in, if a child had answered yes to 'Have you seen adults behaving in ways that you do not think that they should?'33, but not then written anything, I asked if they did want to write something. Some said 'yes' taking their questionnaires back, others said no, but some rubbed out yes and changed it to no (seemingly not wanting to write anything), despite my request that they should not make such changes.

It seems that, when designing questionnaires for use with children, vague terms like mainly and asking for only one answer should be avoided, although multiple answers could complicate coding. Grid answer format can be too complex, as McVie (2003) suggests. She also recommends limiting response lists to 8 items. As girls are more likely to provide written answers, when asked, than boys, additional tick box sections may be needed to ensure that particular data is gained from boys. Additionally, it is worth considering the use of 'cognitive interviewing' to assess how potential respondents comprehend questions and mentally process, recall and make decisions as to their answers, in addition to examining how they respond to question presentation (Willis 2005).

\footnotetext{
32 Analysis revealed a ratio of 250 girls to 204 boys across Questions 67; 69 and 76.

${ }^{33}$ Survey question 76.
} 


\subsection{Linking methods and methodologies}

A combination of methodologies and, or, a mix of qualitative methods appears to be popular within social research, including that with children, perhaps as a result of pressures from funders and policy makers, for researchers to use both qualitative and quantitative methodologies (Brannen 2005). However, despite this interest, the rationale for the mix is often not examined or sufficiently considered (Milburn et al 1995; Bryman 2006). In this section I present the rationale for the linking of methods in this study, together with an examination of the issues encountered. I conclude that whilst, in retrospect, the particular combination of methods used in this study was ambitious, engagement with the practice of implementing such a design, has provided the opportunity to reflect upon issues inherent in combining methods.

\subsubsection{Reviewing the rationale for linking methods}

Discussions of the linking of methods refer to the mixing of several types of qualitative method and to the combining of quantitative and qualitative methodologies (Milburn et al 1995, Bryman 2006). In the literature an array of terminology is used: mixing; combining; integrating; and multi-strategy, all of which suggest different purposes. I have selected Mason's (1994) term 'linking' as the most appropriate to describe the process used in this study, although I use the terms 'mixing methods' and 'combining methodologies' for more general discussion.

Whilst there are perceived limitations about the mixing of methods in qualitative research (see MacDougall et al 2005) it is the combining of methodologies that is seen to be more problematic. It is often assumed that quantitative and qualitative approaches belong to different paradigms, with 
fundamentally opposing ways of viewing and studying the social world. Whilst Bryman (2006) states that these distinctions can be exaggerated, it is important for researchers to recognise not only the differences between the data collected (numerical or textual), but also differences in assumptions about the nature of reality as well as the distance between the researcher and the researched from the phenomena under investigation (Blaikie 2000). Are the data to be collected viewed as objective facts or social constructions representing a changing reality, and can these different views be combined? A further consideration relates to the aims of the study and whether these are to test a predefined hypothesis, or to develop theories from the data (Milburn et al 1995)

The rationale for linking qualitative and quantitative methodologies within this study was 'enhancement' (Byman 2006: 107). Data from children living in one neighbourhood would provide a close-up view, which would then be framed and located within a bigger picture provided by quantitative data from a larger sample of children living in similar circumstances (Mason 2006b). The qualitative and quantitative methodologies were undertaken sequentially and linked through the design and data collection stages (see Brannen 2005 for discussion of the functions of integration). In the interpretative process the qualitative methods were more thoroughly linked and these were prioritised over the quantitative data in the presentation of the findings. The reason for selecting a range of qualitative methods was that each had a particular purpose in relation to the others ${ }^{34}$.

Whilst discussion in the literature primarily focuses on the problems of combining methods across methodologies, there are also issues to be

\footnotetext{
${ }^{34}$ See section 3.1.1.
} 
considered in the mixing of methods within qualitative research, including the way in which the different types of data are linked in analysis. Another issue concerns the actual practice of data collection and the possible shifts in researcher role.

\subsubsection{The practice and problems of linking methods: Data collection}

Within ethnographic studies researchers rarely discuss the ways they move from collecting 'naturalistic' data to undertaking more 'formal' interviews. As a participant with the children in the playground and performing 'assistant' roles within the school building, I had resisted taking on the role of 'adult in charge', leaving the supervision of the children to the other adults present. However, my interviewer role required a change in the research relationships. Working with the children in pairs and then individually, usually in the school library, I was the only adult present and felt obliged, within the context of the school, to take responsibility for the children and their behaviour. Given the focus of this study, reflexive analysis of the resulting tensions led to substantive data. However, it is an aspect of this role that other researchers should be aware of. The fact that I did not experience difficulties subsequently, in administering the questionnaires in school classrooms, was likely to have been due to the presence of class teachers, but also from a confidence in playing a researcher role which I felt to be more akin to my previous teacher role.

\subsubsection{The practice and problems of linking data: Data analysis}

With regard to the use of two methodologies, I was aware that data produced through different research relationships, either determined by the researcher, as in the questionnaire, or raised through dialogue within the 
interviews, could, as Milburn et al (1995) suggest, be incompatible and therefore difficult to integrate. Whilst the survey questionnaire was developed from the insights gained through participating and observing and the initial interview data, the qualitative data were longitudinal, from one group of children, whereas the quantitative data were cross-sectional, from different children. Whilst each phase of the methodology had been conceived of as separate, although linked, it was through the analysis and writing process that I became aware as to how I was actually going to link the close up and broad views in the presentation of the research findings.

Having prioritised the qualitative data, I began coding the interview transcripts in NVivo. Having developed, from the interview data, an initial framework for thesis, I then began to examine my field notes and the family trees for supportive or contradictory explanations.

My particular interest in developing a child standpoint methodology resulted in a predominant focus more on the qualitative aspects of the research. Recognising that there may be concern about the extent to which data collected in one context can be generalised beyond that context I located the close-up view, within a broader population of children. The questionnaire data was selectively analysed in the light of the qualitative findings.

\subsubsection{Representing children's knowledge}

The voices, perspective and knowledge of 17 children, produced over the period of a year, represented through interview data and contextualised through field notes, are the main data used in four of the thesis's substantive chapters. In Chapter 4 the children's family trees are analysed and in Chapter 7 analysis of the field notes augments findings from the interview data. 
Whilst the children were not involved in the analysis of data, I did provide verbal and written feedback, as Morrow (2008) suggests, to all of P7 the children in Swinburn Primary School ${ }^{35}$ and asked for their thoughts about what I had written. The main comments were that I should use bad rather than poor to describe the area, and that I should not use real when referring to their parents.

I have sought to present, and more importantly represent, the voices of the 17 interviewees through the production of vivid, accurate and rich accounts. I view the importance of using their direct quotations as a means of providing accurate, and therefore reliable and valid accounts (Danaher and Briod 2005, referring to Polkinghorne 1983).

\subsection{Ethical practice and reflexivity}

There are a wide range of codes about how research should be undertaken in an ethical manner and, whilst these do not provide the answers, 'they can lead us to ask the right kind of questions' (Alderson and Morrow 2004: 7). Alderson and Morrow's report outlines the ethical issues involved at various stages of undertaking research project with children, including at the planning and dissemination phases which they say are often overlooked. They focus on seeking to ensure that research with children is undertaken in a manner that is just, respectful and beneficial for them.

In addition to using this document, I have found the idea of working towards 'ethical symmetry' (Christensen and Prout 2002) to be one which is congruent with my desire to develop a methodological approach which is

\footnotetext{
${ }^{35}$ Feedback to the Children in Swinburn, see Appendix 12.
} 
respectful of and works for children. I have sought to understand how the power relations between children and adults, resulting from intergenerational differences, were constituted in the context of this study. I adopted a reflexive approach to examine what Sin refers to as the 'multifarious dimensions' of ethics at different stages of the research process (2005: 279). Those of consent, confidentiality, and privacy are detailed by Alderson and Morrow (2004), but that of anonymity less so. Research roles and responsibilities for, rather than towards, children as research participants are relatively unexplored areas of ethical debate.

\subsubsection{Consent}

There is wide acceptance (see Alderson and Morrow 2004) that informed consent relates to an understanding of the purpose, process and outcomes of research, not just to the giving or refusing of permission. Research with children is different from that with most adults, because before one even begins the process of seeking consent from the participants there is an almost mandatory requirement for access to be negotiated with gatekeepers. They are generally protective and can be reluctant to trust researchers possibly censoring the involvement of children (Balen 2000; Cree et al 2002). Gaining access can therefore be one of the hardest parts of undertaking research with children (Alderson 2004).

Initial permission to approach schools was granted in principle from the Local Education Authority with the final decision being made by individual head teachers ${ }^{36}$. In negotiating such access I consciously used my status as a mature student with a background in education. Following permission from

\footnotetext{
${ }^{36}$ Letter to Head Teachers, see Appendix 8.
} 
head and class teachers, parental permission was sought in different forms for the various stages of the research.

My priority was to ensure that the children were able to make their own choice about engaging with the research. Although there is an ongoing debate about the necessity of obtaining parental consent there is little reference to difficulties in doing so, particularly in relation to social deprivation.

Using Alderson and Morrow (2004) idea I held an introductory meeting, in Swinburn Primary School with all of the children in the P6 classes and distributed information/permission leaflets ${ }^{37}$. The aim had been to give the children control of the permission process, leaving them to seek consent from their parents, if they chose to be involved in the research. A few weeks later, I was concerned that some children actively sought my company even they had not returned their forms. I was worried about how to undertake participant observation without parental permission for all of the P6 children. Discussion with the head teacher not only revealed that the school had general problems with the non-return of parental permission slips for school activities, but it also provided a way forward. The head teacher said that she viewed my initial participation with the children as an acceptable part of the school programme, something which she had given permission for, and as such, thought that parents would not be concerned. We agreed that parental permission would definitely be required for the interview stage. I believe that is essential for researchers to discuss parental permission with gatekeepers (See Ensign's 2003 advice on working with communities and

\footnotetext{
${ }^{37}$ Information/Permission Leaflet for Swinburn, see Appendix 9.
} 
how to manage consent) as they may have to deal with issues long after researchers have left the setting.

The group discussions held with the children at the end of the familiarisation phase served as a means of introducing both the style and content of the interviews. I emphasised that they needed to obtain signed parental permission form and offered to speak with their parents. Such personal contact appeared to be appreciated by the parents, although one child said that his father did not like him talking to social workers. Although I explained that I was not a social worker, the idea of speaking about families may have been perceived of in a similar vein as Edwards (2004) points out. Whilst parental permission was viewed as necessary, failure to obtain it resulted in disappointment for one child. There is a continual dilemma resulting from parental consent taking precedence over that of the child. One issue of parental or gatekeeper permission that was not fully considered in this study was in relation to my walking home with children in order to obtain the parental permission.

Whilst being aware of the implications of opt-in and opt out forms of parental permission as outlined by Alderson and Morrow (2004), my experiences in Swinburn Primary School and the anonymity of the questionnaire resulted in my selection of an opt-out process for the survey ${ }^{38}$. This reasoning was supported by the head teachers and the final wording of the letters to parents, based on my draft, left to them individually.

In examining the concept of consent I considered what this meant at different stages of the research process in relation to voluntarism and information. Thorne (1980) asks whether participants are recruited as individual

\footnotetext{
${ }^{38}$ Information/Permission Letter for Survey Parents, see Appendix 10.
} 
voluntary subjects. Although within the familiarisation phase the children were able to choose whether or not to engage with me, because the school had given permission for my presence, voluntarism is open to question. When conducting the survey in schools the children were likely to be constrained by the institutional structure. Although the children were told that they did not have to complete the questionnaire if they did not want to, the fact that it was presented as 'just another piece of schoolwork' (Denscombe and Aubrook 1992) meant that compliance was seen as expected. Consent involves choice without obligation, but choice is always contextual (Masson 2000) and as such can involve various aspects of obligation. The school places a sense of obligation on children to respond appropriately to adult requests. This is generally viewed as not questioning the adult. Therefore consent gained in this context can be viewed as 'educated consent' (David et al 2001). Children can feel a sense of obligation to parents or friends who introduced them to the research (Milne 2003). In that voluntarism concerns free choice it can be linked to the ideas of assent, rather than dissent, to participate. Although Alderson and Morrow (2004) prefer not to use the term assent because of their concerns that researchers work towards gaining children's informed consent, others point to the problematic nature of seeking this. Cock's suggests that assent:

\footnotetext{
'as represented with the research relationship between the researcher and the researcher... removes the reliance on the child demonstrating adult-centric attributes such as maturity, competence and completeness.'
}

Cocks (2006: 257).

Giving children, or for that matter anyone, sufficient information to make an informed decision about participation in research is difficult. As Thorne (1980) suggests this is of particular concern in exploratory studies where the 
strength of flexibility results in researchers having difficulty in being specific, at the start of the research, as to the information sought or the methods that would be used. In this study, although I informed the children that I would be writing about what they said, I did not initially indicate the possible ways in which I might reframe 'their versions of events' (Murphy and Dingwall 2001: 346). Whilst the information for the survey was given to the children through the distribution, in class, of a leaflet ${ }^{39}$ and discussion about research and the specific purpose of my study, there was little time for the children to really consider their participation.

Negotiation, open dialogue and the 'active construction of the research relationship' (Christensen and Prout 2002: 484) were encouraged in the participation and interview stages. The familiarisation phase provided the children with a range of opportunities to develop knowledge of the research and to make generally informed decisions about participating. However, I was not clear about making field notes about children who rarely initiated any contact with me or about the ethics of including details about them in this thesis. ${ }^{40}$ Through negotiating the interview arrangements, I emphasised to the children that their time was as important as my own, and that it was their choice whether they wished to be interviewed during their playtime, 'Golden Time' ${ }^{41}$ or hymn practice. Within the interviews I used Greig and Taylor's (1999) ideas of encouraging an open dialogue on the research process and the children's choice when to end sessions.

One of the negative aspects not only of promoting, but also of actively encouraging children to consider the meanings of the research process, their

\footnotetext{
${ }^{39}$ Information Leaflet for the Survey Children, see Appendix 11.

${ }^{40}$ See list of Children in Swinburn, Appendix 2.

${ }^{41}$ Golden Time was a lesson period in which children were able to select their own activities, such as reading playing board games, or using construction equipment.
} 
desires to be involved or their choice to deny consent, is the potential failure to obtain participants as I had previously found (Milne 2003). Whilst this can also occur in research with adults, the hierarchies of gatekeepers can make the recruitment of additional children problematic.

\subsubsection{Confidentiality, privacy and anonymity}

Related to the concept of informed consent are those of confidentiality, privacy and anonymity. Although these are viewed as central to ethical research practice, their actual meanings are not always distinguished or debated in relation to research with children. Children's own understandings of these issues are explored even less frequently.

My concern about the children's understandings of confidentiality, privacy and anonymity, in relation to topics they spoke about, emphasised the importance of researcher alertness. Although individuals displayed a confidence in checking out that I would not report the names of people they spoke about, there were times when a comment or a look between children caused me to clarify meanings directly. For example, during one interview when a child spoke of being hit by her parents I turned the tape recorder off and asked her to tell me clearly what she was saying, stating that I would have to inform someone if she was being harmed. She was startled and said 'it was nothing like that'. In this case her tone reassured me that I need not have any concerns. The incident emphasised the need for researchers to be alert to and be prepared to handle issues of child protection and, additionally, that children may equate the interviews with speaking to an adult in private about their problems, something which some children could view positively, but others see as negative. 
Spending over a year with children in Swinburn Primary School I gained a lot of information about their lives and family experiences, including parental unemployment, parental and sibling involvement with drugs and crime and also domestic disputes. Many of the details were hinted at by the children and, although I occasionally sought greater clarification, the fact that there was no ongoing explicit discussion appeared to indicate that the children wished to maintain their privacy. I was wary of the dangers of over disclosure in unstructured research (see Mishna et al 2004) and therefore particularly vigilant regarding the possible identification of children. In representing the children in this thesis I have taken care, as Murphy and Dingwall (2001) suggest, to remove, or slightly alter details.

I emphasised, to the children, that whilst I would be telling others what they had said, I would not be using their names, or even that of their school or the city. At the point of the group discussions all the P6 children present selected their own pseudonyms. This enabled me to distinguish between the children and to whom to attribute verbatim quotes, a factor that participants view as important (Corden and Sainsbury 2006). Whilst consent was subsequently obtained for 17 children to participate in the interview stage, I was not clear as to the status of my field notes for other children. When deciding whether, or not, to include data involving these, I considered the relationship between privacy and anonymity, and began from a position of respect for children and considering their potential perspective. In Chapter 5, I chose to include the drawings of four children ${ }^{42}$ who did not participate in the interviews, because these portray particular images of Swinburn as a neighbourhood, but do not reveal information which the children might view as highly personal. In Chapter 7, I thought it was important to include various ways in

\footnotetext{
42 See Appendix 2 for details of the four children.
} 
which those children who did not participate in the interviews interacted with me within Swinburn Primary School, even though only some ${ }^{43}$ had given their consent.

My concern about maintaining the children's anonymity in field notes led me to use 'a girl', or 'a boy' when referring to individuals. However, this did not allow me to track my interactions so I then used the children's real names. I was careful about locking my notebook away and as soon as children had chosen their pseudonym, I altered the names.

The children emphasised privacy, for example one girl said that she preferred to be interviewed individually because it was 'more private'. Also during the interviews two children tried locking the doors of rooms, presumably to maintain their privacy, whilst others stopped speaking if someone entered the room.

\subsection{3}

\section{Researcher roles and responsibility}

Part of research ethics concerns a researcher's responsibility towards their participants, such as protecting them from harm. In relation to research with children, protection from harm has been extended into specific concerns around child protection. In undertaking a reflexive examination of my researcher roles and how I felt about them I considered Christensen's (2004) question of what it meant to be an adult. That I felt freer to participate with the children when there was another adult present caused me to reflect not only upon the generational positioning of power, but also of responsibility.

When engaging with children in Swinburn Primary School outside the interviews I positioned myself with the children in a 'least adult' role

\footnotetext{
${ }^{43}$ See Appendix 2 for the list of participants.
} 
(Mandell 1991) between that of Corsaro's 'big kid' (1997; 2000) and Swain's 'semi-participant' (2005: 199). When undertaking the roles of playmate and classroom assistant I was neutral or even conspiratorial regarding my own performance of adult authority. I was generally able, in the classroom and playground, to ignore the children's 'mis'-behaviour, leaving that responsibility to school staff.

The children were adaptable to my changing roles. However, moving from a participant researcher to an interviewer resulted in a greater awareness of my responsibilities towards the children. Additionally, whilst seeking to reduce my own potential adult power over the children, I had not fully anticipated children's own peer power relations and my responsibilities.

When witnessing one boy physically threatening and intimidating another I chose not to exercise any potential adult authority. By not raising my voice, to question his behaviour, I protected my desired identity, as a different kind of adult within the setting. Yet, had I negated a responsibility towards the less powerful child? Had my feeble enquiry been ineffective, or had I done harm by interfering, suggesting that the 'victim' needed protection from an adult? I could not ignore the fact that whilst children may have their own 'rules' in play they still live in an adult-structured world where there are explicit and implicit divisions between the categories of child and adult and expectations of adult responsibility. Trust can be broken by becoming the adult in authority, but also by not taking on that role if it is expected of you.

'Bauman carefully distinguishes between taking responsibility for and taking responsibility away from the other ... recognising children as social actors does not justify treating children as if they were the same as adults'

Christensen and Prout (2002: 479). 
Researchers may have to make reflective judgements in the split second of something occurring. That I was witness to behaviours, which in another adult role (i.e. as a youth worker or teacher) I might have challenged, was symptomatic of the 'unusual/alternative adult' role I played. The fear of criticism from other adults, and possibly from children themselves, is central to debates about the meaning of ethical practice. I could have overcome many of the tensions of uncertainty had I discussed my role with the staff and the children, at the beginning of the research (Emond (2005). Such a discussion may have clarified whether the children viewed themselves as being free from responsibility with their adult caretakers as 'morally accountable for the actions of children in their care' (Ribbens McCarthy et al 2000: 78).

An important aspect of engagement with children is not having preconceived notions and reflexivity (Mandell 1991; Davis 1998). It was this approach which promoted examination of the embodied nature of my research, including locating myself alongside the children and the roles my female gender and participation in physical play ${ }^{44}$ had within the research engagement (Pole 2007; Coffey 1999). I was aware of the 'moral panics' which surround the touching of children (Piper and Smith 2003: 883). However, I believe that my physicality enabled boys to engage with me, and highlighted my willingness to renegotiate power. Furthermore, the notion of, 'taking responsibility for children' rather than away from them (Christensen and Prout 2002: 479), provides links with Mayall's (2002) idea of 'a sociology for childhood', and a child-standpoint methodology.

${ }^{44}$ See section 7.2.2 for discussion of gender and physical contact in a familiar adult role, 7.4.1 for the role of physicality in inclusion in children's worlds. 


\subsection{Conclusions}

When reviewing my methodological approach in relation to the objective of contributing to debate and practice regarding research with children a key finding was the importance of flexibility of researcher-participant engagement for developing the research process as a form of joint enterprise which is key for a child-standpoint methodology.

The 5 substantive chapters that follow each provide details of how children, living in a relatively deprived area of a Scottish city described and interpreted the nature of child-adult adult relations, in a range of interpersonal and geographical contexts. The children's accounts represent snapshots in time, within their lives and in the recounting. However, their validity extends beyond these contexts. The presentation of children's words, albeit those I have selected, provides researchers with access to their socially constructed knowledge and therefore a means of furthering adult understandings of children and childhood. 


\section{Chapter 4}

\section{CHILDREN, THEIR FAMILIES AND THEIR RELATIONSHIPS WITH RELATIVES}

In this, the first of five chapters which present the study's empirical findings, children's relationships with their adult relatives are examined. The first section begins by considering the ways in which the 17 interviewees described or 'created' their families (Mason and Tipper 2006: 12). This was in terms of who they considered to be family members, and how they viewed blood, marriage and other connections between individuals. In discussing the children's definitions of their family structures 3 of the family trees ${ }^{45}$ constructed by the 17 interviewees are presented together with data from the survey.

In the second section of this chapter the natures of the children's reported contacts with their adult relatives are explored. In addition to speaking about their aunts, uncles and grandparents the interviewees referred to contacts with their adult siblings. In fact, when moving on to consider the children's individual relationships with relatives, in the final section of the chapter, older sisters appeared to play an important role in the lives of a few children.

\subsection{The children's families}

The complexity of many current family structures has required researchers to use a broader model, than that of spouse-spouse, parent-child and siblingsibling family subsystems, when examining family relationships. Yet, use of the term 'extended family kinship' to enable the inclusion of other biological

\footnotetext{
${ }^{45}$ Family trees were produced by the 17 interviewees. Discussion on their production has
} already been presented in 3.2.4 
and non-bio siblings and other extended kin as part of the family structure has seemed insufficient (Cicirelli 1995). Taking the view that the concept of family is not static, but one in which the inter-connectedness between individuals may be based more on social ties than on family form I accepted the children's own definitions (Brannen et al 2000; Smart et al 2001).

The family trees produced by the 17 interviewees revealed that there were differences in their views of what constituted family. These varied across parenting structures and living arrangements. In addition, the children used various terminologies, or relationship labels, to describe their connections with other people in terms of relatedness.

\subsubsection{Parenting structures}

Twelve of the interviewees lived with two parents, 5 with both of their birth parents and 6 with a birth and step-parent (Table $4 a$ ). One child split the week between the houses of his father and step-mother and his mother and her current partner. The term 'step' was one that the children generally used to define the person living with their birth parent, although they also used other terms. ${ }^{46}$ Five children lived in lone mother households. The term 'lone' parent, however, may be slightly misleading as situations varied. In one case, the mother's boyfriend had been living in the child's house for a number of years, although he left during the period of the research. In another situation, the child had regular contact, sometimes staying overnight, with her father who lived nearby.

\footnotetext{
${ }^{46}$ There is further discussion in 4.1.3
} 
Table 4a The Interviewees' Family Connections

\begin{tabular}{|c|c|c|c|c|c|c|c|}
\hline & $\begin{array}{l}\text { 'PARENTS' } \\
\text { Lived with }\end{array}$ & 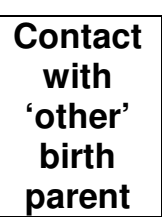 & SIBLINGS & \begin{tabular}{c|} 
Other \\
Adult \\
in \\
house
\end{tabular} & $\begin{array}{l}\text { Older } \\
\text { sibling } \\
\text { out of } \\
\text { home }\end{array}$ & Grandparents & $\begin{array}{l}\text { Aunts } \\
\text { and } \\
\text { Uncles }\end{array}$ \\
\hline Angel & $\begin{array}{l}\text { Mother and } \\
\text { step-father }\end{array}$ & No & Younger & Uncle & & $?$ & Close \\
\hline Breanna & $\begin{array}{c}\text { Birth } \\
\text { parents }\end{array}$ & & Older & Sister & $\begin{array}{l}\text { Sister } \\
\text { close }\end{array}$ & Near City & City \\
\hline Crombie & Mother & Yes & Older & & $\begin{array}{l}\text { Sister } \\
\text { city }\end{array}$ & City & Close \\
\hline Courtney & $\begin{array}{l}\text { Mother and } \\
\text { step-father }\end{array}$ & No & Younger & & & City & Close \\
\hline Gums & Mother & No & $\begin{array}{c}\text { Older } \\
\text { Younger }\end{array}$ & & & $?$ & Close \\
\hline Hayley & $\begin{array}{l}\text { Mother and } \\
\text { step-father }\end{array}$ & $?$ & $\begin{array}{l}\text { Older } \\
\text { Younger }\end{array}$ & & $\begin{array}{c}\text { Sisters } \\
\text { Brothers }\end{array}$ & $?$ & \\
\hline James & $\begin{array}{l}\text { Birth } \\
\text { parents }\end{array}$ & & Older & & Sister & Out of city & Close \\
\hline John A & Mother & Yes & Younger & & & City & Close \\
\hline John B & $\begin{array}{c}\text { Birth } \\
\text { parents } \\
\text { (but } \\
\text { separately) }\end{array}$ & & Older & & $\begin{array}{c}\text { Sister } \\
\text { Brother }\end{array}$ & Close & Close \\
\hline Lily & Mother & Yes & $\begin{array}{l}\text { Older } \\
\text { Younger }\end{array}$ & & & $?$ & Close \\
\hline Lynney & $\begin{array}{l}\text { Father and } \\
\text { step- } \\
\text { mother }\end{array}$ & Yes & $\begin{array}{l}\text { Older } \\
\text { Younger }\end{array}$ & & Sister & $?$ & Close \\
\hline Nicolle & $\begin{array}{l}\text { Mother and } \\
\text { step-father }\end{array}$ & No & $\begin{array}{l}\text { Older } \\
\text { Younger }\end{array}$ & Uncle & Brother & $?$ & Close \\
\hline Peter & $\begin{array}{c}\text { Birth } \\
\text { parents }\end{array}$ & & Younger & & & Close & Close \\
\hline Sarah & $\begin{array}{l}\text { Birth } \\
\text { parents }\end{array}$ & & $\begin{array}{l}\text { Older } \\
\text { Younger }\end{array}$ & & & Close & Close \\
\hline Stacey & $\begin{array}{l}\text { Birth } \\
\text { parents }\end{array}$ & & Younger & & & City & Close \\
\hline Star & Mother & Yes & Younger & & & Close & City \\
\hline Stitch & $\begin{array}{l}\text { Father and } \\
\text { step- } \\
\text { mother }\end{array}$ & No & $\begin{array}{l}\text { Older } \\
\text { Younger }\end{array}$ & & & Close & City \\
\hline
\end{tabular}

Close $=$ within a mile $(20$ minutes walk $)$ 
The majority of the children completing the survey (Table $4 b$ ) also lived with two parents.

Table $4 b \quad$ Survey children's reports of their parenting structures. Survey question 5: Which adults live in your house?

\begin{tabular}{|c|c|c|c|c|c|}
\hline & $\%$ & No. & & $\%$ & No. \\
\hline \multirow{3}{*}{ Two parents } & \multirow[t]{3}{*}{72} & \multirow[t]{3}{*}{270} & Mother and father & 59 & 211 \\
\hline & & & Mother and step-father & 11 & 41 \\
\hline & & & Father and step-father & 2 & 8 \\
\hline \multirow[t]{2}{*}{ Lone parent } & \multirow[t]{2}{*}{26} & \multirow[t]{2}{*}{97} & Mother & 22 & 81 \\
\hline & & & Father & 4 & 16 \\
\hline
\end{tabular}

The survey figures for lone parent families are comparable with UK statistics in 2006 (see Smallwood and Wilson 2007, page 5) ${ }^{47}$, but it is not possible to compare figures for children residing with birth or step-parents. This is because surveys, including the UK census, generally collect data on married and cohabiting families, rather than on step-parenting arrangements. However, comparing the survey figures in this study with another Scottish survey that used child reports (see Todd et al 2007) ${ }^{48}$, those for step-parent families were similar, although a higher proportion of children $(26 \%$ compared to $17 \%$ ) in this study reported living in lone parent families.

The apparently higher number of step-families reported in the interviews, when examined in relation to the survey figures, can be explained through direct knowledge gained from those children. During the familiarisation and interview phases I discovered that children did not always make a

${ }^{47}$ The Labour Force Survey, Office for National Statistics 2006 reported the percentages of dependent children by family type as; married $65 \%$, cohabiting $12 \%$, lone mother family $22 \%$, lone father family $2 \%$.

48 2001/2002 figures from the Health Behaviour in School-aged Children survey for Scotland were $70 \%$ children living with both birth parents, $12 \%$ in step-families and $17 \%$ in lone parent families. 
distinction between biological and step-parents. For example, although Stitch always referred to his step-mother as his mum, Courtney used the terms dad and step-dad interchangeably when she referred to her step-father. Angel called her step-father her dad, saying of her birth father, whom she did not get on with, 'I don't call him dad ... I have actually made a plan myself that his name is not allowed'. Such 'incorrect' responses which alerted me to the ambiguity, as suggested by Sweeting and Seaman (2005), that children's perceptions of 'father' were also likely to have been a feature of the survey answers.

\subsubsection{Family trees}

The idea of asking the children interviewed to produce the diagrammatic trees came from my own confusions as to the relationship between individuals of whom they spoke. Early in the research I had become aware of children's interest in their familial relationships:

As I wandered into the playground two girls started chatting to me asking what I was doing... another two joined in and started talking about their families. Of the four girls present each was one of at least four children with ages ranging from 4-21 years (It would be good to chart these)... A number of the girls spent time with their older siblings, their partners and nieces and nephews. Very family orientated - where do all these family members live?

(Field notes 2: 4/5/04)

On other occasions in the playground, different children, particularly girls, introduced me to their sisters, step-sisters and cousins. Having gained permission to work with 17 of the children, I asked them to produce family trees. Although I conveyed, to the children, the particular format of tracing blood lines ${ }^{49}$, the results enabled analysis of how children viewed their

\footnotetext{
${ }^{49}$ See section 3.2.4 for details on the production of the family trees.
} 
families in terms of whom they included and what these people meant to them.

The trees ranged in size from John A's (Fig 4.1), of 7 people, and of which he said: 'I've got a small family', to Lynney's (Fig 4.2) of 56, which extended over 2 pages and included aunts, uncles, cousins and cousins' children, together with a great-grandmother, a step-grandmother and a dog. John B's tree (Fig 4.3) of 24 people was of an average size, but slightly unusual in that his parents had each had 2 additional relationships. The trees of these 3 children are discussed in detail, and contrasted with those of other children, in order to illustrate the nature of particular family relationships. Some of these relationships were specific to the child in question, but additional types of relationships also featured in other children's families.

John A's tree was the starkest. He knew that his mother was an only child, but could not remember whether his father had any siblings. In Gums's tree, there was also a gap on his father's side, probably as a result the lack of contact Gums reported. Other children mentioned great-grandparents or the partners of aunts and uncles in discussion, but did not include them in their trees. This may have been because the child's recollection of the individual had not been consistent, possibly as a result of limited contact. Other relatives may have been excluded because a child had not known of their existence. Interestingly, in Courtney's case neither her birth father nor any of his relatives were part of her tree. Five children included people who were deceased, such as Nicolle's father, and various grandparents. When the children included these people on their trees and announced that they were no longer living, I encouraged them to place a cross through the name to 
indicate this status. Sarah had not wanted to do this and said 'dinnae score her out, she's still part of our family'.

In addition, to revealing children's views that they considered deceased relatives to still be part of their family; the trees were interesting in displaying how individual children viewed the status of their various aunts and uncles.

In order to examine the ways in which children perceived the membership of their families I have divided the trees into three broad types of family structure; 'vertical', 'horizontal' and 'extended network'. This division was made, partially on the basis of how aunts and uncles were identified, but also through the ways in which other people were included, or excluded, as family members ${ }^{50}$.

Fig. 4.1 John A's family: A 'vertical family structure'

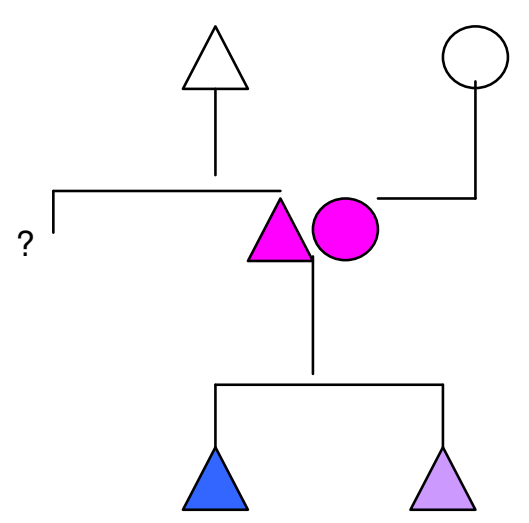

Family Friend 'Uncle'

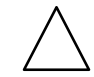

KEY

Parents

John A

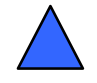

Sibling

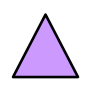

${ }^{50}$ It should also be noted that the trees were a product of the way they were constructed. The detail, or lack of it, resulting to some extent from the interest individual children had in their production. See 4.1.2. 
John A's tree can be seen as a 'vertical family structure' because of his apparent emphasis on the grandparent, parent and child links. This type of tree was also produced by Gums, Crombie, James and Peter, although they also included and named parental siblings.

The 'extended family network' in which the partners of aunts and uncles were included and also named, along with cousins, great-grandparents (even if deceased), great aunts and the previous partners of different relatives, was the type of tree produced by Lynney, 6 other girls and Stitch. 
Fig. 4.2 Lynney's family: An 'extended family network'

first page

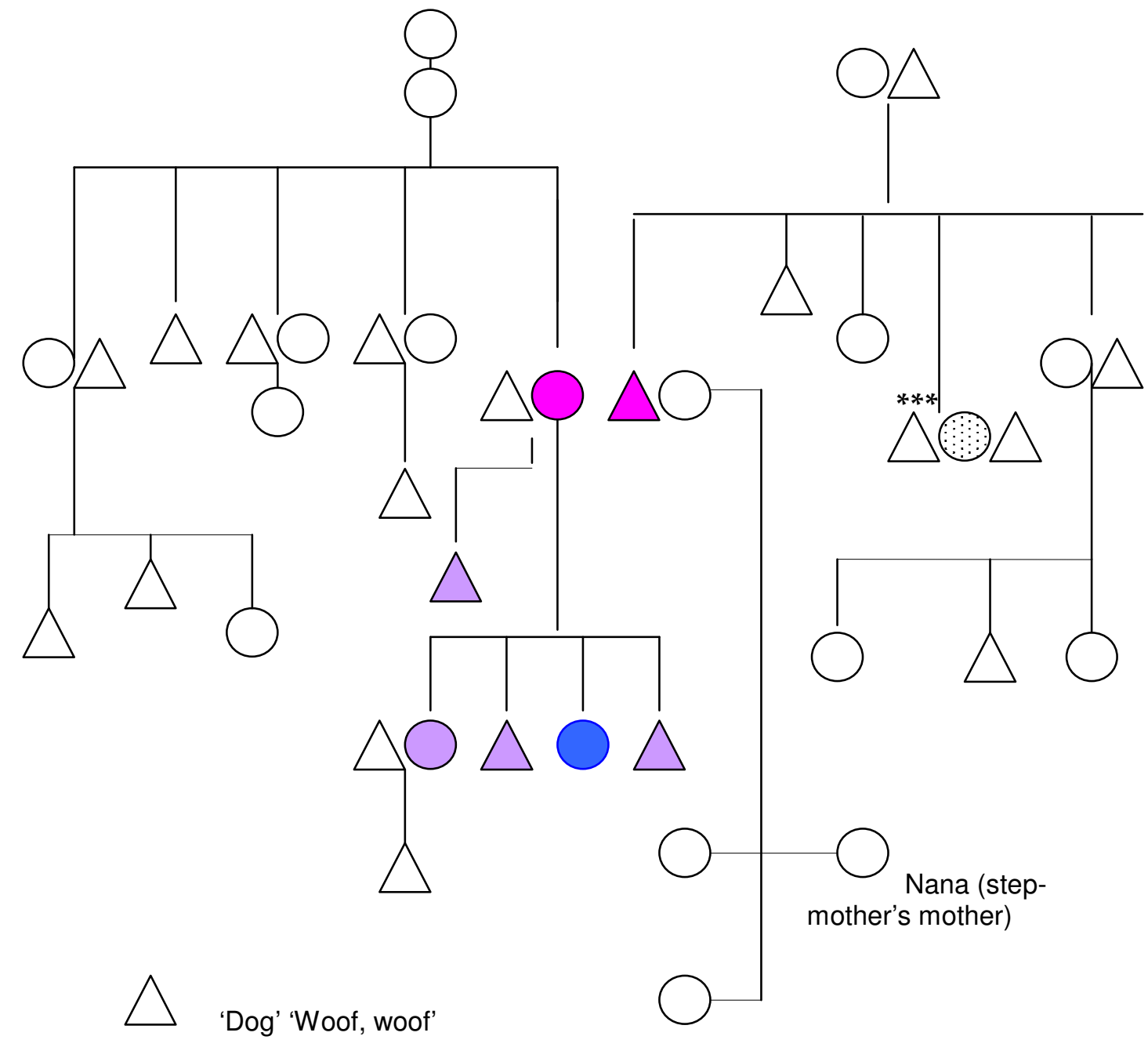

second page

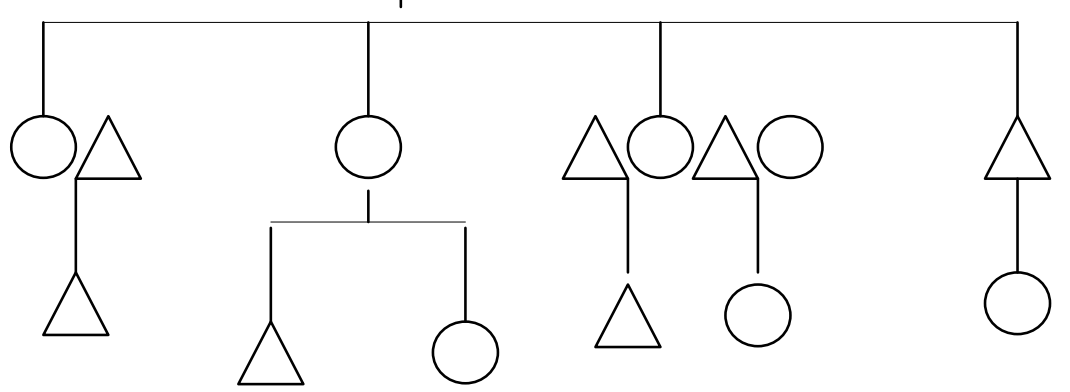

KEY

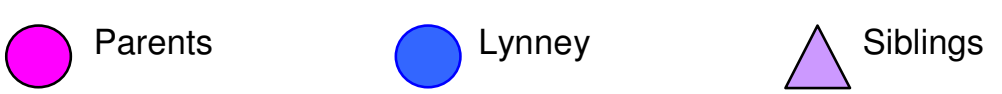


John B's tree was an example of a 'horizontal family structure', where he not only added family members as a result changes in parental marriage or partnership, but also other people with biological connections to these new members. Thus, not only had Angel, Hayley and Nicolle noted that they had gained step, and half-sibling, but also step-grandparents, aunts and uncles.

Fig. 4.3 John B's family: A 'horizontal family structure'

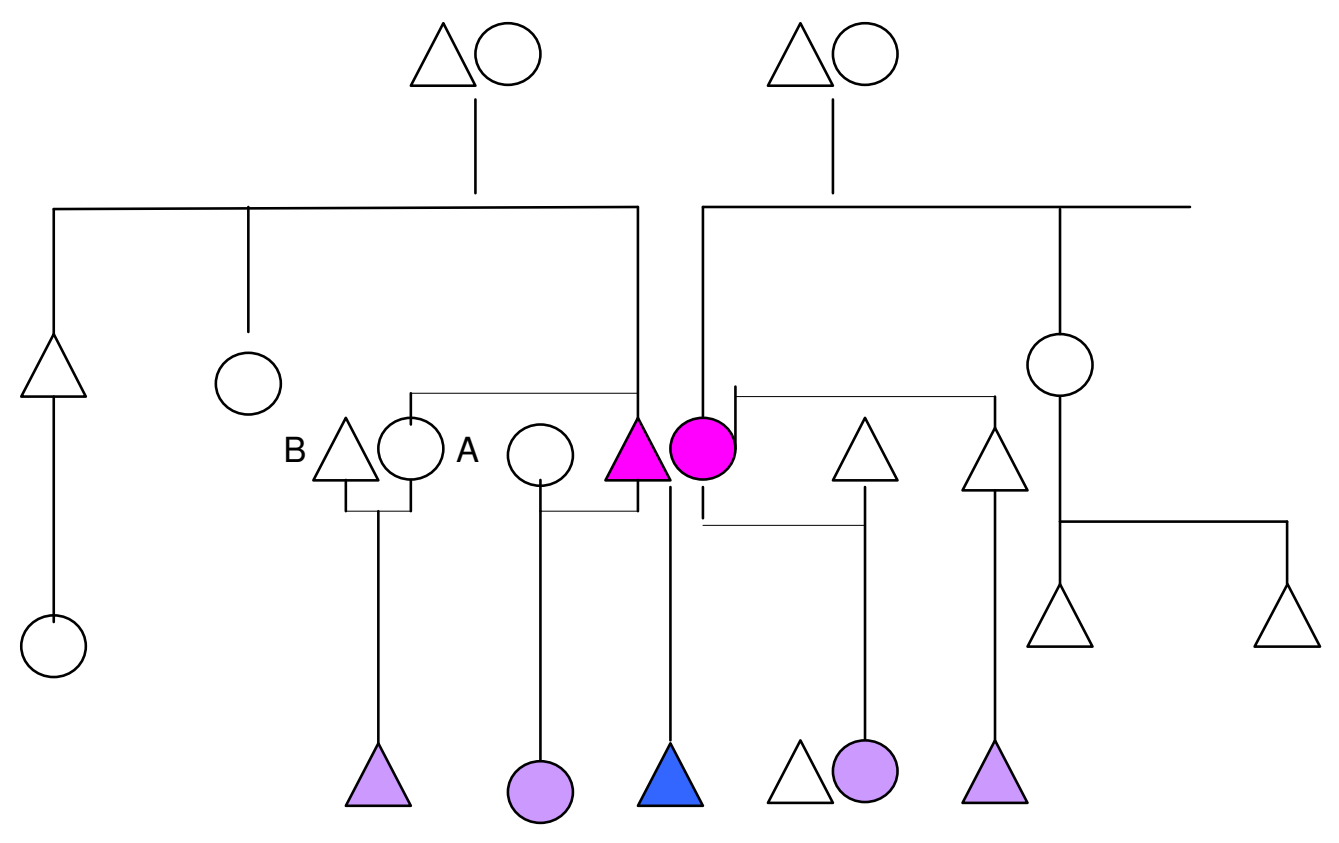

'Mum's cousin's child'

KEY

Parents

John B

Siblings

These 3 tree structures provide a means of examining the children's constructions of family. It is interesting to note that 4 of the 7 boys produced 
'vertical' structures, whilst 7 of the 10 girls produced very detailed extended networks. In producing such detail the girls appeared to be seeking to include everyone they considered to be part of their families. As this may have been a reflection of the place that their families played in their lives, it was probably not coincidental that for Lynney, Stacey, Star and Stitch, all produced detailed trees. Family was importance for these 4 children, although in different ways. ${ }^{51}$

\subsubsection{Real, step and assigned relatives}

Whether or not they are married, the relationship of a parent's new partner to a child is interesting one to consider, for it has an impact on other relationships. Penderson et al (2004) state that terminology such as reconstructed, reconstituted or blended family are now being used to define a range of biological and other relationships that were previously called stepfamilies. In their trees and in conversation, the children used various biological and 'social idioms' to distinguish between the different ways in which they felt connected with, or related to others (Carsten 2000: 16).

Angel used the term real to differentiate her birth father from her current step-father whom she called dad. Crombie appeared to use real in a slightly different way; as a means of denoting that a birth relationship was, in his opinion, a more significant relationship than that of step, because of the direct connection through blood, and birth:

$\begin{array}{ll}\text { Sue } & \text { You have an auntie who lives down at the wee shops? } \\ \text { Crombie } & \text { Well she's not really my auntie; she's my papa's daughter. } \\ & \text { My papa did nae have my dad } \\ \text { Sue } & \text { So your papa is your dad's step-dad? }\end{array}$

${ }^{51}$ More details follow in the chapter sections of 'family contacts' (4.2.2) and 'support to and from relatives' (4.2.3). 
Over half of the interviewees used the term real to denote a birth or blood link between people, either when speaking about their own families or those of other children, as Stacey did when she commented on people who lived in her street:

'Well I don't know if that is his real dad, I'm not sure ...there's his mum, but they call her [first name]. There are [names of two other children], but I don't think that's their real mum either'.

Whilst, not referring to their step-parents as their real parents, Stitch and Angel did not use the prefix step and Courtney did this occasionally. However, Hayley and Nicolle not only used the term to apply to their fathers, but also to their fathers' blood relatives. Overall, it is not known how many of the interviewees parents were married, or whether in the case of step-parenting arrangements this made any difference to the children's viewpoints, but the fact that Stitch, Angel and Courtney all had half-siblings and often omitted the step prefix when speaking about their birth parent's partner could have suggested that they valued the birth connection with their half-sibling.

Over half of the interviewee's parents had had previous or subsequent relationships. As a result of these arrangements, the children's trees and conversations suggested that other people could be drawn into their families. John B was slightly different from these children, in that his parents had each had 2 additional relationships and he had 3 half siblings and a step-brother from the different partnerships. It was interesting to see how he referred to people on his tree. Although, he did not live with all of his siblings, he seemed to have contacts with them and used various terms to refer to their parents. He called his mother's current partner 'dad Tom', and her previous 
partner 'Sean's dad'. He called his father's current partner his step-mum (Fig. 4.3, A), and her previous partner his step-dad (Fig. 4.3, B). It is possible that he needed to name and distinguish these different adults, not necessarily because they were significant to him, but because they were important to his siblings. It is likely that his step-brother, with whom John lived at his father's house, spoke about his own father, and it may have been that the two boys visited him together. Despite the tenuous connections that John B had had with these different adults it seemed that their connections with his siblings was the reason for his inclusion of them as members of his family.

Step was a term used by the children to refer to relationships with a range of adults. In terms of siblings just less than half of the children interviewed had step-siblings and slightly more had half-siblings. There were variations in how the children referred to their step-siblings; sometimes marking them as such on their trees or using such terms when speaking about them. However, those with half siblings rarely used the term. Breanna was the only child to say that she had half-sisters, although she did not mark then as such on her tree. When speaking of people on their trees James and John B both spoke of their half sisters. However, John B did not like the term and insisted that they were his real sisters.

When exploring the 'chains of connections' (Mason and Tipper 2006: 5), that were created through step-parenting arrangements, the interviewees were interested to name the links they already knew existed between themselves. In speaking of Lily, Angel said that she sometimes played or walked home with her, 'actually I could put her as my cousin because her mum is my stepauntie'. Yet, such connections, however, tenuous, were not always seen as 
positive. In one interview John B and Gums had an argument because John B said that they were related, but Gums insisted that they were not.

Yet, whilst step-relationships could mean that children drew other people into their families, these also became confusing:

$\begin{array}{ll}\text { James } & \text { I've got a granny and a granddad } \\ \text { Sue } & \text { But they're not together? } \\ \text { James } & \text { They were married, but they got divorced and my granny } \\ & \text { got remarried and my granddad has got a fiancé. It's kind of } \\ & \text { confusing! }\end{array}$

James implied that he was confused because he was not sure whether to include his grandmother's new husband or his grandfather's fiancé as members of his family. There were also other forms of family connections that the children found equally confusing. For example, when she spoke about her 'papa,' Angel described how this man was not only her stepfather's father but that he had also been connected to her birth father. 'I was with my real dad, my papa knew my real dad and it turned out that he's my papa's cousin Bob!' Whether Angel's 'papa', was her father's cousin Bob, or a cousin of her birth grandfather, it seemed, from the way she spoke, that she was pleased to find a link between the families of her birth and step-fathers.

In addition to being able to draw people into their families by such linkages others were counted as family through the ascription of familial terms. The 'uncle' on John A's tree was not related to him in by blood or partnership, he was a friend of John's parents. He was someone who provided support to his parents and was a person with whom John spent time. Given that neither parent had siblings, it is maybe not surprising that this friend was assigned the role of 'uncle' and was included on John's tree. Although John A was one of only two children to include parental friends on their trees and name 
them as aunts and uncles, other children, such as Hayley, spoke of such relationships with friends of their parents ${ }^{52}$ :

$\begin{array}{ll}\text { Sue } & \text { And your uncle comes round, but he's not really your } \\ \text { uncle? }\end{array}$

The use of 'half and half' seemed to indicate that although Hayley was aware that although her parent's friend was not related to her, he did perform an uncle-like role. Star and John A were also likely to have acknowledged the supportive role played by their 'aunt' and 'uncle', although in Star's case this role could also have been confused by the fact that her 'aunt' was also her god-mother.

Children can not only draw people into their families, but they can also create distance (Mason and Tipper 2006). Not naming individuals or including them on their family tree may have been an example of this, and one particularly applied to position of aunts and uncles related by partnership rather than through a biological connection with a child's parents. There was one instance of a blood relative being distanced by a family, Sarah said:

Right, my mum's mum and dad they've split up with my aunt. See that dad (referring to her family tree) is those cousins' real dad and see those ones, that's their real dad and that's their step-dad. And my granny and granddad's no split up, neither has my mum.

Sarah started speaking of how her maternal grandparents had 'split up' with her aunt, in the sense of not having any contacts or communications with her. However, she also appeared to use the term 'no split-up' to refer to her

52 Relationships between children and their parent's friends are explored in more detail in 5.2.2. 
grandmother and grandfather and to her mother and father as being couples, who were still together as partners. She later said, of her father's sisters, 'we dinnae include they two as our aunties, nor does my dad because he doesn't like them.' Yet despite saying this she included these aunts in her family tree. It is possible that she had been reporting her parents' viewpoints, but that her tree reflected her own sense that they, like her deceased grandmother, were still part of her family, even if her parents were no longer on speaking terms with them.

What this analysis indicates is the ways in which these children have adapted to the complexities of changing family structures, through various modes of 'reckoning' kinship (Mason and Tipper 2006). This not only included the acknowledging and 'weighing up' of 'proper' relatives' but also the process of naming individuals and of creating chains of connections that drew others into their families (Mason and Tipper 2006: $9 \& 5$ ).

\subsection{Contacts with relatives}

Accounts from the interviewees not only provided details of those whom they included as members of their families, but also revealed the range of contacts they had with individual relatives. In outlining how they spent their time when they were not in school these children spoke about relatives visiting their houses and vice versa. The following sections explore the proximity of relatives in spatial, geographical and temporal terms before examining the nature of children's contacts with them. As in the previous section, survey data are used to provide a broader context. 


\subsubsection{Spatial, geographical and temporal proximity}

All of the children interviewed, except Hayley and Breanna, said that they had a grandparent, aunt or uncle who lived within walking distance ${ }^{53}$. In the survey $50 \%$ of the children reported having a grandparent living within walking distance. Just under half $(47 \%)$ said that they had an aunt or uncle living nearby and almost a third (32\%) reported such proximity of both a grandparent and an aunt or uncle. Two of the interviewees had uncles living in their homes at various points during the research. this was slightly more than the $7 \%$ of the children in the survey.

In the survey, the children were asked about the frequency of their contacts with grandparents and with aunts and uncles. The results show some association between the spatial proximity of relatives and the amount of contact the children reported. Over half $(51 \%)$ of the children reported seeing their maternal grandmothers at least once a week ${ }^{54}$ and $63 \%$ to seeing an aunt or uncle in the same time frame ${ }^{55}$. These figures are also comparable with those of Brannen et al (2000). ${ }^{56}$ Over a quarter (26\%) said they saw an aunt or uncle daily and $21 \%$ their maternal grandmother ${ }^{57}$. Given the proximity of relatives, to the children interviewed, including aunts living in the same street, it is possible that they had contact with relatives as they walked around their neighbourhoods. However, only Lily made mention of this,

\footnotetext{
53 Some interviewees specifically mentioned walking, but where they had not I used my own knowledge of the area and defined 'walking distance' as being a mile in measurement or 20 minutes in time. See Appendix 13 for more details.

54 Survey question 13 . The figures for other grandparents were less: maternal grandfathers $41 \%$; paternal grandmother $36 \%$; paternal grandfather $27 \%$.

${ }^{55}$ Survey questions 14 and 18.

${ }^{56}$ Brannen et al (2000) found that $46 \%$ of their sample of 843 had seen their grandparents in the past week and $54 \%$ had seen an aunt or uncle.

57 The figures for other grandparents were less: maternal grandfathers $14 \%$; paternal grandmother 12\%; paternal grandfather 8\%. Survey question 13 .
} 
stating that she saw her aunt every day when the aunt was going to work and she was on her way home from school.

The interviewees spoke of having other relatives living within the city and outside it. Geographical proximity did not necessarily result in more frequent contacts between the children and their relatives. For example, Lily said that one aunt came through from another city on a Sunday, although she saw the aunt who lived closer, less frequently. However, it was more generally the case that children had less contact with those relatives who lived further away. James reported only seeing his grandmother when she came to stay at Christmas and Star and Hayley that they saw their relatives in the school holidays.

\subsubsection{Family contacts}

Spending time with their families, in addition to their friends, appeared to be important to children in the study. In the survey $31 \%$ reported mainly spending time with their family during the week, with $38 \%$ reporting time with friends ${ }^{58}$. Weekends were different as $43 \%$ of the children reported that they spent time mainly with their families and 39\% with their friends ${ }^{59}$. Whilst the degree of contacts which individual children had with their relatives varied, it seemed that family contact could include relatives as well as the child's parents and siblings.

Within the interviews children spoke of such activities as: relatives popping by; weekly arrangements of family members coming 'for their tea' and family visits to grandparents. Such activities appeared to be have been organised

\footnotetext{
${ }^{58}$ Survey question 32. The other answer options were: going to organised activities like clubs; by yourself.

${ }^{59}$ Survey question 33.
} 
by parents and with an expectation for the children to participate. Yet, there seemed to be distinctions in both the way these contacts were made and in their nature. These ranged from fluid arrangements such as Stitch saying, 'we might call them or they might call us' or of occasional outings with aunts and uncles, to regular arrangements where individual relatives, grandparents, single aunts and uncles came on a regular day to the child's house for their tea. Stacey's reports of her aunt, uncle and cousin coming for a meal on Sundays indicated such a regular arrangement. Her description of how they ate from trays on their knees with the children having to share, suggested comfortable informality, which is also apparent her contact with her grandmother:

\begin{tabular}{|c|c|}
\hline acey & $\begin{array}{l}\text { Well, I normally, my gran, her friend is called Annie, and I } \\
\text { says to my granny; 'Does Angry stay next to you? I } \\
\text { thought her name was Angry and my granny went; 'Who's } \\
\text { Angry?, and I went; 'Her sitting there', and she started } \\
\text { laughing and I went; 'What are you laughing?'. 'It's Annie' }\end{array}$ \\
\hline de ( & $\begin{array}{l}\text { So you were just sitting in the room while they were } \\
\text { chatting and then what you might join in chatting with } \\
\text { them? }\end{array}$ \\
\hline Stacey & $\begin{array}{l}\text { They say; 'I dinnae know who that person is?' or something } \\
\text { and I say; 'That's so and so', or something. }\end{array}$ \\
\hline Sue & So would they be asking you questions then? \\
\hline Stacey & Sometimes and they say to my sister; 'Do the cha cha slide' \\
\hline Sue & The 'cha cha slide' what's that? \\
\hline Stacey & $\begin{array}{l}\text { It's a song and it tells you what to do; 'Move to the left put } \\
\text { your hands on your hips'. }\end{array}$ \\
\hline . & Do they say that to you as well or just to your sister? \\
\hline & Both \\
\hline & ere giving a wee shou \\
\hline
\end{tabular}

In contrast, Stitch's reports of contacts with his relatives suggest greater formality, from the arrangement of his parents and siblings and aunt and uncle in another city taking it in turn to visit each other once a month, to his outline of how he spent his weekends: 


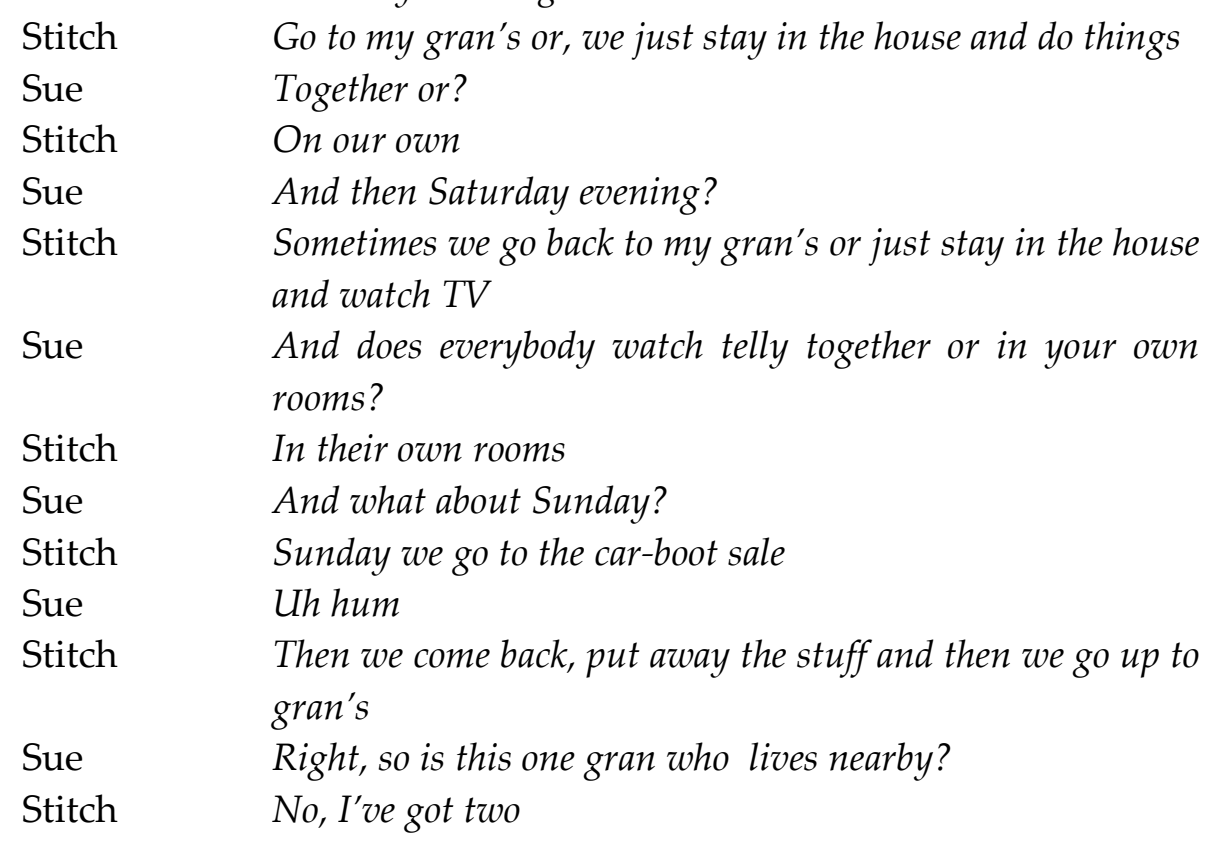

Stitch's account indicates separateness in the activities of individual members, but that they also possessed routines as a family, such as going to the car-boot sale and visiting both sets of grandparents. He said that he regularly stayed overnight with one set. However, his accounts of having tea, watching TV and playing cards with his grandparents were reported factually, without the sense of engagement and enjoyment apparent in Stacey's account.

When children commented, in the interviews, of spending time with their grandparents, aunts and uncles there were indications of routine and particularly, in the case of Stitch's family, a sense of family obligation. However, John A and Stitch did make negative comments about their grandmothers. At one point John stated that his grandmother lived with him, but then later he said that she did not. When asked why he had previously said that she did, he replied 'well she might as well, she's there all the time'. Stitch said that he got on better with three of his grandparents than the 
fourth because 'she's always moaning about my granddad.' That such comments emerged suggests that there may have been other dissatisfactions, just below the surface, and that children may not have always been as content, as they implied, to spend time with relatives. However, they may simply have accepted that visits to grandparents and the appearance of relatives for meals were just another part of their lives that were largely structured by their parents. Such visits may have been, like doing the shopping, a regular feature of family life and something not questioned by the children.

\subsubsection{Support to and from relatives}

Whilst not expressed as such by the children, family visits can be viewed as one of the ways in which a sense of family is maintained. The interviewees spoke of knowing who was a part of their families and having regular contacts seemed to be part of this process. Another point, of knowing who your family, is can also be linked to knowing who can be called upon for support in times of need.

These children did not appear to question the support their parents offered to other relatives. Although they did not use the term support in relation to their uncles, it seemed, from the ways in which Nicolle, Angel and Stacey spoke, that they thought their parents should be offering assistance to these men. Nicolle explained that her aunt, whom she could not remember was her father's or mother's sister, had 'finished with' her husband and that Nicolle's family had taken him in. She said that he was on crutches, but not whether this was the reason he came to live with her family. Angel's uncle also had a disability, 'he's got something wrong with his brain, it's, he's actually a full grown man but (has)...something that plays up in his brain, I can't mind what it's called'. She said that her father was his carer. When I initially spoke to Angel she 
said that he was living with her family, but five months later she reported that he had just obtained his own house, although he still came round for his tea. Stacey said that her father went round every evening to support her uncle, who was disabled.

Breanna's comments, that her sister had found potty training her toddler hard, but that her mother 'was used to it', suggest an acceptance of her mother's use of her own experience to support the sister, who lived at home. However, James's comment about his uncle, 'we see him when he needs stuff, like, he wants a cup of coffee or something' appears to indicate some form of resentment. This was the uncle whom James and his father helped with the gardening, so the comment may have referred to his wanting help as well as coffee. James could have been reflecting his dissatisfaction of cutting grass, holding up fences, and of 'just' being 'a wee helper' and a 'shop boy'. He may also have picked up such a negative tone from his father. This suggests that children can gain negative, as well as positive, impressions about the nature of family support and obligation.

Support was given not only by the children's parents to these relatives, but was also received from them. Nicolle and Angel spoke about their uncles looking after them if their parents were out and John B and Crombie reported that family members 'babysat' them. In general such support appeared to be occasional, but, for Star and Lynney, it seemed to be more frequent. Star, who lived with her younger sister and mother, spoke about her regular contact with various aunts and uncles:

Sue

Star

Sue
Do you see these relatives who live nearby?

Uh huh all the time

And do you go to their house or do they come to your house? 

house sometimes

Sue Um hum, and what sort of things do you do with them?

Star Watch telly, play games and if I'm down at Leefield with my auntie we go for walks... I play with my wee cousin... we watch videos up in his room. And for his birthday me and my wee sister and my uncle and my wee cousin and my auntie went to Disneyland Paris in France

This aunt and uncle also took Star shopping. Such generosity, in terms of buying her clothes and taking her on holidays, was likely to have been a great support to Star's mother, who lived on State benefits. Given the frequency to which Star referred to such treats she was obviously very appreciative. Backett-Milburn et al (2003) received similar reports of the material help given by aunts and uncles, from the children in their study.

Lynney, who initially described enjoying living with her father and stepmother, faced problems, about where she was to stay when her father left. Nine months into the research she said that she had recently been living with one aunt, but that she was moving to live with another. From the following quotation it seemed that her step-mother had been unable to support her:

$\begin{array}{ll}\text { Lynney } & \ldots \text { we dinnae get on too well anymore } \\ \text { Sue } & \text { Do you not? Cause you used to. } \\ \text { Lynney } & \text { She's always too busy. She's always working and } \\ & \text { every time we ask to stay, it's: 'Oh I cannae, I'm } \\ & \text { working. Oh I cannae, I'm doing this. Oh I cannae, } \\ & \text { I'm doing that'. She's a moan. }\end{array}$

Whilst Lynney called this woman her step-mother, it may have been that she had not actually been married to Lynney's father. This may have been a reason why she appeared not to want to take responsibility for his children. In this situation, Lynney's aunts had stepped in to support her. Lynney spoke about how she had been to a third aunt's house for Christmas and that she often stayed there at weekends. She said that another aunt was 
organising her birthday party that included hosting sleep-over. These aunts had not only rallied round to make sure that Lynney had somewhere to live, but they had also paid attention to her emotional well-being by enabling her to enjoy occasions that were important to her. Lynney previously made reference to some difficulties in her relationship with her older sister, but at this time her descriptions of her sister arranging to meet her 'every lunchtime' suggest appreciated support. It is interesting to reflect back to the detail in Lynney's family tree ${ }^{60}$. Her knowledge of individual members was perhaps an indication of the time she spent with them. The support offered, particularly by her father's sisters, appeared to be a reflection of the closeness or feelings of obligation felt by the family members.

\subsection{Children's individual relationships with relatives}

In the survey the children were asked how well they got on with their aunts and uncles ${ }^{61}$, the majority said very well: $74 \%$ for aunts and $71 \%$ for uncles. However, whilst accounts from the interviewees provide an overview of their contacts with members of their extended families, there was generally little sense that many of the children possessed a meaningful relationship with an individual relative. The high figures in the survey, for 'getting on with' aunts and uncles may possibly reflect a notion that not only is one expected to 'get on' with one's family, but also a general sense that the children did, in broad terms, rather than in the context of an individual relationship, 'get on' with these relatives. This section considers interview data the children's independent and autonomous contacts with relatives and the opportunities for such, before examining their accounts on the nature of

\footnotetext{
${ }^{60}$ See page 98

${ }^{61}$ Survey question 66
} 
these contacts, and specifically those which 3 children had with their older sisters.

\subsubsection{Independent and autonomous contacts}

I refer to children's independent contacts as those without their parents' presence, but not necessarily of their own choosing. Their autonomous contacts are defined as those which are self-chosen and 'without parental presence' (Meire 2004: 103). In section 4.2 it appeared that the contacts that the interviewees had with their relatives were generally in the company of parents and siblings, yet as we have seen many had relatives living within walking distance. In the survey nearly half (49\%) of the children said that they visited their grandparents without their parents, $45 \%$ visited aunts and uncles independently and $9 \%$ went independently to visit older siblings. The interviewees provided details of the type of independent visits they made to various relatives. However, a point arose which suggested that the survey figures might have been slightly misleading. It became apparent from the interviews, that when children spoke of visiting relatives without their parents, this also included occasions when they had been taken and left there. For example, in John B's case he was taken to his aunt's house so she could look after him when his mother went out. Whilst he may have been there independently of his mother, the visit was probably not his choice. As has been mentioned, Stitch had regular family contact with two sets of grandparents and spoke of staying with one pair on a regular basis:

$\begin{array}{ll}\text { Sue } & \text { So how often would you stay there? } \\ \text { Stitch } & \text { On Saturdays } \\ \text { Sue } & \text { Is that your choice to go and stay there? } \\ \text { Stitch } & \text { You can choose. If you're no going you get to give it to } \\ & \text { somebody else and then they get their week and our week }\end{array}$


Whilst these visits were independent of his parents, they seemed part of the family routine. The idea of giving your turn to someone else, in this case one of his three brothers, indicated that there was an expectation that at least one of them stayed overnight. In saying that he only stayed overnight if one of his brothers did, suggests that he was not very keen on the idea. Breanna appeared to have free choice from her parents to make arrangements to either visit or to stay overnight with her sister, something which she appeared to enjoy doing. John B spoke of staying at his sister's house and of going to the park and taking the dog for a walk with her and her partner saying 'It's good. It's fun'.

There was an indication from other children that they would like to visit their relatives but that they were prevented from doing so for various reasons Nicolle and James said they were not allowed to stay with their sisters. In both cases it may have been because of the physical distance, as these sisters lived in other towns. Nicolle said 'I'm not allowed to cause my mum says, see how it's a Friday right and if I go and live ${ }^{62}$ with her I will nae come back 'til the Monday'. One interpretation of this is that her mother did not wish her to stay for so long; perhaps she did not trust the older sibling. Certainly this was the impression I received from James. Whilst he did not actually say that his mother did not trust his sister, he indicated that she thought, that as his sister could not look after the house 'the house is a mess, all dirty', that she would not be able to look after James.

In the following examples children's autonomous decisions to visit relatives are apparent. Peter and Gums both spoke of visiting the houses of aunts who lived nearby. The reason they both gave was to play with their younger

62 In Scotland it is common for the terms 'live with' and 'stay with' to be used interchangeably to imply both residing with, and staying for an overnight or longer visit. 
cousins. Gums also spoke of deciding to go on the bus with a friend to visit his grandparents, possibly as way of occupying his time. On another occasion, he said that he could call in on them, after going to a swimming pool in Jameston, in order to obtain a lift home. Whilst these two boys were free to make such visits, there were limiting factors for others. Peter said that he would not visit the house of another aunt because she lived in a different territorial neighbourhood. ${ }^{63}$

\subsubsection{Individual relationships}

There were opportunities for at least half of the children in the survey, and all but one of the interviewees, to have at least weekly contact with a relative. Yet, most of these contacts were in the company of, or at least organised, by parents. This section explores whether there was any sense from the interviewees that they thought that they had an individual relationships with an adult relative, whether their contacts were with other family members, independent or of their own autonomous choice. I am referring to individual relationships in the sense of feeling they were an individual person rather than just a member of the family.

The focus of the study is on child-adult relationships, but during the interviews children made frequent references to other children. It was references to children that most typically portrayed relationships with individuals, but references to cousins were also as taken for granted members of the family. Cousins were mentioned, almost in passing, by the 17 interviewees, but were a common feature on their family trees. In relation to discussions about relatives cousins appeared to feature because of their child status and also as relatives with whom the research children identified. In

\footnotetext{
${ }^{63}$ Issues of, and the impact of, neighbourhood territories are discussed in the Chapter 5.
} 
addition to being a reason for Gum's and Peter's visits to their aunts' houses, Nicolle and Sarah spoke of regularly playing with their cousins. In this sense cousins probably occupied a similar role to that of siblings, of being someone to play with, if closer friends were unavailable.

If the interviewees appeared to make a distinction between their relatives based on their status as children or adults, there was also a sense of how they chose to distinguish between different relatives. This was in terms of volunteering information about a particular relative or how they replied to a direct question such as, 'Do you have a favourite aunt' ${ }^{64}$. In reply Hayley and Lily said that their favourite aunts took them shopping and bought things for them:

Sue
Hayley why was that good then, to be with them?
My auntie takes me all, everywhere, like town, shopping,
takes me down to England, gets me anything I want, if I
want a toy she gets me a toy. She gives me loads of pocket
money

During this paired interview the girls' emphasis on receiving of gifts of goods and money suggested that they were competing with each other. The presentation of gift giving can be viewed in a number of ways. For example Pahl and Spencer (2004 referring to Komter and Volleberg 1997) suggest that gift giving may be considered as a relative's tangible expression of closeness, in the sense that - it's the thought that counts. However, in terms of this research, these children with somewhat restricted vocabularies may have chosen to use the concrete example of gift giving as a way of illustrating the feelings of closeness they either had, or wished to have, with a particular

\footnotetext{
${ }^{64}$ This question was asked of Lily, Nicolle and Hayley as a means of encouraging them to speak about their relationships with adults.
} 
relative. There was a sense from the children that they meant 'She doesn't actually give me all these things, but it feels like she does'.

For Lily one of the reasons that she enjoyed shopping with her aunt was that she was allowed choice, whereas when she shopped with her mother 'my mum has to pick everything for me'. Such expressions of choice and of being treated as an individual were also present in other children's accounts, such as Sarah's of baking cakes with one of her aunts, and especially when 3 children spoke of spending time with their adult sisters. Yet for most of the children interviewed it did not seem that they had any individual relationship with a relative.

\subsubsection{The importance of older sisters}

Nearly a third (28\%) of children completing the survey ${ }^{65}$ reported having an older sibling (aged 16 or above) not living at home. Within their interviews Breanna, John B and Crombie indicated that spending time visiting their sisters in their own homes was important to them.

Breanna had an older sister and nephew living at home, but also another sister living nearby. She reported that she was allowed to take a friend to stay overnight with this sister and said 'I can talk to my sister, she can keep secrets, she's good at that'. It is not known how much choice was involved in John B's and Crombie's visits to their sisters, but from their reports, these relationships appeared to be similar to that between Breanna and her sister, but generally different from those between other children and their relatives. The key feeling revealed through their accounts is one of receiving attention and of being included in the activities of adults. Of his sister Crombie said:

\footnotetext{
65 Survey question 9.
} 
She takes me out ..., out for meals...she takes me places all the time ... I feel quite good with my sister because some people's sisters are like older than my sister and they sit out in the streets and get drunk and stoned and everything ...And they don't have jobs, well my sister's got a job and she's ... and everything'

This account indicates Crombie's respect for his sister. In emphasising her adultness through her responsibility he had possibly been suggesting his own ability to be responsible, through association.

Interestingly, all three of these sisters were the children's half siblings, on their mother's side. Whilst mother-child relationships are not the focus of this study it is interesting to note the frequency in which children mentioned their mothers, as individuals, when asked to speak of adults that they knew and also as a reference point for adult behaviours ${ }^{66}$. It may have been that these sisters played a mother-type caring role for their siblings, but in being younger, closer in age and having a different sort of relationship, they treated their siblings as individuals. This may have been why Breanna, Crombie and John B all reported enjoying spending time with them.

These three children all had the opportunity to spend time with their adult relatives, unlike Nicolle and James who would have liked to spend time independently with their older sisters. Whilst other children did not spend much time independently with adult relatives there was little sense that they desired to do so.

\footnotetext{
${ }^{66}$ There is more discussion on this point in 8.2.3.
} 


\subsection{Conclusions}

Finding or making connections with others seemed important, from the interviews, to the children in terms of creating a sense of belonging and in providing a context for their lives. The centrality of family relations to the children's everyday lives echoes the findings of Crow and Allan (1994) in relation to adults. Whilst studies have been concerned with the impact of family change on children, variations in family form have always occurred (Carsten 2004). From the interviews there was a sense that the children lived with the 'ordinary complexity of kinship' (Mason and Tipper 2006: 5). They appeared to attach importance not only to knowing who counted as a member of their family, to establishing links between family and friends, but also to including others in their families. The naming of individuals and their relationships to themselves appeared to represent the importance of their relatives to children like Stacey and Lynney. The inclusion of parental friends as family members by the ascription of a familial title, suggests a way of legitimising non-familial child-adult relationships.

On the basis of the interviews it can said that these children experienced a range of contacts with familial adults. Their accounts echo the link between 'doing family' and of 'being family' ((Morgan 1996; Silva and Smart 1999), and also to 'displaying family' (Finch 2007). Their accounts of the giving and receiving support in various forms also reflected the notion of family 'obligations' (Finch 1989).

There was evidence, from some of these children that they were beginning to have a sense of their own individuality within the family. For Breanna, Crombie and John B, their relationships with their older sisters appeared to play a important part in this process. The fact that, in this study, these 
relationships were all with sisters is interesting and worthy of further investigation. Gillies and Lucey's (2006) research revealed the caring and guiding role which older siblings played in relation to younger ones, but they state that sibling relationships remain 'surprisingly unexplored'.

Whilst the spatial proximity of relatives made it possible for adult relatives such as grandparents to be part of 'children's social landscapes' (Ross et al 2005: 10), contacts with them were not generally independent or autonomous. Although for Breanna and Gums it seemed that they were developing their own relationships with individual familial adults independently of their parents. Whilst for most of the interviewees the autonomous decision to visit to the houses of their aunts or uncles was to play with a cousin, rather than to spend time with the adult, there are indications of a link between children's autonomous movement and their individual relationships. In contrast, the sense of obligation that surrounded the visits Stitch and his family made to grandparents, suggests his lack of agency to forge his own relationships with them. 


\section{Chapter 5}

\section{CHILDREN'S CONTACTS WITH FAMILIAR ADULTS IN THEIR NEIGHBOURHOODS}

The focus of this chapter is the examination of children's contacts with adults who were familiar to them, in the sense that interviewees spoke about 'knowing' someone. Such knowing included knowledge of a person's name, where they lived and, or, their connections with other people within the neighbourhood. Drawing primarily on interview accounts, there is exploration of the different ways in which the children had contacts with adults outside their family and school.

The interviewees indicated that interactions with parents' friends, friends' parents, geographical neighbours, and with workers in children's clubs had taken place in peoples' houses, including the children's own homes and in various neighbourhood venues including local streets. Numerical data from the survey are used to indicate similarities and differences between the ways children viewed the amount of time they spent with different groups of adults and their ratings of how well they 'got on' with them. The chapter then considers the nature of children's relationships with individual adults.

As the particular neighbourhood context for many ${ }^{67}$ of the children in the study was that of Social Inclusion Partnership (SIP) areas, the chapter begins with a description of the physical nature of the housing schemes where they lived and of Swinburn which, in terms of its general characteristics, typified the SIP areas. This description is based on my own observations and the

${ }^{67}$ All of the children in the study attended schools situated in SIP areas, and it can be assumed that most, although not all, of them lived in the same neighbourhood. 
children's comments, with their drawings ${ }^{68}$ being used to illustrate particular points. Brief outlines of the children's use of, and views of, their neighbourhoods provide further contextual details for their interactions with adults.

The children's perceptions of their neighbourhoods indicate an interrelationship between spatial, social and temporal proximity and knowing people, together with feelings of belonging. The terms neighbouring and neighbourliness are therefore relevant to consider. Drawing on work by Buonfino and Hilder (2006), the term 'neighbouring' is viewed as a neutral one. It refers to social interaction between people living near each other, whereas 'neighbourliness' refers to positive neighbouring,

\subsection{The Children's neighbourhoods}

\subsubsection{The physical environment}

All the children in this study, both in Swinburn and in the survey, attended Primary Schools situated in Social Inclusion Partnership (SIP) areas. As these neighbourhood areas were generally characterised by large public housing schemes it is likely that many of the children lived in the schemes. The neighbourhoods were similar to each other in that the majority were situated on the periphery of the city. They contained a mix of older (30-60 years) accommodation: low level flats; a few high rise blocks; some maisonettes; and newer (3-10 years) terraced housing. The survey figures indicate that $60 \%$ of the children lived in houses as opposed to flats and that $89 \%$ had

\footnotetext{
${ }^{68}$ I asked children in Swinburn Primary School to produce drawings for me of where they played, out of school (For more details see 3.2.4). Parts of the drawings from five children are used in this chapter.
} 
access to a garden, although for $37 \%$ this was shared with others ${ }^{69}$. Local facilities included small shops, community centres and the primary schools where the research took place, and sometimes a leisure centre. The following description of Swinburn, based on observation and children's accounts, gives a sense of the general physical environment of the schemes.

The area of Swinburn was clearly defined by the boundaries of main roads. Turning from these thoroughfares one entered a labyrinth of roads, streets, avenues, views, terraces and places; many ending as cul-de-sacs, or 'culdies', as the children called them. The newer housing lined the roads, but older blocks of flats, community facilities and Swinburn Primary School sat in open patches of green space. There were two shopping areas. One, 'the wee shops', as the children referred to it, had a bakery, a small supermarket and a take-away. A wider range of shops, including a larger supermarket, were situated in and near a covered shopping centre. The children spoke about 'community' centres, a library and various playgrounds, the latter being defined as those for 'the wee ones' and those for 'the big ones'. There was also an area for skate boarding and BMX biking, and 'the field'. This was a place where boys said that they played football and also described it as a location for fights; however, the term appeared to apply to a number of different pieces of open land. The patches of ground between the houses were used by children for various activities, such as football or 'boules', a game involving marbles and holes dug in the ground, apparently by the children. Although used by children, I do not think that these spaces had been designed for play and that games were actually discouraged. Some patches, which seemed to have originally been flat, were now mounds. I presumed

\footnotetext{
${ }^{69}$ In Scotland the residents of a block or 'stair' of flats share a garden, which is usually referred as the 'back green'.
} 
that they had been changed to prevent football games being played on them.

However, this thought did not appear to have occurred to James, who said:

... I dinnae ken what they're for, they could put a park or something on top of it because it's quite big... They've no done anything with it it's just mud with grass on top of it for dogs to crap on ... They could build a mini-golf course or something.

James viewed these pieces of ground as potential play areas or at least spaces that could be used more productively. Although he was the only child to make such a verbal comment about a physical aspect of Swinburn, drawings (Figs. 5.1-5.6) by other children revealed how they used spaces within the neighbourhood and their awareness of particular features. This included: the naming of services such as 'the doctors' and 'the art gallery' (Fig. 5.1); the design of different housing such as flats with balcony walkways (Fig. 5.2); and details such as the corner spiking on fences (Fig. 5.1) and walls round wheelie bins (Fig. 5.3).

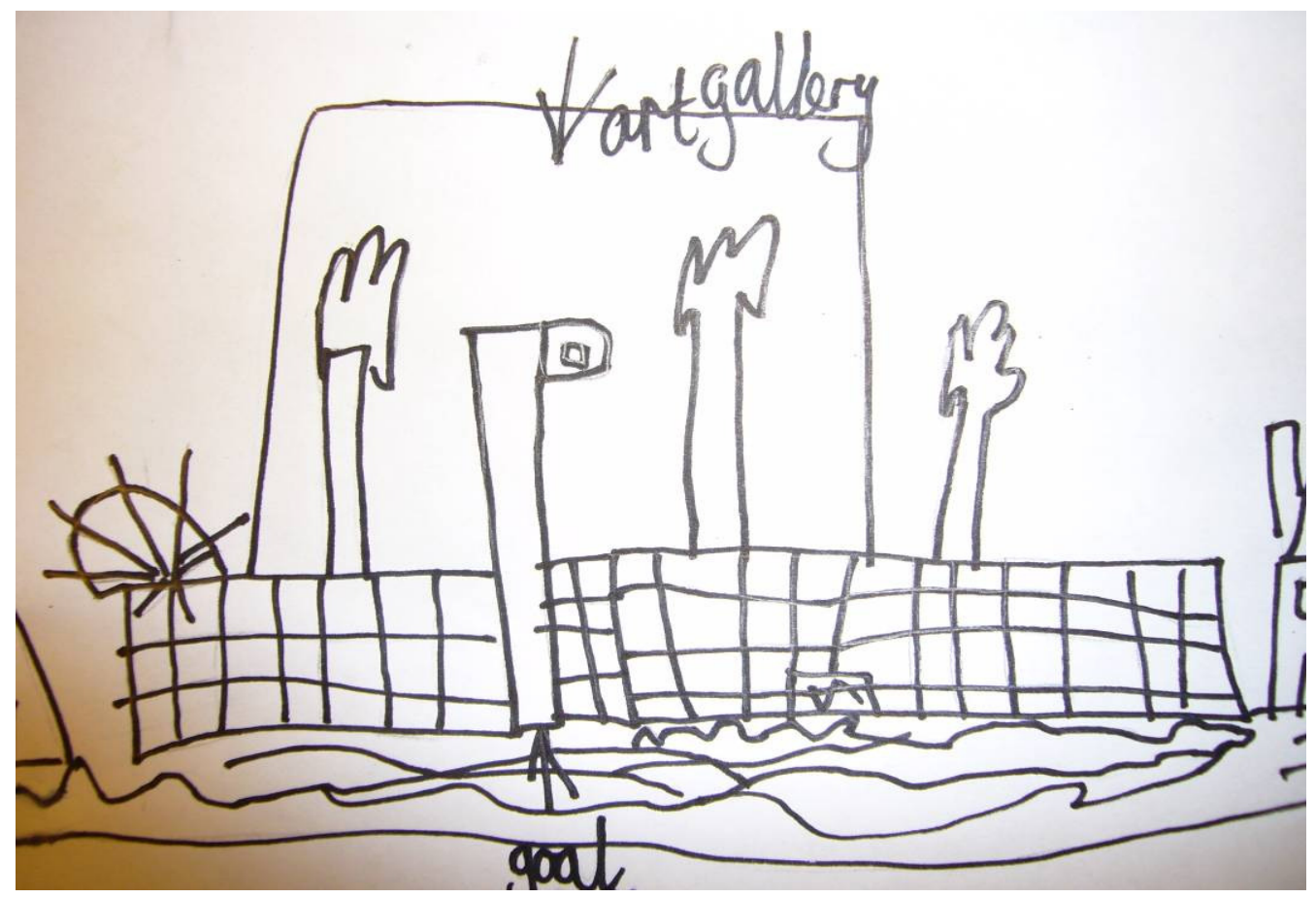

Fig. 5.1 Detail of naming places and of fence details 


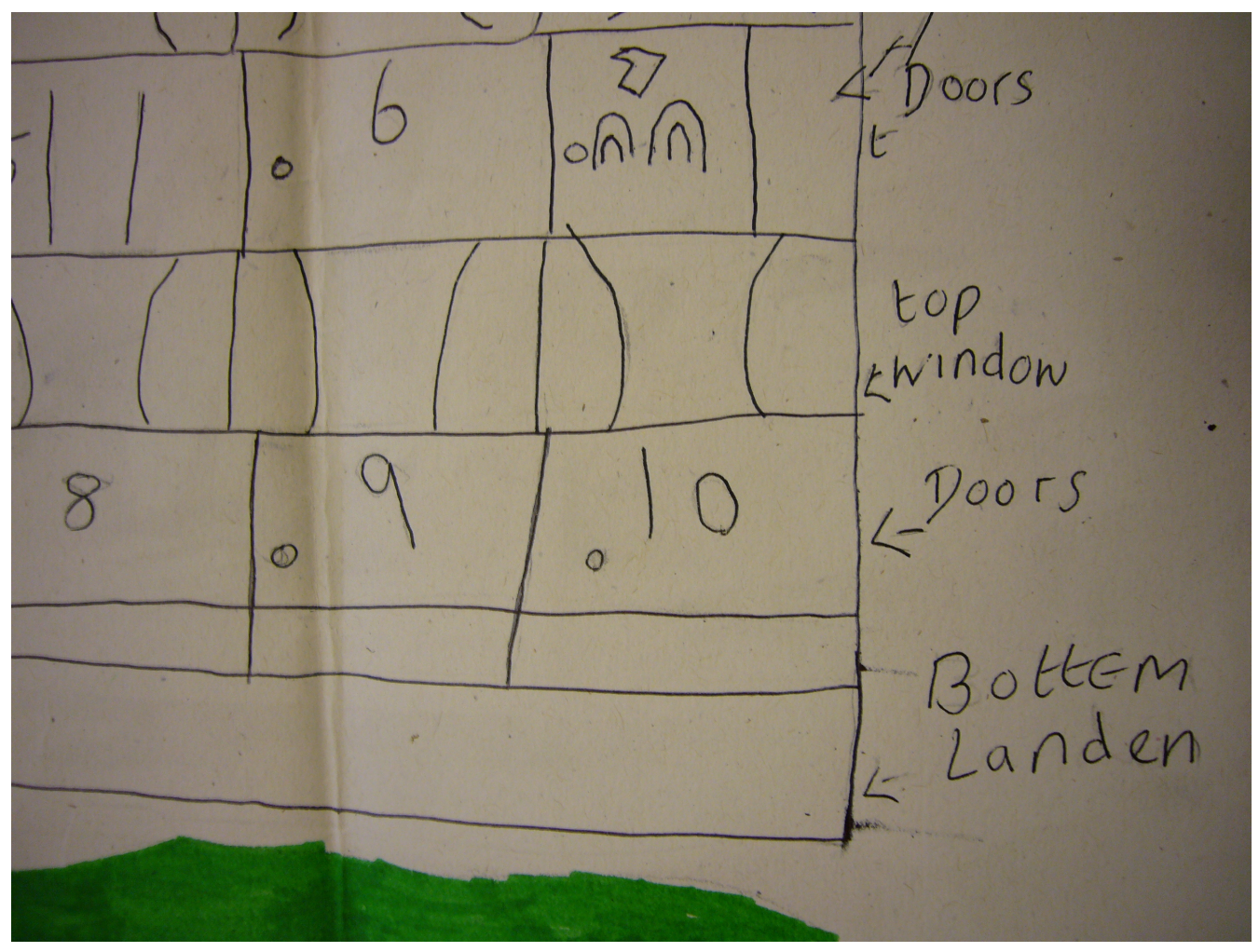

Fig. 5.2 Details of flats with external balcony walkways

The range of details displayed in these pictures indicates issues of possible importance to children, although these had not necessarily been verbalised. For example although Sarah's comment that she did not like the wee shops because 'there's nae bins' indicated a concern for rubbish this was not something mentioned by Stitch. However, the inclusion of birds eating chips from a discarded box in his drawing (Fig. 5.4) of the skate boarding ramps, suggested his awareness of this aspect of the space and a possible concern. 


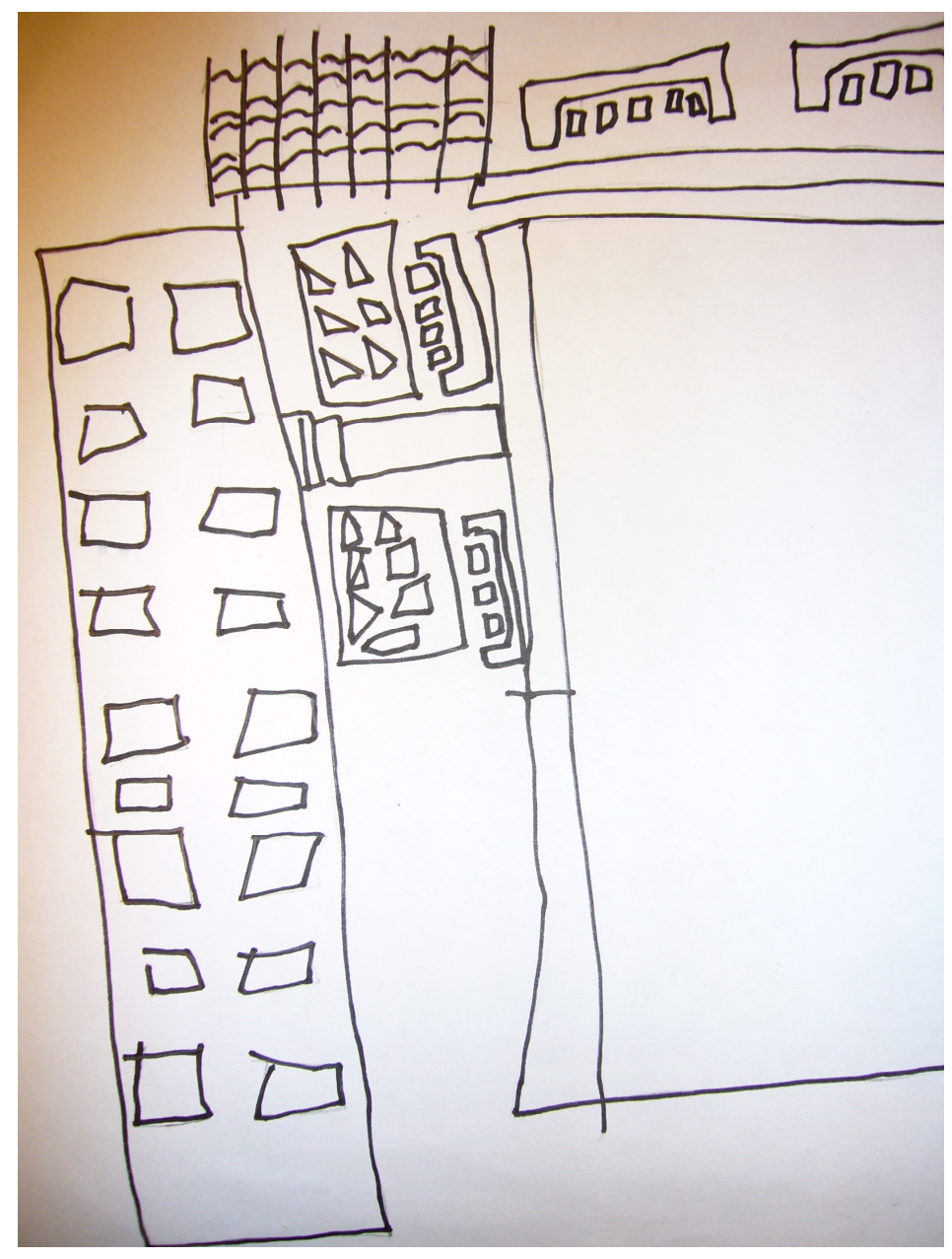

Fig. 5.3 Details of the neighbourhood

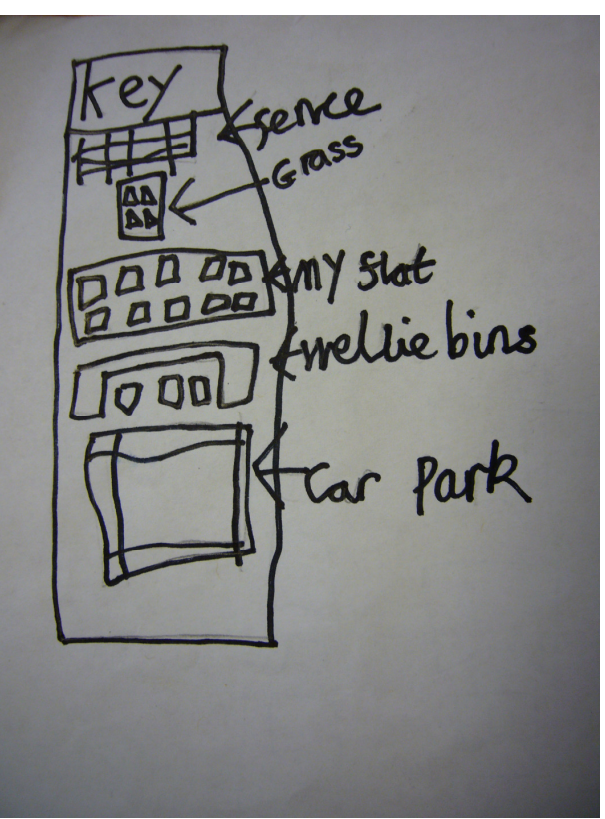




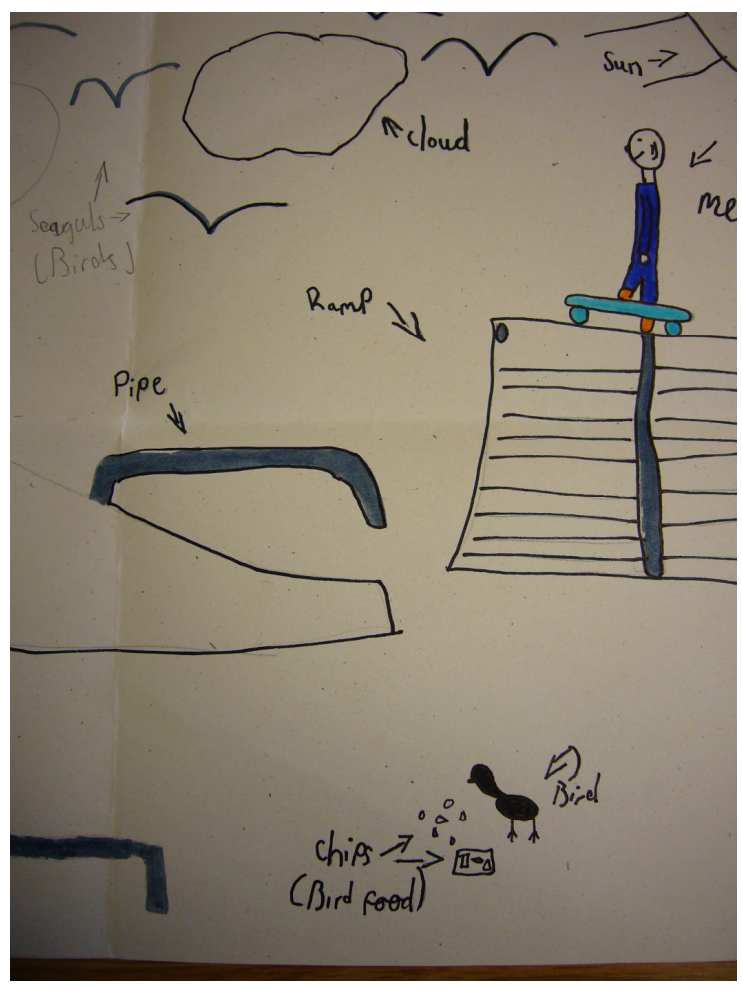

Fig. 5.4 Details of rubbish in the neighbourhood

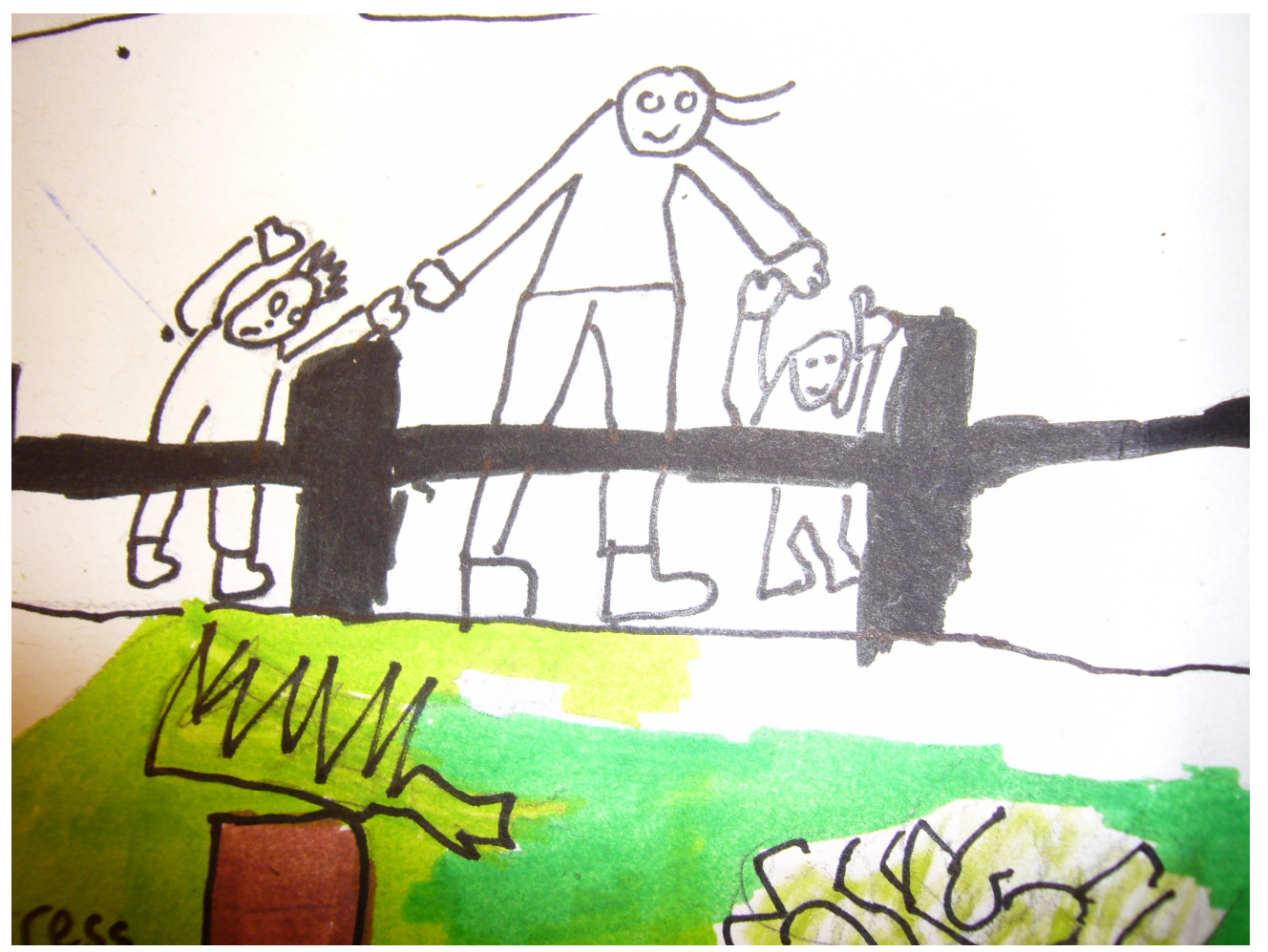

Fig. 5.5 'Anonymous' people watching the football game 


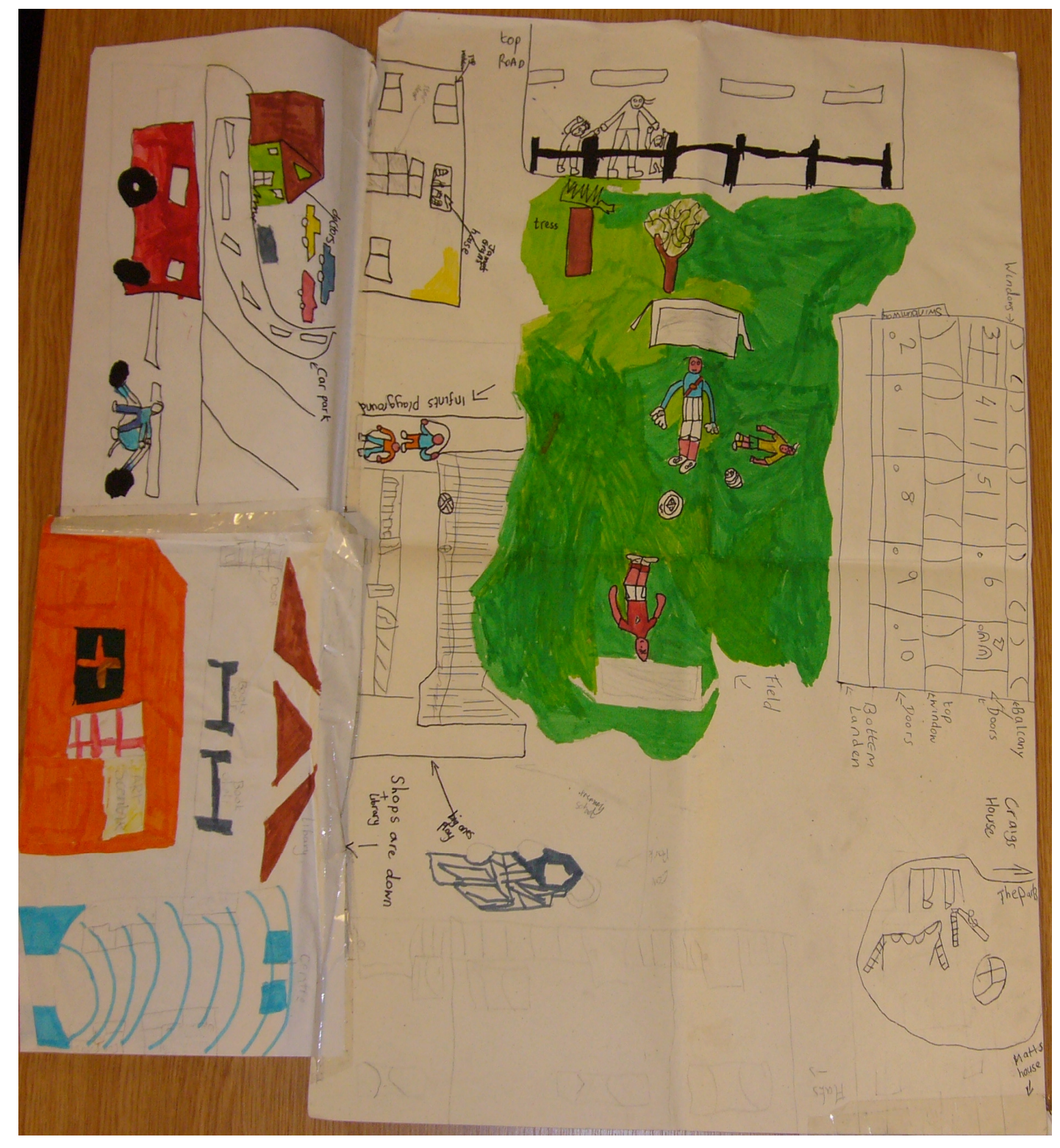

Fig. 5.6 The group drawing by the 'football' boys

What is more relevant to this study is the way in which one of the drawings revealed the children's observations of the social aspects of the neighbourhood. I asked the children to undertake the drawings with those children they played with outside school. Most preferred to do so 
individually, but drawing (Fig. 5.6) was undertaken by a group of boys ${ }^{70}$, for whom football was a major activity and whilst this activity is the central feature, it is situated in a broader social context. The inclusion of friends' houses and 'anonymous' people (Fig. 5.5) provide a sense of the boys' interactions with other children and adults in the neighbourhood.

\subsubsection{Children's use of their neighbourhoods}

The drawings provide details of children's knowledge of their area. This was likely to have been gained through their travels to and from school, clubs, friends' houses and local shops. Results from the survey indicated that around $60 \%{ }^{71}$ of children made such trips, and that, most days, $65 \%$ travelled to school without an adult.

During my informal interactions and in the interviews, children in Swinburn Primary School spoke about using various spaces within the neighbourhood as places of play, including specifically designed play spaces and the roads outside their houses. The survey figures (Table 5a) provide a picture of children spending nearly half $(47 \%)$ of their play time in or close to their homes. The street, whether it was that outside their house or that of a friend, was a popular play venue. The fact that $41 \%$ of the children reported living in a cul-de-sac ${ }^{72}$ may be significant in enabling street play.

\footnotetext{
${ }^{70}$ The group of three boys; Matt, James B, and Craig did not wish to be involved in the interviews, but they were happy for me to keep and use their picture, which they spent a number of weeks completing.

${ }^{71}$ Survey question 40

${ }^{72}$ Survey question 25 .
} 
Table 5a Survey children's reports of where they played and the frequency: Survey question 34: Where do you play? Please tick ALL the different places you play.

\begin{tabular}{|l|l|l|l|l|l|l|l|l|}
\hline & \multicolumn{3}{|l|}{ Everyday } & \multicolumn{2}{l|}{$\begin{array}{l}\text { At least once a } \\
\text { week }\end{array}$} & \multicolumn{2}{l}{$\begin{array}{l}\text { Less than once } \\
\text { a week }\end{array}$} & \multicolumn{2}{l|}{ Never } \\
\hline & $\begin{array}{l}\text { No. of } \\
\text { children }\end{array}$ & $\%$ & $\begin{array}{l}\text { No. of } \\
\text { children }\end{array}$ & $\%$ & $\begin{array}{l}\text { No. of } \\
\text { children }\end{array}$ & $\%$ & $\begin{array}{l}\text { No. of } \\
\text { children }\end{array}$ & $\%$ \\
\hline $\begin{array}{l}\text { Own house or } \\
\text { garden }\end{array}$ & 152 & 47 & 106 & 33 & 25 & 8 & 39 & 12 \\
\hline $\begin{array}{l}\text { Street outside } \\
\text { home }\end{array}$ & 157 & 47 & 108 & 32 & 33 & 10 & 41 & 12 \\
\hline $\begin{array}{l}\text { Friend's } \\
\text { house or } \\
\text { garden }\end{array}$ & 72 & 23 & 130 & 41 & 73 & 23 & 42 & 13 \\
\hline $\begin{array}{l}\text { Street outside } \\
\text { friends home }\end{array}$ & 113 & 35 & 101 & 31 & 55 & 17 & 53 & 17 \\
\hline Playpark & 48 & 15 & 98 & 31 & 90 & 28 & 80 & 25 \\
\hline Open space & 90 & 28 & 98 & 31 & 65 & 21 & 64 & 20 \\
\hline
\end{tabular}

The majority of children in the survey $(80 \%)^{73}$ reported attending at least one club or organised activity on a weekly basis. Of the interviewees, only Crombie and Stitch did not report attending any such activities (Table $5 b)^{74}$; although Peter, along with Gums, said that they only occasionally attended a disco at a community centre in a neighbouring area. Five of the girls attended girls only activities in the form of the Girls' Brigade and the Girls' Club. For the majority of these children the clubs they attended were located within Swinburn.

\footnotetext{
73 Survey question 37

${ }^{74}$ See page 129
} 
Table 5b Interview Children: Range of Regular Activities

\begin{tabular}{|c|c|c|c|c|c|c|c|}
\hline & Monday & Tuesday & Wednesday & Thursday & Friday & Saturday & Sunday \\
\hline Angel & & & Music (CP) & & & & \\
\hline Breanna & & & & GB & GC & & \\
\hline Courtney & & & & GB & $\mathrm{GC}$ & & \\
\hline Gums & & $\mathrm{CC}$ & $\begin{array}{l}\text { FB } \\
\text { Music (CP) }\end{array}$ & SC & Disco* & & \\
\hline Hayley & & $\mathrm{CC}$ & & $\begin{array}{l}\text { SC } \\
\text { GB }\end{array}$ & $\mathrm{GC}$ & & \\
\hline James & $\mathrm{BB}$ & & & & & & $\mathrm{BB}^{*}$ \\
\hline John A & & & & SC & & $\begin{array}{l}\begin{array}{l}\text { Swim } \\
\text { (fam) }\end{array} \\
\text { (a) }\end{array}$ & \\
\hline John B & & Judo & & Judo & & Judo & \\
\hline Lily & & & & $\begin{array}{l}\mathrm{SC} \\
\mathrm{GB}\end{array}$ & & & \\
\hline Lynney & & & & GB & & & \\
\hline Nicolle & & & $\mathrm{CP}$ & & & & \\
\hline Peter & & & & & Disco* & & \\
\hline Sarah & & & & & GC & & \\
\hline Stacey & & & & & GC & & \\
\hline Star & $\begin{array}{l}\text { Swim } \\
\text { (fam) }\end{array}$ & & & SC & GC & & \\
\hline
\end{tabular}

Crombie and Stitch did not report attending any activities on a regular basis

KEY:

The following activities took place in Swinburn:

$\begin{array}{llll}\text { CP } & \text { Children's Project } & \text { CC } & \text { Children's Club } \\ \text { GB } & \text { Girls' Brigade } & \text { BB } & \text { Boys' Brigade } \\ \text { SC } & \text { School Club } & \text { GC } & \text { Girls' Club }\end{array}$

The following activities took place in neighbourhoods adjoining Swinburn:

F/B Football

Swim (fam) Swimming as a regular family activity

Judo

Disco

* Occasional activities

Although Lily was the only interviewee to mention that she saw her friend's mother and workers from children's clubs whilst she was out shopping locally, it is likely that other children also met friends and neighbours as they walked around the area, with or without their parents. As half (8) of the interviewees reported living in families without a car walking was probably a feature of their daily lives. Bostoke (2001) found that walking is a common 
mode of travel for mothers who live on benefit. It is possible that the children completing the survey could have been familiar with different adults because they walked or cycled around their areas to a greater extent than children living in more affluent areas. This supposition is made on the basis that the SIP areas featured in the study shared similar geographical and social features, such as the proximity of housing, low car ownership and higher than average number of families living on benefits (Scottish Neighbourhood Statistics).

\subsubsection{Children's views about living on a 'scheme'}

In Scotland the term 'scheme' is applied to estates of public housing, and often brings with it negative stereotyped views of these being places of poverty, crime and drug taking. In the group discussions I was interested to hear the children in Swinburn Primary School's thoughts about the area. When I asked them whether they thought the area was poor, Joey ${ }^{75}$ said that he thought some people were, although he and his friends were not, 'we've all got play-stations and game boys'. In the feedback session given to the children in Swinburn Primary School76, a suggestion was made by a few children to use the term 'bad', rather than poor to describe the area. This comment did not appear to have been based on any comparison with other areas, but rather on the children's awareness that 'bad things' happened in Swinburn.

The bad things reported included incidences of violence, observations of people drinking and 'junkies', particularly those who 'hung about' the local shopping centre. Many of the children found the shopping centre to be an unpleasant environment:

\footnotetext{
${ }^{75}$ Joey was one of the children involved in the initial group discussion, but who decided not to take part in the individual interviews.

${ }^{76}$ See Appendix 12.
} 
Star I'm allowed to go to in there, but not alone because that's where the people that drink all the time hang about, and that's not very nice

Sue And what about?

Star It smells

Angel It reeks

Sue Does it, of what?

Star Because they all sleep there and they do the toilet there and everything and drink ... and there was this guy sleeping there and he had a cut down his face and it looked sore and next to him was like a wee knife, like a penknife, with blood on it

Sue Oh!

Star It was disgusting, they must have been fighting

Whilst Star said that she was not allowed in the shopping centre by herself, most of the children indicated that they moved around the area unaccompanied, both during the day and into the evening. Such people did not appear to have particularly frightened any of the children and Angel was the only one who spoke of not being allowed out by herself:

Angel I go with my mum and dad, all the bad things that happen in Swinburn and that's why my mum and dad don't let me go by my own, if I go anywhere on my own it's just the front field or the back bit, not the swing park. I don't like it because it's got hardly anything there

Sue So what bad things in the area?

Angel Like people getting battered and stuff like that

Accounts of adults, children or teenager 'battering' or fighting each other were also mentioned by other children in Swinburn Primary School, but there was a particular fight that was spoken about more frequently. The children's reports, of this fight, differed slightly from each other, especially in relation to the descriptions of the weapons that had apparently been involved, but most revealed a fascination with gory details, such as fingers getting chopped off. The exception to this display of interest was Crombie who had actually witnessed the incident, and had clearly been disturbed by it: 
It must have been about from where Pedro is standing to about the end of there, I was like this watching and I could nae sleep for about a week.

It seemed that the other children's reports of the fight were based on rumour rather than direct knowledge. Such comments can be compared with those found in Turner et al's study that children living in areas with high levels of violence may be more aware, than other children of such events, although not necessarily 'accepting of such matters' (2006: 462)

From my contacts with children in Swinburn Primary School I was aware of that although they were only 10/11 years old some had lived in different houses within and beyond the neighbourhood. Reports from the survey (Table $5 c$ ) indicate that nearly two thirds $(65 \%)$ of these children had lived in more than one house. More than half $(60 \%)^{77}$ also reported living in more than one area, although many may not have moved very far as most children $(62 \%)^{78}$ reported that they had only attended one school.

Table 5c Survey children's reports of the number of houses they had lived in. Survey question 29: How many different house have you lived in?

\begin{tabular}{|l|l|l|}
\hline & No. of children & $\%$ \\
\hline One house & 128 & 35 \\
\hline Two houses & 90 & 25 \\
\hline Three houses & 62 & 17 \\
\hline Four to seven houses & 73 & 20 \\
\hline Eight houses and over & 13 & 3 \\
\hline
\end{tabular}

Along with the term 'scheme' being used to describe an area of public housing that of 'schemie' is one applied to the people who live in such a

\footnotetext{
77 Survey question 30

${ }^{78}$ Survey question 31
} 
place. Two interviews revealed an awareness that they might have been referred to as 'schemies', in the sense that they lived on an urban housing scheme $^{79}$. However, they disputed the negative connotations of "poor or disadvantaged ${ }^{\prime 80}$, associated with the definition. Crombie spoke about how people had treated him unreasonably, and said, 'just because we're from Swinburn it doesn't mean we're schemies'. In answer to a question about Swinburn being a place for poor people, Lynney said:

Lynney Well you could say poor, but you dinnae have to be poor to stay in Swinburn. You can maybe be, well no rich, but you've got enough money to survive on and it might be a schemie place you stay in, but its no where you stay it's how you make your house

Sue ... What do you mean by a schemie place?

Lynney You always have to watch your back

Sue $\quad Y e h$ ? Tell me a bit more about that

Lynney Like if you're going up the road, it's quite schemie because like anyone could be behind you and you could get battered if somebody sees you so you always have walk about with your hood up

The idea of having to 'watch your back', by walking round 'with your hood up' to avoid identification, is similar to the idea of keeping a 'low profile' (Turner et al 2006: 460). It also has negative connotations of 'hoodie' culture ${ }^{81}$, although for Lynney wearing a hood was probably a defensive act, a

${ }^{79}$ Sc. colloq. (freq. derogatory). 'An inhabitant of an urban housing scheme (see *SCHEME $n .^{1}$ ); (sometimes) a former resident of such an area; (hence) a poor or disadvantaged person'. I. WELSH 1993 Trainspotting 30 'Ah'm fed up to ma back teeth wi losers, no-hopers, draftpaks, schemies junkies and the likes'. Oxford English Dictionary.

http://dictionary.oed.com/cgi/entry/00319338? (Accessed 28/2/06)

${ }^{80}$ As above.

81 'The term 'hoodie' is used simultaneously to describe both the garment and the individual, with all the cultural connotations that go along with such a label. It is the uniform of a supposedly deviant group and a useful tool against identification, yet also it is an expression of identity reflecting the culture of a generation.' Taylor, S. (2005) Political Constructions of the Anti-Social Community: Developing a Cultural Criminology HSA Autumn Conference 8-9 September 2005. 
protection against being identified with a particular neighbourhood. For the children, Swinburn was a clearly defined geographical location. Not only did the majority of streets have the Swinburn prefix, but there was also identification with the area through gang names such as the 'S.C.F.', the 'Swinburn Casual Fighters'. There were also a few children who said that they would not go into, or even pass through the adjoining neighbourhoods of Easterchurch or Invercraig, home of the 'Y.M.I.'s', the 'Young Mental Invercraigs'.

In addition to Lynney and Crombie's recognition that negative labels could be attached to the neighbourhood and to individuals, John A sought to distance himself from behaviour that could be seen as 'bad', when he commented that although some people let their children swear and stay out late at night, his mother would not. As these three children recognised the way that Swinburn might be viewed by others it is likely that the children undertaking the survey, who lived in other areas, also had some awareness of negative aspects of their neighbourhoods. Yet, despite this possibility, the majority $(84 \%)$ of children in the survey ${ }^{82}$ reported that they liked the area where they lived. The primary reasons given were that they 'had friends who lived nearby' (77\%) and of there 'being good places to play' (70\%) (Table 5d).

\footnotetext{
82 Survey question 72
} 

lived.

Survey question 71: 'I like the area where I live because: Please tick ALL your reasons'.

\begin{tabular}{|l|l|l|}
\hline Reason & $\begin{array}{l}\text { Number of children } \\
\text { choosing each reason }\end{array}$ & $\begin{array}{l}\text { \% of children choosing } \\
\text { each reason }\end{array}$ \\
\hline My friends live nearby & 291 & 77 \\
\hline My adult neighbours are friendly & 237 & 64 \\
\hline $\begin{array}{l}\text { I could go to my neighbours for } \\
\text { help if my mum/dad wasn't in }\end{array}$ & 214 & 57 \\
\hline My grandparents live nearby & 150 & 40 \\
\hline $\begin{array}{l}\text { I have an aunt/uncle who lives } \\
\text { nearby }\end{array}$ & 154 & 41 \\
\hline $\begin{array}{l}\text { I know most of the adults near } \\
\text { where I live }\end{array}$ & 226 & 60 \\
\hline There are good places to play & 263 & 70 \\
\hline Other reasons & 54 & 14 \\
\hline
\end{tabular}

Interestingly, the reasons for liking where they lived that were associated with neighbours and knowing adults were rated higher than having relatives living nearby. These positive features seemed to have influenced the children's perceptions of their areas more than incidents of violence or problems with teenagers (Table 5e).

Table 5e The reasons why survey children did not like the area where they lived. Survey question 72: 'I do not like the area where I live because: Please tick all your reasons'.

\begin{tabular}{|l|l|l|}
\hline Reason & $\begin{array}{l}\text { Number of children } \\
\text { choosing each reason }\end{array}$ & $\begin{array}{l}\text { \% of children choosing } \\
\text { each reason }\end{array}$ \\
\hline I don't get on with other children & 72 & 19 \\
\hline $\begin{array}{l}\text { My adult neighbours are not very } \\
\text { friendly }\end{array}$ & 46 & 12 \\
\hline It does not look very nice & 59 & 16 \\
\hline There is violence in the area & 106 & 28 \\
\hline It is messy & 96 & 26 \\
\hline $\begin{array}{l}\text { Adults are not very nice to } \\
\text { children }\end{array}$ & 52 & 14 \\
\hline Teenagers cause problems & \\
\hline Other reasons & 182 & 49 \\
\hline & 29 & 7 \\
\hline
\end{tabular}

${ }^{83}$ There is discussion on the children's views of 'teenagers' in 8.1.3. 
Whilst the children in this study expressed awareness of negative aspects of their neighbourhoods, they did not seem to make comparisons with other places. Their views seemed to be limited to their own experiences, which is similar to the findings from Backett-Milburn et al's (2003) study. So whilst Nicolle, Star and Courtney made references to their families' financial situations, the children in Swinburn Primary School had not generally considered themselves, or others to be poor. References to 'bad things' and the strategies of avoiding places or keeping their 'head down' were similar to the coping strategies used by the children in Turner et al's study (2006), as was the centrality of social relationships for neighbourhood perceptions.

\subsection{Contacts with adults in the neighbourhood}

As reported above, knowing adults in their neighbourhoods and perceiving their adult neighbours as friendly were clearly important to the children in this study. The survey data provide details of children's contacts with different groups of adults, including parents' friends and friends' parents in terms of the amount of time they reported spending with different groups of familiar adults ${ }^{84}$ (Table $5 g$ ) and also to how well they thought that they 'got on with them' (Table 5f). Together with interview accounts these data provide a picture of the range of child-adult interactions and particular gender differences within them.

\footnotetext{
${ }^{84}$ Survey question 64 asked the children about the amount of time they spent with different groups of adults The terms 'a lot' and 'some time' aimed to gain an impressionistic, emotive sense of children's interactions with adults, they were not defined.
} 


\section{2 .1}

Neighbours

Neighbours were variously defined by children within the interviews as: the people who lived next door; all the people living in ' $m y$ bit'; or even as broadly as all the people they knew. As with their drawings, children's individual accounts revealed a detailed knowledge of the social, as well as of the physical, landscape of their area. This included not only who lived where, but also information about their lives. For example, in telling me about her neighbours, Stacey drew a map of her street and indicated who lived in which house. She then listed all the children's names together with their ages and recounted details of disputes between neighbours.

Most children in the survey said that they 'got on well' with various groups of adults, with $48 \%$ reporting that they got on very well with their next-door neighbours (Table 5f).

Table $5 f \quad$ Survey children's reports of how they 'got on with' particular groups of adults. Survey question 66:'How do you get on with different adults?

\begin{tabular}{|l|l|l|l|l|l|l|l|l|}
\hline Adult group & \multicolumn{2}{l|}{$\begin{array}{l}\text { Children } \\
\text { reporting } \\
\text { very well }\end{array}$} & \multicolumn{2}{l|}{$\begin{array}{l}\text { Children } \\
\text { reporting } \\
\text { quite well }\end{array}$} & \multicolumn{2}{l|}{$\begin{array}{l}\text { Children } \\
\text { reporting } \\
\text { quite badly }\end{array}$} & \multicolumn{2}{l|}{$\begin{array}{l}\text { Children } \\
\text { reporting } \\
\text { very badly }\end{array}$} \\
\hline & No. & $\%$ & No. & $\%$ & No. & $\%$ & No. & $\%$ \\
\hline Mother's friends & 204 & 58 & 92 & 26 & 4 & 1 & 3 & 1 \\
\hline Father's friends & 161 & 48 & 93 & 28 & 1 & 5 & 1 & 4 \\
\hline Friends' mothers & 191 & 54 & 105 & 30 & 3 & 1 & 1 & 1 \\
\hline Friend's fathers & 164 & 47 & 101 & 29 & 5 & 1 & 0 & 0 \\
\hline Next door neighbours & 170 & 48 & 105 & 30 & 5 & 1 & 22 & 6 \\
\hline Other neighbours & 94 & 27 & 128 & 37 & 10 & 3 & 21 & 6 \\
\hline People in clubs & 147 & 43 & 103 & 30 & 13 & 4 & 3 & 1 \\
\hline
\end{tabular}


A quarter $(26 \%)$ of children in the survey stated that they spent 'a lot of time with' their next-door neighbours, more than with any other group of adults (Table 5g).

Table 5g Survey children's reports of 'spending time' with different groups of adults. Survey question 64: 'How much time do you spend with different adults (not your parents or school teachers)?

\begin{tabular}{|l|l|l|l|l|l|l|}
\hline Adult group & \multicolumn{2}{l|}{$\begin{array}{l}\text { Children } \\
\text { spending 'a lot } \\
\text { of time' }\end{array}$} & \multicolumn{2}{l|}{$\begin{array}{l}\text { Children } \\
\text { spending 'some } \\
\text { time' }\end{array}$} & \multicolumn{2}{l|}{$\begin{array}{l}\text { Children } \\
\text { spending 'no } \\
\text { time' }\end{array}$} \\
\hline & Number & $\%$ & Number & $\%$ & Number & $\%$ \\
\hline Mother's friends & 72 & 19 & 211 & 56 & 79 & 21 \\
\hline Father's friends & 43 & 12 & 149 & 41 & 169 & 47 \\
\hline Friends' mothers & 65 & 18 & 145 & 40 & 149 & 41 \\
\hline Friend's fathers & 37 & 10 & 138 & 39 & 180 & 51 \\
\hline Next door neighbours & 91 & 26 & 135 & 38 & 128 & 36 \\
\hline People in clubs & 81 & 23 & 116 & 33 & 149 & 43 \\
\hline
\end{tabular}

The interviewees indicated that they were not particularly interested in spending time with their adult neighbours. Most reported only going to houses where there were children and only when they were present. Although Courtney and Peter said that they would stay and talk to the adults if the children were not in:
Peter I ask if one of her kids is in to muck about with him and if they are nae in I just sit and talk to her
Sue What sort of things might you talk about?
Peter Like how my new house is

John B and Stitch said that they did say hello to their neighbours and Lynney and Angel that they visited their neighbours' homes. Angel reported that she sometimes helped her father to do shopping for their elderly neighbours and that she called in one who lived across the road, apparently by herself:

I go over to her house, talk to her, I sometimes take her round like a present or something..., because I love knitting and weaving, little mats or something. Sometimes, I can just sit and knit like a coloured kind of scarf. 
Hayley said that she liked one of her neighbours:

On the balcony they're really nice. I've got this girl, an adult, and she's got a baby, at the end of my balcony ... she's nice to me, she talks to me when I'm lonely.

Breanna's report that she spoke to her neighbours about such subjects as the films that they each enjoyed, indicated a greater degree of personal engagement. However, in general there did not appear to be a great deal of contact between children and their adult neighbours, I had the impression that they thought it was important to maintain neighbourliness. As Peter said, 'it's better to get on with them so you just talk to them and say, 'Hi yah' if you see them in the street or something'.

\section{Problems with neighbours}

Children in the survey reported that they generally 'got on well' with their neighbours with only $6 \%$ (Table $5 f)^{85}$ reporting 'very badly'; although this proportion was higher than for other groups of adults. However, both the survey and interview children reported having problems with both their next door neighbours and with other neighbours. Over a quarter of children in the survey $(28 \%)^{86}$ said that they had problems with their next door neighbours and $34 \%$ with other neighbours; both of these were greater than descriptions of problems with any other group of adults.

In the survey ${ }^{87}$, similar proportions of girls and boys reported having problems with adults in their areas, including with next-door neighbours. Interviewee accounts suggested that they experienced similar difficulties. Their complaints can be grouped into the following categories: problems

\footnotetext{
85 Page number 137

86 Survey question 68.

87 Survey question 68.
} 
between families where adult conflicts have come to the attention of the children; disputes with neighbours' children such as fighting and adult neighbours intervening; and adult neighbours telling children off or assuming that they are causing problems. Most of the incidents described concerned the negotiation of ownership and use of space.

A commonly reported problem was one of balls going into other people's gardens, or of hitting windows and cars. Interviewee accounts and written responses in the survey ${ }^{88}$ suggest that further conflicts could then have resulted from the children's efforts of retrieval. Yet, whilst such instances were reported there appeared to be greater feeling of injustice in relation to joint or public space within their neighbourhoods. For example, Lily said that her brother had been told off by their neighbours for making a noise when going up and down the balcony walkway on his skate board. Gums complained about 'getting a row' for playing on patches of grass outside houses and stated 'we were only kicking the balls and it's not just their cul-de-sac, it's my cul-de-sac as well!'

The following incident also seemed to be about ownership and rules. Peter indicated awareness that there were some places where he was not meant to play football, and therefore he had possibly been, or expected to be, told off, but his back green ${ }^{89}$ was not one of them:

Peter Cause when we play football out in the back garden it does
nay say no ball games or nought and the ball hit the fence
and she [his neighbour] gave us a row for it.
Sue $\quad$ What for playing football out there?

\footnotetext{
88 Survey question 69.

89 'Back greens' are the shared back gardens (normally enclosed) which 'belong' to all the residents in a block of flats, or tenements as they may also be referred to.
} 
Aye and she said that she would put a complaint into the council, but she had sworn at us, so my mum put in a complaint.

Sue Uh huh and what happened?

Peter For swearing at us, the council got in touch with her and said 'could you refrain what you say to children' and that.

Star and Gums gave examples of experiencing problems with neighbours when they played in the streets outside their houses. These included issues such as neighbours watching them from windows, taking balls away or complaining about things that the children felt were none of their business, as in the following example from Star:

This lady that lives across the road from us in our street if you're playing kerby and the ball goes in front of her she tell you to [whispering] ' $f^{* * *}$ off'... [One time] the ball hit one of the cars and I went 'sorry' and she said 'Dinnae bother doing that or I'll phone the police'. It wis nae her car.

The children appeared to think that these neighbours should have been more tolerant of their childhood play. They commented that some adults had been reasonable and just said to 'hurry up and get it' if their ball went into a garden, but that others were not, as in following example:

Crombie We've got this thing called $x x x$ and the guards let us play football there sometimes. Sometimes they shout [at us], but she [his neighbour] just phones the police and she gets us all in trouble and everything.

Sue Does she?

Crombie Yes for nothing, and the guard says its okay and she always does it even though the police know that the guard said its okay to play there, but he doesn't really want us to play there, but he thinks its okay as long as we don't break anything, smash windows or anything.

Sue Right and what do the police say when they come along?

Crombie They just tell us to get away 
Noise was another boundary issue mentioned by children. In the survey there were complaints about neighbour noise stopping them going to sleep or of waking them up, although there was also recognition that noise could have originated from their houses. However, comments such as that from Stitch, about problems with his old neighbours, 'they kept on moaning all the time... (about) the music and everything, and football', appeared to have been ones made to the child's family rather than to the child themselves. That such complaints were reported is an indication of children identification with issues concerning their families and the importance to them of family.

Although James reported that he deliberately annoyed his neighbours, his comment that he had just been 'messing around' indicated that he thought it was of little consequence. This comment, and a request for neighbours to show greater tolerance, of the noise children made whilst playing, indicates that children thought adults should be more aware of children living in the area. Not only should they tolerate children's noise, but they should also have an awareness of how their own noise could affect a child's sleep. The children seemed to have a clear sense of how 'neighbouring' should operate in relation to children and this included recognition that shared space, like open green areas or the streets were for public use which included children as well as adults.

\section{Support from neighbours}

Despite the indication from the interviewees that most of these children did not appear specifically to desire much contact with their adult neighbours, there was a sense that they should be 'neighbourly' by providing general greetings. A further indication of 'neighbourliness' was the support that children thought that they could ask for from neighbours, if their parents 
were not at home. Figures in the survey (Table 5h) revealed that nearly a third of girls and a quarter of boys would seek help from a neighbour if their parents were not at home. This finding echoes those from studies of adult neighbouring, where adults report feeling able to call on their neighbours in times of need and also the value of the proximity of relatives and of friends (Crow et al 2002).

Table 5h The proportions of girls and boys, in the survey, reporting which adults they felt they could ask for help from if their parents were not at home. Survey question 75: If my mum and dad were not in and I had a problem the person I would go to is: Please tick one box only.

\begin{tabular}{|l|l|l|l|l|}
\hline Adult group & Girls & Boys \\
\hline & Number & $\%$ & Number & $\%$ \\
\hline A relative who lives nearby & 55 & 31 & 57 & 31 \\
\hline A neighbour & 55 & 31 & 44 & 25 \\
\hline A friends' parent & 42 & 24 & 45 & 25 \\
\hline
\end{tabular}

The children interactions with neighbours appear complex. On the one hand it seemed that in general the children did get on with the people who lived near them, and that they felt that they could call on them if they needed to. On the other hand they experienced problems of boundary issues, partly because of their child status, but also because of the proximity of housing and general living and playing space.

\subsubsection{Parental and family friends}

Interviewee's spoke of having contact with the friends of their parents when these adults visited their houses or when they accompanied their parents to the friends' houses. However, the amount of such reported contacts varied between children. For example, Sarah said that her mother did not have any friends and that no-one came to her house, whereas Hayley reported spending time with and being 'looked after' by the friends of her parents. The 
parental friends of Stacey and John A were significant enough to be included on their family trees and Star spoke of contacts with her mother's friend, whom she also referred to as her 'auntie' and her godmother.

Figures from the survey provide details of gender differences in contacts with parental friends, whilst data from the interviews indicated the level of children's choice in such contacts. In the survey more children reported spending 'a lot of time' with their mothers' friends (72\%), than with those of their fathers $(43 \%)(\text { Table } 5 g)^{90}$. Children could also have chosen not to spend time with their parents' friends. Whilst John B said that he went to his room when his father's friends came round, Stitch seemed more ambivalent. He initially said that his father's friends told him to go away, 'so I just go on the computer'. However, he later said that he 'messed around with them'. John B and James both spoke of spending time with their fathers when they were working, but John B was the only child to mention his father's work colleagues or 'bar mates' as he called them. John B's reflections impart an enjoyment spending time with them, although his presence at his father's workplace seemed to be part of the latter's child-care responsibility.

In terms, of the activities undertaken with parental friends ${ }^{91}$, the one most frequently reported by children in the survey, was 'spending some time having a conversation' ( $25 \%$ of girls and $29 \%$ of boys). In addition to talking to their parents' friends, the children interviewed spoke of engaging in activities with them. For example, Star said that she went on weekly swimming trips, with her mother, mother's friend (Stitch's mother), her sister and an aunt, and Peter said that he helped his father and his friend work on a car. He also spoke of enjoying wrestling with them:

\footnotetext{
${ }^{90}$ See page 138.

${ }^{91}$ Survey question 64.
} 

...ken what we do? We get all the mattresses down from upstairs and there's like, he's got three rooms and we get, there's a double bed, there's a single bed, and another single bed

Sue Yeh?

Peter We get them all down in the living room and we set it all out and we have toy wrestling

Wrestling and 'fighting' were activities that Stitch and James also mentioned enjoying with friends of their fathers.

The children's comments suggested a range of contacts with the friends of their parents and but John B was the only child to speak of any actual problems. He said that a friend of his mother's had been 'moany' and that, 'she kept on shouting at me and nagging me and that for doing the slightest wee things'. However, in general, the children reported having good relationships with the friends of their parents. In the survey ${ }^{92} 84 \%$ reported getting on well with their mothers' friends and $76 \%$ with the friends of their fathers (Table $5 f)^{93}$. The reasons listed included: familiarity; length and frequency of contact; kindness and trust.

\section{Gender and friendships}

The indication, from the interviews, that the girls mainly spoke of contacts with their mothers' female friends and the boys of those their fathers' male friends, suggests a gender split. Girls in the survey ${ }^{94}$ reported having a close relationship with a particular friend of their mothers because they were friends with this woman's children. Courtney spoke of her mother and her best friend's mother as having, 'known each other since High School' and, she

\footnotetext{
${ }^{22}$ Survey question 66.

${ }^{93}$ Page 137

${ }^{94}$ Survey question 67.
} 
appeared to enjoy having a shared history with her friend. Breanna also spoke of a similar connection, in that not only did she know a friend of her adult sister, but also this woman's parents:

$\begin{array}{ll}\text { Breanna } & \text {... sometimes she [her sister who lives at home]'s got her } \\ \text { friends around here } & \\ \text { Sue } & \text { And how do you get on with her friends? } \\ \text { Breanna } & \text { Good cause there's one that comes along all the time and } \\ \text { she's like a sister to me } & \text { Is she? } \\ \text { Sue } & \text { I say she's my sister and she just comes along every day } \\ \text { Breanna } & \text { And would you sit and chat to her? } \\ \text { Sue } & \text { Uh hum just sit and talk to her and her mum and dad come } \\ \text { Breanna } & \text { along as well, 'cause they are friends with my mum and } \\ & \text { dad. My sister and her friend went to school together, } \\ \text { primary and secondary. }\end{array}$

In the following discussion Stitch and Peter seemed to imply that their mother's friends were female and that their father's were male, and that they had a preference for spending time with men:

$\begin{array}{ll}\text { Sue } & \begin{array}{l}\text { So you can sit with your dad's pals, but not with your } \\ \text { mum's pals? }\end{array} \\ \text { Stitch } & \text { No, I can't stand women } \\ \text { Peter } & \text { They're pure nippy } \\ \text { Sue } & \text { Are they, why? } \\ \text { Stitch } & \text { Women cannae stand men and men cannae stand women } \\ \text { Peter } & \text { Nuh, 'cause they're nippy because they just keep going on. }\end{array}$

'Going on' may have meant chatting, nagging or moaning, an adult behaviour that the children viewed as negative ${ }^{95}$, although, it could have referred to asking questions. It is possible that these two boys had not been keen to answer the sort of questions that Courtney said her parents' friends asked her, such as how she was or what she was doing at school. Although

\footnotetext{
${ }^{95}$ Further references are to moany adults are made in relation to the workers in a children's club, in section 5.2.4 and also in terms of children's classification of adults as nice or moany in 8.2.2.
} 
Courtney indicated that she had not been concerned about answering such questions, her tone of voice suggested that she had not liked being used as a child minder for their children, when they came to her house.

In contrast to Stitch and Peter, Crombie and Gums spoke of liking their mothers' female friends. Gums spoke of his mother's 'pal' visiting everyday and that he would chat to her about everything:

Oh Brenda she's the best woman...because she's just funny all the time. How long have we got?... Every time she comes round, when they're having a drink on the weekends... [they] give me some beer

It may have been that as Crombie and Gums, unlike Stitch and Peter, lived with lone mothers they had more contact with women. For, although cross gender friendships are becoming more acceptable, Allan (2008) states that they are still comparatively rare for some people. Whilst John A indicated that his 'uncle' helped his mother, he said that this man was a friend of both his parents, it appeared that he was more a friend of his father's. Whilst parental friends may have been couples, Peter's account indicated that he had a preference for one partner over the other. Although he reported that he got on well with his father's friend Peter, he had not liked Peter's girlfriend: 'moany bugger... she's nippy, she annoys me every time'.

Figures from the survey confirm a gender split, even though overall both girls and boys reported spending more time with their mothers' friends, than with their fathers' friends. This information needs to be placed in the context of $33 \%{ }^{96}$ of children reporting not living with their fathers. Another reason, for a lower figure, may have been that their mothers spent more time at home than their fathers.

\footnotetext{
${ }^{96}$ See Chapter 4.1.1.
} 
Table 5i The proportions of girls and boys, in the survey, reporting that they 'got on very well with' particular groups of adults.

Survey question 66: 'How do you get on with different adults?

\begin{tabular}{|l|l|l|l|l|}
\hline Adult group & Girls & Boys \\
\hline & Number & $\%$ & Number & $\%$ \\
\hline Mother's friends & 115 & 67 & 88 & 50 \\
\hline Father's friends & 73 & 45 & 87 & 49 \\
\hline Friends' mothers & 111 & 63 & 80 & 45 \\
\hline Friend's fathers & 80 & 47 & 84 & 47 \\
\hline Next door neighbours & 89 & 52 & 81 & 45 \\
\hline Other neighbours & 48 & 28 & 46 & 26 \\
\hline People in clubs & 70 & 41 & 76 & 44 \\
\hline
\end{tabular}

If mothers' friends are considered to be predominantly women, then it seemed that more girls reported that they 'got on very well' with women, than with men, whereas the boys did not seem to have a clear preference (Table 5i).

\subsubsection{Friends' parents and families}

Most of the friends that children referred to within their interviews lived within Swinburn, although they were not necessarily the same children that they spent time with at school. The exceptions were when contact was maintained with friends from a previous neighbourhood or with friends who had moved away, as in Courtney spending weekends at the house of her friend who had moved to a new area.

Activities such as having 'sleep-overs' at their friends' houses, which four of the girls interviewed spoke of, may have enabled sustained contacts with friends' parents, and led to the type of informal familiarity present in the following account from Breanna:

My friend's mum and dad, they would just be nice. Even if they are in a bad mood they just go 'Oh hi yah hen'. Like my best friend doesn't have to ask if I can go in her house I just go in, and she doesn't have to ask to go in my house, she just comes in. 
Such accessibility to familiar adults appeared to be important for some of the girls, possibly offering opportunities to talk on a one-to one basis. Lily said that she felt more confident speaking to her friends' mothers than to other adults and whilst Lynney said that she would not speak to her friend's mother about her own problems, she would negotiate on a friend's behalf, 'I'd just say 'Stacey's got a problem but she's a bit scared to tell you'.

Frequent contacts with these adults may also have resulted from geographical proximity and friendships between parents, as in Stacey's case:

My mum and my next door neighbour [her friend's mother] are just sitting out the back, or if they are not sitting out the back they're normally in my house.

As with parental friends, the survey points to gender differences. The children reported spending less time with their friends' mothers than with their mother's friends, and also less with their friends' fathers than with their father's friends (Table $5 g)^{97}$. However, they reported 'getting on' almost equally well with both groups of men, but slightly better with mother's friends than friends' mothers (Table 5f) ${ }^{98}$. When comparisons are made between girls and boys (Table 5i) ${ }^{99}$, girls reported getting on better with friends' mothers and boys with friends' fathers, although more boys said that they 'got on well' with their mothers' friends that with other groups. The reasons, given by children in the survey ${ }^{100}$, for getting on well with a particular familiar adult were similar to those given for aunts and uncles and included: length, frequency or enjoyment of contacts; being able to talk to them, and trusting them.

\footnotetext{
97 Page number 137

98 Page number 138

99 Page number 148

100 Survey question 67
} 
The children's contacts with their friends' families also included aunts and grandparents. Breanna said:

Sundays I go to my friends nana's with her and we bake cakes and stuff... and she said 'Are you coming next week' and every time I go she says 'Are you coming next week?' And then I just go.

Through such contacts, and also the proximity of each others relatives, the children's connections with, or at east knowledge of, each other's families was developed. For example, when speaking of his friend, James displayed a detailed knowledge of his life:

$\begin{array}{ll}\text { James } & \text { No he lives with his granny when he's at school, Saturdays } \\ & \text { and Sunday's he's with his nana, Wednesdays' he stays } \\ & \text { with his dad, Sunday five o'clock he's with his mum and his } \\ & \text { step-dad and brothers }{ }^{101} \\ \text { Sue } & \text { So where does his nana live then? } \\ \text { James } & \text { Just two doors down from me } \\ \text { Sue } & \text { And his gran? } \\ \text { James } & \text { You go out the main entrance and you walk down and } \\ & \text { there's a green balcony, I think it's the third, fourth } \\ \text { Sue } & \text { So they are both very close and do his mum and dad live } \\ & \text { round here as well? } \\ \text { James } & \text { They live over there } \\ \text { Sue } & \text { His mum and his dad? } \\ \text { James } & \text { His mum and his step-dad }\end{array}$

\subsubsection{Workers in children's clubs}

As stated earlier ${ }^{102}$ the majority of children in the study reported that they attended a regular leisure activity. In Swinburn most of the clubs that the interviewees spoke about were located within the neighbourhood (Table $5 b)^{103}$. These children and those in the survey often identified facilities by a common name such as 'the Tuesday Club'. However, my local knowledge

\footnotetext{
${ }^{101}$ It is not known which parent's mother was referred to as 'granny' or as 'nana'.

102 See section 5.1.2

103 See page 129
} 
enabled me to distinguish between the different types of: sport, art and drama clubs; uniformed and religious organisations; and 'support groups' 104 . A quarter $(23 \%)$ of the children in the survey reported spending a lot of time with people in clubs (Table $5 g)^{105}$ and $61 \%$ indicated that liking the workers had been an important reason for their attendance. ${ }^{106}$

Other reasons included: 'the activities keep me occupied' (68\%); 'I learn new things' (62\%); 'I go because my friends go' (39\%). However, despite these views from the survey, interviewees made little independent reference to workers in the clubs, the exception being the 6 girls who attended a Girls' Club. Although there was little information provided about the personal characteristics of parental friends and friends' parents, theses girls did elaborate their views about the Girls' Club workers.

Helpful, encouraging, friendly, and cheerful were the type of characteristics these girls appreciated in workers, unlike 'moaning'. Half of the girls said that one of the workers was 'moany' because she told them not to do things.

Reports of another worker, in the Girls' Club indicted that she was more reasonable and open to negotiation:

$\begin{array}{ll}\text { Stacey } & \text { She'll [leave you alone?] if you be good } \\ \text { Star } & \text { She gives us warnings cos I went down the next again week } \\ & \text { I got barred and says 'Am I allowed to come this week? cos } \\ & \text { my sister was doing it as well?', and she went 'Aye' and } \\ & \text {...told me that I was allowed to come. }\end{array}$

As attending a club seemed to be something that the children actively chose to do outside school, they appeared to have expectations that the activity

104 The 'support groups' were organised by organisations which include: One Parent Families, Befrienders and voluntary social work organisations.

105 Page 138

106 Survey question 38 . 
would be enjoyable, and that the adults running the facilities would be different from teachers, such as 'not boring' and not telling them what to do. As Breanna said 'they're not our teachers, they're not there to tell us what to do, they're there to make us have fun'. The girls expressed a particular concern about shouting:

\begin{tabular}{|c|c|}
\hline Courtney & $\begin{array}{l}\text { She is she's really nice, she disnae give you a row, but if you } \\
\text { do something really bad she'll give you a row but she will } \\
\text { nae like }\end{array}$ \\
\hline Breanna & Shout. \\
\hline Courtney & $\begin{array}{l}\text { Shout at you... she's really, really nice and she talks to you. } \\
\text { If you can't do something she just says 'try' and if you } \\
\text { cannae and everybody else is, you just do something else. }\end{array}$ \\
\hline
\end{tabular}

Other girls spoke about alternative strategies to shouting. In relation to the Girls' Club Hayley said '... we've got a wee room ...we go in there for our snack...she takes you in there and just has a word with us or something'. Angel reported that a similar tactic was used by workers at the Summer Playscheme she attended:

They [workers running summer play-scheme] were nice; they never shouted at you, they just put you out in the bit with the chairs [a reception area] to quieten down.

In the survey ${ }^{107} 17 \%$ of both boys and girls reported having problems with people in the clubs during the previous year. Particular instances that were noted $^{108}$ included 'getting into trouble because of fighting', or that the workers did not take any notice the children or of their ideas. Whilst within their interviews girls spoke of experiencing problems in the Girls' Club, and Breanna at Girls' Brigade, such difficulties did not appear to have stopped them attending, unlike Peter who reported 'I went to a club once and there was

\footnotetext{
107 Survey question 68

${ }^{108}$ Survey question 69
} 
nought to do so I just started carrying on and they barred me'. Although John A said that he attended a School Club, he said that he was not interested in going to Boys' Brigade because 'I dinnae like getting told what to do'. I wondered whether he got told what to do in the School Club, but interestingly it was James who pointed out to John 'You dinnae get told what to do. You get told what to do in the classroom and you don't do anything about it'. It may have been that as the School Club took place in school he thought of it 'like school' and was therefore more prepared to be 'told what to do'.

As already noted, it seemed that in general the children expected workers in clubs to behave differently from teachers in school, to listen to them, to talk rather than shout at them and to enable them to have fun. They appeared to understand that within these settings, rules and boundaries were necessary. However, they also wanted to be able to negotiate these. This is perhaps the reason why a few children mentioned trying out different clubs.

\subsubsection{Other adults in the neighbourhood}

The interviewees spoke of contacts they had with adults in different contexts in the neighbourhood. The girls who attended the Girl's Club reported that the 3 women who ran it were local residents and that one was well-known to them, because she also worked in Swinburn Primary School. In addition, Breanna said one of the women was a friend of her sister and that she visited her house. Interviewees also referred to shopkeepers and 'local characters'. Shopkeepers are discussed in Chapter 6, as the children also made reference to people working in shops that were outside the neighbourhood.

James and John B spoke a particular local character: 

adults?

James They dinnae do anything. There's a guy called Bob, he's an adult but there's something wrong with him. He's been taking drugs for ages and his family have died and all that. $H e$ 's walking like that 'Hiiiiii yahhhh paaall'...He walks about like

Sue Yeh? I think I've seen him

John B He doesn't walk about anymore, he drives a car now

Sue/James Does he?

John B [He] drives a wee van

I had also noted 'Bob' whilst walking around Swinburn and found his behaviour, of talking to himself and shouting at people in the street, slightly alarming. However, although he could be perceived as potentially frightening, the boys appeared to have accepted his behaviour as nondangerous, possibly as a result of their familiarity with it.

The characters that children in Swinburn Primary School spoke about most frequently were those whom they described as 'the drunks and junkies' who hung around the shopping centre. These adults were a feature of the area and, like Bob, known to the children by sight and possibly through other connections, as in John A's case:

John A Like I ken one of them, my mum kens one of them, but she is nae pals with them. She was at school and that

Sue So did your mum go to school round here then?

John A No it was a wee while ago. And one of them has got like five children and she always sits and the others sit there

Sue And where are the children?

John A Just get left in the house

From their different accounts of the shopping centre characters, the children sought to steer clear of them, even going so far as avoiding visiting those shops. Whilst there was a suggestion by Crombie that the behaviour of the 'drunks' and 'junkies' could be threatening, 'they ask you for chips and they nick 
your chips', other children said that they were not scared and there appeared to be feelings of relative safety with such familiar characters.

Star was the only interviewee to speak of being frightened by unfamiliar adults when she said that one day she had been scared by some men driving around slowly. In linking this comment to suggestions of children being kidnapped she was perhaps drawing on the discourse of stranger danger which was part of the school programme during the research period. However, there was little evidence that other children saw strangers as posing a threat in their local neighbourhoods ${ }^{109}$.

Interviewee accounts together with reports from the survey indicate a familiarity with a range of different adults, although with different levels of interaction. Contacts with mothers' friends and next door neighbours were the most frequent, probably a result of the home-based nature of the children's lives and possibly a reason why girls reported that they would be as likely to go to a neighbour for help as to a relative (Table 5h) ${ }^{110}$

Although the interview data indicated that that the children did not always choose to interact with adults, the familiarity of friends' parents, particularly for the girls, indicated that, on occasion, children might choose to spend time with these adults, particularly if they had similar interests.

\footnotetext{
${ }^{109}$ Chapter 6 discuses children's constructions of 'strangers'.
}

110 See page 143 
This section considers what the children's reports of their contacts with familiar adults and the interconnections of familial and familiar 'neighbours' meant for the formation of individual relationships with adults.

Although within the interviews girls did speak of enjoying contact with different adults, the boys tended not to talk in as much detail about individual relationships. This may have been a result of differences in reporting styles with girls tending to emphasise communication, such as enquiring about people's wellbeing, sharing information and confiding in adults. Boys tended to focus on activities with adults, such as those with their father's friends, or friends' fathers. I encouraged such a focus on activity in Peter's case because he appeared to be having difficulty speaking about the different adults with whom he had contact:

Sue

So could you think of any other ways to describe them? I'm just using those words because that's what other children have said to me about adults... maybe it's best to say to me the things that you do with them?

Peter I help A's dad and that, with the car, help ...with the shopping

Although Peter and Crombie, as in the following account, were two of the more confident and relatively articulate boys, their difficulties in speaking about adults could have been a result of a lack of descriptive vocabulary or that they had not previously thought about making comparisons between adults:

Sue

Can you think about the different adults that you know, not your mum or school teachers, and think about how some of them are different from each other?

Crombie Oh that's a hard question. 


$\begin{array}{ll}\text { Sue } & \text { Like, some children have said that these adults are moany, } \\ \text { or these ones are nice, or these ones are friendly? } \\ \text { Crombie } \\ \text { Like, my mum's really good friend, she's alright, but she can } \\ \text { be moany sometimes, but not at me at. John A's mum, I like } \\ \text { her. I like everyone really. } \\ \text { Would you say that you liked or got on with some better } \\ \text { than other's and why might this be? } \\ \text { Crombie } \quad \text { I like my mum's good friend really quite a lot because I've } \\ \text { know her quite a long time and she's been nice to me quite a } \\ \text { lot of times, so I like her. I like John A's mum, I like my best } \\ \text { friends mum and dad....[but] I find it easier talking to my } \\ \text { mum or my dad or my family than other people like my } \\ \text { mum's friends. }\end{array}$

The reasons Crombie identified for liking his mother's friend was that he had known her for, 'quite a long time' and that she was 'nice to him'. Although he did not expand on the latter reason, he implied that it was related to her talking to him, similar to the reason given by Hayley about liking her neighbour ${ }^{111}$.

Two girls who seemed to want to have relationships with adults, who were not connected with their parents, were Lynney and Breanna. The familiarity that Breanna felt with her best friend's mother, as noted earlier ${ }^{112}$, may have enabled her to feel comfortable talking to, trusting and confiding in this woman more than members of her own family. She said that she would be embarrassed to tell her family things because 'it could get all about the family', but indicated that her friend's mother would listen and respect her privacy.

For Lynney, it seemed that her neighbours provided a more enjoyable form of company than did her mother. Although she generally lived with her father, she was also expected to spend time with her mother, something she

\footnotetext{
111 See 5.2.1

112 See page 148
} 
reported that she did not enjoy doing. In the following account Lynney may have been seeking a more relaxed atmosphere in her neighbour's house:

$W$ and $K$ (her neighbours) they're husband and wife and I always go over and sit in their house and watch TV and talk to them and that and sometimes, like when I fight with my mum about the state of her house and... I go to my big sister's. [I talk to them about] what's on TV... What I've been doing. What they've been doing.

Breanna's account of her contact with her best friend's mother ${ }^{113}$ and Lynney's above, display a similar sense of being treated as an individual as in the accounts of individual relationships with older sisters. ${ }^{114}$ Although John A and Peter both spoke of spending time with particular men and of enjoying undertaking activities with them the relationships seemed to be at a less intimate, more adult-child, level than those of the girls. John A spoke about mending a computer with his 'uncle', the family friend, but it was difficult to gauge whether he enjoyed this time, or whether he found the contact to be a meaningful relationship in any way. In contrast Peter spoke fondly about his father's best friend Peter, after whom he had been named. He reported that this man was frequent visitor to his house and, in addition to wrestling; Peter helped his father and adult Peter with the car. Yet, Peter did not appear to have had any separate, independent contact with this man.

In relation to workers in the clubs, whilst the majority of children in the survey reported getting on well with them, there was no sense of any individual relationships. Despite the girls having expectations that the Girls' Club workers would behave differently to teachers, my observations of the club were that there were elements similar to school, such as the need for

\footnotetext{
113 See 5.2.3
}

${ }^{114}$ See 4.3 .3 
workers to maintain group control and the process of lining up for their snack. However, the girls made no comment on these aspects.

There was no indication of any individual child-worker relationship in the Girls Club and professional adult-child relationships, such as those with social workers, only featured in a few accounts. However, Star did give an indication of the support she received from a worker at the Children's Project. This Project employed professionally qualified workers to support children who had family or peer problems:

$\begin{array}{ll}\text { Star } & \text { The guy, when I'm having problems with my mum and dad, } \\ \text { they split up, he talks to me. } \\ \text { Oh does he? How often do you go and see him? } \\ \text { Sue } & \text { Only if he's got time and I want to talk to him. } \\ \text { Star } & \text { And does it help do you think, when you were talking to } \\ \text {.. } & \text { him? } \\ \text { Sue } & \text { Uh hum. He was talking about stuff like I should behave for } \\ \text { Star } & \text { Yy mum and stuff like that. } \\ \text { Sue } & \text { Uh huhl behave for your mum? } \\ \text { Star } & \text { And was it helping you in any other way, if you were } \\ \text { Sue } & \text { having problems? } \\ \text { Star } & \text { Well 'cause, if I had a problem like and I wanted to tell } \\ & \text { somebody and nobody would listen I just need to go to him } \\ & \text { and he would listen to me. }\end{array}$

It seemed that Star was able to make autonomous arrangement to see this man, on an individual basis, unlike other children from Swinburn Primary School who attended groups at the Project. It is probable that these children attended because they enjoyed the activities the Project offered rather than being aware of its support remit. In contrast, it seemed that Lynney preferred to seek the support of her neighbours. Possibly because she perceived them as being more readily available, more informal than 'professional' workers, and more importantly of her own choosing. 


\section{$5.4 \quad$ Conclusions}

The data indicate that the children in the study had a range of contacts and interactions with adults in their neighbourhoods. Yet, whilst those in the survey reported that they got on well with different adults, it seemed that those adults outside the family and school were generally on the periphery of the children's lives, unless a child needed support or considered an adult's behaviour problematic. Although the children knew many adults in their neighbourhoods and were able to report observations of adult behaviour, their primary focus was on their families and other children.

The centrality of family and the proximity of relatives, to the children, were indicated in the previous chapter. Here, the findings point to interconnectivity between family, friends and neighbours in the children's everyday lives, similar to that found in adults (Crow and Allan 1994). This includes the sharing of life histories or biographies with parental friends and friends' parents as found by Mason and Tipper (2006) and the blurring of boundaries between friends and family as reported by Pahl and Spencer (2004). The importance of knowing, for being able to identify with others, extends from the children knowing who their family are to knowing different people, including adults, in the neighbourhood.

Whilst children might know a range of adults, the nature of contacts varied, the most complex of which were with geographical neighbours. In relation to the nature of child-adult neighbouring relations, there were indications that these were as ordinary, but also as complex as those between adult neighbours in terms of friendliness and support, but also of problems (Crow et al 2002). The idea that relations between adult neighbours are generally 
viewed as mundane and only examined when disputes happen (Stokoe 2006) also appears to apply to children.

The shared housing spaces of terraces, stairways, balcony walkways and back greens, together with pavements and local shops, provided opportunities for the children to have contacts with their neighbours and to be neighbourly, through the exchange of greetings. However, the children also reported problems of noise, resulting from shared walls and gardens, which were similar to adult complaints about neighbours (Stokoe 2006). In addition, there were specific child-adult neighbouring problems related to what the children viewed as adult control of public space. Their comments reflected views that not only were they entitled to play in the street, but that adults should 'behave' in public, as children also use public places. The finding that children viewed public spaces as belong to everyone, and that they were not owned by adults is similar to that found in Matthews's (2003) study. The fact that many of the survey children reported living in cul-desacs suggests that the city planners may have deliberately designed the street layout with children in mind.

Whilst overall the children liked the areas in which they lived, they did not like the behaviour of some adults. Within the interviews the children indicated their dislike of the behaviour of the drunks and junkies who inhabited the local shopping centre. Their comments suggested awareness that these people's behaviour had been altered by the substances they had taken, as found in Seaman et al's (2006) study. Although they appeared to be more disgusted than frightened, their comments suggest that adults should not behave in such a way in a public space. 
Their expectations of how adults should behave extended to those who worked in children's clubs. Outside school, the children appeared to seek engagement in enjoyable activities, to be recognised as individuals and to be respected. This was evidenced by their comments of workers providing encouragement and of talking to, rather than shouting at them. Whilst the majority of the children said that they liked the workers in the clubs they attended, none gave any indication of a one-to-one relationship. They appeared to see themselves as group members as outlined by Devine (2002) and Milne (2003) with little opportunity, or possibly desire, to develop relationships with individual adults.

On an individual level a child's relationship with their parents' friends, friends' parents or geographical neighbours could fulfil the role of confidant or provider of help when a parent or other family members were unavailable or not suitable. Yet, for most of these pre-adolescent children these relationships did not appear to be as significant as support from nonparental adults later in adolescence (see Blyth et al 1982; Beam et al 2002). Whilst it was clear from my local knowledge and from the children's reports that there were a range of organisations providing help to children with individual or family problems, it appeared that some, such as Lynney, preferred the more informal support of neighbours.

The finding that many of the children had opportunities for independent engagement with a range of non-familial adults, as they moved about their neighbourhoods, challenges the notion that children's contacts with adults are formalised through the institutionalisation of play (see McKendrick et al 2000; Smith and Barker 2000; Alanen 2001b; Zeither 2003a). Whilst it may be the case that some children were transported from one adult controlled 
'island' to another (Zeiher 2001b), for many of the children in this study; the lack of car ownership, the proximity of friends and family and limited family finances meant that through their play in neighbourhood streets, on patches of open space or at their friend's houses, they had contact with a range of different adults. Although many of these contacts were mediated through parents or friends, there is evidence of children making active choices in the types of contacts and relationships they had with adults, with a preference for spending time with those who listened to them rather than 'moaned'.

There is indication that autonomy from parents in the children's development of supportive child-adult relationships, from visiting an elderly neighbour to confiding in a friend's parent. Furthermore, whilst the focuses of their daily lives was family, friendships with other children and play within their local neighbourhoods, some of the children were beginning excursions to other parts of the city in search of broader experiences. This is the core subject of the following chapter. 


\section{Chapter 6}

\section{CHILDREN BEYOND THEIR NEIGHBOURHOODS: ENCOUNTERS WITH ADULTS IN THE PUBLIC WORLD}

The focus of this chapter is on children in the world of the city, beyond their 'local spheres' (Harden 2000: 43). Specifically on the experiences of those 10/11 year olds who were independently mobile beyond their neighbourhoods, and of their contacts with adults as they entered public spaces and places. The term 'public world' is used in this study to differentiate the children's neighbourhood worlds from those beyond. The interviewees made explicit distinction between these two worlds. Nevertheless, there was a sense that being able, through their own confidence or with parental licence to venture further from home and outside their local area, without adult accompaniment, represented greater 'maturity'115

Survey data from several areas are used to examine patterns in the popularity of particular activities and the use of various modes of transport. The finding that over half of the children used public facilities such as swimming pools, cinemas and shopping areas, unaccompanied by an adult, confirms previous findings that around the ages of 10-12, children's territorial range and experiences of the public world increases (Hart 1979; Jones and Cunningham 1999; Valentine 2004). They are given greater 'parental licence' to venture to more places including city centres (Hillman et al 1990; O'Brien et al 2000; Woolley et al 1999). This chapter complements these studies and those of children and of risk (Kelley et al 1998; Scott et al 1998; Harden 2000; Backett-Milburn and Harden 2004). The chapter

115 See 8.1.2 for more discussion on maturity in terms of the children's constructions of 'adult'. 
identifies children's contacts with adults as they moved beyond the familiarity of their local neighbourhoods into spaces full of 'unknowns' (Wells 2005). Interview data revealed children's apparent distinctions between adults in public environments and adults working in public roles. This point is linked to the children's constructions of 'stranger danger' and to the ways in which they dealt with the problematic message of don't talk to strangers in a world full of strangers (Wells 2005).

The final part of the chapter examines how the interviewees referred to particular experiences of being children in the public world, including their feelings of autonomy in unfamiliar environments. The term 'public world' is used to incorporate both spaces beyond children's local neighbourhoods and places used by the general public, such as swimming pools and cinemas, as distinct from what might be termed 'children's spaces and places' (Rasmussen 2004). In the public world there is an expectation for children to be invisible (Matthews 2003). Young children are seen as being 'at risk' from adults through the dangers of traffic and strangers (Kelley et al 1998; Scott et al 1998; Harden 2000; Backett-Milburn and Harden 2004). Yet teenagers are considered to constitute 'a risk' to adults, and to younger children, because of their behaviour and failure to defer to adult expectations (Cahill 1990; Matthews et al 2000).

The choices and strategies made by participants in this study provide useful insights into how children, who were at the boundary of becoming teenagers, made decisions on whether, and how, to navigate their way through different environments. Yet, even for those who appeared to be 'experienced and practiced in coping with public life' there was an awareness that their 
actions were 'limited by their subordinate position in child-adult relations' (Harden 2000: 54).

\subsection{Moving into the public world}

In addition, to talking about how they spent their leisure time in the local area, the children from Swinburn Primary School spoke of venturing, without adult accompaniment, beyond the neighbourhood to a range of places around the city. These included areas where they had lived previously, where they had relatives, or where there were ice-skating rinks and a museum. However, the venues mentioned more frequently were swimming pools, cinemas, and shopping areas. Figures from the survey (Table 6a), provide a broader picture of children's use of these three venues and an indication of their range of movements within, and contacts with, the public world. Over half $(58 \%)$ of the children reported that they went swimming without adult accompaniment ${ }^{116}$, just under a half $(47 \%)$ that they went to the cinema without an adult and a quarter (24\%) to the city centre, also without adult accompaniment ${ }^{117}$.

Table 6a Survey children's reports of visiting cinemas, swimming pools and the city centre without adult accompaniment. Survey questions 41,47 and 53

\begin{tabular}{|l|l|l|l|l|l|l|}
\hline & \multicolumn{2}{l|}{ All children } & Girls & Boys \\
\hline & No. & $\%$ & No. & $\%$ & No. & $\%$ \\
\hline Swimming pool & 218 & 58 & 121 & 67 & 97 & 51 \\
\hline Cinema & 178 & 47 & 84 & 45 & 94 & 49 \\
\hline City centre & 90 & 24 & 43 & 24 & 47 & 25 \\
\hline
\end{tabular}

\footnotetext{
116 There were problems with interpreting the data from Section E 'Places you go without adults' of the survey, these have been discussed in 3.2.5.

117 Survey question 53 used the name of the city's shopping area, rather than that of 'city centre', but this has been removed for the purpose of anonymity.
} 


\subsubsection{The public world}

Harden (2000) refers to different spheres of public space, naming those nearest to children's houses as local and those further away, as public. Public space is distinct from private space, as somewhere 'where people can congregate, socialise and organise in relatively unregulated ways' (Sheller and Urry 2003: 110). Public space can be further distinguished into open, green and civic spaces (Kit Campbell Associates 2001). In addition to differentiating various forms of public space, public places can also be defined in several ways. For example, a 'place' can be viewed as 'a more delimited setting... a space with special meanings and attributes' (Rasmussen 2004: 165, drawing on Relph 1976). Yet, whilst enterprises such as cinemas, swimming pools and shops may be viewed as places for the public, rather than specifically for children, it can be debated whether they are public or private. For example, Valentine refers to shopping malls as 'surrogate private spaces' (2004: 84). Confusion also arises with the growing number of private swimming pools and leisure centres. Unlike public facilities, private venues require membership in addition to charging entrance fee.

\subsubsection{Leisure opportunities beyond the neighbourhood}

In addition to playing in various outdoor spaces within the neighbourhood and attending 'children's clubs', the interviewees, spoke of going swimming, to the cinemas and shopping without adult accompaniment. Fig. 6.1118 provides a diagrammatic picture of the location of the various venues. Their nearest swimming pool was outside the area, about a mile away, and cinemas and shopping areas farther. In addition to visiting a shopping mall and the city centre, interviewees spoke of going to Jameston, an area with a greater range of shops than those available locally, but without many of the

118 See page 170 
chain stores found in larger shopping areas. For the children, who undertook the survey, and who lived in other areas of the city, the location of the swimming pools, cinemas and shopping areas varied. For example, for those living in the neighbourhood named Area A. (Fig 6.1), there was a swimming pool within the area and an edge of town shopping complex, with branded shops and a cinema within walking distance. 
Fig 6.1 A diagrammatic map of the children's journeys from their neighbourhoods to swimming pools, cinema and shopping facilities.

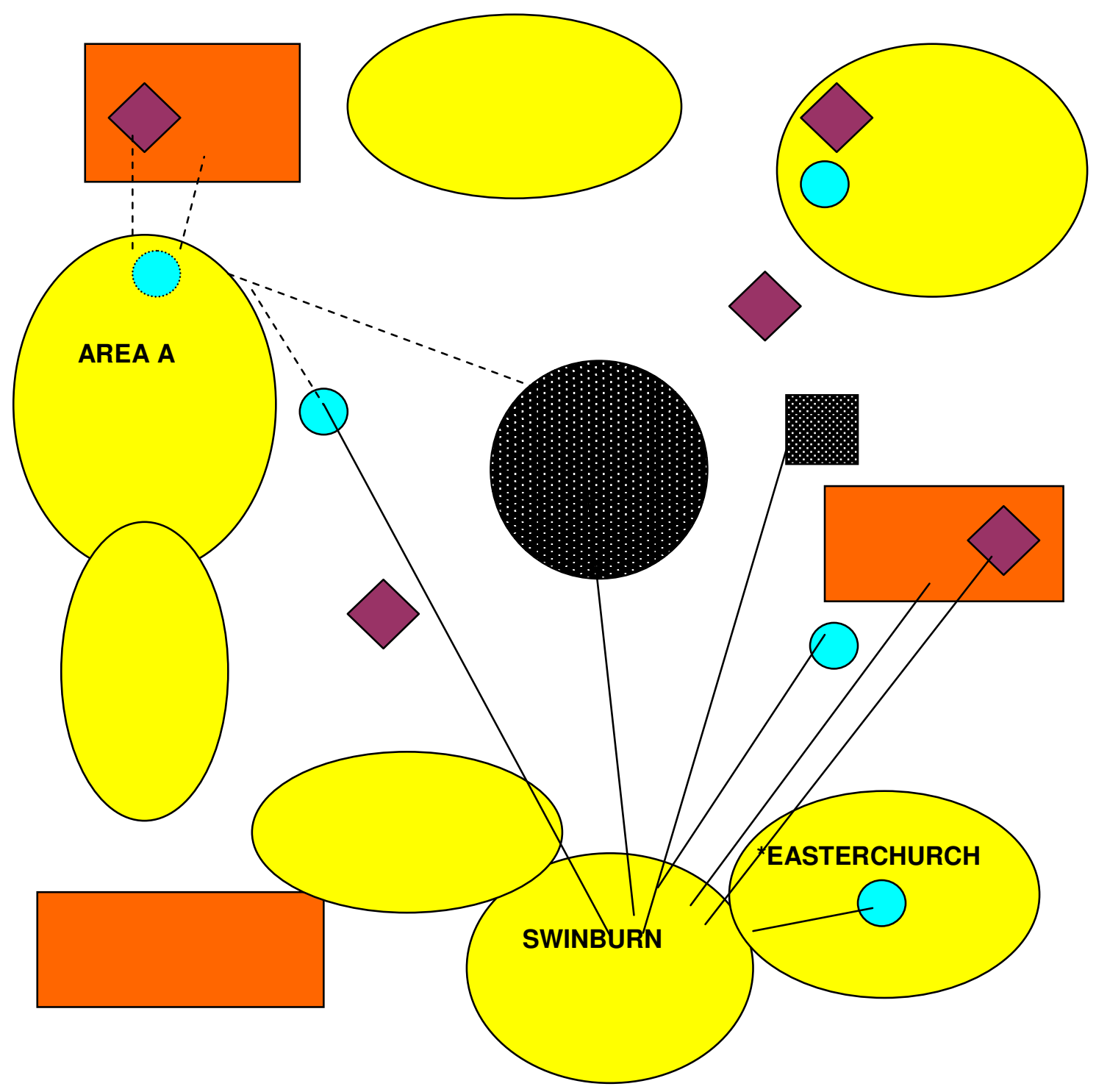

Key

Housing Schemes

Shopping Complexes/Malls

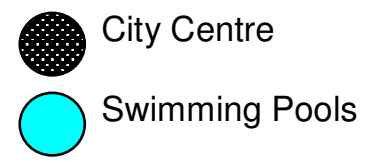

Facilities visited regularly by children from Swinburn

Facilities visited regularly by children from Area A

${ }^{*}$ Easterchurch is mentioned in 5.1.3 in reference to territories. 
However, for all of the children the city centre was not only further away, but it appeared to offer a different type of experience from the shopping malls and complexes because of its larger stores and greater spatial area.

The finding that swimming was a more popular activity for the children to undertake, without adult accompaniment, than visits to the cinema or to the city centre may have been a result of the city council providing primary school children with free admission to their pools. However, the figures for cinema and swimming trips ${ }^{119}$ were very similar to those for children of the same age and living in and around London ( $\mathrm{O}^{\prime}$ Brien et al 2000).

Although interviewees spoke of making independent visits to family members in other parts of the city, in addition to those they made with their parents, they made more comment on their trips to leisure, entertainment and retail outlets about which they spoke. The following account, from Stacey, provides a flavour of a shopping outing:

We (she mentioned the names of two other girls) were meant to be going to Au Naturale up the Shopping Centre, but it's been closed down. We were going to get earrings and stuff for Halloween... We were going to see 'Shark Tale' until my mum bought the DVD yesterday, my gran bought it as well, so we're just going to go shopping... everything was down half price, earrings and necklaces and stuff...We'll just have to go to Logo, there's a really nice necklace ... [But] sometimes I just wander around.

From Stacey's knowledge of the names of shops and their contents there was a sense that this was a trip she made previously. She spoke of shopping in a number of different places she had been to before with her mother, implying that she was now trying them out for herself. Although, on this occasion, Stacey was going to the shopping centre to buy something, she reported that at other times she might 'just wander around'. Such wandering, as opposed to

\footnotetext{
${ }_{119}$ The figures are given in 6.1.
} 
buying, could be taken as showing a lack of purpose, the sort of 'flaneur' activity which Matthews et al (2000), report adults finding problematic in relation to teenagers. However, looking around can be viewed as an important part of shopping, aiding decision making through the development of knowledge of availability and prices. Additionally, for children, and especially girls, consumer culture is seen as an important part of their identity construction (Khan 2006) in their transition from childhood to teenage status (Russell and Tyler 2005).

The children's development of knowledge not only applied to shopping, but also to the existence and location of other facilities. For example, two of the interviewees spoke of going across town to use a particular swimming pool, rather than one which was closer, because the former had diving boards. Such knowledge can widen children's choice of destination and provide greater opportunities for autonomous mobility as indicated by Breanna's accounts. Outside school Breanna spent her leisure time with girls who attended secondary school, reporting that she visited museums, as well as the cinema and city centre and at one point said she said that she was going with a friend to a tattooing studio.

One of the central features of the interview accounts was the group nature of the activities. The shopping trips reported by girls tended to be in the company of one or two friends, whereas trips to the cinema and especially swimming could be in larger groups. This patterning was also evident in the survey data, which also revealed that such groupings were generally of peers, but could also include younger or older friends, siblings and cousins. Meire (2004) suggests that such group travel represents a form of protection, but the interviewees did not reflect on the group nature of their activities, 
other than in a negative sense. Crombie said 'I like going swimming by myself, and then I get a proper swim and I dinnae have to play all the time', and Stacey reported that she did not like the 'riot' type atmosphere in the swimming pool, with people jumping in. However, the importance of having friends for such activities was highlighted by Nicolle who said that she used to go, 'up the town [to] a wee restaurant' with her friends, when she lived at her old house, but now she did not go anywhere because she had no-one with whom to go. Yet, for the interviewees, the presence of older siblings, cousins and friends in such group outings can be seen to represent an 'all pals together' identity similar to that described by Staples (1997) in his history of children's cinema.

The fact that more children went swimming than to the city centre may represent a sort of staged process. Staged in terms of distance, as for most children a swimming pool was closer to their homes than the city centre was. Engagement in certain activities can also be viewed as a staged process if swimming represents a more playful type of engagement than shopping, one that is closer in nature to the kinds of activity the children were familiar with.

\subsubsection{Being independently mobile}

As the substantive focus of this chapter is on the experiences of those 10/11 year olds who were independently mobile beyond their neighbourhoods, two points merit emphasis. Firstly, that these children were in a minority in the survey. For, although the figures indicated that half of them went swimming, without adult accompaniment, fewer went to the cinema or to the city centre. Whilst there were similar numbers of the interview children going to these venues, overall there were more who were independently mobile (Table 6b). 
Table $6 b$ The places that interviewees spoke of visiting without accompaniment from an adult or older child.

\begin{tabular}{|c|c|c|c|c|c|c|}
\hline & $\begin{array}{c}\text { Local } \\
\text { Shopping } \\
\text { Centre }\end{array}$ & $\begin{array}{l}\text { Swimming } \\
\text { Pools }\end{array}$ & Cinema & Jameston & $\begin{array}{c}\text { Shopping } \\
\text { Mall }\end{array}$ & $\begin{array}{c}\text { City } \\
\text { Centre }\end{array}$ \\
\hline Angel & - & - & - & - & - & - \\
\hline Breanna & $\mathbf{X}$ & $\mathbf{X}$ & $\mathbf{X}$ & $\mathbf{X}$ & $\mathbf{X}$ & $\mathbf{X}$ \\
\hline Crombie & $\mathbf{X}$ & $\mathbf{X}$ & $?$ & $?$ & $?$ & $?$ \\
\hline Courtney & $X$ & $\mathbf{X}$ & $\mathbf{X}$ & $?$ & $\mathbf{X}$ & ? \\
\hline Gums & $\mathbf{X}$ & $\mathbf{X}$ & $?$ & $?$ & $?$ & $?$ \\
\hline Hayley & $\mathbf{X}$ & $?$ & $\mathbf{X}$ & $\mathbf{X}$ & $?$ & $?$ \\
\hline James & $\mathbf{X}$ & $?$ & $\mathbf{X}$ & $?$ & $?$ & $?$ \\
\hline John A & $?$ & $?$ & - & - & - & - \\
\hline John $B^{120}$ & $\mathbf{X}$ & $?$ & - & - & - & - \\
\hline Lily & $?$ & $?$ & $\mathbf{X}$ & $\mathbf{X}$ & $?$ & $?$ \\
\hline Lynney & $\mathbf{X}$ & $?$ & $?$ & $?$ & $?$ & $\mathbf{X}$ \\
\hline Nicolle & $\mathbf{X}$ & $?$ & $?$ & $\mathbf{X}$ & $?$ & $\mathbf{X}$ \\
\hline Peter & $\mathbf{X}$ & $\mathbf{X}$ & $\mathbf{X}$ & - & $?$ & - \\
\hline Sarah & $\mathbf{X}$ & - & - & - & - & - \\
\hline Stacey & $\mathbf{X}$ & $?$ & $\mathbf{X}$ & $?$ & $\mathbf{X}$ & $\mathbf{X}$ \\
\hline Star & $\mathbf{X}$ & $\mathbf{X}$ & $\mathbf{X}$ & $\mathbf{X}$ & $\mathbf{X}$ & \\
\hline Stitch & $?$ & - & - & - & - & - \\
\hline TOTAL & 13 & 6 & 8 & 5 & 5 & 4 \\
\hline Approx\% & $77 \%$ & $35 \%$ & $47 \%$ & $30 \%$ & $30 \%$ & $24 \%$ \\
\hline
\end{tabular}

KEY

X Visits this venue - Does not visit this venue

? Not known

Only Angel, Stitch, Sarah and John A spoke of not travelling beyond the neighbourhood without an adult. Angel also reported having restricted mobility within the neighbourhood. Stitch and Sarah said that they were not allowed to go the cinema, the swimming pool, or to the city centre, without

${ }^{120}$ Although John B did not speak of visiting particular venues, he did travel, independently, across the by bus. See 6.1 .3 
an adult. John A reported that he preferred to go out with his mother, so that she could pay. Stitch gave the following reason:

My mum's just too careful about me... They say you're not old enough yet we'll see when you're your brothers' age [13years]...they've got a lot more pals who would help them ...or something!

The second point, about the children's independent mobility concerns their mode of travel. Although a majority of children in the survey reported walking or using buses, a large minority also said that they travelled by car (Table $6 c$ ). Therefore, whilst they used facilities without adult accompaniment $(\text { Table } 6 a)^{121}$, their travel was not necessarily independent.

Table 6c Children's reports of the means of travel to: a cinema, a swimming pool and the city centre: Survey questions 46,52 and 58.

\begin{tabular}{|l|l|l|l|l|l|l|l|l|}
\hline $\begin{array}{r}\text { Means of } \\
\text { Travel }\end{array}$ & Bike & \multicolumn{2}{l|}{ Bus } & \multicolumn{2}{l|}{ Car } & \multicolumn{2}{l|}{ Walk } \\
\hline Venue & $\begin{array}{l}\text { No. of } \\
\text { children }\end{array}$ & $\%$ & $\begin{array}{l}\text { No. of } \\
\text { children }\end{array}$ & $\%$ & $\begin{array}{l}\text { No. of } \\
\text { children }\end{array}$ & $\%$ & $\begin{array}{l}\text { No. of } \\
\text { children }\end{array}$ & $\%$ \\
\hline Cinema & 8 & 2 & 97 & 26 & 55 & 15 & 64 & 17 \\
\hline $\begin{array}{l}\text { Swimming } \\
\text { Pool }\end{array}$ & 8 & 2 & 17 & 19 & 66 & 18 & 118 & 31 \\
\hline City Centre & 6 & 2 & 77 & 21 & 26 & 7 & 8 & 2 \\
\hline
\end{tabular}

Interview accounts provide an interesting picture of the children's developing mobilities. In this neighbourhood half of the children's families did not have a car, a notably higher proportion than the $23 \%$ reported in the survey. Whilst in some of the interviewees spoke of walking to their nearest swimming pool, it appeared that the bus was a popular means of accessing a variety of venues around the city. Their reports indicated a general degree of confidence in using buses, something possibly gained from familiarity in

121 Page 167 
travelling with family members, from an early age, due to non-car ownership.

Two interviewees were frequent bus travellers, although for different reasons. Star spoke of her bus journeys with friends to a mall where they shopped and visited the cinema. John B, who split his week between staying with his mother and his father in different parts of the city, reported making the journeys between the houses by bus, even though both parents possessed cars. However, when he spoke of attending sports lessons, he mentioned that he received a lift.

Other children also spoke of travelling independently by bus to visit relatives in other neighbourhoods or in other cities. In the case of the latter, John B and Nicholle said that their parents saw them onto the bus or coach and that they were met at the other end by the sister or aunts they were visiting.

Whilst there was a general sense from the 'frequent travellers' of feeling comfortable and confident when travelling without an accompanying adult, initial experiences of independence brought anxieties for one boy. James spoke of his father giving him and his friend a lift to the cinema, but that they came back on their own:

We walked most of the way, when we got to Easterchurch we got the bus ...[it was] quite cool [because] nobody stops you from crossing the road yourself, we just legged it over the road when there was cars coming, chicken and all that, quite funny.

James seemed to be testing out his freedom from adult control, by doing something that he knew his mother would disapprove of. He said that he was not allowed out much by himself because his mother was frightened that he might be run over. 


\subsection{Contacts with adults}

The children's use of leisure, refreshment and retail venues beyond their immediate neighbourhoods, and the means of accessing these facilities, presented them with opportunities for contacts with unfamiliar and unknown adults. Although their observations revealed an awareness of adults in the public world, there was little mention of actual contacts. This may have been because, as their reports indicated, they were, in the main, travelling around in groups. However, where particular incidents were reported these tended to be of a negative or problematic nature, although they were generally not explicitly about unknown adults representing a danger. Nevertheless, given that the topic of this study is relationships between children and adults, the discourse of 'stranger danger' could not be ignored. Accordingly, the children were asked for their views on talking to strangers. In their replies, and in their reports of contacts with adults in the world beyond their neighbourhoods, it appeared that the children differentiated between 'adults in public' and 'public workers', as will be shown in the following sections.

\subsubsection{Encounters with adults in public}

It might be expected that the children would encounter a range of adults when moving independently in public spaces. However, although there were reports of problems with adults on buses and in the street, it seemed that the children's contacts with adults, as members of the public, were fleeting. This appears to be in keeping with a general tendency for people to feel uncomfortable encountering unknown people (Valentine 2008: 232, referring to Allport 1954). Additionally, fear of paedophiles means that there is an unwritten 'rule' that adults should not have contact with unknown children. Peter's report that adults had not taken any notice of him when he was 
'mucking around' in the swimming pool changing rooms was therefore unsurprising. It may also have been that the message of stranger danger made some children in the survey report feeling uncomfortable when adults sat next to, or talked to, them on buses. Such examples were uncommon and they may have represented instances when children had been travelling alone, rather than in the more common situation of being with friends. In the survey, 8 children reported ${ }^{122}$ having problems with other passengers on the bus. Two wrote that they did not like adults swearing or arguing with each other, but the remainder seemed more concerned about the possibility of physical contact or of people talking to them; 'they ask questions and I don't like that'. For 2 children in the survey their direct references to being the possibility of being harmed on buses related to the concept of stranger danger. One wrote 'I'm scared that adults on buses might kidnap me because when I was young it nearly happened'. Another stated 'I have a fear that they may hit [hurt?] $m e^{\prime}$.

Yet, whilst being ignored by adults could be viewed as a positive experience by the children, as in Peter's case or in the reports of the children about being on a bus, there were other examples when such behaviour represented a negative experience, as Star and Courtney described:

\begin{tabular}{|c|c|}
\hline Courtney & $\begin{array}{l}\text { When you go up town the adults think that children are } \\
\text { invisible so they just walk into you ...If you're walking in } \\
\text { the town and you're crossing the road when the green man's } \\
\text { on }\end{array}$ \\
\hline Star & $\begin{array}{l}\text { They come from that way and come from that way and they } \\
\text { just barge past you }\end{array}$ \\
\hline
\end{tabular}

Courtney and 3 children in the survey made further comments on such adult incivility, giving examples of adults pushing in front of them in shop queues.

122 Survey question 69 asked the children to write about a problem that they had experienced with an adult in the last year. 
Another child in the survey reported similar rudeness, writing, 'I was in a shop and I bumped into a lady with my basket and I said sorry, but she just gave me a dirty look and tutted'. Star also implied that she had received similar treatment at a bus:

we just were about to get on the bus and he went, 'Aye yous three get over there because we were here before you', but we had got there about ten minutes before them.

Such uncivil behaviour was found to be common among adults (Philips and Smith 2003). The sensitivity of children in this study to particular aspects of adult behaviour was perhaps a result of an awareness of their child status, and, or the assumption that 'adults think that children are invisible'.

Although few children reported direct contact with adults in public, there was sense of their general watchfulness regarding the behaviour of adults around them. Over a third of children in the survey reported that they had seen, 'adults behaving in ways that they did not think that they should'123.

\section{Contacts with strangers}

When asked for their thoughts on speaking to strangers, the interview data, revealed not only differences in their individual attitudes and behaviours, but also some confusion, such as that expressed by Hayley:

I don't know. I don't know if I would or wouldn't 'cause sometimes I talk to strangers. My mum said dinnae, [and] even the school said don't talk to strangers in case they're like baddies and like take you away.

The admission that she had talked to strangers, even though she had received the message that she should not, was common as in the survey over

\footnotetext{
${ }^{123}$ There is further discussion of children's views of adult behaviour in 8.2.1 and 8.2.2
} 
a third (38\%) of children said that they had talked to a stranger ${ }^{124}$. When they spoke about their contact with strangers interviewees reflected upon the reasons why they had spoken to, or might speak to one. For example, Breanna said:

No I wouldn't talk to anybody on the bus or in the street, [but then she added] 'Sometimes I would say 'Has the thirty five went past, or the forty one?' or ask them the time 'Anybody got the time?

She implied that asking a stranger a question was an acceptable action. Peter explained how this was different from speaking to a stranger, 'talking is like talking to them for ages' and he thought that in doing so, 'they would come towards you'. This suggests a recognition that the action of speaking can amount to beginning a process of engagement, and something different from a mere question and response. When the children in the survey were asked for their opinions on 'having a conversation with a stranger'125, most $(82 \%)$ did not think that they should engage in this activity. However, there was greater uncertainty about whether it was all right 'to ask a stranger a question, such as how to get somewhere ${ }^{126}$, as just less than a half $(48 \%)$ replied 'no', but nearly a quarter ticked 'don't know'127. Asking for children's views so starkly, through a one-off questionnaire, revealed the children's uncertainty, but the interview accounts pointed to what could be seen as a realistic attitude towards strangers, borne from their own experiences. This included a slight wariness, but also recognition that it may be useful, and indeed necessary, to engage with unknown adults in certain situations.

\footnotetext{
124 Survey question 61

125 Survey question 62

126 Survey question 63

127 The other answer option was: Yes (25\%).
} 


\section{'Safer' strangers}

In recognising that there may be situations in which they needed to ask a stranger a question, the children appeared to have set themselves particular 'rules'. Stacey said, 'I'd make sure it was a lassie I talked to'. Peter said that he would, 'ask them for the time, but if they're drunk I dinnae'. Gums reported that he would not talk to strangers if they 'looked weird', however, in recognising that there could be situations in which he might need to speak to one, he said;

If you have to, try and ask somebody who looks a wee bit more sophisticated and talk to them [...], with office ID's and stuff on, [because] if they try and take you away you can say that they had such and such an office badge on.

The children seemed to have taken on the message that women are 'safer' people (Harden 2000; Spilsbury 2002; Valentine 2004). Gums' reasoning about the identity badge implied that a person wearing one could be traced. James' association of looks, behaviour and manners, as revealed in the following quotation, were similar to Gums' view of sophistication:

Some adults that I dinnae like, like people that I dinnae ken, I don't ask them questions, but if I see somebody that's nice and kind and that, I'd ask them directions aye. [Nice] like standing, saying hello to people if they dinnae ken them, like good mannered people.

The children appeared to have received the message that unknown adults in public posed a danger to them, but rather than necessarily avoid such people some children assessed the risk that they might pose. To do so they used a variety of visual clues about appearance and behaviour. They based their assessments on the idea that, although a particular peculiarity might not represent a danger, the fact that a stranger looked or behaved unusually might be an indication that they possessed other peculiarities that might be dangerous as Wells (2005 drawing on Goffman, 1971) suggests. The ability to 
make subtle distinctions was also shown in their constructions of the process of engagement and their assessments of how to talk to strangers. The thought that many of the children put into considering whether, or not, to talk to a particular unknown adult could be described as taking a calculated risk and is similar to the approach typically taken by adults.

Whilst there seemed to be a desire on the part of the children for unknown adults not to have contact with them, they also did not want to be invisible. They indicated a desire for adults to notice them, as they did other adults, in the process of moving so that they could avoid knocking into them. This appears to be a wish for the type of to apply a 'civil inattentiveness' referred to by Goffman (1971: 322). Also that adult should accept children's rightful place in queues, but without giving them direct acknowledgment.

\subsubsection{Encounters with public workers}

In terms of the message of 'stranger danger', the interview data revealed an apparent difficulty in deciding who was a stranger (Wells 2005). It seemed that children did not necessarily consider people who worked with the public, in shops or leisure facilities, to be strangers, in the same way as unknown members of the adult public might be. In contrast to initially saying that she would not speak to such 'strangers', Breanna said:

... I started talking to people, like the very first time I went to the pictures they were being really kind and I started talking and the next time I saw them again I started talking just like talk, just say 'Hiya' and they would say 'Hiya.'

This links to the idea presented by Gums, and contained in messages to children, that people wearing badges or uniforms are 'safer' people. Yet, whilst interviewees mentioned 'public workers': such as ticket sellers at the cinema, pool attendants, bus drivers, and those working in cafés and shops, 
they give little detail of their interactions. The accounts that were mentioned were mostly negative, possibly an indication that child-public worker encounters were of a mainly routine nature, and therefore failed to register with the children. One example of a positive interaction on a bus was reported by Star who said:

We went up stairs and we sat down and we started eating our chips and we turned round and there was [another] bus driver sitting behind us and he went 'I'm not looking!'

Although, in this case, Star had not been reprimanded for breaking the rule of not eating hot food on the bus, another incident displayed the complexities involved in child consumer-adult worker relations around rule interpretation and enforcement. The incident concerned Star, but was reported by Breanna:

Like when I went swimming last Saturday, we met Star that's in my class and her pal. In the shallow end you're no supposed to dive in, but you're allowed to jump in. Star jumped in and she was going to get chucked out of the pool for jumping in. The woman [pool attendant] went 'You're no allowed to dive' and Star said 'I never dived' and she went 'Get out now'. Just because she says 'I never dived'. She only jumped in and then we had to go out with her, but then we came back and we went back in. She never noticed.

Breanna and Star had been aware of the rule of not diving into the shallow end, and Breanna implied that it might have been acceptable for Star to be asked to leave if she actually had dived in. However, Star's 'crime', as a child, appeared to have been answering back. Additionally, those who had not even been involved had also been 'chucked out'. That they managed to return to the pool without being noticed, was seen by Breanna as a justified action. The pool attendant may have perceived Star's denial as a form of answering back, a behaviour viewed as overstepping the boundary of respect for the older generation (Thomson and Holland 2002). Whilst Breanna 
seemed aware that talking back, as an active defiance of adult authority, could bring disciplinary action, she indicated that this was not justifiable. Breanna's concern seemed to be that an adult making a similar reply or retort would not have been treated in the same way. Comments from interviewees about adults being 'cheeky'128 towards them suggested an expectation of reciprocal respect, in the same way that adults expect respect from each other.

In the survey $29 \%$ of the children reported having problems with "people working in shops' (Table $6 d$ ). It is not known whether they were reporting incidents in their local shops or in other parts of the city, as interviewees did not differentiate between locations.

\section{Table 6d Children's reports of having problems with 'people working in shops'. Survey question 68.}

\begin{tabular}{|l|l|l|l|l|l|l|}
\hline & \multicolumn{4}{|l|}{ Total } & Girls & \multicolumn{2}{l|}{ Boys } \\
\hline & No. & $\%$ & No. & $\%$ & No. & $\%$ \\
\hline A lot of problems & 30 & 9 & 10 & 6 & 20 & 11 \\
\hline A few problems & 68 & 20 & 34 & 21 & 34 & 19 \\
\hline No problems & 244 & 71 & 122 & 74 & 122 & 69 \\
\hline
\end{tabular}

The occasions when the children in the survey reported being thought of as a potential thief or of actually being accused of stealing 'they think that I am a kid so I might steal something' ${ }^{\prime 29}$, were possibly incidents that occurred in local shops which were observed to often be small and fairly cramped. The fact that that children as young as 10 years do shoplift (see Budd et al 2005), and one child in the survey admitted that he had done so, may appear to justify the wariness of shopkeepers, but the children's interpretation of such

\footnotetext{
${ }^{128}$ There is further mention of adult cheekiness in 8.2.2

${ }^{129}$ Survey question 69
} 
negative treatment was that they were viewed as 'just children', as in the following account from Courtney:

I went into shop and they gave me the wrong change. I went back and said 'You gave me the wrong change', and he went 'I didn't serve you'. It was the one, and he said 'I've never seen you before'... I just went out of the shop... probably just because we were children.

Even though Courtney attempted to assert herself, she appeared aware that her status, as a child, gave her no authority. In deciding to leave the shop, without further discussion, she seemed to have accepted that the shopkeeper possessed more power than she did.

Within the interviews children indicated that adults working with the public were different from other adults in public. Using the children's 'rules' about which strangers to speak to, it is likely that an adult worker was seen as a safer stranger to talk to because s/he could be identified with a particular place. They could also become familiar to children through repeated contacts. A further distinction, apparent in the children's accounts, was that these workers were enforcers of 'rules', such as the codes of behaviour at the swimming pool and on buses, and the law, in terms of there being age restrictions on the sale of certain goods. The children's apparent acceptance of the necessity for rule enforcement is similar to that of adults (see Kellerman 2008 in relation to airport procedures), but they seemed to question it if it was not applied fairly, as in the incident involving the swimming pool attendant. 


\subsection{Experiencing the public world as children}

Whilst most of the 17 interviewees spoke of venturing beyond Swinburn without an adult, and of visiting various public venues, such outings only seemed to be regular activities for Star, Breanna, Courtney, Peter and Gums, as in Courtney's reference to visiting the shopping mall or of going swimming 'every Saturday'. In the survey half of the children (56\%) reported making weekly visits to swimming pools without adults, trips to the cinema were more likely to be monthly, and those to the city centre even less frequently (Table 6e).

Table 6e Children's reports of the frequency of their visits to: a cinema, a swimming pool and the city centre: Survey questions 45,51 and 57.

\begin{tabular}{|l|l|l|l|l|l|l|}
\hline & \multicolumn{2}{|l|}{ Once a week } & \multicolumn{2}{l|}{ Once a month } & \multicolumn{2}{l|}{$\begin{array}{l}\text { Less than once a } \\
\text { month }\end{array}$} \\
\hline & $\begin{array}{l}\text { No. of } \\
\text { children }\end{array}$ & $\%$ & $\begin{array}{l}\text { No. of } \\
\text { children }\end{array}$ & $\begin{array}{l}\text { No. of } \\
\text { children }\end{array}$ & $\%$ \\
\hline Cinema & 52 & 29 & 94 & 52 & 36 & 20 \\
\hline Swimming Pool & 117 & 56 & 66 & 32 & 25 & 12 \\
\hline City Centre & 37 & 42 & 32 & 36 & 20 & 23 \\
\hline
\end{tabular}

The reason for the difference levels of attendance between the two groups is not known, but it may have resulted from the children in the survey being slightly younger than the interviewees ${ }^{130}$. The discussion that follows only draws on the experiences of the latter.

Most of the interviewees appeared to have an awareness of their child status in the public world, whether this was a result of their actual experiences or, as in a few cases, a specific reason why they did not venture beyond the neighbourhood. The main ways in which they spoke about their child status

\footnotetext{
130 The survey was undertaken with P6 children in May 2005, whereas interview data were
} collected between September 2004 and January 2005 when they were in P7. 
were in terms of age and the relationship between age and appearance. They expressed awareness that, as children, they faced a number of restrictions due to their age and adult constructions of children. Additionally, those children who had regular contacts with the public world were aware of the costs of goods and of services, and that their finances were limited.

\subsubsection{Having a non-adult status}

As the interviewees moved into the public world, they spoke about the restrictions that they felt were placed on them because of their age. This was both in terms of their awareness of the age-bounded nature of certain activities and of the relationships between age and appearance. The relationship between height and age was one mentioned by the children in their definitions of 'adult'131.

One example of feeling restricted was the children's references to the use of age categories, which limited their access to certain goods and services. Although Courtney and Star spoke of their experiences of encountering these restrictions, it was Breanna who contributed a wider range of accounts. She spoke of the problems of not being served when she was trying to buy false nails:

In shops sometimes cause they'll no serve you. One time we had to be eleven to get these fake nails and they said that I was no eleven and they says we needed ID and I says I'm too young to have ID and she went 'you've just admitted it' and I went 'but I'm eleven'. She said 'Tell me your date of birth', and I'd forgotten it and she said 'see you have to think about it.'

The above account and that of Breanna going with her friend who was having a piercing revealed her awareness that there are age categories for certain goods. A further complication, for the children, was that age and

\footnotetext{
131 There is more discussion of the children's constructions of 'adult' in 8.1.1.
} 
physical appearance do not necessarily correlate. So, whilst Star, Courtney and Breanna reported that they could pass as older and therefore gain admission to films with a ' 12 ' certificate, at the cinema, without trying, there could also be a downside to being mistaken as older, as Breanna commented:

...and another problem with adults is when we go swimming and you dinnae get in for a child, primary school. Sometimes I dinnae get in for a child... I have to try to get in as a primary school child.

Breanna did not have to try to be viewed as older, but she did have to try to be accepted as her actual age. Looking their age was also a problem reported by Hayley and Lily, although for them this was about feeling that they looked young for their age. The following account concerns a trip to a café in Jameston and their engagement with a waitress:

$\begin{array}{ll}\text { Lily } & \text { She says 'I know yous two, you were here like the other day' } \\ \text { Hayley } & \text { 'Why aren't you with your mum or dad?' } \\ \text { Sue } & \text { Is that what she said? } \\ \text { Hayley } & \text { I says we just wanted to go a walk ourselves } \\ \text { Lily } & \text { We says we just stay over the road and we've just come a } \\ & \text { wee walk } \\ \text { Sue (giggling) } & \text { Why did you say that then? } \\ \text { Lily } & \text { She might call the police } \\ \text { Sue } & \text { Why might she do that? } \\ \text { Hayley } & \text { She does nae like people going } \\ \text { Lily } & \text { She does nae like people } \\ \text { Hayely } & \text { She does nae like children like us, ourselves } \\ \text { Sue } & \text { Why should that be a problem? } \\ \text { Hayley } & \text { Because we're too young } \\ \text { Sue } & \text { Did she actually say that or did you think that she was } \\ & \text { thinking that? } \\ \text { Lily } & \text { She actually says 'you look like you're like' } \\ \text { Hayley } & \text { 'Like seven or eight years old' }\end{array}$

Lily and Hayley appear to have made up the story of living nearby because they felt that they required a justification as to why they were in the café without an adult. They thought that they looked 7 or 8 years old, rather than 
their actual ages of 10, and therefore possibly assumed, that because they appeared to be younger, that they should have been accompanied by an adult, in a public space. They thought that they looked younger because of their small stature, something that they both compensated for by wearing high heels. To reinforce the point, they demonstrated (in the interview) their actual height by removing their shoes.

In addition to age restricting the range of activities in which children are able to participate, interviewees were also aware that the cost of services and goods could limit their participation. For example, Gums thought that going to the cinema was an expensive activity and questioned the point of it when the films could be hired from a video shop, or as in Stacey's case bought, for the family to see at home.

\section{Limited funds}

The following account provides an example of Courtney and Star's awareness, not only of their dependence on their parents, whose financial situation might have been restricted, but also of the expenses involved in a cinema trip, in particular the marketing expectation that they bought a 'Kids Combo' rather than provide their own refreshments.

$\begin{array}{ll}\text { Courtney } & \text { I used to go to the pictures a lot but? } \\ \text { Star } & \text { You've got your wee brother } \\ \text { Courtney } & \text { My mum could nae afford it } \\ \text { Sue } & \text { Right so does she just give you a certain amount of pocket } \\ & \text { money? } \\ \text { Courtney } & \text { I get a fiver every Saturday now } \\ \text { Sue } & \text { Yeh and is that, that's not enough to go to the pictures? } \\ \text { Both } & \text { No } \\ \text { Courtney } & \text { It's } £ 3 \text { odd for your ticket } \\ \text { Star } & £ 2.50 \text { to get in with the ticket and if you don't want to buy } \\ & \text { the big popcorn it's about £10 or something for a popcorn, a } \\ & \text { hot dog and juice and }\end{array}$




$\begin{array}{ll}\text { Courtney } & \text { I don't like hot dogs } \\ \text { Star } & \text { Popcorn, and juice and a packet of 'Smarties' } \\ \text { Courtney } & \text { A Kids Menu } \\ \text { Star } & £ 3.50 \text { a 'Kids Combo' } \\ \text { Courtney } & \text { Something like that } \\ \text { Sue } & \text { You wouldn't just take your own sweets and go down? } \\ \text { Star } & \text { You're not allowed to } \\ \text { Sue } & \text { You're not allowed? } \\ \text { Star } & \text { No you have to buy them in there and I got this tub, with } \\ & \text { one scoop of ice-cream in it and it's } £ 1.50\end{array}$

When money was limited, it was not surprising that going out with an adult could be preferable to making trips with friends. For, as John A said, 'I like going with my mum instead; I don't have to pay my bus fares myself'. Additionally, 3 of the girls reported that they enjoyed going out with their aunts because they were bought goods. The children's concern with money was also revealed in an account Stacey gave of Lynney's attempts to buy '10ps worth' of sweets in a 'sweetie shop' in the city centre. Although this was an account of the difficulties faced in making choices in due to limited finances, it was also a wonderful example of the joy of the embodied experience of being in a shop 'all full of chocolates'.

Even though the children were able to use the leisure and retail facilities they did not have the same access as adults. Their non-adult status placed age restrictions on them and they were further limited by not having control over a source of income. One could therefore ask whether it is possible for children to have autonomy in the public world.

\subsubsection{Experiencing autonomy in the public world}

When the interviewees spoke about their lives and leisure activities it became apparent that their ability to move independently, beyond the 
neighbourhood, varied between individuals. Four children ${ }^{132}$ said that they did not travel beyond the neighbourhood without an adult. In contrast Breanna frequently spoke of going different places, sometimes just on the spur of the moment:

Breanna When I stay with her, me, her friend and Courtney go places. We went to the museum, we go swimming.

Sue What made you think of going to the museum?

Breanna We were sitting in the house one day bored and I said to Courtney do you want to go to the museum? and she said yes and her friend went in the shower and then we all just left. It was good.

Breanna's knowledge of the public world appeared greater than that of other children, possibly because she was exposed to a wider range of situations as a result of spending time with girls a few years older than herself. Her experience of visiting a tattooing studio where her friend was going to get her belly button pierced was something that was likely to be outside the experience of most 10/11 year olds. Her presentations of these experiences were fairly factual, without any sense of adventure or anxiety, suggesting a confidence, unlike the following 2 accounts from James and from Lily and Hayley. These seemed to be examples of these children's early experiences of independent activity beyond Swinburn.

In Lily and Hayley's previous report ${ }^{133}$ of going to a cafe there was a sense that being out 'in town', without an adult, was a new experience for them. However, 5 months later Lily's report of going to the city centre with Nicolle, and buying a pair of shoes was much more factual:

Sue Uh huh so what days is it you normally go shopping?

\footnotetext{
132 See 6.1 .3
}

${ }^{133}$ See 6.3.1 
On a Monday afternoon and a Wednesday afternoon, but on Monday I never went shopping

$\begin{array}{ll}\text { Sue } & \text { And what did you buy? } \\ \text { Lily } & \text { A pair of ballet shoes } \\ \text { Sue } & \text { From Next? } \\ \text { Lily } & \text { They're shoes that you wear outside }\end{array}$

Unlike Lily's apparently new experience with Hayley, James' journey back from the cinema ${ }^{134}$ did not appear to have been so positive. He said that he would not go again because it took too long to get home on the bus. He seemed not to have liked travelling by bus, although he previously reported making an unaccompanied outing:

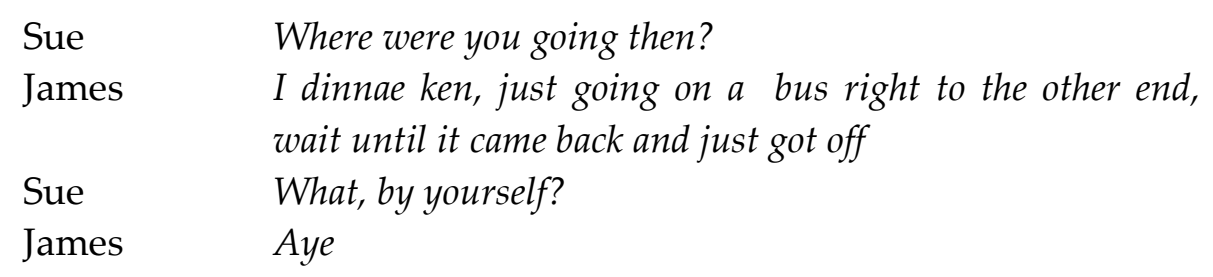

This account suggests a sense of exploration, wanting to find out what things would be like, specifically the process of travelling autonomously as an embodied experience. Yet, whilst James was clearly interested in trying out independent mobility, he said that he would not go as far as Jameston or to the city centre without an adult because 'there's homeless people and everything, junkies, druggies'. When asked when he would go to these places he replied 'when I'm about 13', saying that that was a limit that he had set for himself. Interestingly, this was the same age that Stitch reported his parents setting for him. In contrast, Breanna spoke of her parents allowing her to go out when she was about 10.

James' concern about the type of people he might encounter beyond his neighbourhood was perhaps a reflection of worries about the presence of

${ }^{134}$ Reported in 6.1 .3 
such people in Swinburn. He and Peter were also worried about traffic and losing their bus fares. Peter said 'I dinnae like going too far on the bus cause just in case I lose my bus fares... and then I cannae get home and I'd have to walk'. None of the girls participating in the interviewees mentioned such fears, although Breanna and Star both reported phoning their mothers when they were on their way home. Although these were the only children to mention doing so, it is likely that other children used their mobile phones for such purposes, as the survey revealed that most $(80 \%)$ children possessed a mobile phone.

As discussed, individual children's reports on their views and experiences of speaking to strangers suggested that they were each trying to work out a realistic situation for themselves. That Stitch was adamant that he would not talk to a stranger, but that he would go to the police instead, was possibly less realistic than the scenarios suggested by other children, a result of his limited experiences in the public world. However, a slightly worrying example of talking to strangers was reported by Nicolle who said:

$\begin{array}{ll}\text { Nicolle } & \text { I asked this man...to give me twenty pence for the phone, so } \\ & \text { he gave me } 20 \text { pence for the phone and I went up and came } \\ \text { back down again and got sweeties out of the shop with it }\end{array}$

When I asked whether she was by herself the tone of voice, in her reply 'no,' suggested that this was a silly question; this was clearly not something she would do by herself. She said that she was with her 14 year old cousin who had done this 'loads of times' so she thought that she would try it. Nicolle said that she had done it twice, but that she would not do it again. This example could be seen as an experiment in child-adult contact, using a belief that an 
adult would help a child, if asked. Having tried it out, Nicolle indicted that she wouldn't seek such contact with a stranger again.

\subsection{Conclusions}

The findings suggest that the children's interest in using swimming pools, cinemas and shops can be seen to represent a desire to connect with the world beyond their neighbourhoods. Through participating in activities that were not specifically defined for children the children could be seen to engage with the type of social 'difference' that Frello (2008: 29) speaks of. Their initial forays into the public world by engaging with activities and places already familiar to them through previous family outings, or those from school as in the trip to the museum, supports the view of Martens et al (2004) that children's modes of consumption are a replication of family activity. Additionally, whilst visiting these places may not have been new, the initial experience of going without an adult will have been. It is therefore unsurprising that more children had experience of visiting swimming pools which were generally closer to their homes, than the city centre. Swimming pools also could be seen as being more geared towards children than to the adult, 'public'. The three venues offered different experiences in terms of the children's possible and actual contacts with adults. In the process of being in the public world, these experiences contributed to the children's awareness of themselves as non-adults.

Interestingly, instead of girls appearing to be more restricted than boys as in the two studies already mentioned and others (Hart 1979; More 1986), the survey showed relatively equal numbers of boys and girls engaging in activities in the public world, whilst girls who were interviewed reported 
venturing into the public world more frequently than boys. Accounts from Breanna and Star of keeping their parents informed of their whereabouts correlate with Valentine's findings that parents view girls as more 'responsible' and 'self-aware' than boys in public (2004: 33).

Through enacting mobility without the presence of an adult, by visiting familiar places or trying out a new experience, the children's ability to travel also seemed to represent an actual connection with the public world. 'Ability', is used in the sense of having parental permission and the individual confidence to act, a point made explicitly by James. Whilst swimming is an activity that one needs to go to, films and shopping ${ }^{135}$ can increasingly be enjoyed in the privacy of the home. Although children may not necessarily have this option, it seemed that their actual interest was of being in a cinema and in shops, fulfilling an 'obligation to place' (Urry 2003: 163). In this idea, the children were developing knowledge about the public world through their direct bodily experiences of being in places; through what Urry (2003: 163) refers to 'face-to-place' co- presence.

Going places with friends appeared make venturing into the public world possible, whereas 'having no-one to go with' restricted children's public mobilities. Yet, travelling to, and being in, places in a group may also have produced a cocooning effect. Such 'we-ness' could mean that the focus of group members is directed inwards, towards each other, in the form of a 'micro-community', rather than making any outward connection with others (Symes 2007: 443). It is perhaps such togetherness that adults find potentially threatening in the hanging out behaviour of teenagers (Matthews et al 2000; Thomas 2005). Yet for other commentators, such as Meire (2003) groups can

\footnotetext{
${ }^{135}$ For example through on-line shopping.
} 
be a form of protection. Howeve, there was no sense, from the pre-adolescent children in this study, that their group presence was perceived as negative and only Stitch mentioned the notion of protection through a group. In the interviews there were implicit comments about parental concerns and their monitoring of children's movements. This included the use of mobile phones for such purposes, as also found by Williams and Willams (2005). The children's references, in interviews and the survey, to being accompanied on outings by older siblings, are similar to those found by Fotel and Thomsen (2004). Meire (2004) says that such monitoring represents children's 'semiautonomous', rather than fully autonomous mobility. However, the question may usefully be asked that, if comparison was made with adult mobile phone usage, in terms of the phoning of partners to report whereabouts and anticipated arrival times, would the question of autonomy be raised?

The ability of children in this study to be independently publicly mobile, in the sense of using facilities together with unknown adults, and of physically travelling outside their local neighbourhoods, provided them with a range of opportunities for encounters with adults. Such encounters can be viewed as important in the building of tolerance between diverse social groups, such as those between adults and children as found by Dines et al (2006). The interviewee and survey respondents' interpretations of 'talking' and of 'stranger' enabled them to make necessary connections with adults in public.

In terms of the message of stranger danger, interviewee's interpretations of a 'stranger' did not appear to be applied to people who were working in particular venues. This may be linked to the idea presented by Gums, and contained, as several commentators (for example: Harden 2000; Spilsbury 2002) highlight, in messages to children that people wearing badges or 
uniforms are 'safer' people. For the children there was an indication that danger could come from members of the public and that they needed to assess the risk that such people might pose. Their use of visual clues about appearance and behaviour, demonstrates an ability to make subtle distinctions. The thought that children applied when deciding whether, or not, to talk to a particular unknown adult could be described as calculated risk taking and is similar to the approach taken by adults.

However, the children's reports of shopkeepers assessing them as potential thieves matched those of teenagers in Cahill's study (1990). The difficulties of being children in public, as expressed by Breanna and Courtney, can be compared to Cahill's description of public places as 'hostile environments' (1990: 398) for non-adults and Matthews et al's (undated) ideas of children facing prohibitions. For other interviewee's, they felt their small stature could suggest vulnerability, especially if they were not accompanied by an adult. Such views appear to reinforce the message that children need to be supervised in public spaces because they could be at risk (Cahill 1990).

Nicolle's begging behaviour could be viewed as dangerous, but it may have been a calculated act, a form of 'testing out' of how to be a child in the adult world, similar to that of James playing in the road or Breanna, Star and Courtney sneaking into films they were officially prohibited from seeing. However, there are differences in the ways the children presented such testing. By begging money it seems Nicolle was exploiting her position as a child to get something out of an adult, whereas in seeking to pass as older and gain admission to the cinema the girls seem to have been assessing how their appearance and behaviour were viewed by adults. James playing 
chicken could be viewed as his defiance of adult rules, but perhaps also as a means of assessing his own feelings about being free from adult control.

Particularly relevant to children's connections with the public world was the position of adults working with the public. These 'public workers' provided a means of supporting children's connections, but could also damage them. Interviewees generally thought of them as safe adults because they could be identified through specific places of work and not only spoke to them to purchase goods, etc, but appeared to be more prepared to enter into conversation with them. In doing so they developed familiarity and were in a sense practicing social engagement.

However, greater recognition is needed, from adults, of the barriers faced by children, including the idea that they are at risk if unaccompanied by an adult in public places and spaces. It is this message as presented by parents, the media and the 'stranger danger' campaign which Valentine views as contributing to the view of public spaces as 'naturally' or 'normally' adult spaces (2004: 27). The social construction of children as vulnerable can discourage them 'not only from talking to strangers but also acknowledging "unknown' adults in the public domain' (Mitchell et al 2007: 61). Children's use of city streets and shopping malls not only provides physical routes to specific places, but also signals a move away from the constraints of childhood and offers opportunities for developing understandings of social relations (Matthews 2003). James' initial explorations in the public world and Breanna's wider range of experience in consumer-centred spaces link with Frello's ideas of movement as a way of 'overcoming physical distance', and as 'a metaphor for various activities and attitudes, such as imagination and openness towards new ways of thinking and learning' (2008: 28). 


\section{Chapter 7}

\section{DEVELOPING A RELATIONSHIP WITH AN ADULT}

This chapter examines how children at Swinburn Primary School appeared to develop relationships with me as an adult. It fulfils the study objective of examining children's individual relationships with an adult. As stated in Chapter 3 my initial idea for collecting data on the topic of child-adult relations and relationships had been to undertake an ethnography of children interacting with adults, within a particular site. However, whilst thinking that I had refocused on an interview study, using participant observation as a support method, I realised that that my own interactions with the children, as an adult researcher seeking children's cooperation in my research, were a form of participant observation in adult-child relationships. In other studies such data would be considered as a key part of the researcher's reflexive process. However, due to the substantive focus of this study, on children's relationships with adults, interview and field note data on the relationship between the child participants in Swinburn Primary School and my self as an adult researcher are examined, in this chapter, from the children's perspectives. Moreover, the development of children's relationships with me provides an example of the development of relationships with any non-familiar adult.

There were three perspectives that were predominant amongst the children I had contact with in Swinburn Primary School. In the first, they seemed to treat me as just another adult, and kept me separate from their child worlds. In the second perspective, they viewed me as a different type of adult. Thirdly some children seemed to be interested in blurring perceived boundaries in child-adult relationships through developing contacts with me 
as an individual, either by inviting me to play with them, or by testing out their level of maturity through the ways in which they engaged in the research process. These different ways of relating to me reflected the contexts of our interactions: whether they were in school; in the Children's Project $^{136}$ during the school holidays; or in the street. The chapter begins with an exploration of the impact of the specific socio-spatial contexts, within which the children's interactions with me took place, on the development of their relationship with me.

\subsection{Child-adult contacts in context}

The children appeared to have intuitively recognised that the nature of their social interactions with adults differed between the various physical settings and the contexts within these. They were explicit about defining the childadult hierarchies and some of the boundaries of child and adult behaviour in school, but made no direct comment about boundaries outside this setting. I have therefore drawn on my observations of their behaviour to make interpretations as to how they viewed their relationships with me in the Children's Project and in the neighbourhood streets.

\subsubsection{In school}

The children's awareness of the overall structural hierarchy of the school, and its defining role for their relationships with different adults in this setting, was indicated through their interest in establishing who I was and why I was in their school. I was obviously an adult, but where did I fit in? The children initially positioned me as a teacher by asking me what was my

136 In seeking to maintain contact with the children during the summer holidays, I had arranged with the staff from a Children's Project to use their premises on particular days. See 3.3.2 
'teacher's name', in other words, what was my surname? When I replied that they should just call me Sue, I appear to have implied that I was not a teacher; as it was likely that, in their experience, no teacher would ever have instructed children to call them by their first name. Their response, that they were not allowed to call the school assistants by their first names ${ }^{137}$, indicated that they had then assigned a different status to me.

The children's use of my first name indicated a more informal mode of interaction than the one they had with their teachers. However, I was still an adult in a context where the adults made rules for children, and although they knew which of these applied to them, as children, they seemed, at times, to be confused as to which rules applied to me. This may have been because they thought that there were different rules for adults, but as a visitor they had not know which ones applied to me, or because they were unclear as to whether the rules for children also applied to adults. The children's awareness of a differentiation is evident in the following example:

After lunch it was Assembly ${ }^{138}$ and I asked the children if they usually sat on the floor. They replied, 'there's seats for adults'. I wondered, out loud, if I should sit on the floor with them. From the look on their faces, I understood that they thought that this would not be an appropriate action.

(Field notes 4: 12/5/04)

The children appeared to accept that these different seating positions were part of school life, an example of their second-class status, as was having to

\footnotetext{
${ }^{137}$ A teacher later explained that this instruction was intended to raise the perceived status of the support staff within the school. This rule was not maintained, probably because it was not enforced. The children continued to call the school assistants and me by our first names. ${ }^{138}$ Assembly is a traditional part of the school day or week in the UK. It is a time when different classes from across the school come together to receive information, celebrate successes, and join in a collective experience, often involving songs and a religious or moral theme.
} 
accept the authority of teachers. On one occasion, I observed that a child had given the correct answer to a question posed by a teacher, who then said it was wrong. I later commented to the child that his answer was correct and asked what he thought about the teacher's response. The child just shrugged his shoulders as if to indicate, 'well that's life!' Whilst tacitly accepting teacher authority in this case, at other times the children made covert, and sometimes overt, attempts to undermine school rules and teacher authority.

This included messing about in class and cheating during the marking of work. Lynney was one child who seemed to challenge the system whenever she could. This included ignoring direct teacher instructions or rules such as not playing with mobile phones in class. Lynney appeared to view some rules as being dependent on their context:

At the end of school, I walked out of class and down to the dinner hall with Lynney. She showed me that she had chewing gum in her mouth. I said 'I thought that you weren't allowed that in school?' 'You're not', she replied. I then asked her if she had put the gum in her mouth in class. 'Aye' she replied. 'You could have got into trouble' I stated, but Lynney did not seem to be bothered. 'So! The bell had gone so she [the teacher] should have let us out. It was the end of school!' I asked her if she cared about getting into trouble. She replied, 'No there's not much that she can do'.

(Field notes 32: 3/9/04)

In this example, Lynney viewed her action as justifiable. As it was the end of the school day she apparently thought that the school rules should not apply, but whether they did or did not, seemed to be of little consequence to her.

Child-researcher contacts within the school were contextualised by their physical location within the school boundaries and in terms of the formal or informal aspects of the school timetable. Few of the interviewees were as explicit, or unconcerned, as Lynney in their interpretation of the rules and 
boundaries of behaviour. However, their implicit understanding of what they were allowed to do, where and when influenced how they interacted with each other and with me as a non-teacher.

\subsubsection{Outside the school}

My walks to the bus stop, shops, or around the area provided opportunities for children from Swinburn Primary School to have contact with me. Their calls of 'Hi Sue', whether they were alone, with friends, or with members of their families, represented a general politeness. Yet they seemed to make the choice as to whether, or not, the contact went any further. Once, as I was passing the end of what turned out to be the street where Breanna and Sarah, lived the former called out to me:

'Hi Sue'. Then about 10 children appeared, all saying that Sarah's cat had got a baby bird. One boy came over with the bird in the bottom of a plastic box, sitting on cotton wool pads like a nest. All the children were talking... 'what should we do? ... [I gave some advice]. Breanna asked if it was Thursday [the following day] when she was meant to be seeing me. 'It's today, 1-2' I said. Another girl asked her 'Why [Breanna was going to meet with me]?' Breanna replied that she wanted to. She then said to me, that she had better go.

(Field notes 22: 7/07/04)

Breanna had invited me into her territory, engaged with me and then concluded the contact. The following week, when I went to call on Sarah, Breanna was not as friendly. She told me that she was not able to meet with me that day because she had to go to a playscheme, she then concluded the interaction. She may have acted differently, on this occasion, because I was on her territory without having been invited.

The interest that other children exhibited in the reason why Breanna had spoken to me, an unfamiliar adult, was also present in the following account. 
One day, on my way to the Children's Project, I passed John B who was with other children on a patch of ground near his house and he invited me to play 'boules' with him:

One child started chucking his marbles around and the others ran to collect them. John B gave me some and challenged me to a game of 'boules'. ... After a short while, the children [about 10 of them] divided into two groups, then John B's group then broke up and he and his brother wandered towards their house. I was not sure whether to follow them, so [instead] I walked towards the other group. Then John B waved, so I went over to him. ...Some children asked John B who I was. One thought that I worked in the Children's Project and asked if I was on my break.

(Field notes 26: 21/07/04)

By engaging with me in open public spaces, Breanna and John B attracted comment from other children. These children seemed interested in establishing who I was, in terms of, both the permissibility of contact between children and an unknown adult and why Breanna and John B, as children, choose to have contact with an adult. It is not known whether this was just curiosity or whether the children viewed such contacts between children and adults as unusual or desirable or not.

\subsubsection{The Children's Project}

Use of the Children's Project, as a venue for the children to meet with me during the summer holidays appeared to have implied particular contextual expectations. Due to the children's existing knowledge of the Project, my suggestion to meet there appeared to have given them an expectation that I was setting up a children's summer club. Half of the children who agreed to participate in the second stage of the research turned up at the Project; 
implicitly it seemed to test it out ${ }^{139}$. Courtney and Lynney only appeared once, but Sarah, John A and John B came 2 or 3 times and Stitch on 4 occasions. Of the boys, the latter was very familiar with the Project, having previously attended it, but whilst the other two knew of its existence, they had never been inside. Stitch's familiarity with the place meant that he knew what toys, games and other facilities were available, he also appeared to have particular expectations regarding the nature of child-adult interactions within the setting:

I suggested playing a board game, 'Fox and Hens'. 'I'll beat you', Stitch said. He got out 'Operation', but I said that I didn't think that it was working. He then found a soft toy, 'Ernie the farmer', from Sesame Street and pressed its tummy. It played 'Old MacDonald'. 'Did you know it sang that?' I asked. 'Yes, he replied, I've been to the Children's Project before'. He then got out some books for Ernie to sit on and watch while we played our game.

(Field notes 23: 8/7/04)

Stitch's behaviour, as a 10 year old boy, playing with a soft toy in such a way, and with dressing up clothes and a tea set on other occasions, suggested that he had received messages of acceptance and freedom of choice from the Project workers and expected the same from me. Although the two Johns had not known the Project, as a place of play, they probably deduced the idea from the existence of toys. Even when I decided to try out the research technique of a neighbourhood walk (Morrow 2001) ${ }^{140}$ and get them to tell me about their area as we walked around, they wanted to go to a playground, rather than follow my suggestion:

When I spoke to the boys about not getting much for my research and that they just wanted to play, Stitch said 'No I do want to do the

\footnotetext{
${ }^{139}$ Children's testing out of clubs and activities has already been discussed in 5.2.4
}

${ }_{140}$ As mentioned in 3.3.2. 
project'. He indicated that I should be stronger with them, saying that I was the person who made the decisions about what we were doing.

(Field notes 27: 22/07/04)

Whilst the previous descriptions of Stitch's behaviour, within the Children's Project, indicated his possible expectations of freedom, his comments above suggested a belief that the control of activities ultimately lay with me, as the adult in charge. By saying that he did want to do the project he seemed to indicate that he still wanted to be able to attend. Whether this was to undertake research activities, as I defined the purpose of our summer meetings, or to play, which he appeared to have preferred, he thought that the decision was mine, rather than his.

The differences between school context, the street and the Children's Project seemed to be that in school the children were generally aware that there were rules governing child-adult contacts, although they did not always obey them or know which applied to me, as a different type of adult. ${ }^{141}$ In the street and in the Project it seemed that the children had a sense of having greater power to negotiate their interactions with an adult ${ }^{142}$. Stitch's knowledge of the Project meant that he had a clear expectation of such negotiation. His actions, and my responses, may have conveyed to the two Johns a sense that child-adult negotiation was more acceptable, in this context, than in the formal parts of the school. In the street, it seemed that the children felt that they had a choice in whether, and how to have contact with me.

\footnotetext{
${ }^{141}$ See 7.3

${ }_{142}$ As detailed in methodology 3.2.3 and 3.3.2, I was keen to enable individual children to be able to negotiate their involvement with me and with the research process although I was not always aware of where the boundaries, my own and those of the context, lay.
} 
The research engagement presented the children with a different sociospatial context for contact with an adult, in addition to being situated within those outlined above. Within the adult hierarchy the children seemed to have given me a status that was below that of a teacher, possibly because they used my first name. In the familiarisation phase, the children interacted with me in various ways, in different spaces, but generally their contacts were more informal than those with teachers. However, although the interviews took place in lesson time and within the school building some children took opportunities to explore control over their location and timing or of shifting the power balance during the questioning.

On two occasions when the library, our usual interview venue, was being used for our interviews Stacey and Crombie who sought to assert their own authority in the search for an alternative room, suggesting, 'we can use in here'. Interestingly on both occasions, they suggested that the doors to the room be locked, 'so no-one comes in'143. An example, of the traditional adultchild power balance being shifted by children in the research setting, occurred when some children sought to redefine the interviews as a reciprocal exchange. On 2 occasions, pairs made specific requests to ask me questions, but on another Stacey subtly took control of the interview. She was explaining about who all her neighbours were, and drawing maps of where they lived:

And round the wee corner there (she is drawing more 'maps'), there's a big stair there and wee corner there and some bushes and there's another cul-de-sac over there ... and

${ }_{143}$ On both occasions I suggested that it was not a good idea for them to be alone with an adult in a locked room. 
see it goes up and up and up and it's a really big hill, it's really nice.

Sue Oh right!

Stacey So your house goes like, do you need that bit? [of paper] (she uses it to makes a drawing) There's the stair, and then there's like a buzzer aye? And there's steps?

Sue There's not that many steps.

Stacey Ehh?

Sue There's not that many steps.

Stacey I've only done three.

Sue Well there's only two, in fact there might only be one.

Stacey Right only one step then... and is there like window there, a window there?

Sue Shall I draw it, from the front of the house?

It was not clear why Stacey suddenly started to ask me about my house. It may have been that she did not want to speak about her life, any further. If she was tired of answering my questions, she was very competent at shifting to the role of questioner. She may have been interested in finding out about me, and therefore used a different approach from that of asking outright questions.

Similar to the conclusions drawn about the nature of informal spaces and times within school and out-of-school contexts, the research engagement as a socio-spatial setting, seemed to be approached by the children as one with unknown rules of adult child engagement. In this situation they appeared to feel able to explore where the boundaries of their contacts with me, as an adult, might lie.

\subsection{Just another adult}

Within the adult defined contexts of the school and the Children's Project, it was not surprising that the majority of the children, in the two classes in 
Swinburn Primary School, constructed their relationships with me with reference to those they had with other adults in these settings. This primarily seemed to involve keeping me at a distance either physically or socially, or assigning me to a familiar adult role.

\title{
7.2.1 Distancing
}

My reflections on the children's first meeting with me provide details of an initial form of distancing:

\begin{abstract}
It was not surprising that the children did not want to talk to me, there were five adults in the room. The two class teachers, the head teacher, the deputy head who had been leading a singing session with them and me. How did they see me, walking into the classroom with the teachers, being introduced by the head teacher and then leaving still talking to the teachers?... [Later] I wandered into the classroom and said to a group who were there, 'I'll be around if any of you wanted to ask me questions'. But why would they? It was break time, a time to get away from adult control.
\end{abstract}

(Field notes 1: 26/4/04)

As stated, the children appeared to have no interest in interacting with me. The head teacher's introduction of me to the two P6 classes, my positioning with the teachers, at the front of the room and informal conversations with them, probably suggested to the children that I was just another adult in school, in a category separate from themselves.

In order to make interpersonal contacts with the children during the familiarisation phase, I had acted unconsciously to position myself physically close to their activities. This included sitting at their desks in class or joining them on the floor as they played a game. However, some children may not have liked such physical proximity: 
As it was wet outside the children spent break time either in their classrooms or in the open corridor area [...] One group were playing the game of letter categories, some asked me for my ideas. I sat down to join in and some of the children left. Was I interfering or was this just coincidental?

(Field notes 2: 30/4/04)

Those children who got up from the table may have felt uncomfortable about sitting next to, or close to an adult, or they may not have wanted me, as an adult, to participate in their free time activity. They could also have felt uncomfortable with me as an unfamiliar person.

About half of the boys in the year group seemed to have no interest in me, rarely initiating any conversations, although they were generally polite in replying to any question or comments I made. Yet whilst they appeared to have no interest in having contact with me, they did comment on aspects of my behaviour:

I spent some time at break and lunch times on the Astroturf at the P6 goal end. One boy later said ...that he had noticed me bouncing on the fence (which I had been - again evidence that the children notice adult behaviour). He told me that it could be dangerous standing behind the goal, as one time a teacher had been hit in the face.

(Field notes 5: 13/5/04)

The main way, in which the children maintained some form of distance from me, over time, seemed to be by making a conscious decision not to participate in the interview phase. Over half of the 37 children in the year group chose this option. This included a group of three boys who were the keenest football players. Yet, although one girl, Patterson ${ }^{144}$, also made this choice, she frequently initiated contact with me by making negative

\footnotetext{
${ }^{144}$ See the List of Children in Swinburn Primary School, Appendix 2.
} 
comments about my appearance. Such behaviour may have represented a form of testing, similar to a way in which children might assess their social position with other children ${ }^{145}$.

\subsubsection{A familiar adult role}

Whilst there were times when the children ignored or tested me, there were also occasions when the children tolerated my presence or even sought out contact with me. As, to my knowledge they had not had any previous experience of contact with a researcher, they seemed to be trying to work out what sort of adult I was. The fact, that I had allowed the children to dictate the terms of the relationship was probably due to my own ambivalence as to how position myself in the hierarchical school structure, as well as trying to follow a child-centred approach.

The children seemed to view me as a school assistant, an adult role that was known to them. These women (there were no men in the role) supervised the playground at break times and helped the teachers in the classrooms. In the playground one of their roles was to sort out disputes between children. Initially, the children asked me to perform this task, but when I declined, saying that it was not my job, they desisted. Some children also seemed to expect me to take on another role, performed by the playground assistants, that of companion. The more isolated girls like Sarah and Angel often approached me, to talk. Sarah, in particular, seemed to like physical contact often linking arms with me as she had done with the playground assistants. Such proximity to, and contact with, adults may have offered an alternative to isolation at break-time and also provided protection from the teasing of

\footnotetext{
145 The nature of this testing procession, as an indication of my possible inclusion in the children's worlds', is considered in more detail, later in 7.4.1
} 
other children. Lily was another girl who asked me to join her in games or in walks round the playground. As she was not an isolated girl and included me together with her friends I concluded that she was being friendly. This fitted with the general amiability of her daily greetings, posed as enquiries about my well-being, and her positive comments on aspects of my physical appearance. As a woman, she may have found me to be approachable. Lily also initiated physical contact, through the linking of arms or by playing with my hair.

The children also applied the familiar adult role of school assistant to me in the classroom through showing me their work for approval or engaging in conversation. One boy who often initiated dialogue with me was James. He was the first child to speak to me on my initial day in school and I was later flattered when he asked me to attend his Boy's Brigade ceremony. I became somewhat deflated when I discovered that he had also invited other members of the school staff. One teacher told me that he liked attention. A boy James played with outside school, who interestingly also selected the name James ${ }^{146}$, sought a different form of attention from me, by regularly inviting me to play chess with him. As I was not very good, I wondered whether he gained a sense of satisfaction from having more skill than an adult.

At the Children's Project, it seemed that Stitch had expectations that I would act in a similar way to staff who worked there. From his behaviour, he appeared to have the idea that children, in the Project, had a free choice of activities and that it was the role of the staff to respond positively to children's requests. Stitch and John A found that they could use me to take

\footnotetext{
146 Referred to as James B. The children selected their own pseudonyms in the group
} discussion. See 3.2.3 
them to a playground that they would not have gone to unaccompanied. I was not sure whether this was because they did not want to venture into another territory or whether their parents did not allow them to make such visits unsupervised. Either way, they used my status as an adult to enable them to do things that otherwise they would have been unable to. In giving me this role, I felt that the boys had also, unwittingly, given me responsibility ${ }^{147}$ for their safety and timekeeping. Such responsibility seemed to cast me in the role of playleader; a provider and enabler of activities.

\subsubsection{Change in adult behaviour, change in child responses}

As the only adult present with the children in the interviews, unlike in the playground, I also felt responsibility for their behaviour. It is likely that the children noticed a change in my behaviour and therefore began to test what behaviour I would allow. Gums often messed around with the floor cushions in the library. Having asked him not to do so on previous occasions, he continued:

$\begin{array}{ll}\text { Gums } & \text { I'm just going to keep on doing this. } \\ \text { Sue } & \text { I don't think that that is very good because the way that you } \\ \text { did that you could have landed on the hard floor. } \\ \text { Gums } & \text { I'll do this then. } \\ \text { Sue } & \text { I still don't think that it is a good idea. This is really meant } \\ \text { to be the library. } \\ \text { Gums } & \text { No, no. This is what this is for to play. Eh Miss? (he is } \\ & \text { talking to an other adult, who was briefly in the } \\ & \text { room). } \\ & \text { No Gums I think really... }\end{array}$

Gums appeared to be trying to draw on me and, on this occasion, another adult to legitimise his activity. Other children also used my involvement with them or my presence in a similar way. For example, some told me that it

\footnotetext{
${ }^{147}$ See discussion on responsibility in 3.4.3
} 
was all right for us to cut through the school, if they were with me, because I was an adult. This, however, was not something they would have been able to do on their own.

By casting me in familiar adult roles the children could use me as a supporter, a confidant, a provider of activities or as a supervisor/responsible person. Adults in such roles seemed to be appreciated by isolated children, because they could offer a respite from the difficulties of negotiating social positions in the child world. However, for others there was more of a sense of tolerating the presence of adults as a necessity. As children they seemed to be aware that they possessed little outward control of avoiding adult contact, although they could employ a variety of means to distance themselves, or to test out how the adult might behave.

\subsection{A different type of adult?}

Occasional remarks made during the interviews illustrated how the children thought that talking to me was different from talking to other adults. However, it was mainly from the interviewees' comments and observations of aspects of my behaviour that I ascertained that they viewed me as being different to other adults in the school. Seeing me behaving differently, in terms of indicating my interest in playing with them may have resulted in their interest in spending time with me. But before they did so they appeared to need to test me out, not just in terms of what behaviour I would allow, but also what I would do if they broke 'the rules', and whether I could be trusted to participate in their worlds according to their rules. 


\subsection{1}

\section{A non-conformist}

I was aware that my behaviour did not conform to that of most adults in school, but I was not always sure how the children viewed it. I believed that they generally did have a viewpoint although this was not always expressed, at least to me. My thought that they were likely to have viewpoints arose from realising how acutely they noted the behaviour of adults, both my own and that of adults in general ${ }^{148}$. For example when leaving the school one day I met with Lily, her mother, and a friend. The girls offer me some sweets and then dropped the empty packet on the ground. I automatically picked it up:

'I don't like litter', I said. Lily commented that I had also picked up her crisp packet in the playground, the previous day, and put it in my pocket. At that time I hadn't known whose packet it was and had not said anything. It is interesting that she should have noted it.

(Field notes 5: 13/5/04)

On one occasion, when I accidentally swore, I said sorry, but was reminded by the children present that this was not the first time I had sworn. Because I said that I could not remember the children detailed the previous incident. Despite being surprised that Lily noticed my actions with the crisp packet, it is more understandable that the children noticed my swearing as, to them, within the context of the school, it probably represented a deviant activity for an adult:

I was playing chess with Joey, during Golden Time ${ }^{149}$. He took one of my pieces in a move that I had not anticipated. I exclaimed 'Shi' and looking up from the board saw a number of children with their eyes wide saying 'Ohhh'. James B put his hand over his mouth and looked around to see where the class teacher was. I said sorry and he said

\footnotetext{
${ }^{148}$ Chapter 8 highlights the range of children's observations of adult behaviour.

149 'Golden Time' was a period, usually last thing on Friday mornings, before the end of school for the week, when the children had a free choice of activities, generally once they had finished their school work.
} 
that he had never heard a teacher swear before. I said that I wasn't a teacher. He did not appear to accept this as an excuse, so I admitted that I shouldn't have said it. I made another attempt at an excuse, saying that I hadn't said the word completely; 'I could have been saying 'Sugar', but again James B did not accept this, pointing out that 'shu' was a bit different from 'shi'.

(Field notes 21: 1/7/04)

However, on 3 occasions when teachers told me off, along with the children, they made no comment. Presumably whistling in the corridor between the classroom and the hall and playing in the lunch queue, instead of lining up in an orderly manner, were viewed by the children as relatively minor incidents, compared to swearing, with few consequences. The children might have thought that I had not known what the school rules were, for on other occasions they told me that there were things that I should not be doing, such as drinking from a water bottle in class. Another time, when I was about to eat a sweet, I was duly informed by James that 'you're not allowed sweets in school'. He then lifted up his jumper and proudly revealed that he had a large packet of sweets stuffed down his trousers. James's display of flouting the rules to me, as an adult, may have resulted from a supposition that I was a different sort of adult and therefore one who would not inform on him, but it could also have been a form of testing to see how I would react.

The children possibly marked me out as a different sort of adult because I did not conform to school rules. Whether this was because I did not know what they were, or was not concerned about them, did not seem to be of concern to the children, as long as I did not report their disobedience. The children may also have seen me as different from other adults in the school because not only was I the only adult to eat lunch with them, but I also waited my turn in line. I did not go in front of the children, as did other 
members of staff. The children made no comment to me, but seemed to welcome me sitting with them, often offering invitations. Initially in class, some made faces if I sat next to them, but over time there were invitations for me to join them or to participate in lessons with them.

The children may have viewed me as more accessible than other adults because I positioned myself physically close to them ${ }^{150}$ or and possibly appeared to be more willing, than other adults, to participate in their activities. It is likely that I seemed different to other adults in the school in the way I allowed the children to speak to me. The following exchange might appear to have been a situation in which the boys were deliberately testing out my reactions, but I believe they were initially speaking to me in their every day manner:

John A There's this place it's covered in branches and everything

Sue Covered in branches?

Crombie The Minge

John A That's what people are calling it

Sue The Minge?

John A Aye

(Both boys are giggling behind their hands)

Sue Where is it?

John A You need to climb a fence to get to it

Crombie Do you know what you've been saying?

Sue I think that I might

Crombie What are you saying?

Sue What? A minge?

(Lots more giggling and looking at each other with wide eyes)

Sue So it's obviously a rude word?

Both Aye, Aye

Sue Is it part of the body?

Both Aye (more giggling)

John A That's what it is, a place that's called

Crombie Right, its got bushes everywhere...

${ }^{150}$ Already discussed in 7.2.1 
When the boys first started describing the area where they played and used the term 'The Minge'151 I do not think that they meant to shock me. In fact, I think that I shocked them by using the term, hence their giggling. I think that they had started speaking, and used the word in an everyday sense, but after saying it they became aware they were using a rude word in front of an adult. They then had not expected me to use.

As in the case above, such non-conformist behaviour may have enabled children to be more relaxed in my presence and less concerned about the 'rules' of child-adult interactions. In addition the fact that I did not inform on their infringements seemed to mark me out as trustworthy.

\subsubsection{Trustworthy}

From their behaviour it was apparent that the children felt that they could speak how they wanted to in front of me and even swear:

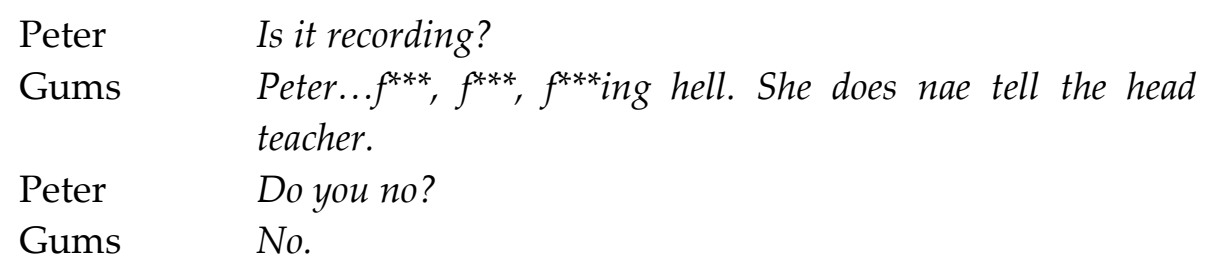

In most cases, as in that above, I made no direct reply, but through my silence indicated that I 'wouldn't tell'. This appeared to have been an important part of my inclusion in the children's games:

One boy said that he could kick the ball over all 3 benches, others also had a go. I sat on the bench and other boys and a girl came along. Three boys were kicking the balls at us. The girl said that she was scared, I was too, but I didn't say. Some of the boys were hesitant about kicking the ball at me. The first boy, who had already hit me with a ball on Wednesday said that I was okay, I didn't tell.

${ }^{151}$ Minge is a slang term for the female genitalia. 
Kicking the balls over people whilst they sat on the bench was part of the game; presumably to reveal the skill of the kickers and also the bravery of the sitters. The possibility of being hit was part of the challenge and therefore presumably not something in which to involve adults. Not informing on the behaviour of others, to adults, is perhaps a key way for children to maintain separateness from adults. However, this was not an absolute rule as there were times when the children did inform on each other, and this seemed to be acceptable. I think that the lines of acceptability were something to do with the status divisions between the children, which resulted in those with high status ${ }^{152}$, or members of their friendship groups, being 'permitted' to inform on the behaviour of those children outside the group.

Trusting other children not to inform on aspects of behaviour or language appeared to be an important part of children's worlds, as was keeping information private. The children indicated that they trusted me with what said in the interviews. At the end of the individual interviews, I asked the following question:

Sue [...] Have you thought that talking to me has been any different from talking to other adults?

Crombie No because I trust you and you've been talking to quite a lot of people in the school

Although Crombie said that he had not found talking to me any different from talking from other adults in the school, he indicated that he thought

\footnotetext{
${ }^{152}$ I assessed Breanna to be high status, a girl whom the other children appeared to look up to, describing her as good at her work. She was also a rebel in the way she dressed. I assessed the highest status boy to be one whom the other children also described as clever. He was the captain of the P6 break time football team, and a member of the school team.
} 
there was a difference in terms of trust. As on a previous occasion, he said that he did not trust the school counselling service:

$\begin{array}{ll}\text { Sue } & \text { What about this new project in school? } \\ \text { Crombie } & \text { I don't trust it at all } \\ \text { Sue } & \text { Do you not, why? } \\ \text { Crombie } & \text { I just dinnae trust it } \\ \text { Sue } & \text { You won't trust it in what sort of way? } \\ \text { Crombie } & \text { Because I believe if a child says 'Oh I'm not really having a } \\ & \text { good time, my mum's had a baby and she's no really paying } \\ & \text { me attention'. They say ...but I think that they'll tell the } \\ & \text { police or someone that can watch out or something. I just } \\ & \text { don't really trust them }\end{array}$

Crombie's view was that that speaking about problems to one adult could bring the involvement of others. Not involving adults seemed linked to the keeping of individual confidences as did the following incident:

$\begin{array}{ll}\text { Sue } & \text {...you weren't here last week, were you, because you were } \\ & \text { staying with your big sister? } \\ \text {... } & \text { How do you know I was at my big sister's? } \\ \text { Lynney } & \text { I can't remember who said } \\ \text { Sue } & \text { Stacey, I bet } \\ \text { Nicolle } & \text { I'll batter Stacey } \\ \text { Lynney } & \text { Well I don't know that it was her, different people tell me } \\ \text { Sue } & \text { different things. What was I going to say? }\end{array}$

The child who had provided me with the information had clearly overstepped a boundary. Interestingly in a subsequent interview Lynney returned to the issue of trust when she and Stacey $\mathrm{B}^{153}$ decided to interview me:

Lynney Do you trust the kids in this school?

\footnotetext{
${ }_{153}$ Stacey B was not one of the 17 children I had parental permission to interview. See the list of children Appendix 2. Her comments have been included to make sense of the dialogue. See 3.4.1 for discussion on issues of consent.
} 


$\begin{array}{ll}\begin{array}{l}\text { Sue } \\ \text { Lynney }\end{array} & \text { Trust in what way? } \\ \text { Sue } & \text { Like would you trust them with your bag? } \\ \text { Lynney } & \text { (not audible)... big place...tempting somebody } \\ \text { Stacey B } & \text { And your bag was just there or on the table or something } \\ & \text { and you said 'I'm just going to go and make a cup of tea', } \\ & \text { would you trust them to leave your bag here or would you } \\ & \text { take it with? } \\ \text { Sue } & \text { I'd probably take it with me, because it would just horrible if } \\ & \text { something did happen wouldn't it so it's better for me to } \\ & \text { take the responsibility. } \\ \text { Both } & \text { Ummm } \\ \text { Stacey B } & \text { If you have personal stuff in your bag or something and they } \\ & \text { looked inside you bag? } \\ \text { Sue } & \text { But would you look in somebody's bag? } \\ \text { Both } & \text { No }\end{array}$

Within the interview, the girls identified two concerns that I actually had regarding leaving personal property alone with children. The first was that they could have stolen things and the second was that I might have had things in my bag that I did not want children to see. My concern about theft was less to do with losing items than the impact that it could have on the perpetrator, hence my feeling regarding my own responsibility. I was more concerned that children did not see my personal things which might have revealed aspects of my identity that I did not want them to know about. For example, cigarettes in my bag would have definitely revealed that I was a smoker. This was a question the children had asked me, but to which I replied evasively 'only occasionally'.

Whilst Lynney and Stacey B asked me about how much I trusted children, they appeared to have been unconsciously questioning how much they could trust me to trust them. This seemed similar to assessing how much they 
could trust me with their behaviour and 'secrets' and how did I, as an adult, treat children ${ }^{154}$

My non-conforming behaviour may have marked me out as a different kind of adult, certainly in the context of the school. As such it seemed that some children felt more relaxed around me and developed an interest in exploring their contacts with me.

\subsection{Blurring child-adult boundaries}

Whilst the children appeared to construct the majority of their interactions with me in the light of familiar contextual adult roles, there were some who seemed to consider that there might be possibilities for a different sort of relationship with me, as an adult.

Although some of the children in Swinburn Primary School appeared to merely tolerate my contact with them, others indicated an interest in engaging with me. There were interviewees who seemed to consider that I could be included in their worlds, on their terms. Additionally Crombie was one child of appeared interested in exploring how he could engage with me on adult-like terms.

\subsubsection{Inclusion in children's worlds?}

Whilst certain children initiated contact with me through having a conversation or inviting me to play an activity, it seemed that these interactions were child-adult engagements similar to those they had with

\footnotetext{
154 There is further exploration of the children's concerns about the behaviour of adults towards children in 8.2.1 and 8.2.2
} 
other adults within the school. However, there were times when I felt that the children included my in their worlds and on their terms.

When regularly queuing with the children for lunch, I was included in various aspects of the lunch-time culture. Children saved a place for me and I for them, when requested. I also reacted the same way as them if someone pushed in front of me. A regular game I participated in involved saying how old you were from the number on your ticket. That mine was a different colour from theirs' did not appear to be important. Different groupings of children initiated me into their own conventions, such as handing out cutlery or fetching water for each other. Eating lunch was a social time and the children could choose who to sit with and what to talk about. Involving me in their groups was a two-way process, sometimes at their own initiation, at other times through my request:

In the queue for break I had asked some of the boys if I could sit with them at lunchtime. Some said that they went home, but I queued with others. When I had my tray I looked to see where they were. I wasn't sure if they wanted me to sit with them, but I wandered over, having spotted where they were sitting. One beckoned to me. They seemed pleased that I had sat with them.

(Field notes 4: 12/05/04)

I think the boys enjoyed having me sit with them because it gave them an opportunity to talk to me freely. Although the girls spoke to me at break times, most of the boys were not able to as their time was taken up with playing football. Both the boys and the girls asked me questions about myself and about the research as we ate lunch. Aspects of the children's interest in me, as a new adult, may also have been applied to a new child. For whilst the children clearly recognised my embodiment and status as an adult, I considered that if I sought greater involvement in their worlds, I would have 
to pass similar tests to those they applied to new children. Pulling chairs out from under me, kicking balls at me or asking me to go to another child and 'say to bogie face that we want her', all appeared to be child-to-child forms of social assessment.

\subsubsection{Physicality}

In the following incident, which took place in the Children's Project during the summer holidays, the boys appeared to have been testing the degree to which I would participate in their activities:

At one point they [John B, John A and Stitch] all got in the Wendy House and said for me to get in too. I started trying to squeeze in, but said that there wasn't enough room. 'Yes there is' they replied, but as soon as I arrived they all climbed out of the window.

(Field notes 27: 22/7/04)

A willingness to participate in physical games, even if you were not very good, seemed to be another form of implicit child-to-child testing. The children invited me to play chase with them even though I stated that I was not very fast. Yet, because I had at least tried to catch them, the girls then ran more slowly and I managed to tag one of them. Sometimes children in Swinburn Primary School appeared unsure as to whether they should have been engaging in physical play with me, as an adult:

At one point two boys were chasing each other and trying to hide behind me. One asked if he could push me, but before I could reply he had pushed me. I think that he had thought of asking because I am an adult, but he pushed me anyway, as if I was a child.

(Field notes 11: 31/5/04)

However, on other occasions my presence next to, and interest in, physical activities may have indicated a willingness to be involved: 
I noticed Stitch, John A, Joey, Courtney and Stacey B messing around in the corner [of the astro-turf]. The boys were trying to pull the girls over. They were all jumping on top of each other. I wandered over and got attacked. 'Teddy intruder' John A and Stitch cried as they grabbed my ankles. As I joined in, falling to the ground, the play got rougher between the children and although they were gentler with me I had to watch that I didn't get rough. I decided to leave, and return to watching the football.

(Field notes 21: 1/7/04)

After this event, John A and Stitch were 2 children who turned up to meet with me in the summer holidays. Their motivation was possibly having something to do and an opportunity to play, rather than necessarily to engage with the research.

A different form of engagement occurred on a visit to John A's and Crombie's houses to obtain parental permission. Discovering that I had been to other children's houses ${ }^{155}$ they invited me to come to theirs'. Having spoken that day about 'The Minge' they asked if I wanted to see it and I replied affirmatively.

[On leaving the school we walked down the road and] John A and Crombie asked if I would be okay climbing over a fence. I said that I didn't really have the right shoes on, but they said that they would be alright. One of them said 'Run' as we passed by the house of the man they said shouted at them, but the other one said 'It's okay Sue's here and she's an adult'... We saw men in an open piece of land that we had to go through and the boys were concerned that we would get told off, but we just walked through. Then we went in the back door of Freddie's ${ }^{156}$ stair and ran out the front one.

(Field notes 15: 14/6/04).

\footnotetext{
155 There is more discussion on obtaining consent through visiting children's house in 3.4.1

156 Freddie was a man who lived in their cul de sac. I'm not sure whether this was his real name or that he had been named after Freddie Kruger, a character from the film 'Nightmare on Elm Street'.
} 
The boys seemed to include me as one of the gang as they climbed over and through fences and ran through a block of flats, caught up in the worry that 'Freddie' might catch them. Yet, they also positioned me as an adult, and thought that because I was with them they would not get told off. This was another example ${ }^{157}$ where children considered that the presence of an adult absolved them of responsibility.

My membership of the gang continued as I remained, for half an hour, with John A and Crombie in their cul-de-sac, together with another two other boys:

They asked me if I wanted to play chase and was I fast? ' $N o^{\prime}$ I replied. Then they asked, 'What about climbing on the skip?' I was not keen on the idea, but used the excuse of the unsuitability of my shoes. Crombie climbed on to it and walked round it, using my shoulders as a support. 'What about going back to the Minge?' they asked. I declined and asked them what they normally did... Crombie's mother arrived home. I said hello, and he told her that I had been through 'The Minge'. I felt embarrassed.

(Field notes 15: 14/6/04).

The negotiation that the boys had with me about what we were going to do appeared to relate to the way they would decide on activities with their friends. It did not seem to occur, to them, that some activities might be viewed as inappropriate for a 49 -year-old woman. I had just climbed a fence and run through a block of flats, so why should I not play chase or climb round a skip? In their bantering about male body parts, they did not appear to have been trying to shock me it was just seemed like their everyday chat and they had ignored the fact that I was female and an adult, as Crombie also seemed to have done when speaking to his mother.

\footnotetext{
157 Similar to the boy's getting me to take them to different playgrounds see 7.2.1
} 
Through their acceptance of me into their worlds of play I felt that there was sometimes an expectation for me to loose my adult status and authority. For example, after playing a game of marbles or 'boules' as the children called the game, with John B and another boy ${ }^{158}$ in the playground during break-time, the latter physically threatened John B to get some of his marbles. My intervention, of asking the boy what he was doing, was ignored. I felt powerless, I could have reported the behaviour to a playground assistant or to a teacher, but felt that I would have lost my trustworthiness with the children ${ }^{159}$.

Both girls and girls engaged with me physically, such as Lily and Sarah interlinking arms and playing with my hair and the boys in chase and the 'Teddy Attack'. Such physicality seemed to be an important part of their play. Although I had very little contact with Craig and Matt, ${ }^{160}$ who were the boys most interested in football, this was probably a result of my lack of interest in the game, rather than my female gender. That I was willing to take part in rough games seemed to have enabled particular children to consider including me in their worlds of play. I also wondered whether my inclusion could have been a way of improving an individual's or group's social standing. However, I think in Crombie's case it was more about enjoying my company, if I was willing to participate in his activities, and also his feeling that he could talk to me.

\footnotetext{
158 The boy was from the year group I worked with, but not one of those involved in the interviews.

159 This incident is discussed in relation to researcher role and responsibility in 3.4.3

160 Craig and Matt were two of the boys who decided not to participate in the interviews, but who drew pictures, along with James B, which are included in Chapter 5 .
} 


\subsubsection{A bridge to the adult world?}

Whilst some of the interviewees seemed to want to include me in their child children's worlds, others appeared to have an interest in being involved in adult worlds. This was demonstrated by the choice they made to spend time with the janitor or to help out in other classes, when they were granted privileges for gaining merit marks for work and behaviour. For the children in P6, engagement with me and with the research process could also be viewed as interest in the adult world. Crombie was a child who showed such interest and who also spoke about spending time with different adults:

$\begin{array}{ll}\text { Sue } & \text { [... I It sounds to me that you spend quite a lot of time with } \\ & \text { adults } \\ \text { Crombie } & \text { Aye } \\ \text { Sue } & \text { Mainly? } \\ \text { Crombie } & \text { I feel better with adults than with children } \\ \text { Sue } & \text { Do you, why is that? } \\ \text { Crombie } & \text { I feel safer and better. Just before Christmas I went... with } \\ & \text { my dad to (...) have you heard of them? It's a skate board } \\ & \text { (...) and I quite like them and he took me to one of their } \\ & \text { concerts as one of my Christmas presents } \\ \text { Sue } & \text { And it was good was it? } \\ \text { Crombie } & \text { Aye, I loved it } \\ \text { Sue } & \text { Is that the first time that you have been to a concert? } \\ \text { Crombie } & \text { Aye } \\ \text { Sue } & \text { Was it quite big? } \\ \text { Crombie } & \text { There was over } 72,000 \text { people there }\end{array}$

It seemed that Crombie equated going to a music concert as an adult activity. In the interviews, he made other references to what may be considered adult topics, such as his sister's job in an adult club. As he spoke, Crombie appeared to have been reporting facts. I considered that he might have unconsciously chosen to speak to me about these subjects because he saw 
them to be adult topics. Following the interviews he became an active member of the Research Advisory Group attending 3 out of 4 meetings to develop the questionnaire. He also asked if he could help me with the questionnaires when I went to other schools. I had not really thought of this as a possibility, but after his suggestion negotiated his involvement with the head teacher, also suggesting that one of the girls be selected to join us. On the day arranged, Crombie was still initiating. He had arrived in his school sweatshirt and reminded the head teacher of the visit. This was good forethought because she had actually forgotten. He was also the one to ask what he and Lily were going to do when we got to the other school:

'What are we going to say?' Crombie asked. What would you like to say?' I said. 'About how you have been working with us', Lily replied and Crombie said, 'and about doing the questionnaire.' 'Fine' I said. Even though the introductions were off the cuff Lily and Crombie showed a great deal of confidence standing in front of the class [...] When a few children put their hands up for help Lily and Crombie gave assistance.

(Notes on administering the questionnaire 20/5/05)

I may have added to Crombie's views that involvement in the research process was a mature action, by sending him a letter through the post. He was the only child that I had done this with. The situation arose because of the difficulties I had arranging an individual interview with him, because he was frequently absent on the day I undertook my research. I therefore sent him a letter saying that I hoped that I would see him in school. He turned up when requested and expressed pleasure having received the letter.

It is possible that Crombie's interest in the research stemmed from an apparent realisation that age boundaries could be blurred. He said one of the things he had learned from being involved in the project was that 'older people 
can go to college [...] I thought it was only young people!' It is interesting that on this occasion I was viewed as an older person, whilst on others, as previously mentioned, my age was not acknowledged.

Crombie's involvement with me is interesting as not only did he appear to enjoy spending time talking with me and exploring the nature of the research process, but as discussed in the previous section, he included me in play activities with his friends. This indicates that through our contacts not only had I become a familiar adult to him, but that we had developed a relationship, although I am not sure how he might have categorised it.

\subsection{Conclusions}

The children's relationships with me varied between individuals, over time and according to the context and situation. The children in Swinburn Primary School were adaptable at relating to me according to the different ways I positioned myself in the playground or within formal lessons and in the change from being a participant researcher to an interviewer. In the school context, they seemed to be well attuned to the behavioural expectations for children and adults, within the formal parts of the school building and the school day. However, within the playground, a domain they probably considered as belonging to children, the rules of behaviour were different. Running, shouting, and to some extent pushing other children all took place, without comment from adults. Because of these different rules, apparently being applied to children, it seemed that they were less sure as to what behaviour to expect from adults. 
The children seemed to make choices regarding how they decided to have contacts with an unknown adult. They appeared to have no problem in approaching me, presumably because my presence in school was accepted as legitimate. Such acceptance was also extended outside the premises. Having assessed that I was not a teacher there was a sense of exploration in finding out what type of adult I was, and within the context of the rule-bounded school, what sort of behaviour they could get away with.

For approximately half of the children in the P6 classes it may have been that my status as an adult represented a boundary. Whilst they might have tolerated me as another adult within the school, accepting my presence or assistance with their work, they chose not to initiate interactions with me. For those boys with a keen interest in football my female gender may have led to them being disinterested in identifying with me. Although, this may have been a result of my lack of interest in football rather than my gender, as my willingness to participate in the children's activities, especially those that were physical may have been the reason that Stitch, John B and Crombie did choose to interact with me. For Lily and Sarah it seemed that my gender was an important factor, in the role of a break-time companion, as it allowed the inclusion of the physical contacts of arm holding and hair playing. Although for Angel, the most isolated of the girls, my gender may not have made a difference in her contacts with me because it is likely that she would have appreciated being able to spend time with anyone who listened to her.

Those children who decided to participate in the interview stage of the research seemed to do so because they either felt comfortable with me or they had an interest in research topic, the process or me. Their feelings of comfort may have resulted from the enjoyment of individual contact with an 
adult in the school setting. Recognising that particular times in the school day were for learning rather than for play, it may have been that the children opted for a new, and possibly more interesting, activity than their regular class lessons.

One of the ways in which teachers appear to maintain power over children is by playing a role, maintaining a distance by the use of the formal Mr or Mrs, and by not revealing aspects of themselves. Researchers too may use such structures when seeking to engage with children as a semi-participant (Swain 2005). However, as the children may have viewed my behaviour as different to that of other adults within the school, they seemed to subject me to various 'tests'. The children would not have called it testing, and I doubt if they were conscious of what they were doing, but it seemed that within the hierarchical and rule bound setting of the school they needed to assess how much I was part of the adult hierarchy. One of the ways in which they did this was to allow me access to rule floating, such as James revealing his hidden sweets. Such disobedience is viewed as making secondary adjustments to rules (Corsaro 1997: Thorne 2004b). Having passed the test of not telling on children's rule breaking to adults, they invited or allowed me to participate in their activities. However, their further acceptance of me into their local peer cultures involved my understanding, what other authors (Corsaro 1997; Devine 2002) refer to as, conventions of interpersonal child relations. In this study this included realising the value placed on participating in games, even if you were scared or not very good.

The development of any relationship takes time and is overlain with a range of expectations resulting from previous experiences and contextual boundaries. Within Swinburn Primary School, where relationships between 
children and adults are structurally defined, the ongoing period of the children's contacts with me gave them opportunities to assess and test interactions with an adult, who appeared to behave differently.

Within the context of the research project children in Swinburn Primary School had opportunities to engage in forms of child-adult interactions and relationships that were focused on engagement and negotiation. Individuals explored shifting the power balance in child-adult relations, letting an adult into their worlds and sought engagement with the expectations of the adult world. These shifts seemed to occur at the level of individual interest in the other person and of building a joint activity.

The children's interest in my participation in their worlds and, or, of engaging in what they may have termed 'adult activities' has resonance with Mayall's notion of generational proximity, where child and adult engagement in a 'joint enterprise' appears to 'strengthen the social relationships embedded in it' (1998: 138). This is seen to be one end of a continuum, the other end of which is represented as conflictual social relations between child and adult worlds resulting from their separateness. The relationships between the children in Swinburn Primary School and myself suggested that generational proximity is possible if adults indicate their interest in, and availability to, engage with children. By not separating myself off into an adult world, but through demonstrating an interest their activities, some children were interested in spending time with me.

This chapter has investigated the different forms of the children's engagement, or non-engagement, with me over the period of a year. Whilst such a lengthy period is not generally possible in most research projects, they are potentially possible in other forms of adult-child engagement. 


\section{Chapter 8}

\section{CHILDREN'S CONSTRUCTIONS OF ADULT AND ADULTHOOD}

What do children think about the adults around them and, more broadly, how do they make sense of 'adulthood'? Childhood and adulthood are relational concepts, in that one can only be conceived of in relation to the other (Mayall 2001). As adults, we have developed a range of normative and academic theories on the nature of children and childhood in comparison to ourselves. ${ }^{161}$ We tend to view children as separate and at odds with the adult world and find difficulties in balancing the conceptions of child vulnerability and dependence with those of child competencies and rights. However, there has been comparatively little examination of children's constructions of the nature of adults and adulthood (although, see Mayall 2002 and research with adolescents by Thomson et al 2002; 2004).

In this final substantive chapter, field notes and interview data, together with written responses to questions in the survey are examined to assess the children's perceptions and constructions of adult and adulthood. The chapter sections reflect the range of the children's responses, from their initial constructions of adult in relation to the obvious distinctions of age, size and growth, towards more complex ideas regarding adult behaviour and responsibilities in general, and specifically those towards children. The ways in which children answered the questionnaire point to confusions in defining child and adult. These issues are discussed together with the children's thoughts about adult-child differences, in terms of generation and social grouping. The children also referred to themselves and to other children as

\footnotetext{
${ }^{161}$ As outlined in Chapter 2.2.
} 
moving towards adulthood and also that adulthood could be seen as a movement away from childhood.

The thoughts of one child, James, are predominantly used in the chapter for the philosophical insights they provide. He was the first child to speak to me. On my first day of fieldwork he approached me:

'I know why adults don't listen to children, it's because we don't exist'. He then went on to say: 'I didn't understand a word of what you were saying on Monday, it was too technical, you need to dumb it down for us'. I replied: 'That's interesting, I'll write it down in my notebook'. 'It's not that interesting', he said. I said that it would help my thinking about things. I found myself wondering why when I was trying to acknowledge what he was saying he seemed to be diminishing it. His phrase, 'dumb it down for us' was also curious... He said that if it would help me he was willing to be involved in the research.

(Field notes 1: 30/4/04)

Within this quote, James revealed different elements as to how he viewed child-adult relations: adults ignore children; adults patronise children, but children can be useful to adults. A literal interpretation of his phrase 'too technical' could be that James viewed the research as a technical process with complicated terminology and that children were too 'dumb' to understand it. My own thoughts were that he considered my presentation to be unclear and that he sought a simpler, more straightforward explanation. His particular views suggest a construction of adult as a dominant status, in relation to child, and, whilst, this represented an element of James's experience, he also seemed to be concerned that the nature of adults, and of children, be viewed in individual, rather than group terms.

In concluding the chapter, an examination is undertaken of the ways in which the children used their contacts with, and observations of adults to develop their constructions of adult and adulthood. Examples of this 
knowledge and the process of its formation provide new perspectives on relations between those defined as children and those defined as adults, particularly in relation to the process of becoming an adult as a separation from, and a loss of, childhood abilities and opportunities.

\subsection{Initial constructions of 'adult'}

When, in the interviews, I asked the children 'What is an adult?' their initial responses tended to be the obvious categorical distinctions of age and size. They also implied that becoming an adult involved the process of growth. Variations in responses as to a specific age when a child becomes an adult were also reflected in the survey responses. Within the interviews children also introduced the category of 'teenager' as a means of distinguishing young people, from both themselves, and from adults.

\subsubsection{Age, size and growth}

When he was asked to define an adult Stitch stated 'An adult is a person that is older than you, much older than you, 20 odd'. However, in a prior discussion he initially said 16 years and then, after discussion with John A, concluded '18 when you're an adult, 16 when you're a young adult'. Responses from other interviewees revealed a similar range of ages and confusion over whether there was one age that could be seen to represent adulthood. In the survey children reported that they went swimming, to the cinema, or to the city centre, without adults ${ }^{162}$. Yet, when answering later survey questions ${ }^{163}$, detailing the ages of those who usually accompanied them, they included ages such as 32 , along with those from 16 to 25 . This lack of consistency in

\footnotetext{
162 Survey questions 41, 47 and 53.
}

163 Survey questions 43,49 and 56. 
applying a definition of 'adult' may have resulted from problems with the wording of the questions ${ }^{164}$, but it could have reflected children's uncertainty in defining an adult by their age. A further explanation could be that whilst recognising that their brothers, sisters, cousins, and occasionally parents, who accompanied them, were over 18 years old, the children defined these people by their familial position rather than their adult status. Given the apparent importance of 'family' to the interviewees, ${ }^{165}$ it could be that they considered an individual's connection with them to be more relevant to them than the person's age or status as a child or adult.

Reflection on the range of answers given by the children provoked an awareness of my own uncertainties in defining child and adult. In reexamining the question wording I noted my own lack of consistency in defining adult. For the question: 'Which adults live in your house?'166 I had given 'brothers and sisters over 16 years old' as an answer option. Yet, in categorising the answers to survey questions about places the children went without adults ${ }^{167}$, I had applied the age of 18. My confusion, and that of the children, is not surprising given the various social, legal and developmental concepts used to define adult status within British legislation. A person is considered mature enough to get married at 16, yet not allowed to vote until 18, even thought they may be working and paying taxes. Ages relating to driving a car, buying alcohol or cigarettes, joining the armed forces and criminal responsibilities also vary:

'Rights are allotted to [children] in confusing chronological juxtaposition...The formal markers of adulthood are incongruous -

164 See 3.2.5.

165 Discussed in Chapter 4.1

166 Survey questions 5 and 8

167 Survey questions 40-58 
the product of different historical policy legacies predicated on assumptions about age, dependency and parenting'

(Thomson et al 2004: 219)

A stated difference between children and adults was physical size, as John A said: 'They're tall and children are small' Although, as Lynney pointed out, there was not necessarily a correlation between size and age 'well my cousin, she's 9 and she's about up to there on me and she's got size 6 feet'. It was likely that, being 10 or 11 years old, most of the children had a classmate who was taller than an adult, although Lily and Hayley's concern was that being 'small'168 might have meant that they could be mistaken for being a younger age.

The sense in which Lynney's comments above suggested a measuring process, and an upward physical growth towards adulthood, was indicative of a general sense from the children that they were in the process of becoming adults. It is possible that, had the research been undertaken with younger children, the link between age and size would have been more prominent. Yet, it seemed that defining adulthood was more difficult the closer one got to it.

\subsubsection{Age defined activities}

Given the structure of the education system and organisation of schools, it is unsurprising that children associated the possibility of engagement in certain activities with specific ages. Within Swinburn Primary School a child's age not only defined which class they were in, but also when they ate their lunch, which playground they used, and which activities they could undertake

\footnotetext{
${ }^{168}$ For further details see 6.3.1
} 
after-school. For example, Peter and Stitch spoke of the restrictions they faced as children in P6:

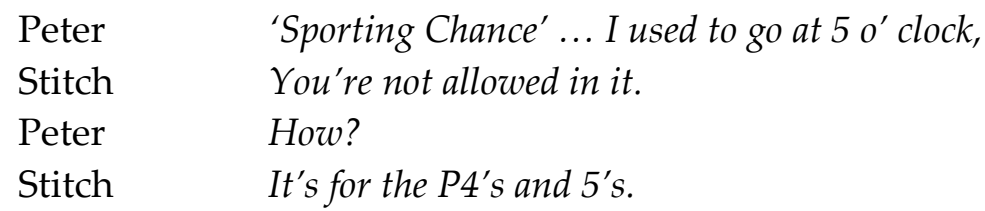

However, whilst they may have felt that they missed out on activities in the present, they looked forward to those they thought they would be able to engage in when they reached High School. Stitch was particularly interested in the idea of being able to make his own computer game, an activity that his older brother told him about. Stitch was a child who seemed to focus more on future activities than did other children. This was possibly as a result of his appearing to face more parental restrictions. For example, he spoke of wanting to visit the cinema but not being allowed to go until he was $13 .{ }^{169}$

In addition, to the children speaking about themselves in terms of future orientation, there was also a sense that they thought about adults in relation to their own past status as children. Thus, whilst the children might have considered themselves to be in the process of becoming adult anticipating the possibilities this could bring, there was a sense that they viewed becoming an adult as a loss of childhood abilities. Interviewees suggested that adults could be distinguished from themselves by their inability to do the things that children could do. For example, Lily said 'adults are nae like that, not that fit to run about, like children can' and whilst Breanna viewed adults as 'more mature' she also thought that 'some of them dinnae know how to have fun'. These comments represent a shift, from the adult-centric view that children lack the competencies of adults, towards a sense that whilst the achievement of

169 See 6.3.2 for more details 
adulthood could open up a greater range of activities, it could also mean a loss of the pleasurable aspects of childhood.

\subsubsection{Teenage}

In addition, to the evident confusion as to whether there was an age at which a child became an adult, the children's references to teenagers indicated the inclusion of a third category of personhood. Teenagers could be viewed to have passed through childhood and were on their way to adulthood, as indicated by Sarah's comment about her cousin. She said that he was '17, 18!' after initially stating that he was 'going to be an adult.' Presumably it was nearing his birthday. When I asked Stitch to define teenage he said '12-15 [years]', however, in speaking about teenagers drinking, in the evenings in the park opposite his house, he later said that they were '14-18 years old'. Although these ages were only specifically used by Stitch in relation to teenage, they are those in everyday usage and ones that were also implied by other children in the study. For instance, Breanna and Courtney spoke of being able to get into category 12 at the cinema because they passed for 'teenagers'. The ages of 12-18 may have been significant for children in their last years of primary school, as the age of 12 represents the start of a new phase of their life, with the transition to secondary school.

Teenagers might have presented actual problems to these younger children in terms of chasing or threatening them, as mentioned by Crombie and Peter ${ }^{170}$. The impact of teenager behaviour also seemed to restrict some children's activities, as Star reflected 'We're not allowed in the park after 8 'cause some people hang about there and they're drinking, teenagers'. Although being viewed as a teenager might have enabled children access to the cinema, the

170 See 8.2.3. 
category was one from which many of the children distanced themselves. Interviewees spoke of the behaviour of teenagers in various negative ways, which included observations of fighting and drinking. Lynney complained about how teenagers sat in a park for younger children and that they were 'spitting at each other and rubbing pooh on it [the play equipment] and they chop the swings down and throw the swings over and smash glass'.

Because of the negative comments made by children during the interviews, the answer option of 'teenagers cause problems', was given for the survey question $^{171}$ that asked the children to give the reasons why they did not like the area where they lived. Their responses indicated that teenagers posed slightly more of a problem for boys (52\%) than for girls (46\%). This difference was likely to be the result of teenagers being seen to represent more of a direct threat to boys, as indicated in the interview accounts of actual experiences. Views expressed in the interviews and survey seem to conform to negative adult stereotypes of adolescence as a separate and problematic stage between the innocence of childhood and the realities of adulthood (Valentine et al 1998; Turner et al 2006).

\subsection{Children's further constructions of 'adult'}

In the following interview, James considered some potential differences between children and adults:

James An adult is just a grown up. A child in a bigger body than a child, because if you think about it everybody's still got a bit of a childhood in them. An adult is really just a child in a big body. That's all.

Sue So what is a child?

${ }^{171}$ Survey question 71 


\begin{tabular}{|c|c|}
\hline James & A child is in a small body. \\
\hline Sue & (laughing) Other ways of describing the difference? \\
\hline James & $\begin{array}{l}\text { We're small, they're right, we're wrong. They're left, we're } \\
\text { right (giggling) I dinnae ken, there's nae much difference if } \\
\text { you think about it. }\end{array}$ \\
\hline Sue & $\begin{array}{l}\text { So do adults treat children differently from how they treat } \\
\text { other adults? }\end{array}$ \\
\hline James & $\begin{array}{l}\text { Uh hum. They think that we're their slaves sometimes. } \\
\text { Sometimes they treat us like normal. }\end{array}$ \\
\hline Sue & $\begin{array}{l}\text { Right so why do you think sometimes they treat children } \\
\text { differently? }\end{array}$ \\
\hline James & $\begin{array}{l}\text { I dinnae ken, (sounding a bit fed up) some of them are } \\
\text { stupid and some of them are quite nice }\end{array}$ \\
\hline Sue & When you say that they treat children normal? \\
\hline Jam & Like other adults, but smaller, mini-adults. \\
\hline
\end{tabular}

From using size as an initial means of differentiating children and adults, James considered other areas of potential difference. The idea of adults 'having a bit of childhood in them' is one that other children also appeared to use as a reference point when speaking about the behaviour of adults, as was that of adult authority and of adults 'being right'. Although, in the interview with James, I prompted the topic of adult treatment of children, it was one that other children spoke about in reference to adult behaviour. This included comments on their experiences and observations of negative adult behaviour towards children, and their views of how children desire to be treated. James' comments indicate that whilst he perceived that there was little overall difference between children and adults, he did acknowledge a range of differences between individual adults. Whilst James's comments did not refer to adult responsibility, it was a topic raised by other children.

\subsubsection{Adult behaviours}

Whilst there were interview references, to adulthood representing a level of maturity, Stacey thought that not all adults might act as such, she said 'An adult's insides have grown properly, like [although] some people have still baby 
brains'. Children in the survey gave details of the types of behaviour that they viewed to be inappropriate for adults. Over a third (36\%) responded affirmatively to the question 'Have you seen any adult (not your parent or school teachers) behaving in ways that you do not think they should?'172 Of the children $(27 \%)$ who chose to give examples, the majority $(15 \%)$ noted drinking, fighting, vandalism, or a combination of these, as negative behaviours. Other examples included smoking, drugs, shouting and swearing. These behaviours are ones that are frequently presented in the media as anti-social. As schoolchildren spend their days surrounded by rules, it is likely that they may have developed a moral critique of bad behaviour from adults, who are themselves critical of children's behaviour and rule breaking. They may also have found some such behaviour frightening. The frequency of such criticism from the children was reminiscent of their capacity for rigid rule application, as exemplified in the novel 'Lord of the Flies'. There were also interesting by 3 children in the survey who saw behaviours such as: 'climbing trees'; 'playing in a puddle' and 'acting like teenagers', as negative. These observations suggested that children saw such behaviours as inappropriate for an adult, because they were activities undertaken by children or teenagers.

Arguing was another type of adult behaviour referred to as negative by children in the study. Not only, might the children have found it unsettling, but it may have represented a lack of maturity, as indicated by Stacey who said that her adult neighbours were 'just like babies' because of the way they argued with each other.

\footnotetext{
172 Survey question 76.
} 
It seemed that the children were particularly aware and critical of adult behaviour that was against 'the rules', in terms of it being socially unacceptable or the type of behaviour that children might be reprimanded for. They seemed to expect adults to 'behave' as in 'behave properly', an instruction children received from parents or school. Whilst the children in this study did not always conform, they were aware of the school rules and of the expectation for socially acceptable behaviour such as being considerate of other people, and of not engaging in behaviour such as arguing. It appeared that they expected adults to set an example for children and to behave appropriately in public, by not fighting or drawing undue attention to themselves by getting drunk or shouting. In particular adults should be aware of how their behaviour affected children.

\subsubsection{Adult behaviour towards children}

In the quotation at the beginning of section 8.2, James said he thought that adults sometimes thought of children as their slaves. He had been talking about his parents getting him to do things in the house and complaining about the way they spoke to him. He also said that they did not take him out enough. Later his comment of 'they should be nice to us once in a while', appeared initially to relate to his views of his parents, but he went on to say 'instead of, 'Oh you get away', like the moany guy in our street'. He also said that adults treated children like dirt, apparently referring to the way that adults in shops ignored them. James's inter-linking of comments on parents, neighbours, shopkeepers and the public suggest that he was not only making a plea to specific individuals to be more considerate and respectful of children, but also to adults as a whole. 
'Moany' was the most common term used by interviewees to describe adult behaviour they did not to like. Breanna considered adults to be 'moanier, some of them are quite moany, more than children', although Lily recognised that it did not apply to all adults:

Adults are a wee bit moany sometimes, and there are adults that aren't moany, and there are adults that are just happy all time, and adults that are really grumpy sometimes.

Whilst the precise meaning of moany was not known, Lily's addition of 'grumpy' gave an indication that the term was applied to people who complained about things. In using it to describe one of the workers in the Girls Club, Breanna, Lily and other girls who attended the club implied that the woman was too controlling in either telling them what to do, telling them off or as Stacey said 'not letting them do stuff'. Peter, Stitch and John A also used it to describe various neighbours and their apparent complaining attitudes.

'Cheeky' was a term used by Lynney and Crombie to describe a form of adult behaviour that was similar to cheeky behaviour by children. Adults seem to apply it to children who they think are not behaving respectfully towards them. In explaining why he thought that a particular woman's behaviour was cheeky Crombie said:

People [children] that have nae got a mum she'll just say 'How's your mum and your dad?'...she knows everyone [and whether they have both parents] and she lies to the police. She'll say; 'I left a TV right here because my friend was coming to collect it'... [She is] annoying and she'll just go up to you and talk about her son.

There seemed to be two reasons why Crombie considered that this, 'nosey woman', as he called her, had acted disrespectfully towards children. Firstly, she had not considered the feelings of children by talking in such a way to 
those who did not have a mother. Secondly, she did not appear to have appreciated that children might not have wanted to hear about her son. Lynney said that the behaviour of a shopkeeper was cheeky because:

'A can of coke was $39 p$ and he says it was $49 p$ he says 'Are you buying any?' [I said] 'No because it's only 39p'. He chucked me out'.

Whilst it was possible that the shopkeeper might have said that Lynney was cheeky to him because she spoke back, she considered him to be 'cheeky' to her in exaggerating the price. Further interpretations of what Crombie and Lynney spoke about were ways in which adults took advantage of their status as adults, as being superior to that of children. As noted previously, in relation to teachers in schools ${ }^{173}$ Lynney was critical of the behaviour of adults towards children. In an incident on a bus Lynney reported that a woman had shouted at her and asked her to give her seat up, Lynney said:

If I was an adult right and I was sitting next to that woman, and that woman spoke to me I'd tell her to shut up...adults will speak to kids like that, but if you were an adult yourself they would nae speak to you like that ...cause adults would hit them back.

Lynney was not only angry about the woman's behaviour towards her as a child, but also that this status meant that she lacked any power to make a response.

The term 'nice' was used as an opposite to moany and appeared to have a broad range of meanings, from okay to friendly and kind. Sarah used the term to apply to adults running clubs. Hayley said her neighbours were nice because 'they let you come in and play with their daughter' and Angel spoke of her aunt being nice because she was given a second chance when she and her siblings had done something wrong. In a similar way, Gums said that his

\footnotetext{
${ }^{173}$ See section 7.1.1
} 
neighbours were nice because 'when you kick the ball in their garden or something they just say, 'Hurry up and get it'. The adults in these cases had all done something considerate for the children or not complained about their behaviour. Within the survey, children also described the people they got on best with ${ }^{174}$ as being nice, kind and friendly.

However, as in the following example from Star, speaking of her aunt and uncle as being nice, the word may not adequately describe the nature of the relationships:

[they] tell me a story and one time I stayed over night ... I was meant to go to school ... and I had a day off and went to Glasgow. ... I got a poncho, new trousers, new tee-shirt and I got the trousers that go with, 3/4 length ones, I got lunch ... we came back to town and went to a Chinese Restaurant for our tea.

The terms nice and moany give a sense of the way in which the children divided adults into two categories. Firstly there were those adults who not only accepted children's behaviour, but were also supportive of them and provided treats and secondly, there were adults who appeared to be intolerant of children.

It could be considered that the division of individual adults into a positive and a negative group enabled the children to predict how to behave around them, and particularly whether to be on their guard, in case they received a 'telling off'. Yet, not all adult behaviour was predicable. It may have been the unpredictable behaviour of one of John A and Crombie's neighbours that led to her being named as 'the witchy woman'. Developing such a construction could be viewed as extreme, and it is not known to what extent the story was told for my entertainment. However, deconstruction enables examination of

${ }^{174}$ Survey question 67 'Out of the adults listed above (question 66) who do you get on best with and why?' 
the elements of adulthood, and particularly of female adulthood that appeared to interest the boys. John A and Crombie began the construction in one interview and, together with Gums, added further embellishments in subsequent meetings with me. Although the application of the term 'witch' to this particular woman may have begun with other children in the neighbourhood, rather than specifically with Crombie or John A, it is likely to have been a child construction, originating from children's literature and visual entertainment. The boys probably referred to this woman as the witchy woman' because she exhibited behaviours they considered to be strange. They reported that she threw water and mice at them, because they were 'playing outside her house'. The water throwing had been an actual incident, because it was mentioned a few times, but the report of mice was unlikely to have been true. It was probably an exaggeration that Crombie made to add effect to the story, and thereby develop the witch myth. It is likely that the boys found the inconsistencies in the woman's behaviour disconcerting, as illustrated by the following incident:

Crombie She'll go like 'Piss off you' and then if we stand there she'll
come back out and she'll go, 'Here have a chocolate biscuit'
and go back in.
She's a nutter. So basically what you are saying is she
comes out gives you a pure bollocking goes back in just for a
chocolate biscuit and comes back out again.

Such inconsistency could be seen to be part of the witch stereotype or archetype: a woman who tempts children and is then horrible to them, although this witchy woman operated the idea in reverse. In seeking to support their view of her as mad, a 'nutter', Crombie drew on adult backing. In recounting situations in which the police were called, he said 'the police just say dinnae go near her, she's mad, she always calls us for no reason'. It may have been that this woman also displayed other characteristics that the boys may 
have viewed as witch-like. It was probable that she lived by herself, without children. She possibly had a certain style of dress and grooming which the children may have considered eccentric. She did not appear to have a cat, but as Gums reported, she did have 'a scruffy wee dog'.

It did not appear that the boys were frightened by this woman and her behaviour, but they found it strange. The archetypes of the witch and other unsavoury characters in fairy stories have historically been used as a means of controlling the boundaries of children's movements and their contacts with unknown people. Although children today have various school programmes promoting messages about 'stranger danger' it appeared that, in this case, the old stories still persisted. As seen in the children's reports on strangers ${ }^{175}$, there seemed to be a tendency for them to interpret the term more in terms of 'strange' rather than 'unknown'. It is interesting to consider why the boys indicated more concern about the inconsistent behaviour of this woman than that of the local character who shouted at people in the street. ${ }^{176}$ The children appeared to have known that this man had mental health problems, but even though the police said that the woman was mad, the boys seemed to enjoy the construction of their witch stories. One explanation could be that whereas they could just walk away from the shouting man, because the woman lived in their cul-de-sac, her behaviour was more noticeable and her complaints had more of a direct effect on their play, particularly when she called the police.

Interviewees indicated a desire for clarity in adult behaviours. They seemed to want to be able to judge whether an individual adult would, or would not, tolerate their presence or behaviour. The construction of the witchy woman

\footnotetext{
175 See 6.2 .1
}

${ }^{176}$ See 5.2 .5 
serves to highlight a difficulty the boys had in not knowing the degree to which their neighbour was tolerant of them, because of her unpredictable behaviour. In apparently finding her strange, presumably compared to other women they knew, they seemed to have exaggerated her characteristics, and created a story about her as an explanation for her strangeness. Whilst, in this case such a construction was that of the boys, there can be wider implications. For example, the application of 'strange', in the sense of deviant, and therefore possibly 'dangerous', to people who look or behave unusually, is one that can lead to the demonisation of individuals (Victor 1998).

The children's construction of adults as tolerant or intolerant, and their apparent expectations of adults to 'behave properly', are reflected in their ideas about the responsibilities that adults should have towards children.

\subsubsection{Adult responsibilities towards children}

Within the category of adult there were individuals and groups who were of varying significance to the children. When, in the paired interviews, I asked them to 'tell me about the adults you know', the children's initial comments about the nature of adults and adulthood focused on child-adult differences. They then began to reflect upon the behaviour of adults, particularly in relation to children. Within this reflection there was a consideration of the similarities and differences between particular groups of adults, as well as between individuals. Parents and teachers were the categories of adult which interviewees made most reference to. This was unsurprising given that the home and school are seen to be the focus of children's lives (Mayall 1998). However, their references to neighbours, people in shops and workers in children's clubs gave a sense of the children's expanding worlds. 
When examining how the interviewees reported adult behaviour towards children there is a sense that they thought that adults had a responsibility towards children. Reports in the survey, ${ }^{177}$ of adult behaviour towards children, and specifically that of parents towards their own children, echoed observations made children in the interviews. The children's references to adult treatment of children appeared to suggest that parents had particular responsibilities, but there were also aspects that were seen as relevant to adults in general. The following two written comments on unsuitable adult behaviour, 'Being drunk and scaring children' and 'Being drunk when they've got children', suggest that although adults have a responsibility to take care of children they may not be able to do so properly if they are drunk. The implications from these comments suggested children viewed that drunkenness could change an adult's behaviour; in a manner that might cause them to frighten children, or mean that they cannot look after them properly or take responsibility for them.

As has been mentioned ${ }^{178}$ children in the survey did not approve of adults arguing. The following two accounts give examples of reasons for this view. Stacey said that she had seen adults in the street arguing and that that they should not have been doing so because 'the [their] kids were at the window'. Sarah also reported an observation from her bedroom window, 'I saw a fight and there's bairns crowding around and my mum had to stop it because the bairns were all seeing'. In these examples, the children appeared to have suggested that adults in general and parents in particular should set an example in their behaviour and also not 'upset' children.

\footnotetext{
177 Survey questions 69 and 76.

${ }^{178}$ See 8.2.1.
} 
Considering children's feelings was a feature in the following account from Courtney of the behaviour of a neighbour towards her young children:

\begin{tabular}{|c|c|}
\hline Courtney & $\begin{array}{l}\text {...they dinnae like understand if they are doing anything } \\
\text { wrong or right }\end{array}$ \\
\hline Sue & Uh huh? \\
\hline Courtney & So she does nae really explain to them that much \\
\hline Sue & $\begin{array}{l}\text { So tell me a bit more because this is quite interesting, what } \\
\text { do you think about this? }\end{array}$ \\
\hline Courtney & $\begin{array}{l}\text { So she's screaming and shouting at these very young } \\
\text { children, who, well she shouldn't be doing it because they're } \\
\text { so young and she just leaves them to cry }\end{array}$ \\
\hline Sue & Uh hum and what should she being doing? \\
\hline Courtney & Comforting them or something \\
\hline $\begin{array}{l}\text { Sue } \\
\text { nice? }\end{array}$ & Uh hum so it sounds like you don't think that it's very \\
\hline Courtney & $\begin{array}{l}\text { I wouldn't like it if I was three years old and she was } \\
\text { screaming at me }\end{array}$ \\
\hline
\end{tabular}

Courtney put herself in the situation of the children in order to empathise with how they might have been feeling and how they may have wanted their mother to behave. She thought that the mother should have explained things to the children rather than shouting at them. John B also implied this view in recounting his observation of an incident in the street. He spoke of seeing a girl being rude to her mother and that her granddad had started punching her and then the girl had sworn. John thought that the granddad should have spoken to her and, 'told her', presumably to stop, rather than hitting her.

These examples, and comments from children in the survey where children reported observing adults hitting or swearing at their own children, revealed similar expectations of parental behaviour to those portrayed by Sarah:

Sometimes they dinnae (answering the question 'how children and adults get on with each other?'). Sometimes the children shout at their own mum and dad and the mum and dad start shouting ... You have to get on good. They have to get on with their bairns or they get put in foster care. If they're not good with their bairns and start hitting them, they're bad. But my mum 
and dad does nae. My mum and dad just says you're grounded, that's all they say.

In referring to her own child-parent relationships, when asked to speak of child-adult relationships, Sarah displayed a common feature in the children's responses, that of speaking about parental relationships, rather than about other adults or adults in general. This tendency suggested that the children used their knowledge of familiar child-adult relationships, particularly the central relationship with their parents, to make sense of the behaviour of other adults.

Within the interviews there was reference to an expectation of support from adults. In Nicolle's case, she spoke about her mother, although she initially began to speak about adults in general:

$\begin{array}{ll}\text { Nicolle } & \begin{array}{l}\text { Because I hate talking to adults about, see when I've been } \\ \text { battered and everything I hate talking to my mum about it } \\ \text { because she just, she does nothing about it she just says go } \\ \text { to their [the other child's] mum and tell them, but their } \\ \text { mum's dinnae really listen, they just say 'oh I'll talk to } \\ \text { him', or 'I'll talk to her'. } \\ \text { Sue } \\ \text { Nicolle }\end{array} \quad \begin{array}{l}\text { I what would you like your mum to do? } \\ \text { go round and tell her son to stop it }\end{array} \\ \text { Sue } & \text { Right so like to stand up for you? }\end{array}$

In this case Nicolle wanted her mother to be more supportive and assertive and do something that would be effective. In the next example she complained about the way her teachers spoke to her and said that she found speaking to me to be different:

Because you discuss things with me and that's the only problem, because my other teacher doesn't... They just say that they are too busy and everything, just to get me out of the way. 
She then described an incident when another child was hitting her and that she told a teacher, who, she reported, had said 'Well I cannae do anything the now'. 'What can I do about it? I'm too busy'. In recounting another time when she had similar problems with the same child and how it had affected her work, she said that she had reported this to the teacher. When the teacher had apparently replied that her work was not good enough, she reported that she had shouted at the teacher. When she had then started crying she said that the teacher was 'trying to be all nicey, nicey'. Nicolle's sarcasm of the teacher's behaviour suggested that she saw it as insincere.

In other instances some children suggested that adults should stand up for them. For example, Crombie and Peter spoke of not liking to use a particular cycle path because they had had experience of being threatened by teenagers whilst using it:

$\begin{array}{ll}\text { Crombie } & \text { Most of them are 13/14, but they just kick you and say 'Get } \\ & \text { out of here or I'm going to really batter you'. } \\ \text { Sue } & \text { So what do the adults do? } \\ \text { Peter } & \text { The adults. } \\ \text { Crombie } & \text { They watch. } \\ \text { Peter } & \text { They stand. } \\ \text { Crombie } & \text { The police don't do anything either. } \\ \text { Peter } & \text { The adults run'cause they're thinking if they try and stop it } \\ & \text { they're going to get battered. }\end{array}$

In this account, the boys appeared to think that the adults should have supported them when they were being threatened, even if they were also anxious. They implied that the provision of such protection was an adult responsibility, and especially one that should be enacted by authoritative figures, such as the police.

The suggestion that adults, because of their age, and authority could protect younger children was made in another account during the same interview. 
Crombie and Peter spoke of playing in the woods at the edge of Swinburn, but that '[the council said] that we're not allowed down to the woods, we have to be with someone that's about sixteen'. Whether or not a council official had actually said this, it was likely that the boys had had an encounter with some kind of official and felt that the person had implied that they were too young to be in the woods unsupervised. At another point Crombie said 'You cannae just go up to a child 'Oh that man tried to get me to have a look at his puppies'179 they would just go, 'Okay' and walk away'. The point he was possibly making was that other children would not be able to provide, or interested in providing, children with the support or help that an adult could. Another child, Lily also suggested that part of an adult's role, in looking after children, was to be aware when children were 'a wee bit worried', and to listen to them. Breanna, in commenting on her experience of the research relationship, said 'you [the researcher] take it slowly, if it's someone else it's all just bluhhh, [what they are saying just] goes in one ear and out the other.' This comment could be interpreted as a suggestion that adults should take their time when speaking to children and possibly an implication that adults might have some responsibility for ensuring that children understand what they are saying. This relates to James's references, made at the beginning of the chapter, suggesting that I 'dumb down' what I was saying to the children. Whilst James and Breanna indicated that they did not always understand what adults were saying, that was not to say that the children felt they were not competent in other areas. For example, Lynney made the following complaints:

Lynney Adults treat us too much like babies.

Sue Uh hum.

\footnotetext{
${ }^{179}$ I believe the reference to puppies comes from the 'Feeling Yes. Feeling No': Personal Safety Programme which the children received at school.
} 
Lynney Unless they're nice adult, but most adults treat us like babies

Sue Right and tell me an example?

Lynney We cannae make a cup of tea, we cannae do this.

Sue Oh really is that the adults in your house?

Lynney No really, my auntie...she'll say 'I cannae believe that I've got an eleven year old making tea and coffee'.

Lynney suggests that she was quite capable of making a cup of tea or coffee, and that she could not understand why her aunt might have been surprised by this. The differences in the views of Lynney and her aunt could be interpreted in generational terms, where children themselves may expect to be viewed as capable and responsible at an earlier age, but also experience more restriction and protection from adults. Whilst they may wish adults to be responsible in their behaviour around children, and to some extent to protect them, this did not appear to be the same as seeing them as incapable, as helpless as 'babies'.

\subsection{Adults as a different generation or social group.}

The last part of this chapter begins with further commentary from James in which he reveals additional constructions of adulthood:

Sue So what do you think that adults might be able to learn from it [the research]?

James

Sue

James

Sue
That children aren't always wee devils, we can sometimes be wee angels and you have to learn more about them than yourself when you were children.

So you have to learn, even though adults have been children, you are saying that they shouldn't really just make assumptions?

Aye.

About what they were like? 


$\begin{array}{ll}\text { James } & \text { Aye 'cause in thae days they could have had five pence for } \\ \text { pocket money and we get five pounds. } \\ \text { Sue } & \text { Uh hum? } \\ \text { James } & \text { So it's like 'Here's like five pence' and you're like 'Where's } \\ & \text { my fiver' 'Oh aye sorry'. } \\ \text { Sue } & \text { So they need to relate it to today? } \\ \text { James } & \text { Aye, like bring it forward fifteen years up to now. }\end{array}$

Previously James had said that he thought that there was little difference between adults and children, and that adults had a bit of childhood in them, but in his comments above he viewed there to be a difference in terms of generation. His recognition that whilst adults were once children, their experiences as such took place at a different point in time, relates to the growing body of theorists (for example; Alanen, Mayall, and Prout) ${ }^{180}$, who consider generation to be a key concept in relations between children and adults. In addition, James's suggestion that adults conceptualise contemporary childhoods in relation to their own is resonant with points made by Philo (2003). The point that James appeared to wish to make was that adults should not assume that they understand children; he thought that, 'they [adults] need to learn more about them [children]'.

James was the only child to make a direct reference to generational differences between childhood and adulthood although Breanna revealed an interest in the past lives of family members in describing conversations with her parents about her grandparents and 'the world war'. There was no direct reference from other children to indicate recognition that their childhoods may have been different from those of their parents. It appeared that they lived in the present, with a view towards the future as a time when they

180 See 2.1.2. 
would be able to do certain things, such as gain admission to certain films officially, or have greater geographical mobility.

Whilst it might initially be considered as surprising that James drew on the dual adult constructions of children, as angels and as devils, used in childhood theory (see Valentine 1996, Scott et al 1998), it is important to consider the context in which he made them. In my experience, the colloquial Scots term 'wee devil', is used in a friendly manner to speak of, or to, children, in reference to their behaviour that is considered to be slightly impudent or cheeky. A child might be called 'a cheeky wee devil' if they were 'insolent, audacious or presuming' (OED) in the way that they spoke to, or acted towards, an adult. In behaving in such a way, it could be viewed that they had overstepped the boundary of respect for adults (Thomson and Holland 2002b). An example of children's views on an adult's reaction to such behaviour was that of Breanna's account of being asked to leave a swimming pool after Star had 'spoken back' to an attendant ${ }^{181}$. It seemed that whilst Breanna accepted the attendant's power to make and to enforce the request, she thought that it had not been justifiable for Star's behaviour. Comments from Crombie and Lynney's about the 'cheeky' behaviour of adults suggested that children had an expectation of two-way respect, and that they did not accept that they should respect adults just because they were of an older generation.

In saying that children were not always 'wee devils' and that they could be 'wee angels', James did not appear to have been applying the binary Apollonian and Dionysian categories as defined by Jones (2001 referring to Jenks 1996) of children as troublesome or of need of protection. It seemed

\footnotetext{
181 See section 6.2.2.
} 
that in his use of contrasting concepts he asked adults to recognise the individuality of every child rather than to categorise them as good or bad. Such a plea for individual recognition was also one he had applied to his own constructions of adult, although other children seem to have been interested in whether a particular adult was good, 'nice', or bad, 'moany.'

In common with James's comment at the beginning of this chapter section, Breanna also thought that adults should learn from children although, children could also learn from adults. She viewed the purpose of the research as:

Just to show children how different adults can be and show adults what we can be like [...] and it's just like basically helping people understand what adults can be like to children and how children feel about it ...[So] adults might realise and not do as much as they normally do, not be as annoying in shops. They might no', like how I was saying about some adults don't know how to have fun.

In Breanna's comments, she suggests that children and adults were separate social groups and there was seemingly a view, among the children, of childhood and adulthood as inhabiting slightly different worlds. The adult world was one that they had limited contacts with, lacking the ability, permission or interest to participate in it. Their knowledge of this other world appeared to have been gained primarily through direct and indirect observation, or their experience of interacting with adults, rather than direct participation. The children's alertness to the behaviour of adults around them has been demonstrated earlier in this chapter, and also in relation to myself.

There was a sense from the children that some thought that they were invisible to adults. Not only had they reported that adults pushed them on the street or in front of them in shops, but that they failed to acknowledge 
their presence. They also gave examples of adult behaviour that they thought some children might not understand or which might upset them, or as in the following example, could be viewed as inappropriate. Stacey reported that she had spent time with her adult neighbours and recounted the way they spoke about each other. On one occasion she said that she had accompanied some of them into a house whilst the owner was on holiday. It appeared that Stacey had viewed her status as somewhat ambiguous. In retelling the incident she had given the impression that not only did she think that the neighbours should not have gone into the house, but that she was not sure why she had been included. Crombie also reported on elements of the life of his sister, her boyfriend and their flatmates. However, in both cases it was not clear whether the children had been bystanders, or if they had consciously been included in the discussions or activities they spoke about. Such examples suggest a possible state of semi-existence in the adult world, children being present, but not fully included; a version of being seen but not heard?

\section{Child-adult friendships}

The following section concerns children's references to spending time with adults and whether they considered friendships between children and adults to be possible. The indication from a few children, that such friendships could exist, provides further insight into the ways in which they define adult in relation to child. Crombie's preference of spending time with adults and of feeling 'better' could be interpreted as feeling more mature in addition to feeling safer. However, whilst he said that he spent a lot of time with adults, Lynney was the only child to say that she had an adult as a friend. She said that she was around adults more than children, except for when she was in school, although she also said that she didn't like adults. It is likely that 
Lynney along with the other children, experienced child-adult relations within the school setting as different from those at home. She may also have experienced a more negotiated child-adult relationship at home due to living with her step-mother and then with her aunts, rather than with her mother. These women may have allowed her more agency and autonomy, than in a mother-daughter relationship. However, her comment of not liking adults ruling her life may also have referred to adults making decisions for her, such as when she had to move away from her father's home. When Lynney, announced, during an interview, that she had an adult friend, Nicolle, who was also present, expressed surprise. She commented that she did not think that it was all right to be friends with an adult. Although Nicolle offered no explanation for her thoughts, she hinted at a distinction between the possibility of child-adult friendships and the advisability of such.

It is not known how Lynney was defining friendship, but some sense can be gathered from the way she described the process of interaction with one of her adult neighbours:

$\begin{array}{ll}\text { Lynney } & \text { Can I tell you something? } \\ \text { Sue } & \text { What? } \\ \text { Lynney } & \text { Sometimes you know when I'm bored I say 'Come out' and } \\ & \text { she goes 'Huh?', and I goes 'Just come out' and then } \\ & \text { sometimes she comes out and sits out the front with me... } \\ & \text { and tells me to play games and the like, tells me how to play } \\ & \text { games and plays games with me. }\end{array}$

It is interesting to consider why the woman responded to Lynney's demanding tone, and also why Lynney appeared to gain a sense of satisfaction from instruction in this situation, when she had previously reported that she did not like adults telling her what to do. It may have been that despite the reference to being 'told' how to play games, what Lynney 
sought to convey was a sense of enjoyment in a one to one, two-way interaction with an adult. The element that seemed important for Lynney was the way in which this neighbour responded to her as an equal person rather than as a child. It is also relevant to note that through her one-to-one engagements with me during the research process, Lynney developed a different position in her view of adults than the one she had started with. When she spoke about what she had learned from the research and from talking with me she said 'How to speak nicely to adults, just a wee bit. Like how to communicate with them a bit better'.

Yet, whilst Lynney had accepted possibilities for communication between children and adults, there was the sense, from other children, that children and adults inhabited different social worlds, with incompatible sets of actions and social expectations. Such thoughts may have underlain Nicolle's apparent reference to the inappropriateness of friendship between children and adults. In the following example, it seemed that although Gums had invited me to play with him he had had certain expectations as to what the rules of engagement between us, as a child and as an adult should be:

One boy [Gums] had been put out of class. I sat down next to him. He made a face at me, I made one back. He asked me to help him colour in his picture. When he started messing around I said that it wasn't fair because I was doing his work. 'So!' he said... At one point he was playing with a $£ 1$ coin and said that if he got heads it was mine. Heads appeared, he gave me the coin and I put it in my pocket. He looked at me and said, 'Give it back'. I asked him if he had been playing with a child whether he would have expected them to give the coin back. He replied, 'But you're an adult'. 'I'm not a teacher', I said. 'No', he returned, 'but you're still an adult'. I gave the coin back.

(Field notes 4: 12/5/04) 
In pocketing the coin I had overstepped Gums' expectations as to how an adult should have behaved. The situation seemed to have given him a specific interest in asserting a belief that adults must play by different rules. In this context he appeared to have felt able to draw a boundary between adult and child, rather than assuming that the power lay with the adult.

\section{$8.4 \quad$ Conclusions}

Adapting an analogy from Jenks (2005: 2) it could be said that whilst the adult' is somehow familiar to the child, they are also somewhat strange. The children in this study, like other children, lived their lives surrounded by adults, in various roles as well as individual personas. Although it seemed that they had not previously consciously considered the nature of adulthood, the process of the study enabled them to begin to express their individual and collective knowledge of the adult world.

It is unsurprising that differences between adults and children were initially viewed in terms of age, development and growth, given the dominance of the psychological model of the life-course (Kelle 2001). Despite academic challenges to this model, it still underlies our educational system, and is part of everyday thinking (Hill and Tisdall 1997; James et al 1998; Scott et al 1998). Whilst the observable difference of physical size was mentioned as a distinction between a child and an adult, there was a realisation that this was not always applicable. It may be that, whilst these children identified people as young and old mainly by their appearance, it was not necessarily possible to identify a person's actual age. Even if age is known, there can still be difficulties in determining a person's adult status. Within the process of thinking about the meaning of adult it appeared that interviewees 
considered further observable differences and began to focus on the behaviour of adults. It could have been that they were drawn to thinking about this because their own behaviour was something that adults commented on.

Examination of individual commentaries within this study has provided insight into children's thoughts in three areas. Those of: adult responsibility towards children; the achievement of adulthood resulting in a loss of childhood and the separation of child and adult worlds.

There was indication from survey respondents and interviewees that they felt that adults had a range of responsibilities towards children in general and particularly as parents towards their own. In broad terms, adults should behave properly by not participating in anti-social behaviour, possibly to set an example to children. Specifically, adults are expected to use their higher status, knowledge and possibly their size, to protect children. However, in enacting this responsibility, interviewees suggested that adults should recognise the competencies of children. Adults need to, as Lynney said 'understand what adults can be like to children and how children feel about it'.

There was an indication from the children's comments that the process of becoming adult seemed to mean a loss of childhood, including the positive aspects of playing and having fun, and that this created a separation between children and adults. Their references to teenage, as a category between those of childhood and adulthood, indicated a sense of recognising the anxiety and ambivalence experienced by adolescents, as found by Gordon et al (2006).

Whilst developing their perspectives on the nature of adult and of adulthood some of the interviewees seemed to have actively considered whether there 
were any real differences between the categories of adult and child. Yet, despite an apparent wish to view adults and children as individuals, it appeared that the children experienced a line, or a boundary, separating them from adults and childhood from adulthood (Cahill 1990). James seemed to recognise that the boundary between the dominant adult and the submissive child was based on the power of adults to define where the line is drawn. However, the views of the children in this study as to where the boundary was placed appeared to be different to where adults might place it. The reference to the cheekiness of adults is one such example where children see adult behaviour as disrespectful, or cheeky towards them, as in the past adults have considered the cheeky behaviour of children as disrespectful to them.

Some interviewees appeared to feel that they lived in a state of semiexistence in the adult world, feeling that they were 'invisible' or 'don't exist. If, as it seemed, the children's primary social contacts were child or family orientated $^{182}$ and that they experienced invisibility in other settings, it was not surprising that their knowledge of the wider adult world was gained through observation rather than participation. Their apparent continual watchfulness of adult behaviour may be a result of trying to understand the adult world, but it may also be due to their experiences of adult control resulting in a continual wariness of being reprimanded for doing something wrong. Yet, whilst the children noticed adult presence, their comments suggested that they did not think that adults were necessarily aware of children's presence, whether it was at windows, as mentioned by Stacey and Sarah, or even in the same space.

\footnotetext{
${ }^{182}$ See Chapter 4
} 
It also appeared to be difficult for the children to construct ideas about an adult without a contextual reference. This can be seen as echoing points that Lee (1999) makes about theoretical and everyday constructions of child and that the nature of childhood and child activity varies within different settings. To develop their thinking about adults, the children sought reference points and used those adult roles and individuals with whom they were most familiar, their parents and school teachers who inhabited the main sites of childhood (Mayall 1994b). Although interviewees spoke about these adults, when asked about other adults, they may have been drawing some implicit comparison between the behaviour, or expected behaviour, of adults that they knew and other, unknown or less familiar adults. The categorisation of individuals, in overall terms, as positive, 'nice,' towards children, or as negative, 'moany' seemed to have enabled them to anticipate how to respond. However, adults whose behaviour was inconsistent, like the witchy woman, seemed to cause confusion.

The calls made by James to view adults as individuals could be interpreted as a personal desire to be seen as himself, rather than as a 'slave', available to undertake adult defined tasks when required, but invisible at other times. Such recognition of themselves as individuals has been displayed by other interviewees. For example, the pleasure Crombie and John B appeared to gain from spending time with their sisters ${ }^{183}$, and Lily being able to choose her own clothes when out shopping with her aunt.

Furthermore, the suggested desire from children for recognition of their individual characters links to findings from Beam et al's (2002) study of those non-parental adults whom adolescents selected as their VIPs (very important

183 See 4.3.3. 
persons). The adolescents choose people who had a combination of positive adult qualities like being able to provide advice and peer-like characteristics of being non-judgemental and fun. The adult VIP's view of their involvement in terms of 'the adolescent being fun to be around' (opt cited), links to James' statement that we all 'still have a bit of childhood in [us]' and suggests that there was recognition by children of the possibilities for greater connection with adults. 


\section{Chapter 9}

\section{CONCLUSIONS AND CONTRIBUTIONS}

This study arose from my personal views regarding the exclusion of children from adult society, and the distance between child and adult worlds. Adult treatment of children, which portrays them alternatively as angels and as devils, reflects a view that children are different from adults and that they may not necessarily be treated fairly (Leach 1994). My interest in elucidating the broad level of relations between children and adults, from the perspective of children, developed from my personal and professional history of working with children. In the introduction, I defined my use of the terms relations and relationships and my premise that a person's actual contacts with individuals of a different social group, influenced their general views of members of that group. The empirical investigation focused on children's reports of their contacts and interactions with a range of adults, and on the nature of their individual connections, or relationships, with relatives and other adults familiar to them. In addition, to interviewing children specifically about the nature of adulthood, I also explored their reports for evidence of their relations with adults and their conceptualisation of them as a different social category.

The first section of this final chapter draws together the key substantive findings from Chapters 4 to 8 in relation to the research aim and objectives stated in Chapter 1: investigating the contacts, interactions and relationships that children living in urban Social Inclusion Partnership (SIP) areas had with various groups of adults, within and beyond their families; considering how these contacts influenced their constructions of childhood and adulthood and their feelings about their status as children. The overall 
conclusion being that children do experience their worlds as separate from those of adults, but that they are interested in the adult world and in having contacts with individual adults.

The contributions that the children's knowledge makes to academia and to related policy debates are highlighted in relation the theoretical discussions raised in Chapter 2. There is then discussion of the methodological conclusions and contributions to the practice of researchers and professionals working with children. The final section of the thesis discusses the overall strengths and weaknesses of the study and concludes with my thoughts on the further areas of study in relation to understanding and improving childadult relations.

\subsection{Exploring child-adult relations and relationships: Drawing conclusions}

This study has explored child-adult relations and relationships from the perspective of individual children, whose childhoods shared particular cultural and generational factors. In cultural terms the children attended schools, and most lived in housing schemes, located within relatively deprived areas of a city. Many had relatives living nearby and knew their neighbours. The children considered that their ages, and stage of schooling placed them at a transitional status, between that of child and that of teenager. Their views of the current different statuses afforded to children, teenagers and adults represents recognition of the social and political construction of generational differences. At this point in time, the beginning of the $21^{\text {st }}$ century, the children were aware of the conflictions between adult 
acceptance of the rights of children together with acknowledgement of their competencies, but also their assumptions of a need to protect children.

The initial focus of the study was on child-adult contacts within local neighbourhoods, including the private settings of children's own homes, the homes of their friends and institutional settings, such as children's clubs. Whilst child-parental relationships were not an initial focus of the study, the references that interviewees made to their parents and to spending time with their families ${ }^{184}$ highlighted the importance of child-parent relations to understanding children's relationships with adults beyond the home and to their constructions of other child-adult interactions. Additionally, interviewee accounts of their movements beyond Swinburn, together with the survey finding that approximately half of those children were also venturing to other areas of the city without adult accompaniment, revealed possibilities for children to have contact with a wider range of adults, in public places and spaces.

This chapter section, grounded in the children's voices, brings together the findings from Chapters 4 to 8 , drawing out the overall conclusions in five areas. Those of: child-adult contacts and interactions; children's individual relationships with adults; children's constructions of 'child' and 'adult'; familial and familiar connections in urban areas of deprivation and children's mobilities in the public world.

\subsubsection{Child-adult contacts and interactions}

The first objective of the study was to investigate children's contacts and interactions with adults within their residential areas. However, as we have

\footnotetext{
184 This was based on general references to undertaking activities with their families, which generally meant their immediate family of parents and siblings.
} 
seen, the findings emphasis the importance of parental and familial relationships and extend beyond local neighbourhoods into the broader public world of the city. The first conclusion, I draw from the children's reports, is that their contacts and interactions with adults can be viewed as a continuum from parental, through familial and familiar to stranger. A key part of children's contact with each of these different categories of adult was the development of knowledge, of 'knowing' them. A second conclusion, which cuts across the individual chapters, is that of proximity and opportunity. In order to develop knowledge of adults, children need opportunities to meet and engage with them. The geographical proximity of neighbours and relatives provided the children with opportunities for various forms of interaction. An individual child's 'ability' to experience contact with unknown adults in public, is also related to the theme of proximity and opportunity. An additional factor relating to the possibilities for children to interact with adults is the way in which the adults, in various contexts, conceptualised the nature of children and childhood. However, as the findings have shown, the children also had particular expectations of adults in different situations. The following section will outline the importance to the children in this study of knowing adults and the functions of proximity and opportunity in this process.

\section{Knowing adults}

The terms 'know' and 'ken'185 seemed to be used by the interviewees in the sense of knowing something about a person, whether it was their name, where they lived or their links to other known people, especially to their parents and friends. As discussed in Chapter 4, the children appeared to have a specific need to establish who counted as members of their family,

\footnotetext{
185 The term 'to ken' is Scots for 'to know'.
} 
including the inclusion of non-familial adults by the ascription of familial terms. The fact that the original meaning of 'familiar' was 'pertaining to one's family or household' (OED) highlights the role that the children's familial and familiar connections played in their sense of belonging and their social identities.

When interviewees spoke of the adults they knew, they not only included people with whom they spent time or who were related to them, but also those who were familiar to them in the context of the neighbourhood. From the ways in which individual children spoke about their daily lives and the people around them, it seemed that they had a detailed knowledge of the lives of familiar others.

Whilst there is concern for children venturing into the public world full of 'unknowns' (Wells 2005), it is interesting that some used the concept of 'knowing' as a means of deciding which 'strangers' they might approach if they need to. People wearing badges or uniforms could be identified and therefore known.

\section{Proximity and opportunity}

Linked to the children's references of knowing a range of familiar adults were their comments on the nature of their contacts. Knowing their neighbours seemed to result from meetings on balcony walkways, or in the street, and of general greetings or because they played with their children. Whilst many of the children reported having regular contacts with their relatives when they 'came for their tea' or 'babysat' them, the fact that many lived within walking distance did not necessarily mean that children visited 
them frequently. Few children spoke of taking opportunities to visit them, other than if they wanted a lift, or to play with their cousin.

Proximity, in terms of the geographical closeness of neighbours and relatives, provided opportunities for the children to have contacts with them. In addition, a child's individual ability to experience proximity to unknown adults in public provided them with opportunities for other child-adult contact. Ability, in this sense, is defined as having parental permission to be out in public, and also their individual feelings and confidence about being in unfamiliar environments and having contact with adults. An additional factor relating to children having an opportunity to experience proximity to unknown adults in public leisure, entertainment and retail venues was whether or not they had friends to accompany them.

\subsubsection{Children's individual relationships with adults}

The second objective of the study was to investigate the nature of children's individual relationships with relatives and familiar adults. The definition of relationship, as used in the introduction to the study, is the existence of a connection between two or more people. As with the previous section on child-adult contacts and interactions, knowing and proximity also played key parts in the children's development of individual relationships with adults. The first conclusion, in relation to individual child-adult relationships, is the importance of children being able to spend time with an adult, without the presence of parents, and of being treated differently, with opportunities for negotiation The second conclusion, regarding relationships with individual adults, is the role that testing and trusting play in the relationship-forming process. 


\section{Time and negotiation}

Although the children did not use the term relationship, the ways in which they spoke of knowing someone and of spending time with them provided a sense of their relationships with adults. The nature of the relationships between the children in Swinburn Primary School and myself provide examples of how, from being an unknown adult, I became known. Through their use of the term 'ken', individual interviewees implied that they knew me, not only in terms of what I was doing, i.e. what my research was and how I was conducting it, but also what I was like as a person. This familiarity occurred through the time they spent in proximity and in engagement with me.

In referring to relationships with particular relatives, individual children spoke of being taken out, being bought things, of having a choice, of being included in the activities of adults, and of enjoying their company. Inclusion and choice suggest that the children's relationships with these adults involved a jointly negotiated process.

\section{Testing and trusting}

Testing was not something that any of the children actually spoke about, but it was very evident in their interactions with me. As those who work in schools or other institutions, or who are parents, know, testing the boundaries of what adults will allow in particular situations appears to be implicit behaviour amongst children. Yet, whilst testing where the limits of my adult power lay was an aspect of the children's interactions with me, they also appeared to be testing out the degree to which I, both as an adult and as an individual, should be allowed to enter not only their domains, but also their worlds. For example, the revealing of forbidden sweets could be viewed 
as testing out my reactions as an adult. However, instructions to pass a rude message onto another child or comments, from several children that 'she doesn't tell' if hit by a ball being deliberately kicked at me, seemed to be the same sort of testing behaviour that children would conduct with other children to assess their suitability for membership of their friendship group. My trustworthiness also appeared to be important to the children; this was implicit in the 'not telling', but was also mentioned directly by two children. However, they phrased their enquiry in terms of whether I trusted children.

\subsubsection{Children's constructions of 'child' and 'adult'}

The third objective of the study was to consider how children's contact, interactions and relationships with different adults, influenced their constructions of 'child', 'adult', 'childhood' and 'adulthood' and their feelings about their status as children, in settings beyond the home and the school.

The children in this study were reaching a transition point in their lives, preparing to move from primary to secondary school and approaching puberty. Their accounts indicated that age was important to them, as it defined those activities they were able to participate in and those they were not. The conclusion drawn from this is that children conceptualise themselves not only as being different from adults, but of inhabiting separate worlds. A second conclusion is that children expect adults to behave differently from other children.

\section{Child and adult worlds}

Interviewees spoke about looking forward to aspects of being older, particularly to having access to goods and services that were currently 
denied to them because of their age. However, they also seemed reticent about approaching adulthood and expressed views that adults, in comparison to children, were less physically fit or less able to have fun. They conveyed the view that child and adult worlds were separate from each other through their watchfulness and interpretations of adult behaviour and by the continual references made by interviewees to other children.

The children's observations of adults suggested their sense of adults having power over them. The fact that adults bumped into them in the street or failed to acknowledge them in shops could have been because of their size, as could the example of the adults' supposed concern about two girls being in the café without adult accompaniment ${ }^{186}$. References to their invisibility and also to adults' negative attitudes and behaviours towards them, suggested that the children viewed adults as seeing themselves as superior.

Within the interviews there was also a sense that the worlds of children living in Swinburn were mainly populated by other children, with adults only being noticeable if their behaviour was particularly friendly or moany, or they were complaining about the children.

\section{Children's expectations of adults}

The children interviewed and those in the survey reported how they thought adults should behave towards children, and this particularly highlighted their distinctions between adults who they thought of as 'nice' and those who were 'moany'. However, how these thoughts influenced the children's actual contact and interactions with adults was sometimes less clear.

\footnotetext{
186 See section 6.3.1
} 
There were references to a belief that adults should protect children because of their size, their status as adults and possibly their parental role. Yet, more broadly speaking, the children had a desire to have their existence

recognised and also their right to be in, and to use, particular places. They felt that they should be able to play in the streets outside their houses without being watched or reprimanded, because such public space belonged to them as well as to the adult residents.

The fact that the children thought adults should 'behave' and be responsible, act responsibly in relation to children, and take responsibility for children may have resulted from their expectations of parents and teachers; adults whom the children used as reference points. Yet, whilst the children saw adults as having a responsibility to be aware of their presence, to listen to them and to understand them, they also had a desire for adults to treat them as they would other adults.

One boy's view that there was little real difference between children and adults indicates a sense that there could be greater connections between children and adults. The children's reflections on what they had learnt from participating in the research, including the ability to communicate more effectively with adults also point to such possibilities.

\subsubsection{Familial and familiar connections in urban areas of deprivation}

Whilst this study was undertaken with children living in urban areas that were relatively deprived, the children made little direct reference to this fact, other than referring to 'schemies', even when specific questions were asked. 
The conclusion drawn from the children's loyalties to their neighbourhoods is the importance to them of knowing local adults and of having friendly adult neighbours, in addition to having friends and relatives living nearby. Although only one interviewee explicitly expressed a view of the importance of good neighbour relations, other interview accounts and survey data suggest that children enjoyed talking to the adults who lived around them, and that they felt they could call on their adult neighbours for support if there was a problem and their parents were not at home.

\subsubsection{Children's mobilities in the public world}

The investigation of children's movements within and beyond their neighbourhoods was not an initial objective of the study. However, reports from children in Swinburn Primary School of visiting relatives, shopping, attending the cinema or of going swimming, suggest a connection between their ability to be mobile and their contacts with adults. Whilst only a proportion of the 10/11 year olds in this study reported moving beyond their neighbourhoods without the accompaniment of adults, there appeared to be a connection between children's independent mobility providing opportunities for autonomy in their choice of contact, interaction and relationships with adults. Having freedom to move beyond their neighbours enabled children make choices in where they wanted to go and who to have contact with.

The themes of proximity and opportunity are continued in this section not only in relation to the process of travel and the distance to particular venues but also regarding the opportunity for the children to experience diversity in environmental and social terms (Dines et al 2006). The children's reports of feeling anxious and uncomfortable in the presence of unfamiliar people, 
when using public facilities, might have arisen from the messages they had received about not speaking to strangers. Whilst these messages appeared to be unrealistic for many children, because of their recognition that they might need to ask a stranger a question, the messages still seemed to influence the thinking of other children about contact with unknown adults. Through their reported observations of the behaviour of adults, they described a world of adult incivilities. Furthermore, the children's awareness of their child status and of the 'prohibitions' facing them, represented barriers to forming connections with aspects of the public world. Some felt that their small stature increased their visibility as children, especially if they were not accompanied by an adult; the resulting behaviour of the adults they encountered appeared to contribute to their belief that children need to be supervised in public spaces (Cahill 1990).

\subsection{The contributions of the study}

This section highlights the contributions the study makes to academia and to public policy. The details of child-adult interactions gathered in this study readdress a tendency in previous studies to focus primarily on child-parent and pupil-teacher relationships. Greater knowledge of informal child-adult relationships can begin to re-direct the former sociological privileging of formal over informal relationships. Such a stance may have reinforced social policies that exacerbated a tendency to view childhood in terms of privatisation, family orientatedness and institutionalisation. A specific contribution of the study, as a whole, is its demonstration that the direct voices of children can challenge us, as adults, not only to reassess our own lay and academic knowledge, but also to bring children's experiences and 'knowledge' (Mayall 2000: 120) more fully into public debates. 


\subsubsection{Contributing to academic knowledge and debate}

There are four specific areas in which the knowledge of the children, who participated in this study, contributes to academic knowledge and debate about children and the social world. These areas are: conceptualisations of childhood; child-adult interactions; neighbourhood relations and children's mobilities in the public world.

The children's reports highlight how their contacts with adults and their experiences of generational relations, influenced their everyday lives and their conceptualisations of themselves as 'children' and others as 'adults' or as 'teenagers'. The fact that they viewed the worlds of children and adults as being separate from each other is unsurprising given the 'othering' of children by adults (Scott et al 1998, Williamson and Butler 1995) and their physical marginalisation (James 1993; Qvortrup 1994; Gillis 2003). It is difficult to say how the degree to which the children's differentiation between child and teenager was influenced by stereotypical adult constructions of teenagers as being problematic (Valentine et al 1998; Turner et al 2006). This study provides particular information of how children gain knowledge about the adult world. Whilst their lives were predominantly child centred, their watchfulness of adult behaviour and of adult incivilities around them enabled them to form constructs not only of adult behaviour, as it is, but how they thought it should be.

This study confirms the proximity of relatives to many children (Brannen et al 2000; Ross et al 2005), and also highlights that the nature of the childrelative contact is predominantly in the company of parents or at least arranged by them. Whilst such contacts seemed to be presented by the children as part of 'being', 'doing' (Morgan 1996; Silva and Smart 1999) and 
'displaying' (Finch 2007) family, few children made autonomous visits to their adult relatives. However, the indication that independent ${ }^{187}$ visits to the homes of adult sisters were important to a few children confirms the suggestion by Gillies and Lucey (2006) of the need for further exploration of sibling relationships and particularly those between child and adult siblings.

Whilst few children appeared to have an individual relationship with a 'very important' non-paternal adult, in the sense that Beam et al (2002) use the term when referring to adolescent selection of supportive adults, there were similarities in terms of particular types of characteristics. The children's references to appreciating adults who listened to, and played with, them and gave encouragement and choice, are similar to characteristics noted by Beam et al (2002) and suggest that these adults acknowledged the desire of the children to be recognised as individuals (Mayall 1994b).

The study confirms the centrality of family to children (Crow and Allan 1994) and their recognitions of the 'ordinary complexity of kinship' (Mason and Tipper 2006). In addition, it highlights the importance to children of having links between family, friends and neighbours (Crow and Allan 1994), in terms of connections over time and of shared biographies (Mason and Tipper 2006). Knowing people in the neighbourhood, and the children's sense of neighbouring and neighbourliness provide further evidence of the importance of familiarity for the development of feelings of safety, wellbeing and a sense of belonging within a neighbourhood (Forrest and Kearns 2001, Seaman et al 2006).

\footnotetext{
${ }^{187}$ Independent, as meaning without parental accompaniment, although the visit may have been organised by parents.
} 
The children reports, of their experiences of the world beyond the home, school and playground, point to the significance of the notion of 'the street' (Matthews 2003) and that of 'boundaries' (Hill 2005b). Streets were not only the settings for such leisure activities as street play or window shopping, but they also provided the children with a variety of social encounters, and therefore opportunities for increasing their social knowledge, within and beyond their neighbourhoods. Although some children were moving beyond their neighbourhoods in search of leisure, entertainment and retail opportunities, it seemed that others were considering how to negotiate such mobility in terms of parental and their own boundaries of age, space and distance, and risk. Examples were provided of how the children's developing environmental and social familiarity; individual needs and interests; and their sense of self enabled their navigation from the familial to unknown (Spilsbury 2002; Ross 2007). Some children were not 'islanded' (Zeiher 2001b) in their homes, schools or children's clubs and activities. Furthermore and consumerism, specifically as the type of embodied experience discussed by Urry (2003), in relation to co-presence, was an important part of children's leisure time.

The range of movements of these 10/11 year olds was similar to that found in other studies of children's mobilities (Hillman et al 1990; O'Brien et al 2000). Additionally whilst similar areas of activity, such as visiting shopping areas, are mentioned by O'Brien et al (2000), this study provides more detail and extends the discussion of children's mobilities to include the purpose of travel (Axhausen 2002; Urry 2003). Yet, there is a need for further research into children as consumers and their access to leisure, entertainment and retail facilities. 


\subsubsection{Contributing to public policy}

As indicated above, the range of knowledge gained about children in the public world suggests particular implications for public policy in relation to children's access to leisure facilities, and to their presence in public places. In addition, children's use of and views of their neighbourhoods, specifically in areas of deprivation, provide pointers for policies relating to neighbourhood design and consultation. For example, asking children for their ideas for ways in which open neighbourhood spaces might be used more effectively, and for their opinions of cul-de-sacs as living and playing spaces.

The use by 10/11 year olds of swimming pools, cinemas and shopping malls indicates that these may represent transitional spaces, a form of shielding children from the adult world, between their familiar neighbourhoods and the broader public world. The finding that over half of the children in this study spoke of using swimming pools run by the city council, indicated the possible role that free access can provide in encouraging children not only to engage in a physical activity but also to use a facility used by the adult public. Encouraging, rather than restricting, children's use of public environments is seen as a means for enabling people to experience diversity in this case between children and adults, and also as a way of enhancing communities (Dines et al 2006; Mitchell et al 2007). There may be value in local governments developing policies that specifically consider the impact of location and pricing on children's abilities to access such provision. In addition, they could also give consideration to the ways in which officials engage in public consultations with children, as well as with adult public.

In relation to policy formation, the children's knowledge of and ideas about child-adult interactions could be integrated with those of adults, as 
suggested by Turner et al (2006), for the benefit of children as individuals and for the communities in which they live.

\subsection{Methodological findings and conclusions}

In this study, I was as interested in the methodological process of being an adult researcher seeking children's views, as I was in the actual data of their experiences and 'knowledge' (Mayall 2000: 120) of child-adult relations. In seeking to develop a child standpoint methodology, I have highlighted negotiation as a key element of the research engagement, and also explored the idea of the research process as a joint generational enterprise. This has involved reflecting on my adult power, whilst collecting the data, during the writing process and in constructing end products.

Jones refers to the growing interest in and concern for children within society, and therefore the importance of hearing their views in research, but he says, 'we can not fully close the gap between our (adult) views of the world and those of children' (2001: 173). However, the methods used in this study do point to ways in which adults can gain children's viewpoints. The fact that the children interviewed stated the benefits of spending time speaking with an adult researcher highlights the value of participation and talk methods. They considered that the research process had enabled them to improve their communication with adults and also increased adult understanding of the nature and capabilities of children in the world today, rather than in adult memories.

In this study, negotiation with the child participants was an important element of the active construction of research relationships (Christensen and 
Prout 2002). Through providing the children with a range of choices during the participation and interview stages, elements of researcher and adult power were renegotiated. An important methodological finding is the role of play in research with children and in particular the impact that a researcher's willingness to engage physically, in games and activities, can have in the research process. This seemed to be especially important in aiding the research participation of boys, but also in terms of building child-adult relationships.

\subsubsection{Contributing to research debate and practice}

The methodological findings of this study make specific contributions in terms of the value of participation and conversational methods with children, in terms of enabling generational proximity and engagement in a joint enterprise. This is especially so when there is recognition of their autonomy and the process of engagement is negotiated.

The enjoyment children took in spending time talking to an adult and their apparent lack of interest in doing activities, even drawing, that seemed similar to schoolwork, suggests that whilst such activities may be useful, the value of talk as a research method with children should not be overlooked (Harden et al 2000).

The possibilities for positive relationships offered by harmonious 'generational proximity' (Mayall 1998: 138) appear to be significant not only for research engagement, but also for the development of positive adult-child relations. The key element relevant to the development of generational proximity involves an openness and willingness on the part of the adult to cross, rather than maintain, adult-child boundaries. This entails considering issues of power, reciprocity and negotiation. Being able to put oneself in a 
position where there is not a need to take control makes it easier not to take such control. Researchers are engaged in a professional process and need to ensure that their conduct is appropriate for the task and the setting. However, when research is conducted with children, particularly using participant observation methods, some researchers consider adopting roles such as 'least adult' whilst others maintain a distance (Swain 2005). It seems, in part, that where the boundary is placed reflects researchers' experience and personalities. As part of the reflexive process I suggest that researchers need to look at the practices they use to create or maintain a boundary between themselves and children.

\subsubsection{Contributing to 'professional' practice}

Many of the points mentioned above in relation to research engagement with children could be useful to child-adult relationships within other settings such as social work, health, education and youth work. They suggest ways in which opportunities for positive child-adult interactions could be facilitated both for the benefit of children as individuals and for the communities in which they live, or ways negative interactions could be diminished. The findings point to ways in which children can be engaged in public participation and consultation (Mannion and l'Anson 2004). This highlights the value of Percy-Smith's (2006) suggestion of a collaborative and relational model of child participation which is based on dialogue, learning and mutual reciprocity between children and young people and recognition of the processes involved in child-adult interaction. Such a method could also be used with public workers in the transitional spaces used by children and in the broader public world. 


\section{$9.4 \quad$ Concluding thoughts}

This exploratory study has involved the collection and analysis of children's perceptions of their relations and relationships with adults. The fact that focus has been on children living in Social Inclusion Partnership areas, may be seen as a weakness, with questions of the relevancy of the findings to other child-adult relations, such as those between adult and children of different ages and backgrounds. However, the details gained from spending an extended period of time with children in one neighbourhood, can also be viewed as a strength. Methodologically, the study's strengths were the level of participation I allowed myself, was given by the children and allowed by the school staff. The methodological weakness was the design of the questionnaire, where insufficient time had been allocated to piloting.

Future research could examine the relations that older, younger or middleclass children have with adults. This would enable comparisons to be made with the findings from this study. However, I think that value would be gained from ethnographic evaluations of a range of specific child-adult engagements, such as neighbourhood consultations or community events and activities, which would include child and adult views. The results of such studies would provide greater detail of the nature of child-adult interactions as a balance to recent surveys and reports revealing British adults' intolerance and fear of interacting with (Barnardo's 2008; Furedi 2008) children. 


\section{References}

Alanen, L (2000) 'Review Essay. Visions of a social theory of childhood', Childhood 7(4): 493-505.

Alanen, L. (2001a) 'Explorations in generational analysis', in L. Alanen and B. Mayall (eds.), Conceptualizing Child-Adult Relations, London: RoutledgeFalmer.

Alanen, L. (2001b) 'Childhood as a generational condition: children's daily lives in a central Finland town', in L. Alanen and B. Mayall (eds.), Conceptualizing Child-Adult Relations, London: RoutledgeFalmer.

Alanen, L. (2003) 'Childhoods: the generational ordering of social relations', in B. Mayall and H. Zeihler (eds.) Childhood in a Generational Perspective, London: Institute of Education, University of London.

Alanen, L. (2004) Theorising children's welfare presented at WELCHI Network Workshop 1: New perspectives on childhood, University of Leeds 12-13 November 2004.

Alanen, L. and Mayall, B. (eds.) (2001) Conceptualizing Child-Adult Relations, London: RoutledgeFalmer.

Alder, P. A and Alder, P. (1994) 'Social reproduction and the corporate other: The institutionalization of afterschool activities', The Sociological Quarterly 35 (2): 309-328.

Alderson, P. (1995) Listening to Children. Children, Social Research and Ethics, Ilford, Essex: Barnardo's.

Alderson, P. (2004) 'Ethics', in Fraser, S., Lewis, V., Ding, S., Kellett, M., and Robinson, C. Doing Research with Children and Young People, London: Sage.

Alderson, P. and Morrow, V. (2004) Ethics, Social Research and Consulting Children and Young People, Ilford, Essex: Barnardos.

Allan, G. (1996) Kinship and Friendship in Modern Britain, Oxford: Oxford University Press.

Allan, G. (2008) 'Flexibility, friendship and family', Personal Relationships 15: $1-16$. 
Alldred, P. and Burman, E. (2005) 'Analysing children's accounts using discourse analysis', in S. Greene and D. Hogan, Researching Children's Experiences. Approaches and Method, London: Sage.

Anderson, S, Bromley, C. and Given, L. (2005) Public attitudes towards young people and youth crime in Scotland, Scottish Executive Educational Research Programme. Findings No 7.

Arber, S. (2003) 'Gender and generation: Changing pension inequalities over time' in G Allan and Jones Social Relations and the Life Course, Basingstoke: PalgraveMacMillan.

Axhausen, A. (2007) 'Activity spaces, biographies, social networks and their welfare gains and externalities: Some hypotheses and empirical results, Mobilities 2(1): 15- 36.

Backett-Milburn, K., Cunningham-Burley, S. and Davies J. (2003) 'Contrasting lives, contrasting views? Understandings of health inequalities from children in differing social circumstances', Social Science and Medicine 57(4): 613-623.

Backett-Milburn, K. and Harden, J. (2004) 'How children and their families construct and negotiate risk, safety and danger', Childhood 11(4):429-447.

Backett-Milburn, K. Mauthner, N. and Parry, O. (1999) 'The importance of the conditions and relations of project design for the construction of qualitative data: some experiences from collaborative team working', International Journal of Social Research Methodology, 2 (4): 297 - 312.

Balen, R. (2000) 'Listening to children with cancer', Children and Society 14(3): 159-167.

Barnardo's (2008) The shame of Britain's intolerance of children Press releases 17/11/2008 http://www.barnardos.org.uk/news_and_events/media_centre

Barker, J. (2006) 'Are we there yet?': Exploring aspects of automobility in children's lives, PhD Thesis, dspace.brunel.ac.uk. http://hdl.handle.net/2438/432 (accessed 12/11/07)

Barker, J. and Smith, F. (2001) 'Power, Positionality and Practicality: Carrying out Fieldwork with Children', Ethics, Place and Environment $4(2): 142-147$ 
Barker, J. and Weller S. (2003) 'Never work with children?': The geography of methodological issues in research with children', Qualitative Researcher 3(2): 207-227.

Beam, K., Chen, C. (2002) 'The nature of adolescents' relationships with their 'very important' non parental adults', American Journal of Community Psychology 30(2): 305-325.

Blaikie, N. (2000) Designing Social Research, Cambridge: Polity.

Blanchet-Cohen, N. and Rainbow, B. (2006) 'Partnership between children and adults? The experience of the International Children's Conference on the Environment', Childhood 13(1): 113-126

Blyth D. A., J. P. Hill, et al. (1982) ‘Early adolescents' significant others: Grade and gender differences in perceived relationships with familial and nonfamilial adults and young people', Journal of Youth and Adolescence 11(6): 425-450.

Borland, M., Laybourn A., Hill, M., and Brown, J. (1998) Middle Childhood: The Perspectives of Children and Parents, London: Jessica Kingsley Publishers Ltd.

Bostock, L. (2001) 'Pathways of disadvantage? Walking as a mode of transport among low-income mothers,' Health $\mathcal{E}$ Social Care in the Community 9(1): 11-18.

Boyce, I. (2006) 'Neighbourliness and privacy on a low income estate'. Sociological Research Online 11(3) www.socresonline.org.uk/11/3/

Brannen, J. (1999) 'Reconsidering children and childhood: Sociological and social policy perspectives', in E.B. Silva and C. Smart (Eds.) The New Family? London: Sage.

Brannen, J. (2005) 'Mixing methods: The entry of qualitative and quantitative approaches into the research process', International Journal of Social Research Methodology 8(3) 173-184.

Brannen, J. and O'Brien, M. (1995) 'Childhood and the sociological gaze', Sociology, 29 (94): 729-37. 
Brannen, J. and O'Brien, M. (1996) 'Introduction', in J. Brannen and M. O'Brien (Eds.) Children in Families: Research and Policy, London: The Falmer Press.

Brannen, J., Alldred, P. and Jones, D. (1996) 'Children's construction of family and kinship', in J. Brannen and M. O'Brien (eds.) Children in Families: Research and Policy, London: The Falmer Press.

Brannen, J., Heptinstall, E. and Bhopal, K. (2000) Connecting Children: Care and Family Life in Later Childhood, London: RoutledgeFalmer.

Bryman, A. (2006) 'Integrating quantitative and qualitative research: how is it done?' Qualitative Research 6(1) 97-113.

Buchner, P. (1990) 'Growing up in the eighties: Changes in the social biography of children in the FRG,' in L. Chisholm et al., Childhood, Youth and Social Change, London: Falmer

Budd, T., Sharpe, C. and Mayhew, P. (2005) Offending in England and Wales: First results from the 2003, Crime and Justice Survey. Home Office Research Study 275, London: Home Office

Buonfino, A. and Hilder, P. (2006) Neighbouring in Contemporary Britain, York: Joseph Rowntree Foundation.

Cahill, S. (1990) 'Childhood and public life: Reaffirming biographical divisions', Social Problems 37(3): 390-402.

Carsten, J. (2000) Cultures of Relatedness, Cambridge: Cambridge University Press.

Carsten, J. (2004) After Kinship, Cambridge: Cambridge University Press.

Caulfield, C., Hill, M. and Shelton, A. (2005) The Experiences of Black and Minority Ethnic Young People Following the Transition to Secondary. Glasgow: SCRE

Chawla, L. and Malone, K. (2003) 'Neighbourhood quality in children's eyes', in P. Christensen and M. O'Brien (Eds.) Children in the City: Home, Neighbourhood and Community, London: RoutledgeFalmer.

Christensen, P. (2004) 'Children's participation in ethnographic research: Issues of power and representation', Children and Society 18(2): 165-176. 
Christensen, P. and James, A. (2000) Research with Children: Perspectives and Practices, London: Falmer Press.

Christensen, P. and Mikkelsen, M. (2008) 'Jumping off and being careful: children's strategies of risk management in everyday life', Sociology of Health $\mathcal{E}$ Illness 30(1): 122-130

Christensen, P. and Prout, A. (2002) 'Working with ethical symmetry in social research with children', Childhood 9(4): 477-497.

Christensen, P. and Prout, A. (2003) 'Children, places, spaces and generation', in B. Mayall and $\mathrm{H}$ Zeiher Childhood in generational perspective, London: Institute of Education.

Cicirelli, V. G. (1995) Sibling Relationships Across the Life Span, London: Springer

Cocks (2006) 'The ethical maze: Finding an inclusive path towards gaining children's agreement to research participation', Childhood 13 (2): 247-266.

Cockburn, T. (2002) 'Concepts of social inclusion/exclusion and childhoods. Paper presented to Challenging 'Social Inclusion': Perspectives for and from Children and Young People, Conference Paper: University of Edinburgh 4-6 December 2002.

Coffey, A. (1999) The Ethnographic Self: Fieldwork and the Representation of Identity, London: Sage.

Cook, D. (2003) 'Spatial biographies of children's consumption', Journal of Consumer Culture 3 (2): 147-169.

Communities Scotland http://www.communitiesscotland.gov.uk (accessed $11 / 10 / 07)$

Connolly, M. and Ennew, J. (1996) 'Children out of place', Childhood 3(2): 131145.

Corden, A. and Sainsbury R. (2006) 'Exploring 'Quality': Research participants' perspectives on use of verbatim quotations', International Journal of Social Science Research Methods 9: 97-110.

Corsaro, W. (1997) The Sociology of Childhood, Thousand Oaks, CA: Pine Forge Press. 
Corsaro, W. (2000) 'Entering and observing in children's worlds: a reflection on a longitudinal ethnography of early education in Italy', in P. Christensen and A. James (eds.) Researching with Children: Perspectives and Practices, London: Falmer Press.

Cree, V. E., Kay, H. and Tisdall, K. (2002) 'Research with children: sharing the dilemmas', Child and Family Social Work, 7(1): 47-56.

Crow, G. and Allan, G. (1994) Community Life: An Introduction to Local Social Relationships, Hemel Hempsted: Harvester Wheatsheaf.

Crow, G., Allan, G. and Summers, M. (2002) 'Neither busybodies or nobodies: Managing proximity and distance in neighbourly relations', Sociology 36(1):127-145.

Currie, C. (2001) 'Socioeconomic circumstances among school-aged children in Europe and North America', K. Vleminckx and T. M. Smeeding (eds.) Child Well-Being, Child Poverty and Child Policy in Modern Nations, Bristol: Policy Press.

Danaher, T. and Briod, M. (2005) 'Phenomenological approaches to research with children', in S. Greene and D. Hogan, Researching Children's Experiences. Approaches and Methods, London: Sage.

Davis, J. M. (1998) 'Understanding the meaning of children: A Reflexive process', Children and Society 12 (5): 325-335.

Davis, J., Watson, N., and Cunningham-Burley, S. (2000) 'Learning the lives of disabled children: Developing a reflexive approach', in P. Christensen and A. James (eds.) Researching with Children: Perspectives and Practices, London: Falmer Press.

David, M., Edwards, R and Alldred, P. (2001) 'Children and School-based Research: 'informed consent' or 'educated consent', British Educational Research Journal 27(3): 347-365.

Denscombe, M. and Aubrook, L. (1992) "It's just another piece of schoolwork': The ethics of questionnaire research on pupils in schools', British Educational Research Journal 18(2): 113-131

Devine, D. (2002) 'Children's citizenship and the structuring of adult-child relations in the primary school', Childhood 9(3) 303-320. 
Dines, N., Cattel, V., with Gesler, W. and Curtis S. ( 2006) 'Public spaces and social relations in East London', Findings Ref 1925, www.jrf.org.uk (accessed1/9/2006)

Edwards, R. (2004) 'Present and absent in troubling ways: families and social capital debates', The Sociological Review 52(1): 1-21.

Edwards, R. and Alldred, P. (1999) 'Children and young people's views of social research. The case of research on home-school relations', Childhood 6(2): 261-281.

Edwards, R., Mauthner, M. and Hadfield, L. (2005a) Children's understanding of their sibling relationships, London: National Children's Bureau for the Joseph Rowntree Foundation.

Edwards, R., Hadfield, L., Lucey, H.and Mauthner, M.(2005b) ‘Who is a Sister and a Brother? Biological and Social Ties', South Bank University: Families and Capital Social Research Group.

Edwards, R., Hadfield, L., Lucey, H. \& Mauthner, M. (2006) Sibling Identity and Relationships: Sisters and Brothers, Routledge, London.

Elsley, S. (2004) 'Children's experience of public space' Children and Society 18: $155-164$.

Ellis, S. (2003) 'Changing the Lives of Children and Older People: Intergenerational Mentoring in Secondary Schools. Intergenerational Mentoring Project: Phase 3 Evaluation Report', The Beth Johnson Foundation/Manchester Metropolitan University.

Emond, R. (2005) 'Ethnographic research methods with children and young people' in S. Greene and D. Hogan, Researching Children's Experiences. Approaches and Methods, London: Sage.

Engel, S. (2005) 'Narrative analysis of children's experience' in S. Greene and D. Hogan, Researching Children's Experiences. Approaches and Methods, London: Sage.

Ensign, J. (2003) 'Ethical issues in health research with homeless youths', Journal of Advanced Nursing Studies 43(1): 43-50. 
ESRC Research Programme. Children 5-16 Growing into the 21 $1^{\text {st }}$ Century. http://www. hull.ac.uk/children5to16programme/

Finch, J. (1987) 'The vignette technique in survey research', Sociology 21(1): 105-114.

Finch, J. (1989) Family obligations and social change, Cambridge: Polity Press in association with Basil Blackwell.

Finch, J. (2007) ‘Displaying families', Sociology 4(1): 65-81.

Forrest, R. and Kearnes, A. (2001) 'Social cohesion, social capital and the neighbourhood', Urban Studies 38(12): 2125-2143.

Fotel, T. and Thomsen, U. (2004) 'The surveillance of children's mobility' Surveillance E Society 1(4) 535-554.

Frello, B. (2008) 'Towards a discursive analytics of movement: On the making and unmaking of movement as an object of knowledge', Mobilities 3(1): 2550 .

Furedi, F. (2008) 'Thou salt not hug'. The New Statesman, 26 ${ }^{\text {th }}$ June 2008.

Gillies, V. (2003) Family and Intimate Relationships: A Review of the Sociological Research. London: South Bank University.

Gillies, V. and Lucey, H (2006) 'It's a connection you can't get away from: Bothers and sisters and social capital'. Journal of Youth Studies 9 (4) 479-493.

Goffman, E. (1971) Relations in public: microstudies of the public order, London: Allen Lane.

Goodenough, T., Williamson, E., Kent, J. and Ashcroft, R. (2003) "What did you think about that': Researching children's perceptions of participation in a longitudinal genetic epidemiological study' Children and Society 17(2): 113-125.

Gordon, T., Holland, J., Lahelma, E. and Thomson, R. (2005) 'Imagining Gendered Adulthood: Anxiety, Ambivalence, Avoidance and Anticipation' European Journal of Women's Studies 12(1): 83-103.

Graham, G. and Hill, M. (2003) Transition to secondary school. Glasgow: SCRE. 
Graue, E. M. and Walsh, D. J. (1998) Studying Children in Context, Thousand Oaks, CA: Sage.

Greene, S. and Hill, M. (2005) 'Researching children's experiences: methods and methodological issues' in S. Greene and D. Hogan, Researching children's experiences. Approaches and methods. London: Sage.

Greig, A. and Taylor, J. (1999), Doing Research with Children, London: Sage.

Guardian (2006) 'Fear of teenagers is growing in Britain, study warns'. http://www.guardian.co.uk/society/2006/oct/23/youthjustice.

Hallden, G. (1994) 'The family - a refuge from demands or an arena for the exercise of power and control - children's fictions on their future families', in B. Mayall (ed.) Children's childhoods observed and experienced, London: Falmer Press

Hallett, C, Murray, C. and Punch S. 'Young people and welfare. Negotiating pathways' in C. Hallett and A. Prout, Hearing the voices of children. Social policy for a new century, London: RoutledgeFalmer.

Hammersley, M. and Atkin, P. (1983) Ethnography: Principles in Practice London: Routledge.

Harden, J. (2000) 'There's no place like home. The public/private distinction in children's risk theorizing of risk and safety' Childhood 7(1): 43-59.

Harden, J., Scott, S., Backett-Milburn, K. and Jackson, S. (2000) 'Can't talk, won't talk: Methodological issues in researching children, Sociological Research Online 5(2).

Hart, R (1979) Children's Experience of Place, New York: Halsted Press.

Highet, G. (2005) Cool with Change, Questionnaire. Centre for Research on Families and Relationships

Hill, M (2005a) 'Ethical considerations in researching children's experiences' in S. Greene and D. Hogan, Researching children's experiences. Approaches and methods. London: Sage.

Hill, M (2005b) 'Children's boundaries: within and beyond families' in L. McKie and S. Cunningham-Burley, Families in society. Boundaries and relationships. Bristol: Policy Press. 
Hill, M. (2006a) 'Children's voices on having a voice. Children's and young people's perspectives on methods used in research and consultation', Childhood 13(1): 69-89.

Hill, M., Laybourn, A. and Borland, M. (1996) 'Engaging with primary aged children about their emotions and well-being: Methodological Considerations', Children and Society 10(2): 129-144.

Hill, M., and Tisdall, K. (1997) Children and Society. Harlow: Addison, Wesley, Longman Ltd.

Hillman, M. (2006) 'Children's rights and adults' wrongs', Children's Geographies, 4(1): $61-67$.

Hillman, M., Adams, J. and Whitlegg, J. (1990) One False Move: a Study of Children's Independent Mobility. London: Policy Studies Institute.

Himmelweit, S. and Sigala, M. (2004) 'Choice and the Relationship between identities and behaviour for Mothers with Pre-School Children: Some implications for Policy from a UK Study', Journal of Social Policy 33 (3): 455-478.

Holloway, S.L. and Valentine, G. (2000) 'Spatiality and the New Social Studies of Childhood', Sociology 34(4): 763-783.

Hood, S., Kelley, P. and Mayall, B. (1996) 'Children as research subjects' Children and Society 10(2): 117-128.

Horne, C., McIlwaine, M. K. and Taylor K.A. (2005) 'Civility and order. Adult social control of children in public places', in C. Morril, D. A. Snow, and C. H. White (eds.) Together alone. Personal relationships in public places, California: University of California Press.

Horsby-Smith, M. (1993) 'Gaining Access' in N. Gilbert, Researching Social Life London: Sage.

Horton, J. and Kraftl , P. (2006) 'What else? some more ways of thinking and doing 'Children's Geographies", Children's Geographies 4(1): 69-95.

Hutchby, I. and Moran-Ellis, J. (eds.) (1998) Children and Social Competence: Arenas of Action, London: The Falmer Press. 
James, A. (1993) Childhood Identities: Self and Social Relationships in the Experience of the Child. Edinburgh: Edinburgh University Press.

James, A. (2001) 'Ethnography in the study of children and childhood', in P. Atkinson, A. Coffey, S. Delamont, and J. Lofland and L. Lofland, Handbook of Ethnography. London: Sage.

James, A., Jenks, C. and Prout, A. (1998) Theorizing Childhood, Cambridge: Polity Press.

Jamieson, L. (2003) 'Friendships and relationships across the lifecourse', CRFR News 3. Centre for Research on Families and Relationships.

Jamieson, L., Morgan, D., Crow, G. and Allan, G. (2006) 'Friends, Neighbours and Distant Partners: Extending or Decentring Family Relationships?' Sociological Research Online, 11, (3).

Jenks, C. (2005) Childhood (2nd Edition) London: Routledge.

Jensen, A. and McKee, L (2003) 'Introduction: Theorising childhood and family change' in A. Jensen and L. McKee Children and the Changing Family: Between Transformation and Negotiation. The Future of Childhood Series. London: Routledge Falmer.

Jones M. and Cunningham, C. (1999) 'The Expanding Worlds of Middle Childhood' in E. K. Teather (ed), Embodied Geographies: Spaces, Bodies and Rites of Passage. London: Routledge.

Jones, O. (2001) “Before the dark of reason': Some ethical and epistemological considerations on the otherness of children', Ethics Place and Environment 4(2): 173-178.

Karsten, L. (2003) 'Children's Use of Public Space: The Gendered World of the Playground' Childhood 10(4)457-474.

Kay, H., Cree, V., Tisdall, K., and Wallace, J. (2003) 'At the Edge: Negotiating Boundaries in Research with Children and Young People', Forum: Qualitative Social Research 4(2).

Kelle, H. (2001) 'The discourse of development'. How 9-12 year old children construct 'childish' and 'further developed' identities within their peer culture' Childhood 8(1): 95-114. 
Kellett, M. and Ding, S. (2004) 'Middle childhood' in S. Fraser, V. Lewis, S. Ding, M. Kellett and C. Robinson Doing Research with Children and Young People, London: Sage.

Kelley, P. Hood, S. and Mayall, B. (1997) 'Children's accounts of risk', Childhood 4(3): 305-324.

Kemp, A., Dean, J. and MacKay, J. (2002) Child Poverty in Social Inclusion Partnerships, Scottish Executive Publications Online http://www.scotland.gov.uk/cru/kd10/blue/crisp-10.asp 17/3/04.

Khan, S. (2006) 'Harnessing the Complexity of Children's Consumer Culture' Complicity: An International Journal of Complexity and Education 3(1): 39-59.

Kirby, P. and Gibbs, S. (2006) 'Facilitating Participation: Adults' Caring Support Roles within Child-to-Child Projects in Schools and After-School Settings', Children $\mathcal{E}$ Society 20 (3): 209-222.

Kit Campbell Associates (2001) Rethinking Open Space, Open Space Provision and Management: A Way Forward, A Report for the Scottish Executive Central Research Unit, Edinburgh: The Stationary Office.

Leach, P. (1994) Children First. London: Penguin.

Lee, N. (1999) 'The challenge of childhood: Distributions of childhood's ambiguity in adult institutions', Childhood 6: 455-474.

Lee, N. M. (2001). Childhood and Society: Growing Up in an Age of Uncertainty. Buckingham: Open University Press.

Lewis, A. and Lindsay G. (2000) 'Emerging Issues', in A. Lewis and G. Lindsay (eds.) Researching Children's Perspective. Buckingham: Open University Press.

Lewis, A. and Porter, J. (2004) 'Interviewing children and young people with learning disabilities: Guidelines for researchers', British Journal of Learning Disabilities 32(4): 191-197.

Leyshon, M. (2002) 'On being 'in the field': practice, progress and problems in research with young people in rural areas', Journal of Rural Studies 18: 179-191. 
Linn, S. (2004) Consuming kids: The hostile takeover of childhood (New York: The New Press).

Lofland, J. and Lofland, L. (1995) Analyzing Social Settings: A Guide to Qualitative Observation and Analysis (3rd ed.), Belmont, CA: Wadsworth.

Lucey, H. and Reay. D (2000) Identities in transition: anxiety and excitement in the move to secondary school, Oxford Review of Education 26(2): 191-206.

Lucus, A. (2003) The Presence of Past in Children's Literatures Westport, CT: Greenwood Publishing.

Lupton, D. (1999) Risk and Sociocultural History, Cambridge: Cambridge University Press

McDonald, R., Shildrick, T., Webster, C., and Simpson, D. (2005) 'Growing up in poor neighbourhoods. The significance of class and place in the extended transitions of 'socially excluded' young adults. Sociology 39(5): 873-893.

McKendrick, J., Coleman, S., Dobson, D., and Robinson, B. (1998), Culture, Gender and Children's Environments, SPA Working Paper 38, School of Geography, University of Manchester.

McKendrick, J., Bradford, N. and Fielder, A. (2000) 'Time for a party: Making sense of the commercialisation of leisure space for children', in S. L. Holloway and G. Valentine (eds.), Children's Geographies, Playing, Living and Learning, London: Routledge.

McNamee, S. (1997) “I won't let her in my room': Sibling strategies of power and resistance around computer and video games', in: J. Seymour and P. Bagguley (eds) Relating Intimacies: Power and Resistance, Basingstoke: Macmillan.

Mcneish, D. and Gill, D. (2006) 'Editorial: UK policy on children: Key themes and implications'. Children's Geographies, 4(1): 1-7.

McVie, S. (2003). Information from Edinburgh Youth Transitions and Crime Study Technical Report Steps 3 and 4, Draft. 
MacDougall, C. Shiller, W. and Darbyshire, P (2005) 'Multiple methods in qualitative research with children: more insight or just more?' Qualitative Research 5(4) 417-436.

Mandell, N (1991) 'The least-adult role in studying children', in F. C. Waksler, Studying the social worlds of children, London: Falmer Press.

Mannion. G. and l'Anson, J. (2004) 'Beyond the Disneyesque: Children's participation, spatiality and adult-child relations. Childhood 11(3): 303-318.

Margo, J., Dixon M., Pearce., N and Reed. (2006) Freedom's children: Raising youth in a changing world. Executive summary, London: IPPR.

Martens, L., Southerton, D., Scott, S. (2004) 'Bringing Children (and Parents) into the Sociology of Consumption: Towards a Theoretical and Empirical Agenda', Journal of Consumer Culture 4(2) 155-182.

Mason, J (1994) 'Linking qualitative and quantitative data analysis', in A. Bryman and R. G. Burgess (eds.) Analysing Qualitative Data, London: Routledge .

Mason, J. (2006a) 'Mixing methods in a qualitatively driven way', Qualitative Research 6(1) 9-25.

Mason, J. (2006b) Real Life Methods Working Papers: Six strategies for mixing methods and linking data.

Mason, J and Tipper, B (2006) Children, kinship and creativity. Working Paper, Morgan Centre for the Study of Relationships and Personal Life, University of Manchester.

Massey, D. (1998) 'Spatial construction of youth cultures', in T. Skelton and G. Valentine (eds.) Cool Place. Geographies of Youth Cultures, London: Routledge.

Masson, J. (2000) 'Researching Children's Perspectives: legal issues' in A. Lewis and G. Lindsay (eds.) Researching Children's Perspective, Buckingham: Open University Press.

Matthews, H. (2003) 'The street as a liminal space: the barbed spaces of childhood', in P. Christensen and M. O'Brien (eds.) Children in the City, Home Neighbourhood and Community, London: RoutlegeFalmer. 
Matthews, H., Limb, M (1999) 'Defining an agenda for the geography of children: review and prospect', Progress in Human Geography, 23(1) 61-90.

Matthews, H., Limb, M., and Taylor, M (undated) Exploring the 'fourth environment': young people's use of place and views on their environment, ESRC Report. Project L12925103.

Matthews, H., Taylor, M., Percy-Smith, B., and Limb, M. (2000) 'The unacceptable flaneur. The shopping mall as a teenage hangout', Childhood, 7(3): 279-294.

Mauthner, M. (1997) 'Methodological aspects of collecting data from children: Lessons from three research projects', Children and Society 11(1): 16-28.

Mauthner, M (2002) Sistering: Power and Change in Female Relationships London: Palgrave MacMillan.

Mauthner, M (2005) 'Distant Lives, Still Voices. Sistering in Family'. Sociology 39(4): 623-642.

Mauthner, M. and Doucet, A. (1998) 'Reflections on a voice-centred relational method in J. Ribbens and R. Edwards (eds.) Feminist Dilemmas in Qualitative Research, London: Sage.

Mayall, B. (1994a) 'Introduction' in B. Mayall, Children's Childhoods Observed and Experienced, London: Falmer Press.

Mayall, B. (1994b) 'Children in action at home and school', in B. Mayall Children's Childhoods Observed and Experienced, London: Falmer Press.

Mayall, B. (1998) 'Children, emotions and daily life at home and at school', in G. Bendelon, and S. J. Williams Emotions in Social Life: Critical Themes and Contemporary Issues, London: Routledge.

Mayall, B. (2000) 'Conversations with Children: Working with generational issues', in P. Christensen and A. James (eds.) Researching with Children. Perspectives and Practices, London: Falmer Press.

Mayall, B (2001) 'Understanding childhood in London', in L. Alanen, and B. Mayall (eds.) Conceptualizing Child-Adult Relations, London: RoutledgeFalmer. 
Mayall, B. (2002) Towards a Sociology for Childhood: Thinking from children's lives, Buckingham: Oxford University Press.

Meire, J. F. (2004) Perils. Pleasures and Parents: Children aged 10-13 on their growing autonomous mobility, The Second European Conference: Child in the City, October 2004, London.

Milburn, K., Fraser, E., Secker, J. and Pavis, S. (1995) 'Combining methods in health promotion research: some considerations about appropriate use', Health Education Journal 54 347-356.

Milne, S (2003) The Adults that Children Know, unpublished Masters Dissertation, University of Edinburgh.

Mishna, F., Antle, B. J. and Regehr, C. (2004) 'Tapping the perspective of children. Emerging ethical issues in qualitative research', Qualitative Social Work 3(4): 449-468.

Mitchell, H., Kearns, R. A. and Collins , D. C. A. (2007) ' Nuances of neighbourhood: Children's perceptions of the space between home and school in Auckland, New Zealand', Geoforum 38(4): 614-627.

Moore, R. (1986) Childhood's Domain: Play and Places in Childhood Development, London: Croom Helm.

Morgan, D. (1996) Family Connections, Cambridge: Polity Press.

Morgan, D.L. (1997) Developing Focus Groups as Qualitative Research (2 ${ }^{\text {nd }}$ Ed.), Newbury Park, CA: Sage.

Morrow, V. (1998) Understanding Families: Children's Perspectives, London: National Children's Bureau.

Morrow, V. (1999a) Searching for social capital in children's accounts of neighbourhood and networks: A preliminary analysis, LSE Gender Institute Discussion Paper Series, No 7.

Morrow, V. (1999b) 'Conceptualising social capital in relation to the wellbeing of children and young people: a critical review,' The Sociological Review 47(4): 744-765. 
Morrow, V. (2000) “Dirty looks' and 'trampy places' in young people's accounts of community and neighbourhood: implications for health inequalities', Critical Public Health 10(2): 141-152.

Morrow, V. (2001) 'Using qualitative methods to elicit young people's perspectives on their environments: some ideas for community health initiatives' Health Education Research, Theory and Practice 16(3): 255-268.

Morrow, V. (2003) 'Improving the neighbourhood for children: possibilities and limitations of 'social capital' discourses', in P. Christensen, and M. O'Brien, Children in the City, London: Routledge Falmer.

Morrow, V. (2004) 'Networks and neighbourhoods: Children's accounts of friendship, family and place', in C Phillipson, G. Allan and D. Morgan (eds.) Social Networks and Social Exclusion, Aldershot: Ashgate Publishing Ltd.

Morrow, V. (2008) 'Ethical dilemmas in research with children and young people about their social environments' Children's Geographies 6(1): 49-61.

Morrow, V. and Richards, M (1996) 'The Ethics of Social Research with Children: An Overview', Children and Society 10(2): 90-105.

Morrow, V. and Connolly, P. (2006) 'Editorial' Children E Society, 20(2): 87-91.

Moss, P. and Petrie, P. (2002) From Children's Services to Children's Spaces: Public Policy, Children and Childhood, London: RoutledgeFalmer

Murphy, E. and Dingwall, R. (2001) 'The ethics of ethnography', in P. Atkinson, A. Coffey, S. Delamont, and J. Lofland and L. Lofland, Handbook of Ethnography, London: Sage.

Nestmann, F. and Hurrelmann, K. (eds.) (1994) 'Child and adolescent research as a challenge and opportunity for social support theory, measurement and intervention: And vice versa', in F. Nestmann and K. Hurrelmann (eds.) Social Networks and Social Supports in Childhood and Adolescence, Berlin: de Guyter.

O'Brien, M. (2003) 'Regenerating children's neighbourhoods. What do children want?' in P. Christensen and M. O'Brien (eds.) Children in the City, Home, Neighbourhood and Community. London: RoutlegeFalmer. 
O'Brien, M, Alldred, P and Jones, D (1996) 'Children's constructions of Family and Kinship' in J. Brannen and M. O'Brien (eds.) Children in Families, London: Falmer Press, 84-100.

O'Brien, M., Jones, D., Sloan, D., and Rustin, M. (2000) 'Children's independent spatial mobility in the urban public realm', Childhood, 7(3): 257-277.

Oldman, D. (1994) 'Adult-child relations as class relations' in J. Qvortrup, M. Bardy, G. Sgritta, H. Wintersberger (eds.) Childhood Matters, Aldershot: Avebury.

Pahl, R. and Spencer, E. (2004) 'Personal communities: Not simply families of 'fate' or 'choice" Current Sociology 52(2): 199-221.

Pain, R., Grundy, S., Gill, S., Towner, E., and Sparks, G. (2005) 'So long as I take my mobile': mobile phones, urban life and geographies of young people's safety', International Journal of Urban and Regional Research 29(4): $841-830$

Penderson, M., Carmen, M., Alcón, G., Moreno Rodriguez, C. and Smith, R. (2004) in Currie C. (ed.) Young People's Health in Context: International report, from the HBSC 2001/02 survey, WHO Policy Series: Health policy for children and adolescents Issue 4, Copenhagen: WHO Regional Office for Europe.

Percy-Smith, B. (2006) 'From Consultation to Social Learning in Community Participation with Young People', Children, Youth and Environments 16(2): 153-179.

Philips, T. and Smith, P. (2003) 'Everyday incivility' Sociological Review 51(1): 85-108.

Philo, C. (2000) 'The cornerstones of my world', Childhood, 7(3): 243-256.

Philo, C. (2003) 'To go back up the side hill: Memories, imaginations and reveries of childhood', Children's Geographies 1(1): 7-23.

Piper, H and Smith, H. (2003) 'Touch' in Educational and Child Care Settings: dilemmas and responses' British Educational Journal 29(6): 179894. 
Pole, C. (2007): 'Researching children and fashion: A embodied ethnography', Childhood 14(1): 67-84.

Pratt, S. and George, R. (2005) 'Transferring friendship: Girls' and boys' friendships in the transition from primary to secondary school', Children and Society 19:16-26.

Prout, A. (2000) 'Children's participation: Control and self-realisation in British late modernity', Children and Society 14: 304-315.

Prout, A. (2002) Participation, policy and the changing conditions of childhood, presented to Challenging 'Social Inclusion': Perspectives for and from Children and Young People, University of Edinburgh 4-6 December 2002.

Prout, A. (2003a) 'Preface' to P. Christensen and M. O'Brien (eds.) Children in the City: Home, Neighbourhood and Community, London: RoutledgeFalmer.

Prout, A. (2005) The Future of Childhood, London: RoutledgeFalmer.

Punch, S. (2002a) 'Research with Children - the same or different from research with adults?' Childhood 9 (3): 321-341.

Punch, S. (2002b) 'Interviewing strategies with young people: The 'secret box', stimulus materials and task-based activities', Children and Society 16(1): $45-56$.

Punch, S. (2004) 'Negotiating autonomy: Children's use of time and space in rural Bolivia. Commentary', in V Lewis, M. Kellett, C. Robinson, S. Fraser and S. Ding The Reality of Research with Children and Young People, London: Sage.

Punch, S. (2007) 'You can do nasty things to your brothers and sisters without a reason': Siblings' backstage behaviour', Children and Society 22: 333-344.

Qvotrup, J. (1994) 'Childhood matters: An introduction', in J. Qvotrup, M. Bardy, G. Sgritta, H. Wintersberger (eds.) Childhood Matters, Aldershot: Avebury.

Rasamussen, K. (2004) 'Places for children - children's places', Childhood, 11 (2): 155-173. 
Rasamussen, K., and Smidt, S. (2003) 'Children in the neighbourhood: The neighbourhood in children', in P. Christensen and M. O'Brien (eds.) Children in the City, Home Neighbourhood and Community, London: RoutlegeFalmer.

Ribbens McCarthy, J., Edwards, R. and Gillies, V. (2000) 'Moral tales of the child and adult: Narratives of contemporary family lives under changing circumstances', Sociology 34(4): 785-803.

Ritala-Koskinen, A. (1994) 'Children and the construction of close relationships: How to find out children's point of view', in J. Brannen and M. O'Brien (eds.) Childhood and Parenthood, London: University of London.

Ritchie, J., Spencer, L. and Connor, W. (2003) 'Carrying out qualitative analysis' in J. Ritchie and J Lewis (eds.) Qualitative Research Practice. A Guide for Social Science Students and Researchers, London: Sage.

Rogers, A. G. (2005) 'Interviewing children using an interpretative poetics in S. Greene and D. Hogan Researching children's experiences: Approaches and methods, London: Sage.

Ross, N. (2002) Making Space: Children's Social and Environmental Geographies, unpublished PhD thesis, University of Dundee.

Ross, N. J. (2007) 'My Journey to School...': Foregrounding the Meaning of School Journeys and Children's Engagements and Interactions in their Everyday Localities'. Children's Geographies 5(4); 373-391.

Ross, N., Hill, M., Sweeting, H. and Cunningham-Burley, S. (2005) Grandparents and Teen Grandchildren: Exploring Intergenerational Relationship Edinburgh: Centre for Research on Families and Relationships.

Rubin, H. J. and Rubin, I. S. (1995) Qualitative Interviewing: The Art of Hearing Data Thousand Oaks, CA: Sage.

Russell, R. and Tyler, M. (2005) 'Brading and Bicolage: Gender, consumption and transition', Childhood 12(2): 221-237.

Sampson R. J., Morenoff, J.D. and Earls, F. (1999) 'Beyond Social Capital: Spatial dynamics of collective efficacy for children, American Sociological Review 64(5): 633-660. 
Scott, S., Jackson, S. and Backett-Milburn, K (1998) 'Swings and roundabouts: risk, anxiety and the everyday worlds of children', Sociology 32(4): 689-705.

Scottish Census Records Online http://www.scrol.gov.uk

Scottish Executive (2004) Protecting Children and Young People: The Charter, www.scotland.gov.uk/childrenscharter (accessed 18/1/2007).

Scottish Government (1999) Social inclusion partnership fund replaces urban programme' Newswebsite 11/03/1999 http://www.scotland.gov.uk/News/ Releases/ 1999 (accessed 11/10/2007).

Scottish Government (2008) See the Person http://www.seetheperson.info/about (accessed 9/7/08)

Scottish Neighbourhood Statistics http://www.sns.gov.uk

Seaman, P., Turner, K., Hill, M., Stafford, A. and Walker, M. (2006) Parenting and Children's Resilience in Disadvantaged Communities, Joseph Rowntree Foundation: National Children's Bureau.

Sheller, M. (2004) 'Mobile Publics: Beyond the Network Perspective', Environment and Planning D: Society and Space 22: 39-52.

Sheller, M. and Urry, J.(2003) 'Mobile transformations of 'public' and 'private' life', Theory Culture and Society 20 (3): 107-125.

Sibley, D. (1995) 'Families, and domestic routines: Constructing the boundaries of childhood', in S. Pile and N. Thrift, Mapping the Subject: Geographies of Cultural Transformation, London: Routledge.

Silva, E. B. and Smart, C. (eds.) (1999) The New Family, London: Sage.

Sin, C. H. (2005) 'Seeking informed consent: Reflections on research practice', Sociology 39(2): 277-294.

Sirota, R. (2001) 'The birthday: A modern childhood socialization ritual' in M. du Bois-Reymond, H Sunker and H. Kruger (eds) Childhood in Europe New York: Peter Lang.

Smallwood, S and Wilson, B. (2007) National Statistics, Focus on Families 2007, Basinstoke: Palgrave Macmillan 
Smart, C. (2006) 'Children's narratives of post-divorce family life: from individual experience to an ethical disposition', The Sociological Review 54 (1): 155-170.

Smart, C., Neale, B., and Wade, A. (2001) The changing experience of childhood: families and divorce, Cambridge: Polity Press.

Smith, D. J. and McVie, S. (2003) 'Theory and method in the Edinburgh study of youth transitions and crime' British Journal of Criminology 43: 169-195.

Smith, F. and Barker, J. (2000) 'Contested spaces: Children's experiences of out of school care in England and Wales', Childhood 7(3): 315-333.

Solberg, A. (1990) 'Negotiating childhood's: Changing constructions of age for Norwegian children', in A. James and A. Prout Constructing and Reconstructing Childhood, London: Falmer Press.

Solberg, A. (1996) 'The challenge of child research: From being to doing', in J. Brannen and M. O'Brien (eds.) Children in Families: Research and Policy, London: The Falmer Press.

Spencer, L., Ritchie, J. and O'Connor, W. (2003) 'Analysis, Practices, Principles and Processes', in J. Ritchie and J Lewis (eds.) Qualitative Research Practice: A Guide for Social Science Students and Researchers, London: Sage.

Spilsbury, J. (2002) “If I don't know them, I'll get killed probably'. How children's concerns about safety shape help-seeking behaviour', Childhood 9(1): 101-117.

Staples T. (1997) All Pals together. The story of children's cinema, Edinburgh: Edinburgh University Press.

Stafford, A. Laybourn, A., Hill, M. and Walker, M. (2003) 'Having a say: Children and young people talk about consultation', Children and Society 17(5): 361-373

Stephen, D. and Squires, P. (2004) “They're still children and entitled to be children': Problematising the institionalised mistrust of marginalised youth', Britain' Journal of Youth Studies 7(3): 351-369. 
Stokoe, E. (2006) 'Public intimacy in neighbour relationships and complaints', Sociological Research Online 11(3) www.socresonline.org.uk (accessed 04/2007).

Such E. and Walker, R. (2004) 'Young citizens or policy objects? Children in the 'rights and responsibilities', Journal of Social Policy 34(1): 39-57.

Swain J. (2005) 'An ethnographic approach to researching children in junior school', International Journal of Social Research Methodology 9(3): 199-213.

Sweeting. H. (1999) Reports from 11 year olds and their parents in respect of their family structures, MRC Medical Sociology Unit Working Paper No. 71.

Sweeting, H. (2004) The West of Scotland 11-16 Study: Teenage Health, University of Edinburgh: 18.

Sweeting, H. and Seaman, P. (2005)' Family within and beyond the household boundary: children's constructions of who they live with' in L. McKie and S. Cunningham-Burley, Families in society. Boundaries and relationships, Bristol: Policy Press.

Symes, C. (2007) 'Coaching and training: A ethnography of student communting on Sydney's suburban trains' Mobilities 2(3): 443-461.

Thomas, M. E. (2005) 'Girls, consumption space and the contradictions of hanging out in the city', Social and Cultural Geography 6(4): 587-603.

Thomas, N. and O'Kane, C. (2000) 'Discovering what children think: Connections between research and practice', British Journal of Social Work 30 (6): 819-835.

Thomsen, T. (2004) 'Children-Automobility's immobilized others?' Transport Reviews 24(5): 515-532.

Thomson, R. and Holland, J (2002a) 'Young people, social change and the negotiation of moral authority', Children and Society 16: 103-115.

Thomson, R., Bell, R., Holland, J., Henderson, S., McGrellis, S. and Sharpe, S. (2002b) 'Critical moments: Choice, chance and opportunity in young people's narratives of transition', Sociology 36(2): 335-354. 
Thomson, R., Holland, J. Hendeson, S and McGrellis, S. (2003) 'Researching childhood: Time, Memory and Method, in G. Allan and G. Jones (Eds.) Social Relations and the Life Course, Basinstoke: Palgrave Macmillian.

Thomson, R., Holland, J., McGrellis, S, Bell, R., Hendeson, S and Sharpe, S. (2004) 'Inventing adulthoods: a biographical approach to understanding youth citizenship', The Sociological Review 52(2): 218-239

Thorne, B. (1980) 'You Still Takin' Notes?" Fieldwork and Problems of Informed Consent, Social Problems 27(3): 284-297

Thorne, B. (1993) Gender Play, New Brunswick, N.J: Rutgers University Press.

Thorne, B (2004a) 'Editorial. Theorizing age and other differences', Childhood 11(4): 403-408.

Thorne, B. (2004b) 'Gender Play: Girls and Boys in School in The reality of research with children and young people', in V. Lewis, M. Kellett, C. Robinson, S. Fraser and S. Ding The Reality of Research with Children and Young People, London: Sage.

Todd J., Smith R., Levin K., Inchley J., Currie D. and Currie C. (2007) Family structure and relationships and health among schoolchildren. HBSC Briefing paper 12. http://www.education.ed.ac.uk/cahru/publications

Turner, K., Hill, M., Stafford, A. and Walker, M. (2006) 'How children from disadvantaged areas keep safe', Health Education, 106(6): 450-464.

Urry, J. (2002) 'Mobility and Proximity', Sociology, Vol. 36(2): 255-274.

Urry, J. (2003) 'Social networks, travel and talk', British Journal of Sociology 54(2): 155-175.

Urry, J. (2007) Mobilities, Cambridge: Polity.

Vaillancourt, P. (1973) 'The Stability of Children's Survey Responses', Public Opinion Quarterly 37(3): 373-87.

Valentine, G. (1996) 'Children should be seen and not heard: the production and transgression of adults 'public space', Urban Geography, 17(3): 205 220. 
Valentine, G. (1997a). 'My Son's a Bit Dizzy.' 'My Wife's a Bit Soft': gender, children and cultures of parenting', Gender, Place $\mathcal{E}$ Culture, 4 (1): 37 -62.

Valentine, G. (1997b) 'A safe place to grow up? Parenting perceptions of children's safety and the rural idyll', Journal of Rural Studies 13: 137-148.

Valentine G. (1997c) “"Oh Yes I Can." "Oh No You Can't": Children and Parents' Understandings of Kids' Competence to Negotiate Public Space Safely', Antipode 29(1): 65-89.

Valentine, G. (1999) "Oh please, mum. Oh please, dad': Negotiating children's spatial boundaries' in L. McKie., S. Bowlby and S. Gregory (Eds.), Gender, Power and the Household, Basingstoke: McMillan Press.

Valentine, G. (2004) Public Space and the Culture of Childhood, Aldershot: Ashgate.

Valentine, G. (2008) 'Living with difference: reflections on geographies of encounter' Progress in Human Geography 32(3): 323-337.

Valentine, G., Skelton, T. and Chambers, D. (1998) 'Cool places. An introduction to youth and youth culture' in T. Skelton and G. Valentine Cool Places: Geographies of Youth Culture. London: Routledge.

Veitch, J., Salmon, J. and Ball, K. (2007) 'Children's Perceptions of the Use of Public Open Spaces for Active Free-play', Children's Geographies, 5(4): 409 422.

Victor, J. S. (1998) 'Moral panics and the social construction of deviant behaviour: A theory and application to the case of child ritual abuse', Sociological Perspectives, 41(3): 541-565.

Waksler, F.C. (1991) Studying the social worlds of children, Sociological readings. Philadelphia: Falmer Press

Weller, S. (2007) 'Sticking with your Mates? Children's Friendship Trajectories during the Transition from Primary to Secondary', Children $\mathcal{E}$ Society 21(5): 339-351

Wells, K. (2005) 'Strange Practices: Children's discourses on transgressive unknowns in urban public space', Childhood 12(4), 495-506. 
West. P., Sweeting, H., and Speed, E. (2001) 'We really do know what you do?: A comparison of reports from 11 year olds and their parents in respect of parental economic activity and occupation', Sociology 35(2) 539559

White, D., Raeside, R. and Barker, D. (2000) Road Accidents and Children Living in Disadvantaged Areas: A Literature Review, Scottish Executive Central Research Unit.

WHO (1998) A World Health Organisation Cross National Survey. Health Behaviours of Scottish Schoolchildren. Questionnaire, Spring 1998 Secondary 4.

Williams, S. and Williams, L. (2005) Space invaders: the negotiation of boundaries through the mobile phone. The Sociological Review 53(2): 314331.

Williamson, H. and Butler, I. (1995) Children speak: Perspectives on their social worlds', in J. Brannen and M. O'Brien (eds.) Childhood and Parenthood, London: University of London.

Willis, G. B. (ed) (2005) Cognitive Interviewing. A Tool for Improving Questionnaire Design, Thousand Oaks, Cal.: Sage Publications.

Wiles, R., Crow, G., Charles, V. A. and Heath, S. (2006) Informed Consent and the Research Process: Following Rules or Striking Balances? Sociological Research Online.

Woolley, H. (2006) 'Freedom of the city: Contemporary issues and policy influences on children and young people's use of public open space in England', Children's Geographies 4(1): 45-59.

Woolley, H., Dunn, J., Rowley, G. and Spencer, C. (1999) Young People and Town Centres, London, Association of Town Centre Management.

Wyness, M. (2000) Contesting Childhood, London: Falmer Press.

Wyness, M. (2006) Childhood and Society. An Introduction to the Sociology of Childhood, Basingstoke: Palgrave MacMillan. 
Wyness, M., Harrison, L. and Buchanan, I. (2004) 'Childhood, politics and ambiguity: Towards an agenda for children's political inclusion', Sociology 38(1) 81-99.

Zeiher, H. (2001a) 'Dependent, independent and interdependent relations: children as members of the family household in West Berlin', in L. Alanen and B. Mayall (Eds.) Conceptualizing Child-Adult Relations, London: RoutlegeFalmer.

Zeiher, H. (2001b) 'Children's islands in space and time: The impact of spatial differentiation on children's ways of shaping social life' in M. du Bois-Reymond, H Sunker and H. Kruger (eds.) Childhood in Europe New York: Peter Lang

Zeiher, H. (2003) 'Shaping daily life in an urban environment', in P. Christensen and M. O'Brien (Eds.) Children in the City, Home Neighbourhood and Community, London: RoutlegeFalmer. 
Appendix 1

Letter to the Director of Education

$2^{\text {th }}$ February 2004

Dear M ...,

\section{Re: Conducting Academic Research in the city of ...'s Educational Establishments}

I am writing to ask for permission to carry out academic research in schools and community education establishments in the city, and for clarification as to the procedures I should follow to make contact with individual establishments.

I am a mature PhD student at the University of Edinburgh working under the direction of Professor Lynn Jamieson and Dr Kathryn Milburn at the Centre for Research on the Family and Relationships.

The focus of my study is child - adult relations in the context of the city's peripheral housing neighbourhoods: (areas were named in the original). My initial

methodological approach is an ethnographic one which will involve me spending time with, and interviewing P6/P7 children in various settings, including a school, out-of-school clubs, as well as open spaces, over a period of six-nine months, (April - December 04). After this I would like to undertake a comparative survey with children in schools in the other peripheral areas. (Research Outline attached)

I have an Enhanced Disclosure Scotland Certificate issued in December 2003, and will ensure that children, parents and education staff are clear as to the purposes and procedures of the research, issues of confidentiality and anonymity. I will obtain informed consent.

I have many years experience of working with children and parents in and out of school (CV attached) and can ensure you that the research will be conducted in a thoroughly professional manner.

Yours sincerely,

Sue Milne 


\section{Appendix 2}

\section{The Children in Swinburn Primary School}

\section{Children who did not participate in interviews:}

In addition to the 17 children who participated in the interviews a further 10 are referred to in this thesis. They did not wish to, or were unable to, gain parental permission to participate in the interviews.

\section{*James B}

James B and his mother gave their initial permission for his participation in the research, but he did not wish to be interviewed. A friend of James' outside school, but in school he spent most of his time with Matt and Craig, particularly playing football. He was keen on playing chess with me in Golden Time.

\section{Stacey B}

Present in the interview with Lynney on 14/1/05. Lynney requested that Stacey attend the interview, because it was Lynney's last day in school. I had agreed pointing out that I was not going to ask her any questions.

\section{Paterson}

Paterson and her mother gave their initial permission for her participation in the research, but she declined to be interviewed. She often spoke to me, making comments on my appearance

\section{Jerry}

She was a friend of James'. I had initially thought that she was a boy as she had short hair and was the only girl in P6 to play football. She was very interested in taking part in the research, but could not obtain parental permission, despite me visiting her house twice at her request.

\section{Girl A}

She informed me that her mother had said that she was not to take part in the research, yet she constantly sought out my company most break times. She was disliked by nearly all of the other children. In P7 she began to spend time with Angel.

\section{Pedro}

His grandmother lived in the same cul-de-sac as Crombie and John A.

\section{Bond}

He said that his father did not like social workers and that he was not allowed to take part in the research. 


\section{*Joey}

He was a boy whom James sometimes spent time with outside school. He appeared not to be interested in football and was not interested in taking part in the research, although he did produce an interesting picture of the neighbourhood. This is included in Chapter4.

\section{*Craig}

He was viewed (by the children) as the 'captain' of the break time football 'team'. He was also a member of the official school team. He was a popular boy and one whom other children considered as the 'cleverest' boy in the year group.

\section{*Matt}

Was a keen football player and friends with Craig and James B.

* The group drawing produced by James B, Craig and Matt is included in Chapter 4, as is Joey's. 


\section{Appendix 3}

\section{List of Transcribed Interviews}

Initial Group/Paired Discussions (6 undertaken but only 3 transcribed)

1. $1 / 6 / 04$

2. $14 / 6 / 04$

3. $14 / 6 / 04$

Paired/Group Interviews (16)

4. ${ }^{*} 15 / 7 / 04$

5. ${ }^{*} 21 / 7 / 04$

6. ${ }^{*} 29 / 7 / 04$

7. $26 / 8 / 04$

8. $26 / 8 / 04$

9. $3 / 9 / 04$

10. $10 / 9 / 04$

11. $17 / 9 / 04$

12. $17 / 9 / 04$

13. $24 / 9 / 04$

14. $24 / 9 / 04$

15. $24 / 9 / 04$

16. $1 / 10 / 04$

17. $8 / 10 / 04$

18. $8 / 10 / 04$

19. $8 / 10 / 04$

Individual Interviews (22)

20. *21/7/04: 10/9/04: 3/12/04

23. *29/7/04: 17/12/04

25. $26 / 8 / 04: 14 / 1 / 05$

27. 15/10/04: 7/1/05

29. $26 / 11 / 04$

30. $26 / 11 / 04$

31. $3 / 12 / 04$

32. $3 / 12 / 04$

33. $3 / 12 / 04$

34. $10 / 12 / 04$

35. $10 / 12 / 04$

36. $10 / 12 / 04$

37. $7 / 1 / 05$

38. $7 / 1 / 05$

39. $14 / 1 / 05$

40. $21 / 1 / 05$

41. $28 / 1 / 05$
James A, Stitch, Peter (+ Bond and Gerry)

Crombie with John A

Gums with John B

John A and Stitch

John A., Stitch, and John B.

Stitch and John B

Lily, Hayley and Nicolle

Lynney with Stacey

John A. and James A

James A and John B

Angel and Star

Breanna, Peter and Gums

Peter and Crombie

Courtney and Breanna

Lynney and Nicolle

Stitch and Peter

Crombie and Gums

Star and Courtney

Lily and Hayley

Sarah

John B

James A

Stacey A

Star

Courtney

Peter

John A

Gums

Hayley

Angel

Nicolle

Lily

Stitch

Lynney

Breanna

Crombie 


\section{Appendix 4}

\section{Individual Interview Topic Guide}

Key Questions

a) Check information on:

- $\quad$ Family members

- $\quad$ Relatives

b) How you spend your time when you are not in school?

1. What do you generally do in the evenings? For example what did you do yesterday after school?

- who with, location?

- After tea?

- Regular daily or weekly things - like clubs - which days?

2. Did anyone visit your house?

3. Are you ever outside late without an adult?

- Time, location?

- How safe would you feel walking alone in the area after dark? (from young person's questionnaire)

4. What do you generally do at the weekend? For example last weekend what did you do?

- outings, visitors, play: where, who?

- normal or special weekend - why?

- regularly activities?

5. Did your parents go out? Who usually looks after you?

- how do you get on with them?

6. If your mum and dad weren't in and you had a problem who would you go to?

c) Places you go to without adults

1. What places do you go to in Swinburn?

- shopping centre without an adult, by yourself?

- If no why not?

- Places don't go to - why not?

2. What do you think about Swinburn?

3. Do you go to the Cinema Which one?

Swimming pool Which one?

Jameston

Main shopping street

4. What other places outside Swinburn do you go to: the woods, other shops, playgrounds, cafés? 
5. How often do you go to the Cinema; Swimming pool; Jameston; Main shopping street

- Last time, who with, younger children?

- How do you get there?

d) Friends

1. Who do you normally play with in school/at home any difference?

2. Who are your best friends?

e) Adults

1. What is an adult?

2. Thinking about all the different adults that you know who are not your parents or school teachers?

- Who is moany and why?

- Who is nice and why?

- Who is friendly and why?

3. Have you seen any adults' behaving in way's that you think that they should not?

4. Do you think that adults treat children differently from the way they treat other adults?

f) Confidence in talking to adults

1. Adults that you know such as your neighbours or parents friends? What do you talk to them about?

2 Have you talked to adults you don't know or asked them for anything? how did you feel?

3. What are your views on talking to strangers?

g) Anything else you want to say about what you think about adults?

h) Your views about the research

1. Do you think that you have learnt anything?

2. What are your thoughts about talking to me: Any differences from talking to other adults?

3. Do you think that the research is important, why? 


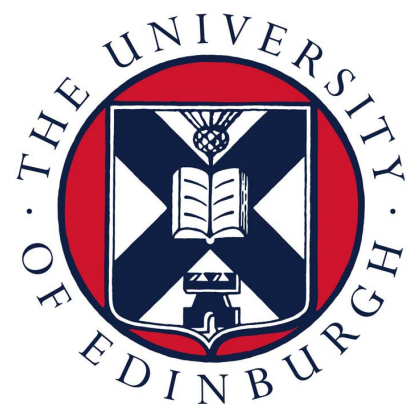

\section{A Survey of the Lives of Children and their Relationships with Adults}

My name is Sue Milne. I am a researcher at the University of Edinburgh. This survey is trying to find out more about the lives of P6 children living in different parts of the city. Children in different schools are all being asked the same questions. All the answers will be put together in a report to give a picture of children's lives to help adults understand children better.

Why P6 children? I have chosen your age group because you are facing a number of changes in your lives, such as moving into P7, thinking about going to High School and becoming a teenager.

As you are getting older you are also probably having contact with different adults. Some questions ask about the adults that you know not your parents or school teachers - and about how well you get on with them.

This is not a test there are no right or wrong answers only what is true for your own life and what YOU think. So please try to answer honestly.

Some of the questions ask about your parents this can be your mum or step mum or your dad or step-dad. When it says sisters or brothers these can also be step or half sisters or brothers.

Please do not put your name on the questionnaire as all the answers that you give are private. I will also not tell any one the names of the schools. If you do not understand anything please ask for help. 


\section{A Details about yourself}

1. Areyou a Girl

Boy

2. How old are you

3. Do you think for your age you look? Please tick ONE only

Older

Younger

Your age

4. Would you describe yourself as Please tick ALL that apply British

Asian

Black

Chinese

White

Other

B Your Family

5. Which adults live in your house?

Mum

Dad

Step-mum/dad's partner

Step-dad/mum's partner

Brothers over 16 years old

Sisters over 16 years old

Any other adults

Who?

6. Do you also live somewhere else some of the time

Yes $\square$ Go to 7
No $\square$ Go to 9

7. How often do you stay at this other house? 
8. Which adults live there?

Mum

Dad

Step-mum/dad's partner

Step-dad/mum's partner

Brothers over 16 years old

Sisters over 16 years old

Any other adults

Who?

9. Do you have any older brothers or sisters who live somewhere else?

No $\square$ Go to 11

Yes sister/s $\square$ brother/s $\square$ How old are they?

10. Do you ever visit any of them without your parents? Please tick which

No $\square$ Yes sister/s $\square$ brother/s

11. Do you have any younger brothers or sisters? No $\square$ Yes

12. Do you have any grandparents?
No
Go to 18
Yes
Go to 13

13. How often do you see your grandparents?

\begin{tabular}{|l|l|l|l|l|l|}
\hline & $\begin{array}{l}\text { Every } \\
\text { day }\end{array}$ & $\begin{array}{l}\text { At least } \\
\text { once a week }\end{array}$ & $\begin{array}{l}\text { Less than } \\
\text { once a week }\end{array}$ & $\begin{array}{l}\text { In the } \\
\text { holidays }\end{array}$ & $\begin{array}{l}\text { Never } \\
\text { see them }\end{array}$ \\
\hline Mum's mum & & & & & \\
\hline Mum's dad & & & & & \\
\hline Dad's mum & & & & & \\
\hline Dad's dad & & & & & \\
\hline $\begin{array}{l}\text { Other } \\
\text { grandparents }\end{array}$ & & & & & \\
\hline
\end{tabular}

14. Do any of your grandparents live nearby (close enough so you can walk to their house)? Yes $\square \quad$ No $\square$

15. Do you ever visit any of them without your parents? No $\square$ Yes $\square$ 
16. Do you have any aunties or uncles?

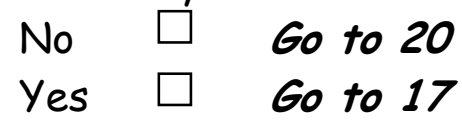

17. How often do you see your aunties and uncles? Please tick ONE box only

I see at least one of them everyday

I see one or more of them at least once a week

I only see any of my aunties and uncles less than once a week

18. Do any of your aunties and uncles live nearby (close enough so you can walk to their house)? $\quad$ Yes $\square \quad$ No $\square$

19. Do you ever visit any of them without your parents?

No $\square$ Yes $\square$

\section{Where you live}

The next questions are about your MAIN house

20. What is the name of the place where your main house is?

21. What is the postcode? don't know

22. Is it? Please tick one a house

a flat

somewhere else

where

23. Do you have a garden/back green? Yes $\square \quad$ No $\square$

24. If yes is the garden just for Please tick one your family shared with other families

25. Do you live in a cul-de-sac (a road where cars have to go out the same way that they come in)?

Yes

No

26. Do you have your own bedroom?

Yes $\square \quad$ No $\square$

27. Do you have the internet in your house? Yes $\square$ No

28. Have you lived in that house all your life? Yes $\square$ No 
29. If no how many different houses have you lived in?

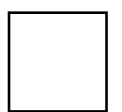

30. Have you lived in this area all your life? Yes $\square$

31. If no how many different schools have you been to?

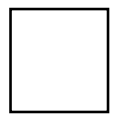

D How you spend your time when you are not in school

32. In the evenings would you say that you mainly spend your time:

Please tick ONE only

with your family

with your friends

going to organised activities like clubs

by yourself

33. At the weekends would you say that you mainly spend your time:

Please tick ONE only

with your family

with your friends

going to organised activities like clubs

by yourself

34. Where do you play? Please tick ALL the different places you play

\begin{tabular}{|l|l|l|l|l|}
\hline & Everyday & $\begin{array}{l}\text { At least } \\
\text { once a } \\
\text { week }\end{array}$ & $\begin{array}{l}\text { Less than } \\
\text { once a } \\
\text { week }\end{array}$ & Never \\
\hline $\begin{array}{l}\text { In your house/garden } \\
\text { your house }\end{array}$ & & & & \\
\hline On your balcony & & & & \\
\hline $\begin{array}{l}\text { In your friend's } \\
\text { house/garden }\end{array}$ & & & & \\
\hline $\begin{array}{l}\text { In the street outside } \\
\text { your friends house/s }\end{array}$ & & & & \\
\hline $\begin{array}{l}\text { In a park with play } \\
\text { equipment }\end{array}$ & & & & \\
\hline In an open green space & & & & \\
\hline $\begin{array}{l}\text { Somewhere else. } \\
\text { Where? }\end{array}$ & & & & \\
\hline
\end{tabular}


35. Outside school how do you mainly spend your time? Please tick ONE only

I mainly spend time with children my own age

I mainly spend time with children younger than me

I mainly spend time with children older than me

36. Which children do you spend time with outside school AND at weekends?

\begin{tabular}{|l|l|l|}
\hline & $\begin{array}{l}\text { After school and } \\
\text { evenings }\end{array}$ & At Weekends \\
\hline Friends from school & & \\
\hline Children who live nearby & & \\
\hline Brothers/sisters/cousins & & \\
\hline Other. Who? & & \\
\hline
\end{tabular}

37. What clubs and organised activities do you regularly do each week?

\begin{tabular}{|l|l|}
\hline & Name of Club or Organised Activity \\
\hline Monday & \\
\hline Tuesday & \\
\hline Wednesday & \\
\hline Thursday & \\
\hline Friday & \\
\hline Saturday & \\
\hline Sunday & \\
\hline
\end{tabular}

38. What do you think about the clubs and organised activities you go to? Please tick ALL the things you think

They keep me occupied

I am learning new things

I go because my friends go

I like the people who work there

I would still go even if my friends did not go

They are boring

Yes Sometimes No
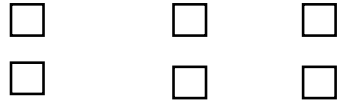

$\square \quad \square$

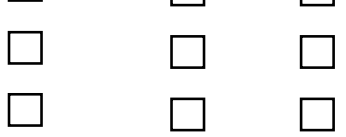

39. Please write down anything else you want to say about clubs and/or organised activities. 
E Places you go to without adults

40. Which of following do you do without an adult?

\begin{tabular}{|l|l|l|l|l|}
\hline & $\begin{array}{l}\text { Most } \\
\text { days }\end{array}$ & $\begin{array}{l}\text { At least } \\
\text { once a } \\
\text { week }\end{array}$ & $\begin{array}{l}\text { Less than } \\
\text { once a } \\
\text { week }\end{array}$ & Never \\
\hline Travel to and from school & & & & \\
\hline Go to friend's houses & & & & \\
\hline Play in the street & & & & \\
\hline Go to the local shops & & & & \\
\hline Go to the library & & & & \\
\hline Cycle on the main road & & & & \\
\hline
\end{tabular}

41. Do you EVER go to the pictures/cinema without an adult?

No $\square$ Go to 47

Yes $\square$ Go to 42

42. Who do you usually go with: Sister/brother

Please tick ALL that apply Cousins

Friends

By myself

43. What are their ages?

44. Which cinema do you go to without an adult?

45. How often do you go:

At least once a week

At least once a month

Less then once a month

46. How do you get there, mainly?

By bike

Please tick ALL that apply

By bus

By car

Walk

47. Do you EVER go to a swimming pool without an adult?

No $\square \quad$ Go to 53

Yes $\square \quad 60$ to 48

48. Who do you usually go with: Sister/brother

Please tick ALL that apply Cousins

Friends

By myself 
49. What are their ages?

50. Where do you go (name of the pool)?

51. How often do you go:

At least once a week At least once a month Less than once a month

52. How do you get there, mainly?

By bike

Please tick ALL that apply

By bus

By car

Walk

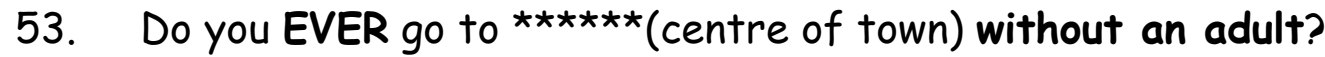

No $\square \quad$ Go to 60

Yes $\square \quad$ Go to 54

54. What do you go there for?

To eat in a café/McDonalds

To look around the shops

To buy things

Other reasons

What?

55. Who do you usually go with: Sisters/brother

Please tick ALL that apply Cousins

Friends

By myself

56. What are their ages?

57. How often do you go:

At least once a week

At least once a month

Less than once a month

58. How do you get there, mainly?

By bike

Please tick ALL that apply

By bus

By car

Walk 


\section{F Talking to adults}

59. I feel able to talk to adults that I know very well (not my parents or school teachers)

all of $\square \quad \begin{aligned} & \text { most of } \\ & \text { the time }\end{aligned} \quad \begin{aligned} & \text { some of } \\ & \text { the time }\end{aligned}$ not much $\square$ never
the the time

60. I feel able to talk to adults that I do not know very well:

all of $\square \quad$ most of $\square$ some of $\square$ not much $\square$ never $\square$ the time the time the time of the time

61. I have talked to a stranger before yes $\square$ no

62. I think that it is okay to ask a stranger a question, like how to get somewhere?

$$
\text { yes } \square \quad \text { no } \square \quad \text { don't know }
$$

63. I think that it is okay to have a conversation with a stranger

$$
\text { yes } \square \quad \text { no } \square \quad \text { don't know }
$$

\section{$G \quad$ Spending time with adults}

64. How much time do you spend with different adults (not your parents or school teachers)?

\begin{tabular}{|l|l|l|l|l|}
\hline & $\begin{array}{l}\text { A lot } \\
\text { of } \\
\text { time }\end{array}$ & $\begin{array}{l}\text { Some } \\
\text { time }\end{array}$ & $\begin{array}{l}\text { No } \\
\text { time }\end{array}$ & $\begin{array}{l}\text { Mainly doing? } \\
\text { A Having a conversation } \\
\text { B Playing games with them } \\
\text { C Shopping } \\
\text { D Going out somewhere } \\
\text { E Helping them do } \\
\text { something } \\
\text { F Them helping you do } \\
\text { something } \\
\text { G Something else WHAT }\end{array}$ \\
\hline My mum's friends & & & & \\
\hline My dad's friends & & & & \\
\hline My friends' mums & & & & \\
\hline My friends' dads & & & & \\
\hline My neighbours & & & & \\
\hline My aunts & & & & \\
\hline My uncles & & & & \\
\hline Adults running clubs & & & & \\
\hline
\end{tabular}


65. How do you like to spend your time? Please tick ONE only Always with adults

Mainly with adults

About half with adults and half with children

Mainly with children

Always with children

\section{H Your Views about adults}

66. How do you get on with different adults?

\begin{tabular}{|l|l|l|l|l|l|l|}
\hline & $\begin{array}{l}\text { Very } \\
\text { Well }\end{array}$ & $\begin{array}{l}\text { Quite } \\
\text { Well }\end{array}$ & $\begin{array}{l}\text { Neither } \\
\text { well } \\
\text { Nor badly }\end{array}$ & $\begin{array}{l}\text { Quite } \\
\text { Badly }\end{array}$ & $\begin{array}{l}\text { Very } \\
\text { Badly }\end{array}$ & $\begin{array}{l}\text { Does } \\
\text { not } \\
\text { apply }\end{array}$ \\
\hline Next door neighbours & & & & & & \\
\hline Other neighbours & & & & & & \\
\hline My friends' mums & & & & & & \\
\hline My friends' dads & & & & & & \\
\hline My mum's friends & & & & & & \\
\hline My dad's friends & & & & & & \\
\hline $\begin{array}{l}\text { My adult sister's/ } \\
\text { brother's friends }\end{array}$ & & & & & & \\
\hline My aunts & & & & & & \\
\hline My uncles & & & & & & \\
\hline People who run clubs & & & & & & \\
\hline
\end{tabular}

67. Out of the adults listed above who do you get on best with and why?

68. Have YOU had any problems with adults in the last year?

\begin{tabular}{|l|l|l|l|}
\hline & $\begin{array}{l}\text { A lot of } \\
\text { problems }\end{array}$ & $\begin{array}{l}\text { A few } \\
\text { problems }\end{array}$ & No problems \\
\hline My next door neighbours & & & \\
\hline Other neighbours & & & \\
\hline Adults in your area & & & \\
\hline People working in shops & & & \\
\hline Adults running clubs & & & \\
\hline Other adults in shops & & & \\
\hline Adults on buses & & & \\
\hline $\begin{array}{l}\text { Adults somewhere else } \\
\text { Where? }\end{array}$ & & & \\
\hline
\end{tabular}


69. Please write about ONE of these problems

J. Your views about the area where you live

70. I like the area where I live because: Please tick ALL your reasons My friends live nearby

My adult neighbours are friendly

I could go to my neighbours for help if my mum/dad wasn't in My grandparents live nearby

I have an aunt/uncle who lives nearby

I know most of the adults near where I live

There are good places to play

Other reasons

What?

71. I don't like the area where I live because: Please tick ALL your reasons

I don't get on with other children

My adult neighbours are not very friendly

It does not look very nice

There is violence in the area

It is messy

Adults are not very nice to children

Teenagers cause problems

Other reasons

What?

72. Overall: Please tick one only

I like the area where I live

I do not like the area where I live

73. In the daytime I feel safe in my neighbourhood Please circle ONE NUMBER

Never Sometimes All of the time

$\begin{array}{lllll}1 & 2 & 3 & 4 & 5\end{array}$


74. When it is dark I feel safe in my neighbourhood Please circle ONE NUMBER
All of the time
Sometimes
5
4
3
2
Never
1

75. If my mum and dad were not in and I had a problem the person I would go to is: Please tick one only

A neighbour

A relative who lives nearby

A friend's parent

Somebody else

Who?

76. Have you seen any adults (not your parents or school teachers) behaving in ways that you think that they should not?

$$
\text { Yes } \square \quad \text { No } \square
$$

If yes please write about one thing

$K \quad$ Other parts of your life

77. Do you have a mobile phone? No $\square$ Yes $\square$

78. Does your family (mum, dad or someone who lives in your house) have a car or van?

No

Yes one

Yes two or more

79. How many holidays (going away for a week or more) have you had since (and including) this summer?

Staying with relatives or friends none $\square \quad 1$ or $2 \square \quad 3$ or more

Staying somewhere you have to pay none $\square \quad 1$ or $2 \square \quad 3$ or more

In England, Scotland, or Wales none $\square 1$ or $2 \square \quad 3$ or more $\square$

Abroad none $\square 1$ or $2 \square \quad 3$ or more

THANK YOU VERY MUCH FOR YOUR TIME 


\section{Meeting with Research Advisors}

$4 / 2 / 05$

Crombie, Star, John A, Lacey, Stacey A, Paterson (for a bit)

\section{The Children's questions}

1. Are you a boy or a girl?

2. What is your name? (won't be in the results, anonymous)

3. Have you got brothers or sisters?

4. How (who?) are your relatives?

5. What relatives do you get along with?

6. Do you spend more time with your friends or your family?

7. Where do you play with your friends?

8. Do you go to any clubs?

9. What places do you go without adults (but with friends)?

10. What adults do you spend time with?

11. Do you work with (spend a time with?) a lot of adults?

12. Do some adults spend time with you?

- Helping with schoolwork

- Help tidy up

- Respect you

- Help with young people

- Give you money

13. Do you play games (activities?) with each other (adults?)

- Who?

- Mum, dad

- Big sister, brothers

- Uncle or auntie

- Nana, grandpa

- Neighbours

$\circ$ friends

- What?

- Chess, monopoly, connect 4, snakes and ladders (board games)

- Go shopping

14. How do adults treat you?

- Hit you

- Be nice

- Be unkind

- Be kind

15. Do you know many adults?

16. What do you think about adults?

17. How do you get on with adults?

18. Do you have a good relationship with adults? 
- Yes

- No

- Why

19. Do you get on well with adults?

- Aggressive

- Disagreeing

20. How do adults act around you?

- Arguing

- Fighting

- Shouting

- Friendly

- Nice

- Angry

- Hurtful

21. How (who?) (do you have any friends who are adults) are your adult friends?

22. Do you feel good about leaving (living in?) the area?

- Yes

- To get to a friends house

- To get to a club

- There's a better park there

- They have to get somewhere

- No

- They will get battered

- They don't like the people there

- They don't want to get there

- They don't like that area

23. What would you do if a stranger asked if you wanted a lift?

24. Do you trust strangers?

- Yes

- Because they would be really friendly

- They have good experiences before

- They like adults

- They were bored

- No

- They don't know who they are

- They have had bad experiences before

- They don't like adults

- In case bad things happen

- Why

25. How do you get on with your life?

Thank you for your time 


\section{Piloting the Questionnaire}

The fourth draft was piloted with eleven of the P7's in Swinburn school on $15^{\text {th }}$ April 2005. All had volunteered to be involved, giving their time during their free choice period. One boy, new to the school and who I had not met before left after about 10 minutes, not completing the questionnaire. Another boy did not manage to finish it in time and I helped another to complete his. The other eight children took between 20 and 35 minutes to fill in the questionnaire. Most of the children sat together, although two chose to sit by themselves (one was a case study child, Hayley who had said previously that she preferred to be interviewed alone because it was private). There was some chat between the children and initially some silliness from the boys saying that they were going to put down that they were a girl, but this calmed down and of the children worked steadily.

In relation to the content it was unfortunate that some of the numbers were out of sync as it confused some children and others made comments. Most of the children said it was okay to fill in although two said that they did not like question 64 . They had put a line through it and said that I should not ask such questions as it was private. I said that I didn't see how that question was any more private than the others. They said it was.

In relation each question I have noted the children's comments and also examined how they have filled in the answers. I have then made decisions as to how to adapt some. - in italics

\section{1. / 2. / 3. No problems}

4.

5. / 7. 'What about brothers and sisters?'

Changed these two questions to include older sisters and brothers removing question 9.

Another problem with the question is that it says 'live', but most of the children interpret it as 'stay'. This might be an interesting analytical point. I will make 'live' bold and see if this makes any difference. The interpretation may be linked to Scottish/local terminology of 'Where do you stay?' meaning 'Where do you live?'

6. / 8. - 12. No problems

13. One child said that she only saw her grandparents in the holidays. This seemed like a good category to have so I have included it

14./ 19. No problems 
20. Problem with the term 'area'. The children appear to be defining it as their immediate area such as their street which they then named.

I think the best way round this is to do the question as a whole class one. I have also changed 'area' to place to see if this makes any difference.

21. - 30. No problems

31. Potential problem it schools have merged are children counting that as one or two school.

Do as a whole class question.

32. / 33. No real problems although some children ticked more than one box

34. Some children only ticked one box. This may be the reality of their lives, but to encourage them include more details if relevant the instruction has been made fuller.

35. AND The instruction requires the children to only tick one box as it speaks OTHERS about but in many cases the children appear to have ticked all the boxes that are relevant to them. There may be a number of different reasons why they have done this:

- They are not reading the word mainly and therefore answer all the things they do.

- They are reading mainly but not only reading the instruction to only tick one

- They are reading the question and the instruction but do not wish to/can not say which they do mainly when some things may be more or less equal. They may not wish to make a choice as a number of the boys did not when I asked them who their best friend was.

In this case I will give sentences rather than phrases as the choice and make mainly and tick one in bold and see if this makes any difference.

36. Some children only answered the part after school leaving out weekends.

I have added weekends to the question.

37. Some of the children's spelling is unclear.

It may be worth asking the teacher if there is somewhere I can write up the names of places for the children copy when they ask how to spell a word.

38. Some of the children only ticked one reason.

The instruction has been altered and a new question added.

40. No problem 
41. One child ticked no and then went on to answer the questions - it is therefore difficult to know how to interpret this.

42. - 58 The only problems are those mentioned before, spelling and ticking more than one box. As there are a number of differing instructions I have decided to simplify them and ask the children to tick all that apply. The how often questions are not problematic as the categories are exclusive.

60. - 64. No real problems except one child ticked two boxes

65. Probably the most difficult question due to it's number of requirements. I think that the best thing is to take the children through it.

66. One child ticked two boxes, so I have made it 'tick $O N E^{\prime}$

67. One child only ticked the box for next door neighbours. But I do not think that the question is problematic

68.

Only five out of the eight children answered this question. Maybe because it requires writing, maybe because they could not or did not want to say.

69.

Some children only ticked a few boxes. I think this probably does reflect their thinking. Only two children wrote about a problem. Is this:

- not wanting to write?

- not feeling confident at spelling?

- Not feeling strong enough about something?

I think that the problems should be coded separately and have therefore given it a question number

70. - 75. No apparent problems although I don't know how the children were defining area? Do as a whole class question - but towards the end rather than at the beginning.

76. Only two children chose not to write anything. I don't think the example needs to be separated into another question as it is just a yes no question

77. / 78. No problems

79. $\quad$ Most children ticked the boxes rather than writing in the numbers. I have therefore decided to give them numbers 


\section{Appendix 8}

\section{Letter to Head Teachers}

$16^{\text {th }}$ November 2004

Dear

\section{Research Project: Child/Adult Relations}

The Resources Officer within the Local Authority Education Quality Services Department has given me permission, in principle, to conduct research with children in schools in the city. This permission does not oblige schools to participate, but I would be grateful for your permission to carry out research with P6 children in your school.

I am a mature PhD student at the University of Edinburgh working with the support of Professor Lynn Jamieson and Dr Kathryn Milburn at the Centre for Research on Families and Relationships. The focus of my study is 'Child-adult relationships beyond the home and school' in the context of the city's Social Inclusion Partnership areas. I have already spent nine months collecting detailed information from one group of children and now intend to conduct a survey with a larger number of children across the city.

In addition to seeking your permission to ask all the P6 children in your school to fill in a questionnaire I would also ask you to send out permission letters to parents (I will provide these). Having gained parental permission I would conduct the questionnaires with the children. It is likely that this would take about 40 minutes per P6 class. I have an Enhanced Disclosure Scotland Certificate issued in December 2003 and many years experience of working with children and parents in and out of school. I can ensure you that the research will be conducted in a thoroughly professional manner.

At this stage I am asking for permission conduct the survey with P6 children in your school between March and May 2005. If you are willing to give this please could you inform me of the number of P6 children in your school? I will then contact you in January to give you further details of the research process and ask you for suitable dates.

If you wish any further information please e-mail me at S.E.Milne@sms.ed.ac.uk or write to me at CRFR. Thank you very much for your time.

Yours sincerely

Sue Milne 


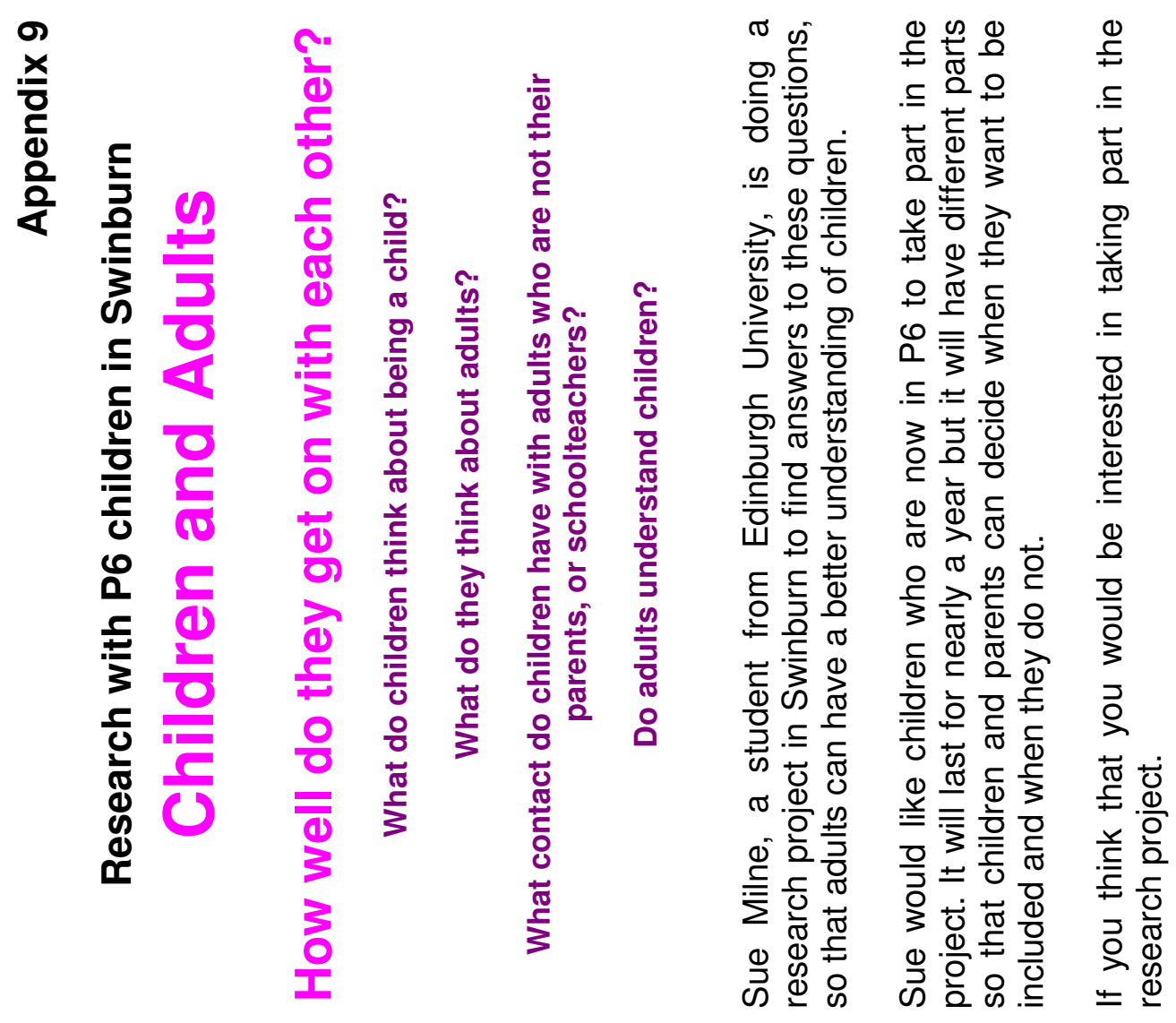

品 


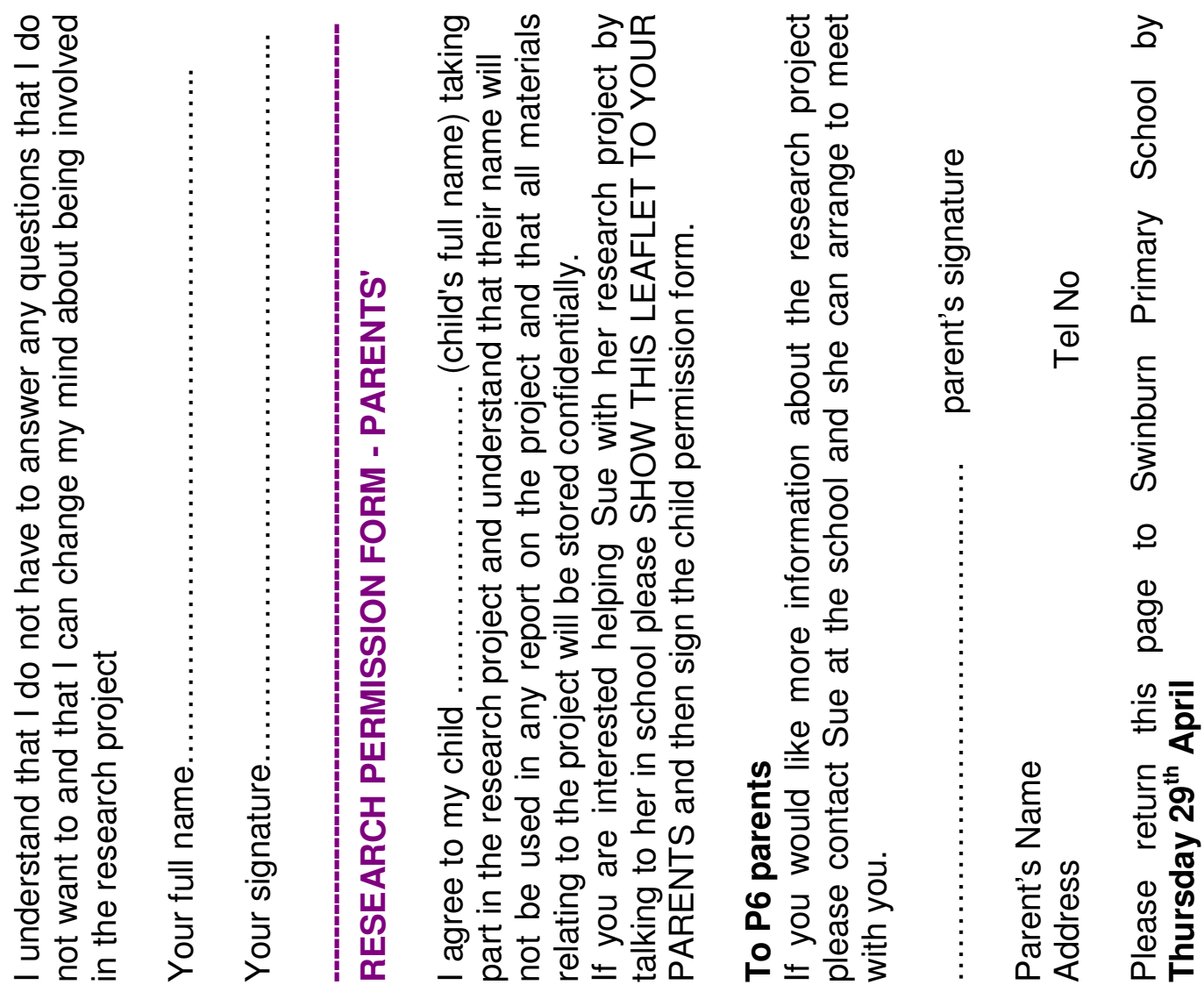

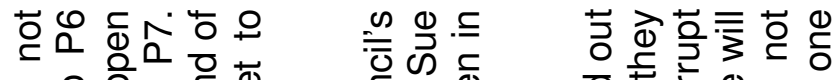

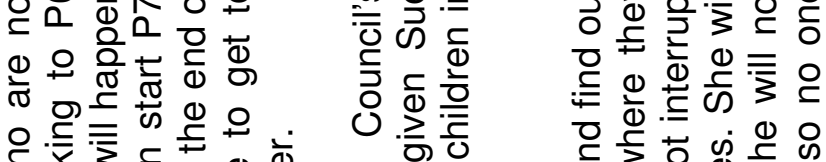

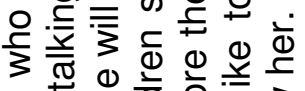

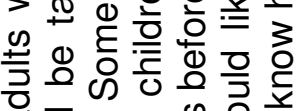

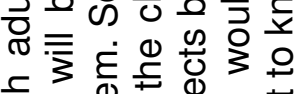

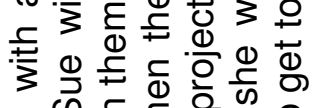

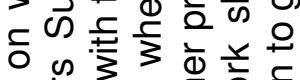

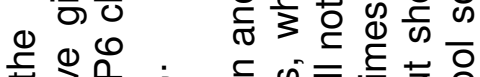

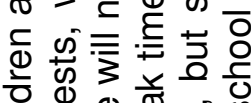

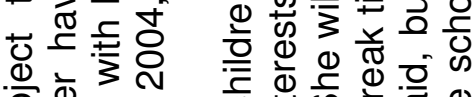

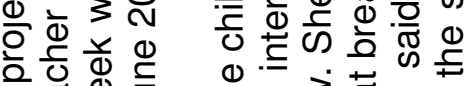

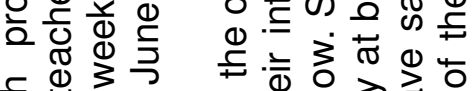

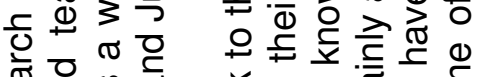
-

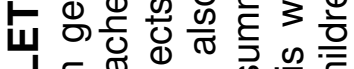

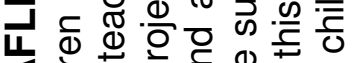

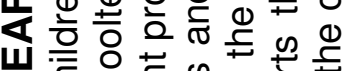

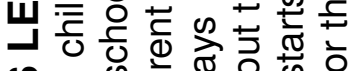

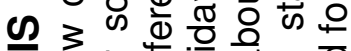

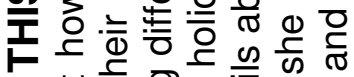

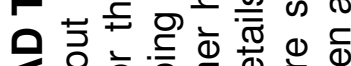

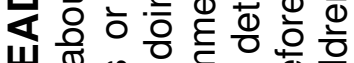

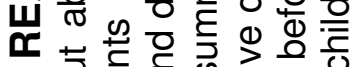

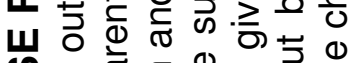

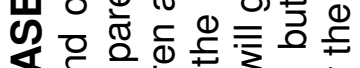
岸 ঠั

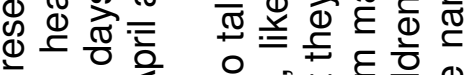

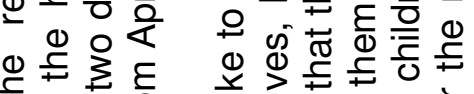

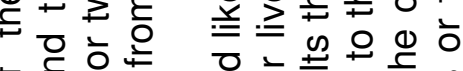

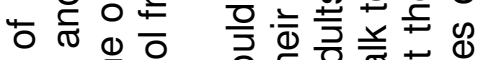

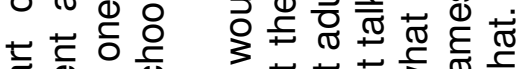
ฮัญ 잉

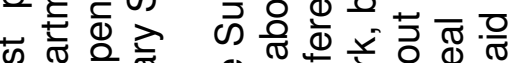

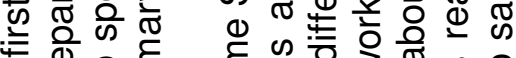

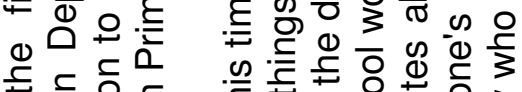
드으은 흔 휴에 음 해을

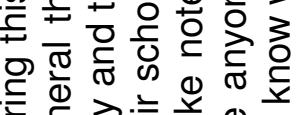
வ

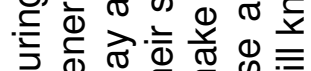

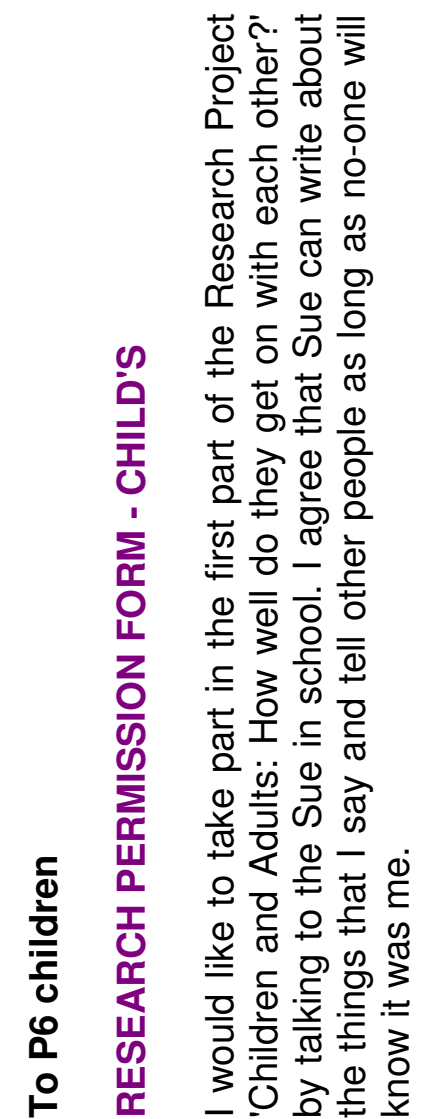




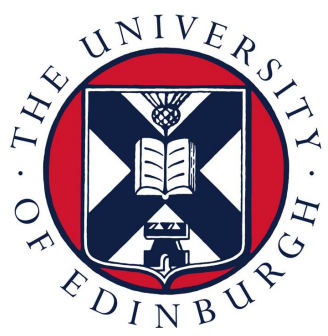

A Survey of the Lives of Children and their Relationships with Adults.

\section{Dear Parent}

I am a researcher at the University of Edinburgh and I have been given permission by ... from ... the Education Department and the Head Teacher to ask your P6 child to complete a questionnaire in class

on

I am trying to find out about the lives of children aged 10/11 years living in different parts of the city. I am interested in the adults (not parents or school teachers) that children have contact with at home, in their neighbourhoods and in children's clubs. The answers will be put together into a PhD report and also a number of journal articles to help adults understand children better.

The children will be asked NOT to put their names on the questionnaires so that they can not be identified. The report will not name the participating schools.

You can contact me by e-mail S.E.Milne@sms.ed.ac.uk, or if you wish any further information please phone Professor Kathryn Milburn on 01316501000 or Professor Lynn Jamieson on 01316511832.

Yours sincerely

Sue Milne

If you are happy for your child to take part in the research you do not need to do anything. But if you DO NOT wish your child to do the questionnaire please return the slip below to the school.

\section{Please return this slip to the school}

I DO NOT WANT my P6 child to take part in the Research Project child's name. class 
둔
$\frac{x}{0}$
$\frac{1}{0}$
$\frac{0}{2}$

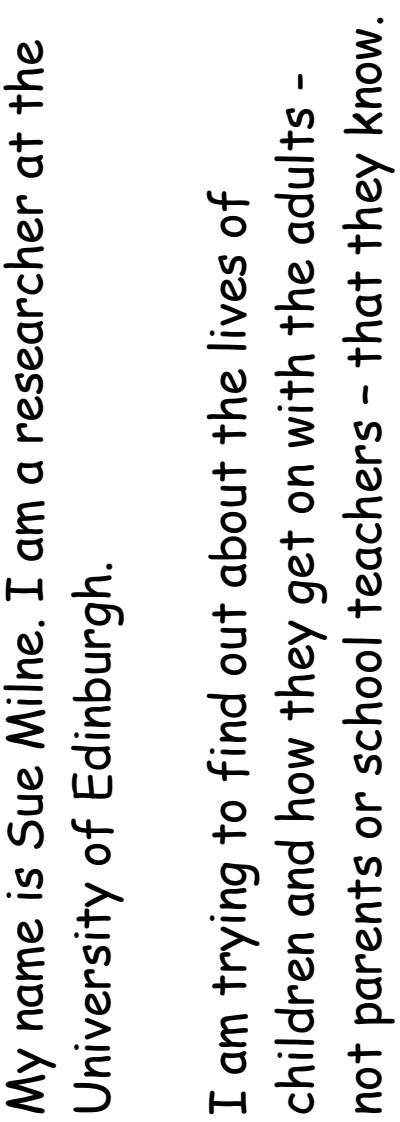

ले
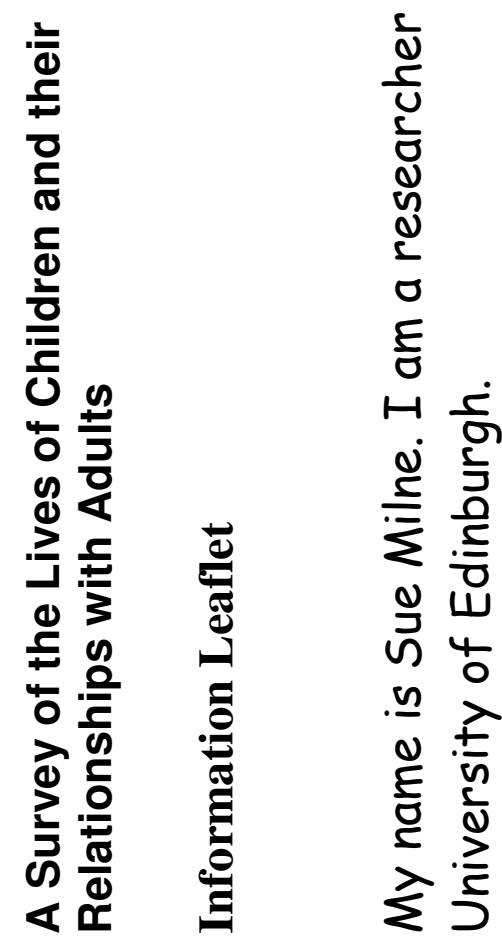

을 언

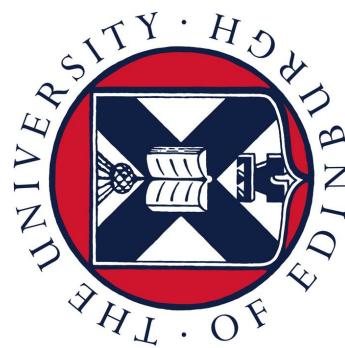

$+$

의 울

정

흠 은

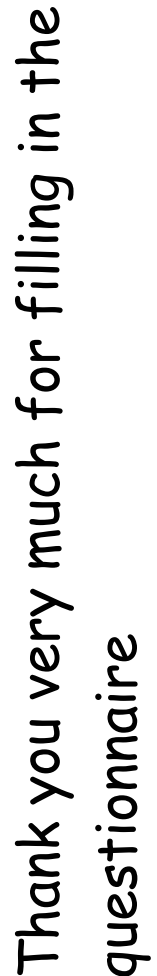



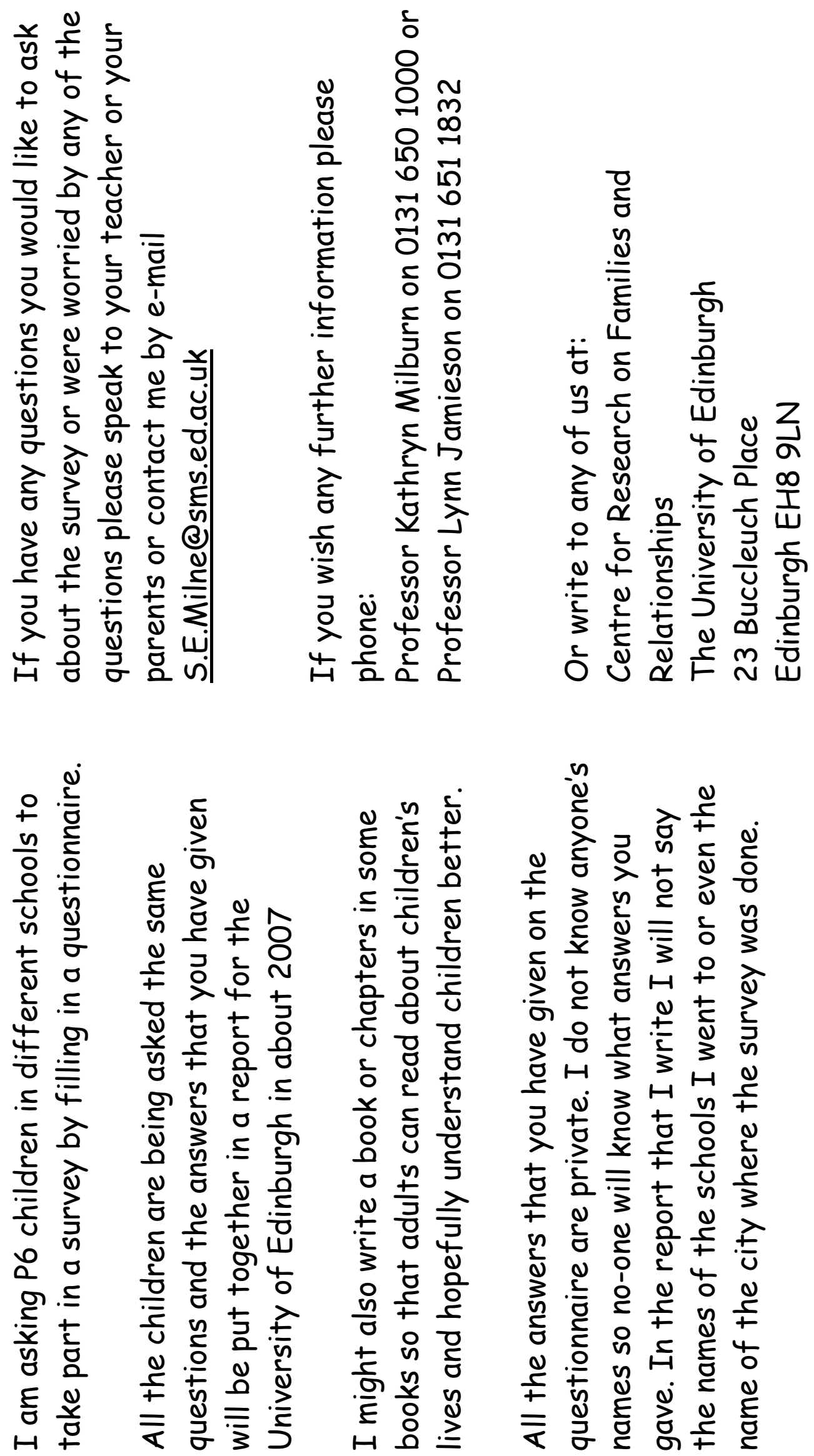


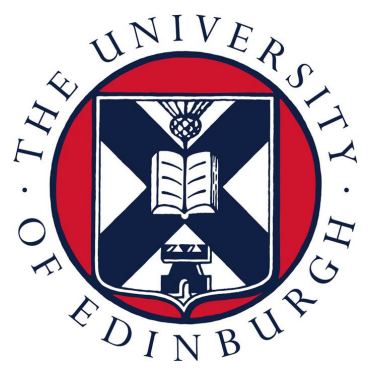

\section{Feedback to the children in Swinburn}

\section{My Family, Neighbours and Other Adults: Children's Stories of their Contacts with Adults beyond the Home and School.}

\section{INTRODUCTION}

Since April 2004 I have been working with children in a school in a Scottish city. The school is in an area that has been defined by politicians as 'poor', although none of the children thought this. What I wanted to find out was:

- Who are the adults that children have contact with?

- What children think about adults who are not their parents or school teachers

- What children think about where they live

- What children think about how they are treated by adults in general

At the beginning of my research the children were in P6 now they are in P7. To start with I spent time with all the children, and then 17 choose to tell me more about their lives. These children can be seen as representative of children in general because they have various differences and similarities. There are girls and boys, some children who find school work easy and some who find it hard and need extra help. Some children who need help with their behaviour and some who have physical problems with their bodies. Some of the children live in houses and some live in flats. Some live with both their real parents, others live with a step mum or step dad or just with their mum. Some children's parents have cars, others do not so they travel by bus. All of the children have brothers and/or sisters, although some of these are older and live in their own houses. 


\section{WHAT I HAVE FOUND OUT SO FAR}

\section{Family}

- Most children spend a lot of time with their families even though many also like spending time with their friends

- Most children have weekly, if not daily, contact with grand parents, aunts and uncles

Whilst my research is really about the contacts and relationships you have with adults who are not your parents or school teachers I found it interesting that most of you chose to tell me quite a lot about your families.

\section{The Neighbourhood}

- Most of the children like living in the area, especially because they have their friends nearby, although some said that they thought it was getting more violent

- Nearly all of the children told me about one incident where a guy had been stabbed and had some of his fingers chopped off

- Most children feel confident about going to the shops, the park, their friend's houses and riding their bikes around

- Most get on well with their neighbours, although a number, mainly, boys talked about complaints from some neighbours

- All of the children complained about the state of the shopping centre, and many did not go in there

- Some of the children go into the neighbouring areas, although others are worried about being 'battered'

\section{Clubs}

- All of the children go to at least one club, and some, mainly girls, go to a few

- Most like the people who ran the clubs although these adults did not appear to be very important to them

\section{Good relationships with adults}

- Some of the children spoke about the good relationships that they had with adults who were not their parents or school teachers.

- Some, mainly girls, said how they greeted their neighbours and sometimes went into their houses, although this was often to play with younger children 
- Some of the boys talked about how they spent time with their dad's or older sister's male friends, messing about 'play fighting' or 'going on the computer'.

- A few of the girls talked about how they engaged in conversations, about films, television programmes and other topics, with adults they knew.

\section{Comments on adult behaviour}

- Many of the children had stories to tell about adults behaving 'badly'.

- Many of these stories were about adults being drunk

- Most of the children were concerned about how 'bad' adult behaviour might affect children, particularly the children of the adults observed.

- They were concerned that children, especially younger ones, might get upset or scared.

\section{Moving beyond the home and school}

- The children have different levels of confidence about going far from home without an adult.

- Some children spend most of their time in their own house or playing nearby

- Most of the children have been on a bus, swimming or to the cinema with their friends and without adults.

- Nearly half the children regularly go out with their friends at the weekends, mainly swimming, to the pictures or shopping up town

- A few children feel confident enough to go up town by themselves

- More of the girls go more frequently on independent outings than the boys

\section{Adults in Public}

- A number of the children who made 'independent' outings complained about how some adults in shops treated them.

- They said that shop assistants would often serve adults behind them first or sometimes refuse to serve them at all

- Many of the children said that they thought that shopkeepers made assumptions about children being thieves 


\section{Strangers}

- Whilst most of the children said that they wouldn't talk to strangers a number made a distinction between 'talking to' and 'asking questions'

- Many children realise that they may need to ask a stranger a question and had worked out ways to feel safe

Age

- Most of the children were aware that they were reaching a time of change in their lives especially in terms of thinking about the transition to High School.

- Those children who were spending more time doing things without adults were finding some problems about age limits and about how old they looked.

\section{The Research}

- All of the children have enjoyed taking part in the research and have a clear understanding of what the research was about

- Many said that it had made them think about things that they had not thought about before

- Some said that they had learned to have a broader opinion about adults

- Some said that participating in the research has given them more confidence in talking to adults

\section{CONCLUSIONS}

The things that I have found out have made me think more about how children develop an understanding of the world beyond the home and school. How they begin to try new things, go different places and be out in the world surrounded by unknown adults.

Being with friends, going to clubs and moving around the neighbourhood independently seems increases their contacts with different adults and appears to help children gain confidence in communicating with adults. Then as this confidence grows the children begin to travel further afield and have contact a greater range of adults. However whilst many of the children appear to show a good awareness of and ability to be in the adult world on adult terms their abilities are often not recognised and they report being ignored and treated as 'second class citizens' 


\section{NEXT STEPS}

What I have found out is based on the stories from 17 children. I have found these very interesting and would like to know if you agree with what I have found out. I am therefore going to give you a feedback sheet to fill in.

I also want to know if children living in other 'poor' areas have similar experiences with adults and the same thoughts. I am therefore going to do more research with P6 children in other schools. I will not have time to use the tape recorder to interview lots of children so I have asked twenty two schools if I can give their P6's a questionnaire to fill in. Some have said yes, a few have said no and I am waiting to hear from others

To help me prepare the questionnaire I would like some P7 children from this school to work with me, for three weeks during Golden Time. If you are interested see the back of the feedback sheet. 


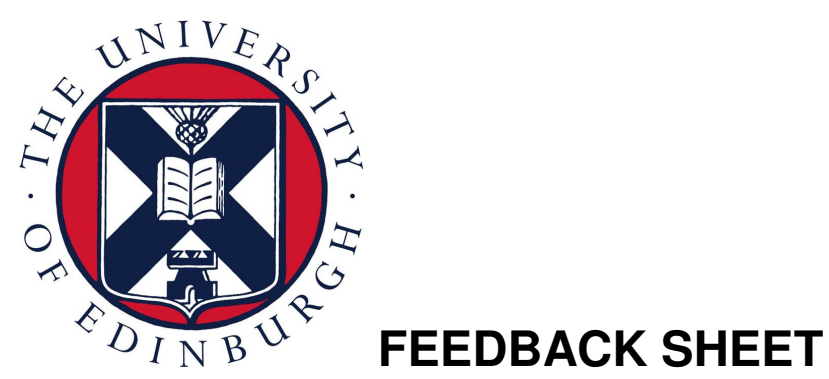

\section{My Family, Neighbours and Other Adults: Children's Stories of their Contacts with Adults beyond the Home and School}

I would like your ideas about the research and about what I have just told you. I would be grateful if you would answer the following questions. You don't have to do them all just the ones you want to.

1. What do you think about what I have found out?

- Is it true or not true? What bit/s?

- Is it interesting or not interesting? What bit/s?

2. What do you think is the most important thing that I have found out?

3. What things should I find out from other children?

4. Is there anything else you want to say about the research?

\section{BECOMING A RESEARCH ADVISOR}

To help me prepare the questionnaire I would like some P7 children from this school to work with me, for three weeks during Golden Time. If you are interested please give me your name and then answer some of the questions 1-4 and question 5.

5. You should choose me to a research advisor because?

\section{NAME}

When you have got some ideas please give me THIS SHEET and I will speak to you before home time today. From the answers that you have given on this feedback sheet and/or what you tell me, I will choose children who I think have some good ideas and are able to concentrate and wok hard. 